DOC. 20041004.0005

QA: QA

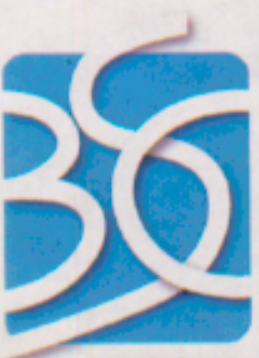

BECHTEL

SAIC compwruc

ANL-EBS-PA-000001 REV 02

September 2004

\title{
WAPDEG Analysis of Waste Package and Drip Shield Degradation
}

Prepared for:

U.S. Department of Energy

Office of Civilian Radioactive Waste Management

Office of Repository Development

1551 Hillshire Drive

Las Vegas, Nevada 89134-6321

Prepared by:

Bechtel SAIC Company, LLC

1180 Town Center Drive

Las Vegas, Nevada 89144

Under Contract Number

DE-AC28-01RW12101 


\section{DISCLAIMER}

This report was prepared as an account of work sponsored by an agency of the United States Government. Neither the United States Government nor any agency thereof, nor any of their employees, nor any of their contractors, subcontractors or their employees, makes any warranty, express or implied, or assumes any legal liability or responsibility for the accuracy, completeness, or any third party's use or the results of such use of any information, apparatus, product, or process disclosed, or represents that its use would not infringe privately owned rights. Reference herein to any specific commercial product, process, or service by trade name, trademark, manufacturer, or otherwise, does not necessarily constitute or imply its endorsement, recommendation, or favoring by the United States Government or any agency thereof or its contractors or subcontractors. The views and opinions of authors expressed herein do not necessarily state or reflect those of the United States Government or any agency thereof. 
QA: QA

WAPDEG Analysis of Waste Package and Drip Shield Degradation ANL-EBS-PA-000001 REV 02

September 2004 


\section{OCRWM}

\section{Scientific Analysis Signature Pagel ChANGE History}

2. Scientific Analysis Title

WAPDEG Analysis of Waste Package and Drip Shield Degradation

3. DI (including Revision Number)

ANL-EBS-PA-000001 REV 02

\begin{tabular}{|l|l|}
\hline 4. Total Appendices & $\begin{array}{l}\text { 5. Number of Pages in Each Appendix } \\
\text { Two (2) }\end{array}$ \\
\hline
\end{tabular}

\begin{tabular}{|c|c|c|c|}
\hline 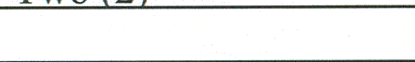 & Printed Name & Signature & Date \\
\hline 6. Originator & Kevin G. Mon & Ruin Mon & $9 / 29 / 2004$ \\
\hline 7. Checker & Ted Koppenaal & Led Kogrenaal & $9-29-2004$ \\
\hline 8. QER & Charlie Warren & & $9 / 29 / 04$ \\
\hline 9. Responsible Manager/Lead & Dennis Thomas & & $1 / 29 / 04$ \\
\hline 10. Responsible Manager & Neil Brown & Ma & 9129104 \\
\hline
\end{tabular}

11. Remarks

For TSPA-LA.

Kevin Mon is responsible for the entire document.

Bryan Bullard and Alda Behie made significant contributions.

Output DTN: MO0310MWDWAPAN.002 [DIRS 165800]

\begin{tabular}{|c|l|}
\hline \multicolumn{2}{|c|}{ Change History } \\
\hline 12. Revision No. & \multicolumn{1}{|c|}{ 13. Description of Change } \\
\hline 00 & Initial Issue. \\
\hline $00 / 01$ & $\begin{array}{l}\text { Interim Change to incorporate changes due to the removal of backfill and new/revised } \\
\text { upstream inputs. Names of Alloy 22 outer barrier lids changed to outer closure lid and } \\
\text { middle closure lid. Discussion added for recommended versus used uncertainty models } \\
\text { Section 6.1. }\end{array}$ \\
\hline 01 & $\begin{array}{l}\text { Revision to incorporate changes for TSPA-LA. Incorporate changes in upstream } \\
\text { process models. Conform to AP-SIII.10Q. The entire model documentation was } \\
\text { revised because the changes were too extensive to use Step 5.8d) of AP-SIII.10Q }\end{array}$ \\
\hline 02 & $\begin{array}{l}\text { Revision to incorporate changes for regulatory integration. The entire scientific } \\
\text { analysis documentation was revised and the changes were too extensive to use change } \\
\text { bars. The previous revision was prepared as a model report. This revision does not } \\
\text { contain model development and is prepared as a scientific analysis. }\end{array}$ \\
\hline & \begin{tabular}{l} 
\\
\hline
\end{tabular} \\
\hline
\end{tabular}




\section{INTENTIONALLY LEFT BLANK}




\section{CONTENTS}

Page

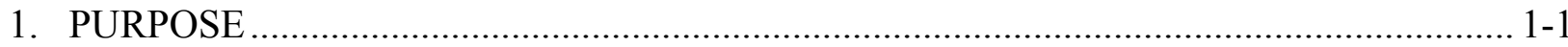

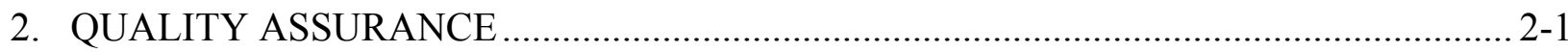

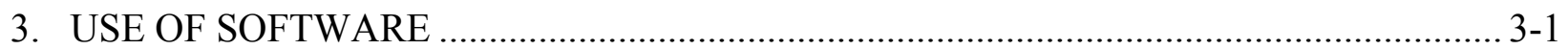

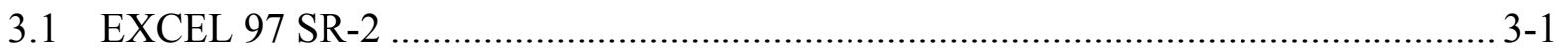

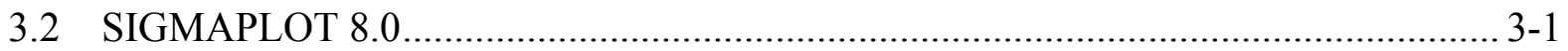

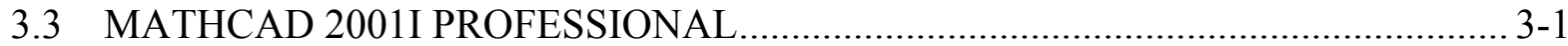

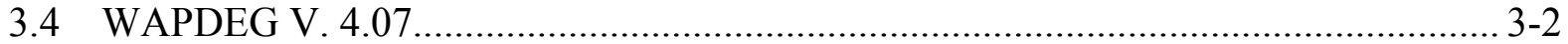



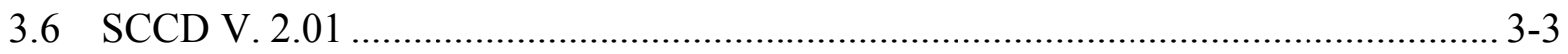

3.7 GOLDSIM V. 7.50.100 ................................................................................. 3-3

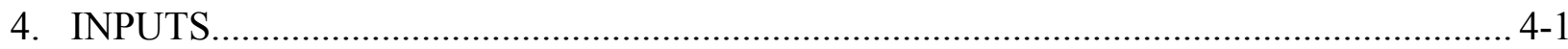

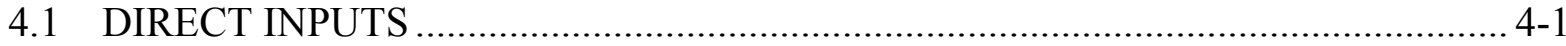

4.1.1 Waste Package and Drip Shield Design Input ............................................... 4-3

4.1.2 Drip Shield General Corrosion Model Inputs ..................................................... 4-4

4.1.3 Alloy 22 Waste Package Outer Barrier General Corrosion Model Inputs........ 4-6

4.1.4 Weld Flaw Inputs ................................................................................. 4-8

4.1.5 Stress and Stress Intensity Factor Profile Inputs........................................... 4-9

4.1.6 Slip Dissolution Inputs........................................................................ 4-13

4.1.7 Waste Package Outer Barrier Microbially Influenced Corrosion Inputs ........ 4-15

4.1.8 Waste Package Early Failure Analysis Inputs ............................................... 4-16

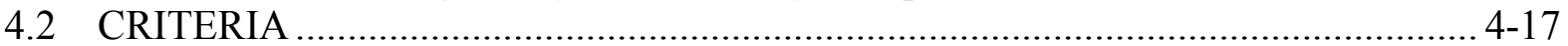

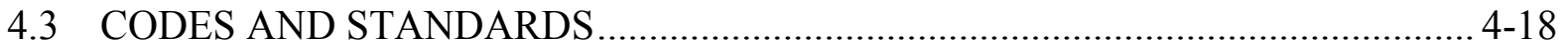

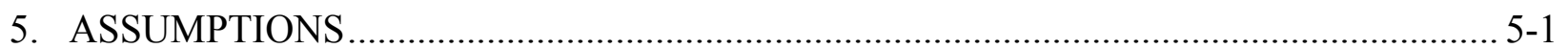

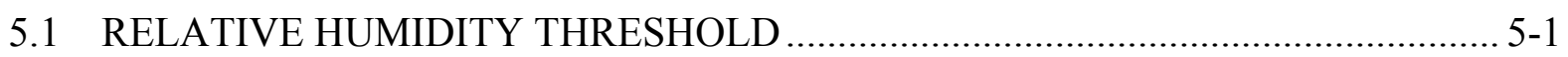

5.2 CORROSION BEHAVIOR OF THE WELD REGIONS ........................................ 5-1

5.3 CORROSION BEHAVIOR OF THE OUTER LID CLOSURE WELD REGION ..... 5-2

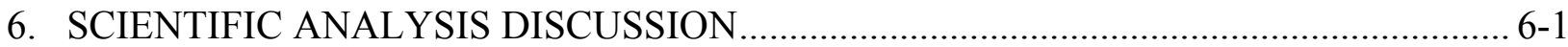

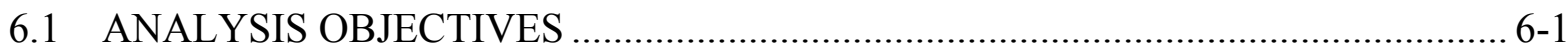

6.1.1 Alternative Scientific Approaches and Computational Methods

Considered ......................................................................................... 6-3

6.2 FEATURES, EVENTS, AND PROCESSES INCLUDED IN ANALYSIS ................. 6-4

6.3 DESCRIPTION OF INTEGRATED WASTE PACKAGE DEGRADATION

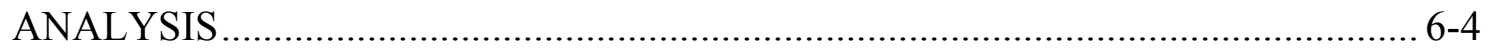

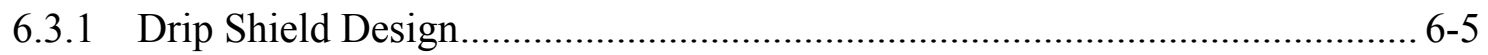

6.3.2 Waste Package Design............................................................................... 6-6

6.3.3 Drip Shield General Corrosion Model Discussion .......................................... 6-9

6.3.4 Waste Package Outer Barrier General Corrosion Model Discussion .............. 6-10

6.3.5 Waste Package Stress Corrosion Cracking Model Discussion ........................ 6-12 


\section{CONTENTS (Continued)}

6.3.6 Waste Package Microbially Influenced Corrosion ...................................... 6-19

6.3.7 Inside-Out Degradation......................................................................... 6-19

6.3.8 Waste Package Early Failure Analysis ....................................................... 6-20

6.4 INTEGRATED WASTE PACKAGE DEGRADATION ANALYSIS

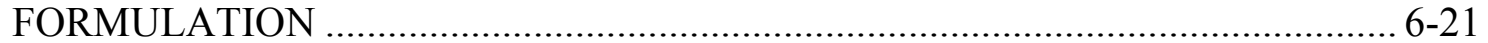

6.4.1 GoldSim Implementation Overview ............................................................. 6-21

6.4.2 WAPDEG-GoldSim Interface Overview................................................... 6-24

6.4.3 Number of Patches and Number Waste Package-Drip Shields Design

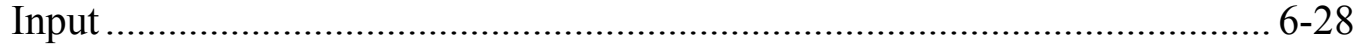

6.4.4 Waste Package Design Input .................................................................... 6-29

6.4.5 Waste Package and Drip Shield Exposure Conditions Implementation......... 6-31

6.4.6 Drip Shield General Corrosion Implementation ...................................... 6-35

6.4.7 Waste Package Outer Barrier General Corrosion Implementation ................. 6-36



6.4.9 Stress and Stress Intensity Factor Profile Implementation ............................ 6-40

6.4.10 Slip Dissolution Implementation .......................................................... 6-42

6.4.11 Waste Package Outer Barrier Microbially Influenced Corrosion Implementation 6-44

6.4.12 Implementation of Early Failure of Waste Packages................................... 6-45

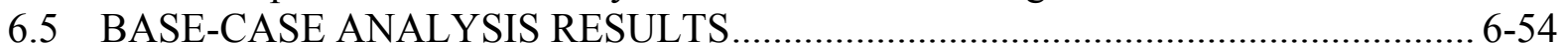

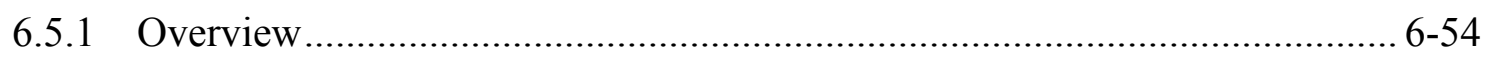

6.5.2 Commercial Spent Nuclear Fuel Integrated Waste Package Degradation Analysis Base-Case Results........................................................................ 6-56

6.5.3 Codisposal Waste Package Integrated Waste Package Degradation Analysis Base-Case Results .................................................................... 6-60

6.5.4 Number of Drip Shield and Waste Package Pairs Sensitivity Study ............. 6-65

6.6 SUMMARY OF BARRIER ANALYSIS ....................................................... 6-66

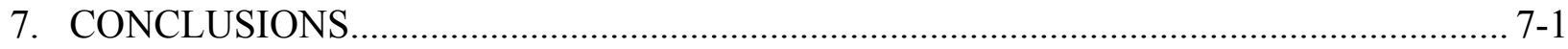

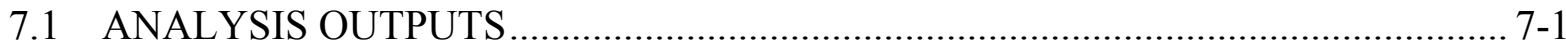

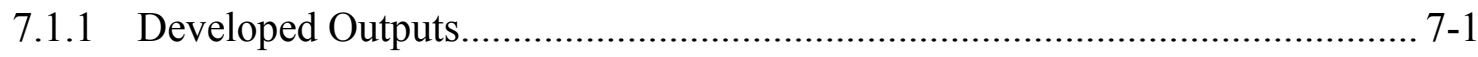

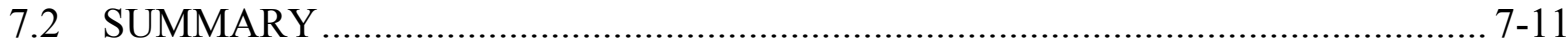

7.3 YUCCA MOUNTAIN REVIEW PLAN CRITERIA ….................................... 7-12

7.3.1 System Description and Demonstration of Multiple Barriers....................... 7-12

7.3.2 Degradation of Engineered Barriers ................................................ 7-12

8. INPUTS AND REFERENCES ............................................................................. 8

8.1 DOCUMENTS CITED ..................................................................................... 8 8 -

8.2 CODES, STANDARDS, REGULATIONS, AND PROCEDURES ......................... 8-3

8.3 SOURCE DATA LISTED BY DATA TRACKING NUMBER ............................... 8-4

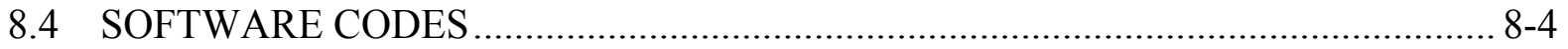




\section{FIGURES}

1. Schematic Representation of Waste Package Patches

6-6

2. Schematic of Waste Package Configuration in IWPD Analysis to Implement Stress

Corrosion Cracking of Dual Closure Lids of Waste Package Outer Barrier

3. Effect of Scaling General Corrosion Distribution by a Size Factor of Four..................... 6-12

4. Schematic of the Dual Closure Lids of Waste Package Outer Barrier ............................. 6-13



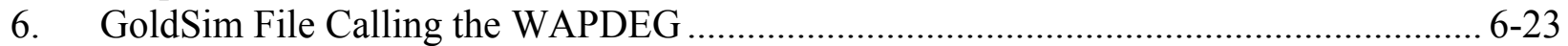

7. Contents of the Linked_Files Container Element..................................................... 6-23

8. Contents of the GS_Elements Container Element ......................................................... 6-24

9. Interface Between the GoldSim Software and the WAPDEG DLL for CSNF Waste

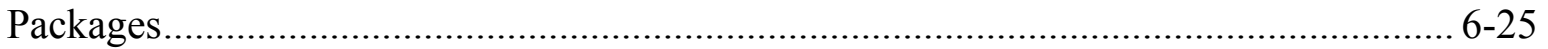

10. Other Input Links to IWPD_CSNF (contents of the WP_Degradation Container).......... 6-28

11. Schematic Temperature Versus Time Profiles for a Peak Temperature of $220^{\circ} \mathrm{C}$ and Decay Terms of 0.4 and 0.8 .

12. Schematic Relative Humidity Versus Time Profiles for a Peak Temperature of $220^{\circ} \mathrm{C}$, Decay Term of 0.4, and Scale Terms of 4 and 8.

13. Contents of the Gen_Corr_DS Container Element

14. Contents of the Gen_Corr_WPOB Container Element ………………………............. 6-37

15. Contents of the CWD Container Element (Global CWD DLL Inputs) ............................ 6-39

16. Contents of the CWD CSNF Container Element...................................................... 6-39

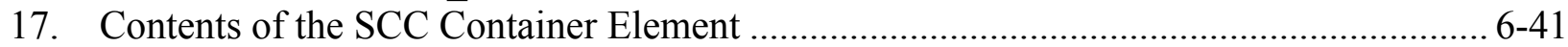

18. Contents of SCC_Outer_Lid Container Element......................................................... 6-42

19. Example GoldSim Implementation to Determine the Fraction of Early Failed Waste

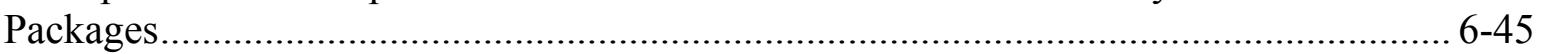

20. Example GoldSim Implementation to Determine the Number and Failure Time of Early Failed Waste Packages ....................................................................................... 6-48

21. Contents of NumEFPaks_Input Element ................................................................... 6-49

22. The Upper- and Lower-Bounds, Mean, and $95^{\text {th }}, 75^{\text {th }}, 25^{\text {th }}$, and $5^{\text {th }}$ Percentile Confidence Intervals of the First Breach Profile of CSNF Waste Packages With Time for the IWPD Analysis.

23. The Upper-Bound, Mean, and $95^{\text {th }}, 75^{\text {th }}, 25^{\text {th }}$, and $5^{\text {th }}$ Percentile Confidence Intervals of the First Breach Profile of CSNF Drip Shields With Time for the IWPD Analysis .... 6-58

24. The Upper- and Lower-Bounds, Mean, and $95^{\text {th }}, 75^{\text {th }}, 25^{\text {th }}$, and $5^{\text {th }}$ Percentile Confidence Intervals of the First Crack Breach Profile of CSNF Waste Packages With Time for the IWPD Analysis

25. The Upper- and Lower-Bounds, Mean, and $95^{\text {th }}, 75^{\text {th }}, 25^{\text {th }}$, and $5^{\text {th }}$ Percentile Confidence Intervals of the First Patch Breach Profile of CSNF Waste Packages With Time for the IWPD Analysis

26. The Upper- and Lower-Bounds, Mean, and $95^{\text {th }}, 75^{\text {th }}, 25^{\text {th }}$, and $5^{\text {th }}$ Percentile Confidence Intervals of the Average Number of Crack Penetrations per Failed CSNF Waste Package Profile With Time for the IWPD Analysis. 


\section{FIGURES (Continued)}

Page

27. The Upper- and Lower-Bounds, Mean, and $95^{\text {th }}, 75^{\text {th }}, 25^{\text {th }}$, and $5^{\text {th }}$ Percentile Confidence Intervals of the Average Number of Patch Penetrations per Failed CSNF Waste Package Profile With Time for the IWPD Analysis

28. The Upper- and Lower-Bounds, Mean, and $95^{\text {th }}, 75^{\text {th }}, 25^{\text {th }}$, and $5^{\text {th }}$ Percentile Confidence Intervals of the First Breach Profile of CDSP Waste Packages With Time for the IWPD Analysis.

29. The Upper-Bound, Mean, and $95^{\text {th }}, 75^{\text {th }}, 25^{\text {th }}$, and $5^{\text {th }}$ Percentile Confidence Intervals of the First Breach Profile of CDSP Drip Shields With Time for the IWPD Analysis .... 6-62

30. The Upper- and Lower-Bounds, Mean, and $95^{\text {th }}, 75^{\text {th }}, 25^{\text {th }}$, and $5^{\text {th }}$ Percentile Confidence Intervals of the First Crack Breach Profile of CDSP Waste Packages With Time for the IWPD Analysis

31. The Upper- and Lower-Bounds, Mean, and $95^{\text {th }}, 75^{\text {th }}, 25^{\text {th }}$, and $5^{\text {th }}$ Percentile Confidence Intervals of the First Patch Breach Profile of CDSP Waste Packages With Time for the IWPD Analysis

32. The Upper- and Lower-Bounds, Mean, and $95^{\text {th }}, 75^{\text {th }}, 25^{\text {th }}$, and $5^{\text {th }}$ Percentile Confidence Intervals of the Average Number of Crack Penetrations per Failed CDSP Waste Package Profile With Time for the IWPD Analysis

33. The Upper- and Lower-Bounds, Mean, and $95^{\text {th }}, 75^{\text {th }}, 25^{\text {th }}$, and $5^{\text {th }}$ Percentile Confidence Intervals of the Average Number of Patch Penetrations per Failed CDSP Waste Package Profile With Time for the IWPD Analysis

34. The 95th Percentile Confidence Intervals and Means Using 250, 500, 1,000, and 3,400 Drip Shield-Waste Package Pairs of the First Breach of CSNF Waste Package Profile With Time for the IWPD Analysis 


\section{TABLES}

Page

1. Summary of IWPD Analysis Inputs ……………....................................................... 4-1

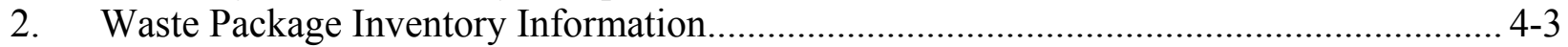

3. Waste Package and Drip Shield Dimensions ................................................................ 4-4

4. Cumulative Distribution Function for General Corrosion Rates for Under Side of the

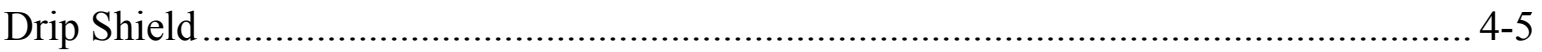

5. Cumulative Distribution Function for General Corrosion Rates for the Top Side of the

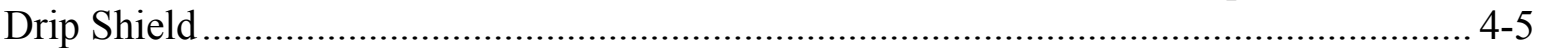

6. Primary General Corrosion Rate Distribution ................................................................. 4-6

7. General Corrosion Slope Term $\left(C_{l}\right)$ Distribution .......................................................... 4-8

8. Manufacturing Defect Analysis Inputs and Their Sources ............................................ 4-9

9. Stress and Stress Intensity Factor Profile Inputs and Their Sources ................................ 4-10

10. Stress Coefficients Used in the IWPD Analysis for the Outer and Middle Closure Lids of Waste Package Outer Barrier in Metric Units (i.e., stress in MPa)..................... 4-10

11. Stress Intensity Factor $\left(\mathrm{K}_{\mathrm{I}}\right)$ Vs. Depth Tables (due to Sz Hoop Stress) for the Outer and Middle Closure-Lids of Waste Package Outer Barrier ................................................ 4-11

12. Slip Dissolution Inputs Used in the IWPD Analysis and Their Sources .......................... 4-14

13. Waste Package Outer Barrier Microbially Influenced Corrosion Inputs and Their

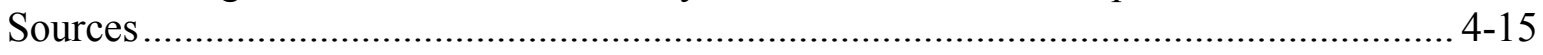

14. Waste Package Early Failure Inputs and Their Sources ............................................... 4-16

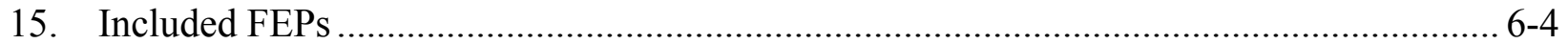

16. Probability of Nondetection Inputs Used in the IWPD Analysis and Their Sources ....... 6-15

17. Weld Flaw Analysis Inputs Used in the IWPD Analysis and Their Sources ................... 6-16

18. Waste Package Early Failure Inputs to the GoldSim Software ..................................... 6-21

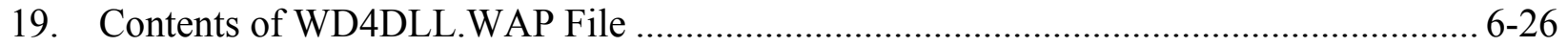

20. Column Contents of the Failure_Opening_CSNF Element............................................ 6-27

21. Combinations of Peak Temperature, $\mathrm{T}_{0}$, Decay Term, $a$, and Scaling Term, $b$, Used to Create Representative Thermal Hydrologic Histories ....................................................... 6-33

22. Waste Package Early Failure Parameters and Their Sources .......................................... 6-45

23. Early Failure Waste Package Unconditional Probability Values ...................................... 6-46

24. Multinomial Sampling Algorithm (Three Waste Package Types) .................................. 6-47

25. Contents of the WAPDEG_Inputs_EF Element ...................................................... 6-49

26. Contents of Linked_Files Container .............................................................................

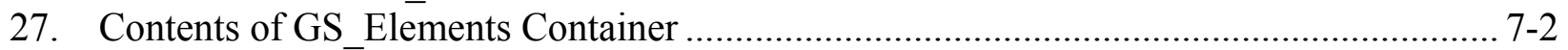

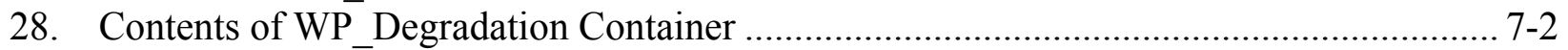

29. Contents of the Gen_Corr_DS Container Element....................................................... 7-2

30. Contents of the Gen_Corr_WPOB Container Element …………................................. 7-2

31. Contents of the CWD Container Element............................................................... 7-3



33. Contents of the SCC_Outer_Lid Container Element......................................................... 7-4

34. Contents of the SCC_Middle_Lid Container Element ............................................... 7-5

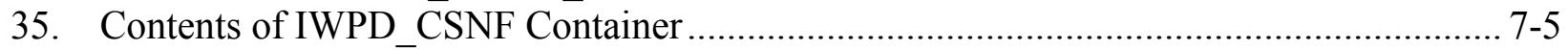

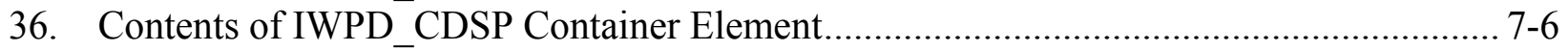

37. Contents of CWD_CSNF Container Element........................................................... 


\section{TABLES (Continued)}

Page

38. Contents of CWD CDSP Container Element................................................................ 7-7

39. Waste Package Early Failure Parameters and Their Sources .......................................... 7-8

40. Early Failure Waste Package Unconditional Probability Values ..................................... 7-8

41. Early Failure Waste Package Conditional Probability Density Function ......................... 7-8 


\section{ACRONYMS}

$\begin{array}{ll}\text { AP } & \text { absorber plate } \\ \text { CDF } & \text { cumulative distribution function } \\ \text { CDSP } & \text { codisposal } \\ \text { CFR } & \text { Code of Federal Regulations } \\ \text { CPP } & \text { cyclic potentiodynamic polarization } \\ \text { CSNF } & \text { commercial spent nuclear fuel } \\ \text { DHLW } & \text { defense high-level radioactive waste } \\ \text { DLL } & \text { dynamic link library } \\ \text { DOE } & \text { U.S. Department of Energy } \\ \text { DTN } & \text { Data Tracking Number } \\ \text { EBS } & \text { engineered barrier system } \\ \text { EPRI } & \text { Electric Power Research Institute } \\ \text { FEPs } & \text { features, events, and processes } \\ \text { HAZ } & \text { heat-affected zone } \\ \text { HLW } & \text { high-level waste } \\ \text { IMARC } & \text { Integrated Multiple Assumptions and Release Code } \\ \text { IWPD } & \text { Integrated Waste Package Degradation } \\ \text { LA } & \text { License Application } \\ \text { LC } & \text { localized corrosion } \\ \text { LTCTF } & \text { Long Term Corrosion Test Facility } \\ \text { NDE } & \text { nondestructive evaluation } \\ \text { NRC } & \text { U.S. Nuclear Regulatory Commission } \\ \text { RH } & \text { relative humidity } \\ \text { SC } & \text { Safety Category } \\ \text { Sd } & \text { standard deviation } \\ \text { SMR } & \text { Software Management Report } \\ \text { SNF } & \text { spent nuclear fuel } \\ \text { SR } & \text { Site Recommendation } \\ \text { TMRB } & \text { Technical Management Review Board } \\ \text { TPA } & \text { Total-system Performance Assessment } \\ \text { TSPA } & \text { Total System Performance Assessment } \\ \text { YS } & \text { yield strength } \\ & \end{array}$




\section{INTENTIONALLY LEFT BLANK}




\section{PURPOSE}

As directed by Technical Work Plan for: Regulatory Integration Modeling and Analysis of the Waste Form and Waste Package (BSC 2004 [DIRS 171583]), an analysis of the degradation of the engineered barrier system (EBS) drip shields and waste packages at the Yucca Mountain repository is developed. The purpose of this activity is to provide the TSPA with inputs and methodologies used to evaluate waste package and drip shield degradation as a function of exposure time under exposure conditions anticipated in the repository. This analysis provides information useful to satisfy Yucca Mountain Review Plan, Final Report (NRC 2003 [DIRS 163274]) requirements. Several features, events, and processes (FEPs) are also discussed (Section 6.2, Table 15).

The previous revision of this report was prepared as a model report in accordance with AP-SIII.10Q, Models. Due to changes in the role of this report since the site recommendation, it no longer contains model development. This revision is prepared as a scientific analysis in accordance with AP-SIII.9Q, Scientific Analyses and uses models previously validated in (1) Stress Corrosion Cracking of the Drip Shield, the Waste Package Outer Barrier, and the Stainless Steel Structural Material (BSC 2004 [DIRS 169985]); (2) General Corrosion and Localized Corrosion of Waste Package Outer Barrier (BSC 2004 [DIRS 169984]); and (3) General Corrosion and Localized Corrosion of Drip Shield (BSC 2004 [DIRS 169845]). The integrated waste package degradation (IWPD) analysis presented in this report treats several implementation-related issues, such as defining the number and size of patches per waste package that undergo stress corrosion cracking; recasting the weld flaw analysis in a form as implemented in the Closure Weld Defects (CWD) software; and, general corrosion rate manipulations (e.g., change of scale in Section 6.3.4). The weld flaw portion of this report takes input from an engineering calculation (BSC 2004 [DIRS 170024]) and uses standard mathematical methods to enable easier implementation. The IWPD analysis also provides guidance on implementation of early failures (importance sampling and multinomial distribution usage). These manipulations are evident from standard scientific practices, approaches, or methods and do not require changes to the previously validated models.

The IWPD analysis itself (Section 6.4), not the resultant curves from executing the IWPD analysis presented in Section 6.5 (which are for illustrative purposes), is used directly in total system performance assessment (TSPA). The IWPD analysis simulates general corrosion and stress corrosion cracking of the waste package outer barrier and general corrosion of the drip shield. The effects of igneous and seismic events and localized corrosion on drip shield and waste package performance are not evaluated in this report. The outputs of this report are inputs and methodologies used by TSPA to evaluate waste package and drip shield degradation as a function of exposure time under exposure conditions anticipated in the repository. The analyses presented in this report are for the current repository design (BSC 2004 [DIRS 168489]).

Analysis outputs presented in Section 6.5 are for illustrative purposes only and do not represent output for use in TSPA nor should they be used to evaluate repository performance. The drip shield and waste package degradation profiles presented in Section 6.5 result from the use of representative thermal hydrologic history files (Section 6.4.5) produced to allow the IWPD analysis to be exercised in this report. The drip shield and waste package degradation profiles generated in TSPA-LA will make use of the thermal hydrologic history files appropriate for the 
repository. Also, the results of the localized corrosion (pitting and crevice corrosion) are not presented in this report because evaluation of this degradation mode would require (in addition to of the actual thermal hydrologic history files appropriate for the repository) in-drift geochemical inputs, which will only be available to TSPA. Therefore, localized corrosion is implemented directly in TSPA. The drip shield and waste package degradation profiles presented in Section 6.5 provide evidence that the IWPD analysis implementation functions properly over a range of input parameter values.

The IWPD analysis applies to degradation of Titanium Grade 7 and Alloy 22. The limitations on the IWPD analysis result from the models implemented within it. The corrosion models developed in General Corrosion and Localized Corrosion of the Drip Shield are intended to apply to the Titanium Grade 7 alloy used for the drip shield plates (BSC 2004 [DIRS 169845], Section 1.2). The treatment of stress corrosion cracking is restricted to the waste package outer barrier. Degradation of the Stainless Steel Type 316 waste package inner vessel is not analyzed.

The following scientific analyses or models reports provide direct or indirect inputs to this report: Analysis of Mechanisms for Early Waste Package/Drip Shield Failure, General Corrosion and Localized Corrosion of the Drip Shield, General Corrosion and Localized Corrosion of Waste Package Outer Barrier, and Stress Corrosion Cracking of the Drip Shield, the Waste Package Outer Barrier, and the Stainless Steel Structural Material. This report provides direct or indirect inputs to the following scientific analyses or models reports: Screening Analysis for Criticality Features, Events, and Processes for License Application, FEPs Screening of Processes and Issues in Drip Shield and Waste Package Degradation, Features, Events, and Processes: System Level, and Total System Performance Assessment (TSPA) Model/Analysis for the License Application. 


\section{QUALITY ASSURANCE}

The quality assurance program applies to the development of this technical product. Technical Work Plan for: Regulatory Integration Modeling and Analysis of the Waste Form and Waste Package (BSC 2004 [DIRS 171583]) determined that this activity is subject to Quality Assurance Requirements and Description (QARD) (DOE 2004 [DIRS 171539]) requirements. All waste package configurations have been determined to be important to waste isolation in accordance with AP-2.22Q and, therefore, are classified as Safety Category (SC) in Q-List (BSC 2004 [DIRS 168361], Appendix A; BSC 2004 [DIRS 170992]). The drip shields have been determined to be important to waste isolation in accordance with AP-2.22Q and, therefore, are classified as Safety Category (SC) in Q-List (BSC 2004 [DIRS 168361], Appendix A; BSC 2004 [DIRS 170992]).

The inputs to this report are documented according to AP-3.15Q, Managing Technical Product Inputs. The methods used to control the electronic management of data as required by AP-SV.1Q, Control of the Electronic Management of Information, were accomplished in accordance with the technical work plan. The process for control of the electronic management of information on evaluation of work activities, processes, or process functions (AP-SV.1Q, Section 5.0) is followed to ensure accuracy, completeness, and security of information and data used in preparation of this report. Examples of process controls mentioned in AP-SV.1Q are (a) access to the information contained on personal computer is password protected; (b) secured backup copies are appropriately labeled and stored before changes are made and kept until the changes are confirmed and correct; (c) physical electronic media (tape, diskette, CD-ROM, etc.) are appropriately labeled; and (d) for nonphysical electronic media, transport mechanisms can be e-mail, TCP/IP, NetBios, etc. and methods of receipt verification may include visual inspection, transmission verification settings, check sums, application information integrity check, etc.

This document was prepared in accordance with AP-SIII.9Q, Scientific Analyses, and reviewed in accordance with AP-2.14Q, Document Review. 


\section{INTENTIONALLY LEFT BLANK}




\section{USE OF SOFTWARE}

\subsection{EXCEL 97 SR-2}

Excel 97 SR-2 is a commercial off-the-shelf software program used in this report. The computations performed using Excel in this report use only standard functions and are documented in sufficient detail to allow an independent technical reviewer to reproduce or verify the results by visual inspection or hand calculation without recourse to the originator. The formulas or algorithms used and a listing of inputs to and outputs from the formulas or algorithms are sufficiently documented to allow results to be reproduced. Therefore, this software is exempt from LP-SI.11Q-BSC, Software Management. Excel 97 SR-2 is appropriate for its intended use because it offers the mathematical and graphical functionality necessary to perform and document the numerical manipulations used in this report. Excel 97 SR-2 was executed on an Optiplex GX260 Workstation (CRWMS M\&O tag 152849, located in the Summerlin Offices, Las Vegas, Nevada) equipped with the Windows 2000 operating system.

\subsection{SIGMAPLOT 8.0}

SigmaPlot 8.0 is a commercial off-the-shelf software program used in this report. No computations are performed in this report using SigmaPlot 8.0; therefore, this software is exempt from LP-SI.11Q-BSC, Software Management. SigmaPlot 8.0 is appropriate for its intended use because it offers the graphical functionality necessary to perform and document the plots used in this report. SigmaPlot 8.0 was executed on an Optiplex GX260 Workstation (CRWMS M\&O tag 152849, located in the Summerlin Offices, Las Vegas, Nevada) equipped with the Windows 2000 operating system.

\subsection{MATHCAD 2001i PROFESSIONAL}

MathCad 2001i Professional is a commercial off-the-shelf software program used in this report. The computations performed using MathCad 2001i Professional in this report use only standard functions and are documented in sufficient detail to allow an independent technical reviewer to reproduce or verify the results by visual inspection or hand calculation without recourse to the originator. The formulas or algorithms used and a listing of inputs to and outputs from the formulas or algorithms are sufficiently documented to allow results to be reproduced. Therefore, this software is exempt from LP-SI.11Q-BSC, Software Management. MathCad 2001i Professional is appropriate for its intended use because it offers the mathematical and graphical functionality necessary to perform and document the numerical manipulations used in this report. MathCad 2001i Professional was executed on an Optiplex GX260 Workstation (CRWMS M\&O tag 152849, located in the Summerlin Offices, Las Vegas, Nevada) equipped with the Windows 2000 operating system. 


\subsection{WAPDEG V.4.07}

WAste Package DEGradation (WAPDEG) (WAPDEG V4.07, STN: 10000-4.07-00 [DIRS 161240]) is developed software used in this report, in accordance with LP-SI.11Q-BSC, Software Management, to calculate drip shield and waste package degradation profiles. The WAPDEG software is qualified. The following information is used to identify the WAPDEG software:

- Software Title: WAPDEG

- Software Tracking Number: 10000-4.07-00

- Version Number: 4.07

This software was obtained from the software configuration manager in accordance with appropriate procedures. WAPDEG was executed on an Optiplex GX260 Workstation (CRWMS M\&O tag 152849, located in the Summerlin Offices, Las Vegas, Nevada) equipped with the Windows 2000 operating system. WAPDEG Version 4.07 was selected for this application, because it was specifically designed to calculate drip shield and waste package failure profiles. There are no limitations on outputs due to the software selected. The use of the software was consistent with its intended use and within its range of validation.

\subsection{CWD V. 2.0}

Closure Weld Defects (CWD) (CWD V2.0, 10363-2.0-00 [DIRS 162809]) is developed software used in this report, in accordance with LP-SI.11Q-BSC, Software Management, to calculate the probability of the occurrence and size of weld flaws in the closure-lid welds of the Alloy 22 waste package outer barrier. The CWD software is qualified. The following information is used to identify the CWD software:

- Software Title: CWD

- Software Tracking Number: 10363-2.0-00

- Version Number: 2.0

This software was obtained from the software configuration manager in accordance with appropriate procedures. CWD was executed on an Optiplex GX260 Workstation (CRWMS M\&O tag 152849, located in the Summerlin Offices, Las Vegas, Nevada) equipped with the Windows 2000 operating system. This software was selected for this application because it was developed to calculate the probability of the occurrence and size of weld flaws in the closure-lid welds of the Alloy 22 waste package outer barrier. There are no limitations on outputs due to the software selected. The use of the software was consistent with its intended use and within its range of validation. 


\subsection{SCCD V. 2.01}

Stress Corrosion Cracking Dissolution (SCCD) (SCCD V2.01, STN: 10343-2.01-00 [DIRS 161757]) is developed software used in this report, in accordance with LP-SI.11Q-BSC, Software Management, to calculate the stress and stress intensity factor profiles in the closure-lid welds of the Alloy 22 waste package outer barrier. The SCCD software routine is qualified. The following information is used to identify the SCCD software:

- Software Title: SCCD

- Software Tracking Number: 10343-2.01-00

- Version Number: 2.01

This software was obtained from the Software Configuration Manager in accordance with appropriate procedures. SCCD was executed on an Optiplex GX260 Workstation (CRWMS M\&O tag 152849, located in the Summerlin Offices, Las Vegas, Nevada) equipped with the Windows 2000 operating system. This software was selected for this application because it was developed to calculate the stress and stress intensity factor profiles in the closurelid welds of the Alloy 22 waste package outer barrier. There are no limitations on outputs due to the software selected. The use of the software was consistent with its intended use and within its range of validation.

\subsection{GOLDSIM V. 7.50.100}

GoldSim (GoldSim V7.50.100, STN: 10344-7.50.100-00 [DIRS 161572]) is acquired software controlled in accordance with LP-SI.11Q-BSC, Software Management. GoldSim was used to pass input to the developed software listed in this Section. The GoldSim software is qualified. The following information is used to identify the GoldSim software:

- Software Title: GoldSim

- Software Tracking Number: 10344-7.50.100-00

- Version Number: 7.50 .100

This software was obtained from the software configuration manager in accordance appropriate procedures. GoldSim was executed on an Optiplex GX260 Workstation (CRWMS M\&O tag 152849, located in the Summerlin Offices, Las Vegas, Nevada) equipped with the Windows 2000 operating system. This software was selected for this application because it has the capabilities to interface with external software routines and was specifically configured to call the developed software discussed in this section. There are no limitations on outputs due to the software selected. The use of the software was consistent with its intended use and within its range of validation. 


\section{INTENTIONALLY LEFT BLANK}




\section{INPUTS}

This section describes the direct inputs used to construct the integrated waste package degradation (IWPD) analysis, the criteria and codes and standards applied in this analysis. Treatment of uncertainties in inputs will be discussed in this section and in Section 6.

\subsection{DIRECT INPUTS}

Since the time to waste package breach due to stress corrosion cracking (SCC) and general corrosion is well beyond the regulatory period, and the waste package design may further change as the design matures, it is appropriate and justified to use the waste package dimensions and weld volumes from the IED identified in Design and Engineering, D\&E/PA/C IED Typical Waste Package Components Assembly 1 of 9 (BSC 2003 [DIRS 165406]) and the documents listed on this IED, based on TMRB decision 2004-066 (BSC 2004 [DIRS 171478]).

Table 1. Summary of IWPD Analysis Inputs

\begin{tabular}{|c|c|c|c|}
\hline Input Name & Input Source & DTN & Input Value \\
\hline $\begin{array}{l}21 \text { PWR Waste Package } \\
\text { Configuration Dimensions }\end{array}$ & $\begin{array}{l}\text { Repository Design, Waste } \\
\text { Package, Project 21-PWR } \\
\text { Waste Package with Absorber } \\
\text { Plates, Sheet } 1 \text { of } 3 \text {, Sheet } 2 \text { of } \\
3 \text {, and Sheet } 3 \text { of } 3 \\
\text { (BSC } 2001 \text { [DIRS 157812]) }\end{array}$ & $\mathrm{N} / \mathrm{A}$ & See Section 4.1.1 \\
\hline $\begin{array}{l}5 \mathrm{HLW} / 1 \text { DOE Short } \\
\text { Waste Package } \\
\text { Configuration Dimensions }\end{array}$ & $\begin{array}{l}\text { Repository Design, Waste } \\
\text { Package Project } 5 \text { DHLW/DOE } \\
\text { SNF - Short Waste Package, } \\
\text { Sheet } 1 \text { of } 3 \text {, Sheet } 2 \text { of 3, and } \\
\text { Sheet } 3 \text { of } 3 \\
\text { (BSC } 2001 \text { [DIRS 157817]) }\end{array}$ & $\mathrm{N} / \mathrm{A}$ & See Section 4.1.1 \\
\hline $\begin{array}{l}5 \mathrm{HLW} / 1 \text { DOE Long } \\
\text { Waste Package } \\
\text { Configuration Dimensions }\end{array}$ & $\begin{array}{l}\text { Repository Design, Waste } \\
\text { Package Project } 5 \text { DHLW/DOE } \\
\text { SNF - Long Waste Package, } \\
\text { Sheet } 1 \text { of } 3 \text {, Sheet } 2 \text { of 3, and } \\
\text { Sheet } 3 \text { of } 3 \\
\text { (BSC } 2001 \text { [DIRS 157818]) }\end{array}$ & $\mathrm{N} / \mathrm{A}$ & See Section 4.1.1 \\
\hline Drip Shield Thickness & $\begin{array}{l}\text { Repository Design Project, } \\
\text { Repository/PA IED Interlocking } \\
\text { Drip Shield and Emplacement } \\
\text { Pallet. } \\
\text { (BSC 2004 [DIRS 169220], } \\
\text { Table 5) }\end{array}$ & $\mathrm{N} / \mathrm{A}$ & See Section 4.1.1 \\
\hline $\begin{array}{l}\text { Waste Package Inventory } \\
\text { Information }\end{array}$ & $\begin{array}{l}\text { Repository Design Project, } \\
\text { RDP/PA IED Typical Waste } \\
\text { Package Components } \\
\text { Assembly (2). } \\
\text { (BSC 2003 [DIRS 163855], } \\
\text { Table 11) }\end{array}$ & $\mathrm{N} / \mathrm{A}$ & See Section 4.1.1 \\
\hline
\end{tabular}


Table 1. Summary of IWPD Analysis Inputs (Continued)

\begin{tabular}{|c|c|c|c|}
\hline Input Name & Input Source & DTN & Input Value \\
\hline Weld Volumes & $\begin{array}{l}\text { Repository Design Project, } \\
\text { RDP/PA IED Typical Waste } \\
\text { Package Components } \\
\text { Assembly (5). } \\
\text { (BSC } 2003 \text { [DIRS 164610], } \\
\text { Table } 18 \text { and 19) }\end{array}$ & $\mathrm{N} / \mathrm{A}$ & See Section 4.1 .4 \\
\hline $\begin{array}{l}\text { Drip shield general } \\
\text { corrosion rate (Titanium } \\
\text { Grade } 7 \text { ) }\end{array}$ & $\begin{array}{l}\text { General Corrosion and } \\
\text { Localized Corrosion of the Drip } \\
\text { Shield } \\
\text { (BSC 2004 [DIRS 169845], } \\
\text { Section 6.5.5) }\end{array}$ & $\begin{array}{l}\text { MO0408MWDGLCDS.002 } \\
\text { [DIRS 171486] }\end{array}$ & See Section 4.1.2 \\
\hline $\begin{array}{l}\text { Alloy } 22 \text { waste package } \\
\text { outer barrier general } \\
\text { corrosion inputs }\end{array}$ & $\begin{array}{l}\text { General Corrosion and } \\
\text { Localized Corrosion of Waste } \\
\text { Package Outer Barrier } \\
\text { (BSC 2004 [DIRS 169984], } \\
\text { Section 6.4.3) }\end{array}$ & $\begin{array}{l}\text { MO0409MWDUGCMW.000 } \\
\text { [DIRS 171714] }\end{array}$ & See Section 4.1.3 \\
\hline Weld flaw analysis inputs & $\begin{array}{l}\text { BSC } 2004 \text { [DIRS 170024] } \\
\text { BSC } 2004 \text { [DIRS 169985] } \\
\text { BSC } 2001 \text { [DIRS 157812] } \\
\text { BSC } 2001 \text { [DIRS 157817] } \\
\text { BSC } 2001 \text { [DIRS 157818] } \\
\end{array}$ & $\begin{array}{l}\text { LL030607012251.065 } \\
\text { [DIRS 163968] }\end{array}$ & See Section 4.1 .4 \\
\hline $\begin{array}{l}\text { Stress intensity factor }\left(\mathrm{K}_{\mathrm{l}}\right) \\
\text { vs depth }\end{array}$ & $\begin{array}{l}\text { Stress Corrosion Cracking of } \\
\text { the Drip Shield, the Waste } \\
\text { Package Outer Barrier, and the } \\
\text { Stainless Steel Structural } \\
\text { Material } \\
\text { (BSC } 2004 \text { [DIRS 169985]) }\end{array}$ & $\begin{array}{l}\text { LL030607012251.065 } \\
\text { [DIRS 163968] }\end{array}$ & See Section 4.1.5 \\
\hline $\begin{array}{l}\text { Stress coefficients for } \\
\text { outer and middle closure } \\
\text { lids }\end{array}$ & $\begin{array}{l}\text { Stress Corrosion Cracking of } \\
\text { the Drip Shield, the Waste } \\
\text { Package Outer Barrier, and the } \\
\text { Stainless Steel Structural } \\
\text { Material } \\
\text { (BSC } 2004 \text { [DIRS 169985]) }\end{array}$ & $\begin{array}{l}\text { LL030607012251.065 } \\
\text { [DIRS 163968] }\end{array}$ & See Section 4.1.5 \\
\hline $\begin{array}{l}\text { Yield strength, YS } \\
\text { (various temperatures) }\end{array}$ & $\mathrm{N} / \mathrm{A}$ & $\begin{array}{l}\text { MO0003RIB00071.000 } \\
\text { [DIRS 148850] }\end{array}$ & See Section 4.1.5 \\
\hline Slip dissolution inputs & $\begin{array}{l}\text { Stress Corrosion Cracking of } \\
\text { the Drip Shield, the Waste } \\
\text { Package Outer Barrier, and the } \\
\text { Stainless Steel Structural } \\
\text { Material } \\
\text { (BSC } 2004 \text { [DIRS 169985]) }\end{array}$ & $\begin{array}{l}\text { LL030607012251.065 } \\
\text { [DIRS 163968] }\end{array}$ & See Section 4.1.6 \\
\hline $\begin{array}{l}\text { Waste package outer } \\
\text { barrier microbial induced } \\
\text { corrosion inputs }\end{array}$ & $\begin{array}{l}\text { General Corrosion and } \\
\text { Localized Corrosion of Waste } \\
\text { Package Outer Barrier } \\
\text { (BSC 2004 [DIRS 169984], } \\
\text { Section 6.4.5) }\end{array}$ & $\begin{array}{l}\text { MO0409MWDUGCMW.000 } \\
\text { [DIRS 171714] }\end{array}$ & See Section 4.1.7 \\
\hline $\begin{array}{l}\text { Waste package early } \\
\text { failure inputs }\end{array}$ & $\begin{array}{l}\text { Analysis of Mechanisms for } \\
\text { Early Waste Package/Drip } \\
\text { Shield Failure } \\
\text { (BSC 2004 [DIRS 170024]) }\end{array}$ & $\mathrm{N} / \mathrm{A}$ & See Section 4.1.8 \\
\hline
\end{tabular}




\subsubsection{Waste Package and Drip Shield Design Input}

In this report, as in TSPA-SR (CRWMS M\&O 2000 [DIRS 153246], Table 4.1-1), two nominal waste package configurations are considered. The first is referred to as the commercial spent nuclear fuel (CSNF) waste package configuration (CRWMS M\&O 2000 [DIRS 153246], Table 4.1-1) for which the 21-PWR AP waste package configuration parameters are used (BSC 2001 [DIRS 157812]). The second configuration is the codisposal (CDSP) waste package configuration (CRWMS M\&O 2000 [DIRS 153246], Table 4.1-1) whose length is considered to be the average length of the $5 \mathrm{HLW} / 1$ DOE SNF long (BSC 2001 [DIRS 157818]) and short (BSC 2001 [DIRS 157817]) waste package configurations. The waste package inventory information for the repository is shown in Table 2. Note that commercial spent nuclear fuelcontaining waste package configurations (e.g., 21-PWR AP) and naval fuel-containing waste package configurations (i.e., naval short and long) are represented by the CSNF waste package configuration and HLW-containing waste package configurations (e.g., 5 HLW long only) are represented by the CDSP waste package configuration.

Table 2. Waste Package Inventory Information

\begin{tabular}{|l|c|c|}
\hline $\begin{array}{c}\text { Waste Package } \\
\text { Configuration }\end{array}$ & $\begin{array}{c}\text { Nominal Quantity } \\
\text { for LA }\end{array}$ & $\begin{array}{c}\text { Nominal Waste } \\
\text { Package } \\
\text { Configuration }\end{array}$ \\
\hline 21-PWR AP & 4,299 & CSNF \\
\hline 21-PWR CR & 95 & CSNF \\
\hline 12-PWR AP Long & 163 & CSNF \\
\hline 44-BWR AP & 2,831 & CSNF \\
\hline 24-BWR AP & 84 & CSNF \\
\hline 5 IPWF & 0 & N/A \\
\hline 5 HLW Short/1 DOE SNF Short & 1,147 & CDSP \\
\hline 5 HLW Long/1 DOE SNF Long & 1,406 & CDSP \\
\hline 2 MCO/2 HLW & 149 & CDSP \\
\hline 5 HLW Long/1 DOE SNF Short & 31 & CDSP \\
\hline 5 HLW Long Only & 679 & CDSP \\
\hline Naval Short & 144 & CSNF \\
\hline Naval Long & 156 & CSNF \\
\hline
\end{tabular}

Source: BSC 2003 [DIRS 163855], Table 11.

Based on Table 2, the total number of waste packages represented by the CSNF and CDSP waste package configurations in the repository are 7,772 and 3,412, respectively.

The 21-PWR waste package configuration is an appropriate representation of the CSNF waste package configuration since the 21-PWR AP waste package is the most common configuration in the repository (BSC 2003 [DIRS 163855], Table 11). The 5 HLW/1 DOE SNF (codisposal) long and short waste package configurations are appropriate representations of the CDSP waste package configuration since these are the most common High-Level Waste (HLW) waste package configurations in the repository (BSC 2003 [DIRS 163855], Table 11).

Relevant waste package and drip shield dimensions were obtained from information exchange drawings (IED) (BSC 2003 [DIRS 165406]; BSC 2004 [DIRS 169220]) or design products listed on IEDs (BSC 2003 [DIRS 165406]) and are presented in Table 3. 
Table 3. Waste Package and Drip Shield Dimensions

\begin{tabular}{|c|c|c|}
\hline Input Name & Input Source & Input Value \\
\hline $\begin{array}{l}\text { 21-PWR Waste Package Outer } \\
\text { Barrier (Shell) Outer Diameter (OD) }\end{array}$ & $\begin{array}{l}\text { BSC } 2001 \text { [DIRS 157812] } \\
\text { Sheet } 2 \text { of } 3\end{array}$ & $1,564 \mathrm{~mm}$ \\
\hline $\begin{array}{l}\text { 21-PWR Waste Package Inner } \\
\text { Barrier Length }\end{array}$ & $\begin{array}{l}\text { BSC } 2001 \text { [DIRS 157812] } \\
\text { Sheet } 2 \text { of } 3\end{array}$ & $4,775 \mathrm{~mm}$ \\
\hline $\begin{array}{l}\text { 21-PWR AP Waste Package Outer } \\
\text { Barrier Thickness }\end{array}$ & $\begin{array}{l}\text { BSC } 2001 \text { [DIRS 157812] } \\
\text { Sheet } 3 \text { of } 3\end{array}$ & $20 \mathrm{~mm}$ \\
\hline $\begin{array}{l}5 \text { HLW/1 DOE SNF Short Waste } \\
\text { Package Outer Barrier (Shell) Outer } \\
\text { Diameter (OD) }\end{array}$ & $\begin{array}{l}\text { BSC } 2001 \text { [DIRS 157817] } \\
\text { Sheet } 2 \text { of } 3\end{array}$ & $2,030 \mathrm{~mm}$ \\
\hline $\begin{array}{l}5 \text { HLW/1 DOE SNF Short Waste } \\
\text { Package Outer Barrier (Shell) } \\
\text { Nominal Outer Diameter }\end{array}$ & $\begin{array}{l}\text { BSC } 2001 \text { [DIRS 157817] } \\
\text { Sheet } 1 \text { of } 3\end{array}$ & $2,110 \mathrm{~mm}$ \\
\hline $\begin{array}{l}5 \mathrm{HLW} / 1 \text { DOE SNF Short Waste } \\
\text { Package Inner Barrier Length }\end{array}$ & $\begin{array}{l}\text { BSC } 2001 \text { [DIRS 157817] } \\
\text { Sheet } 2 \text { of } 3\end{array}$ & $3,200 \mathrm{~mm}$ \\
\hline $\begin{array}{l}5 \text { HLW/1 DOE SNF Short Waste } \\
\text { Package Outer Barrier Thickness }\end{array}$ & $\begin{array}{l}\text { BSC } 2001 \text { [DIRS 157817] } \\
\text { Sheet } 3 \text { of } 3\end{array}$ & $25 \mathrm{~mm}$ \\
\hline $\begin{array}{l}5 \text { HLW/1 DOE SNF Long Waste } \\
\text { Package Outer Barrier (Shell) Outer } \\
\text { Diameter (OD) }\end{array}$ & $\begin{array}{l}\text { BSC } 2001 \text { [DIRS 157818] } \\
\text { Sheet } 2 \text { of } 3\end{array}$ & $2,030 \mathrm{~mm}$ \\
\hline $\begin{array}{l}5 \mathrm{HLW} / 1 \text { DOE SNF Long Waste } \\
\text { Package Inner Barrier Length }\end{array}$ & $\begin{array}{l}\text { BSC } 2001 \text { [DIRS 157818] } \\
\text { Sheet } 2 \text { of } 3\end{array}$ & $4,827 \mathrm{~mm}$ \\
\hline $\begin{array}{l}5 \text { HLW/1 DOE SNF Long Waste } \\
\text { Package Outer Barrier Thickness }\end{array}$ & $\begin{array}{l}\text { BSC } 2001 \text { [DIRS 157818] } \\
\text { Sheet } 3 \text { of } 3\end{array}$ & $25 \mathrm{~mm}$ \\
\hline Drip Shield Plate Thickness & BSC 2004 [DIRS 169220], Table 5 & $15 \mathrm{~mm}$ \\
\hline
\end{tabular}

The waste package outer barrier (shell) outer diameter and waste package inner barrier length are used to calculate the waste package surface area for use in determining the fraction of area subject to stress corrosion cracking. The waste package outer barrier thickness is used indirectly in the formulation of inputs to the analysis (see Section 6.3.2), while the drip shield thickness is used directly in the WAPDEG_Inputs element of the IWPD analysis (Section 6.3.1 and Table I-1, Row 40). Because these are design-related parameters, there is no uncertainty treatment for these parameters.

The information listed in Table 3 are design-related parameters which were obtained from controlled and confirmed sources and, thus, do not require data tracking numbers.

\subsubsection{Drip Shield General Corrosion Model Inputs}

Details of the general corrosion rate distributions used for the under side and top side of the drip shield are developed in General Corrosion and Localized Corrosion of the Drip Shield (BSC 2004 [DIRS 169845], Section 6.5.5) and are tracked with DTN: MO0408MWDGLCDS.002 [DIRS 171486]. These inputs are qualified. Also, see Section 6.3.3 for a discussion of the drip shield general corrosion model and Section 6.4.6 for discussion of its implementation. The general corrosion rate cumulative distribution function applicable to the under side of the drip shield is shown in Table 4. The general corrosion rate cumulative distribution function applicable to the top side of the drip shield is shown in Table 5. 
Table 4. Cumulative Distribution Function for General Corrosion Rates for Under Side of the Drip Shield

\begin{tabular}{|c|c|c|}
\hline Sample & $\begin{array}{c}\text { Rate } \\
(\mathbf{m m} / \mathbf{y r})\end{array}$ & $\begin{array}{c}\text { Cumulative } \\
\text { Distribution Function }\end{array}$ \\
\hline 1 & $0.00000000 \mathrm{E}+00$ & 0.0000 \\
\hline 2 & $7.90540100 \mathrm{E}-06$ & 0.2500 \\
\hline 3 & $7.90899600 \mathrm{E}-06$ & 0.3125 \\
\hline 4 & $7.91733600 \mathrm{E}-06$ & 0.3750 \\
\hline 5 & $7.99205500 \mathrm{E}-06$ & 0.4375 \\
\hline 6 & $1.59679640 \mathrm{E}-05$ & 0.5000 \\
\hline 7 & $1.60740360 \mathrm{E}-05$ & 0.5625 \\
\hline 8 & $2.35658240 \mathrm{E}-05$ & 0.6250 \\
\hline 9 & $2.37302160 \mathrm{E}-05$ & 0.6875 \\
\hline 10 & $2.40329080 \mathrm{E}-05$ & 0.7500 \\
\hline 11 & $3.99976910 \mathrm{E}-05$ & 0.8125 \\
\hline 12 & $7.14961090 \mathrm{E}-05$ & 0.8750 \\
\hline 13 & $7.91641200 \mathrm{E}-05$ & 0.9375 \\
\hline 14 & $1.12788228 \mathrm{E}-04$ & 1.0000 \\
\hline
\end{tabular}

Source: BSC 2004 [DIRS 169845], Section 6.5.5;

DTN: MO0408MWDGLCDS.002 [DIRS 171486].

Table 5. Cumulative Distribution Function for General Corrosion Rates for the Top Side of the Drip Shield

\begin{tabular}{|c|c|c|}
\hline Sample & $\begin{array}{c}\text { Rate } \\
\text { (mm/yr) }\end{array}$ & $\begin{array}{c}\text { Cumulative Distribution } \\
\text { Function }\end{array}$ \\
\hline 1 & $0.00000000 \mathrm{E}+00$ & $0.00000000 \mathrm{E}+00$ \\
\hline 2 & $4.18430800 \mathrm{E}-06$ & 1.42857143E-01 \\
\hline 3 & $7.90540100 \mathrm{E}-06$ & $1.78571429 \mathrm{E}-01$ \\
\hline 4 & $7.90899600 \mathrm{E}-06$ & $2.14285714 \mathrm{E}-01$ \\
\hline 5 & $7.91733600 \mathrm{E}-06$ & $2.50000000 \mathrm{E}-01$ \\
\hline 6 & $7.99205500 \mathrm{E}-06$ & $2.85714286 \mathrm{E}-01$ \\
\hline 7 & 1.59679640E-05 & 3.21428571E-01 \\
\hline 8 & 1.60740360E-05 & 3.57142857E-01 \\
\hline 9 & $1.65389750 \mathrm{E}-05$ & 3.92857143E-01 \\
\hline 10 & $2.10450870 \mathrm{E}-05$ & $4.28571429 \mathrm{E}-01$ \\
\hline 11 & $2.35658240 \mathrm{E}-05$ & 4.64285714E-01 \\
\hline 12 & $2.37302160 \mathrm{E}-05$ & $5.00000000 \mathrm{E}-01$ \\
\hline 13 & $2.40329080 \mathrm{E}-05$ & 5.35714286E-01 \\
\hline 14 & 2.52784890E-05 & 5.71428571E-01 \\
\hline 15 & 3.99976910E-05 & 6.07142857E-01 \\
\hline 16 & $4.26207080 \mathrm{E}-05$ & $6.42857143 \mathrm{E}-01$ \\
\hline 17 & $4.28647310 \mathrm{E}-05$ & $6.78571429 \mathrm{E}-01$ \\
\hline 18 & $5.15303020 \mathrm{E}-05$ & 7.14285714E-01 \\
\hline 19 & $6.33683700 \mathrm{E}-05$ & $7.50000000 \mathrm{E}-01$ \\
\hline 20 & $6.49668830 \mathrm{E}-05$ & $7.85714286 \mathrm{E}-01$ \\
\hline 21 & 7.14961090E-05 & $8.21428571 \mathrm{E}-01$ \\
\hline 22 & 7.91641200E-05 & 8.57142857E-01 \\
\hline 23 & 8.22028960E-05 & 8.92857143E-01 \\
\hline 24 & $1.11563286 \mathrm{E}-04$ & $9.28571429 \mathrm{E}-01$ \\
\hline 25 & $1.12788228 \mathrm{E}-04$ & 9.64285714E-01 \\
\hline 26 & 3.19409704E-04 & $1.00000000 \mathrm{E}+00$ \\
\hline
\end{tabular}

Source: BSC 2004 [DIRS 169845], Section 6.5.5;

DTN: MO0408MWDGLCDS.002 [DIRS 171486]. 
These inputs are appropriate for their intended use because they were developed for this purpose while providing a reasonable estimate of the general corrosion behavior of Titanium Grade 7 subjected to the exposure conditions in the repository.

DTN: MO0408MWDGLCDS.002 [DIRS 171486] contains the file, 1_Year_CDFs.pdf, that contains the general corrosion rates for the top and under sides of the drip shield used in this report.

The variation in these inputs is entirely due to uncertainty (BSC 2004 [DIRS 169845], Section 6.5.5). Therefore, a single general corrosion rate is sampled from each distribution and applied to all drip shields in the repository. The general corrosion rate sampled for the outside surface of the drip shield is independent of the general corrosion rate sampled for the inner surface of the drip shield because the environments above and below the drip shield are not significantly correlated (BSC 2004 [DIRS 169845], Section 6.5.5).

\subsubsection{Alloy 22 Waste Package Outer Barrier General Corrosion Model Inputs}

\subsubsection{Primary Alloy 22 General Corrosion Rate Distribution}

In General Corrosion and Localized Corrosion of Waste Package Outer Barrier (BSC 2004 [DIRS 169984], Section 6.4.3; DTN: MO0409MWDUGCMW.000 [DIRS 171714]), general corrosion rates determined from 5-year weight-loss samples with the crevice geometry were used to generate a cumulative distribution function for the general corrosion rate $\left(R_{o}\right)$ used in the IWPD analysis at an exposure temperature of $60^{\circ} \mathrm{C}(333.15 \mathrm{~K})$. General Corrosion and Localized Corrosion of Waste Package Outer Barrier (BSC 2004 [DIRS 169984], Section 6.4.3) states that $R_{o}(\mathrm{~nm} / \mathrm{yr})$ is given by a Weibull distribution (Evans et al. 1993 [DIRS 112115], Chapter 41) with scale parameter, $\alpha$, equal to $8.88 \mathrm{~nm} / \mathrm{yr}$, shape parameter, $\beta$, equal to 1.62 , and location parameter, $\theta$, equal to 0 . This is a two-parameter Weibull distribution since the location parameter, $\theta$, is zero. The parameters are summarized in Table 6.

Table 6. Primary General Corrosion Rate Distribution

\begin{tabular}{|l|l|l|}
\hline \multicolumn{1}{|c|}{ Input Name } & \multicolumn{1}{|c|}{ Input Value } & \multicolumn{1}{c|}{ Units } \\
\hline Weibull Scale, $\alpha$ & 8.88 & $\mathrm{~nm} / \mathrm{yr}$ \\
\hline Weibull Shape, $\beta$ & 1.62 & $\mathrm{~N} / \mathrm{A}$ \\
\hline
\end{tabular}

Source: BSC 2004 [DIRS 169984], Section 6.4.3;

DTN: MO0409MWDUGCMW.000 [DIRS 171714].

The cumulative distribution function for a two-parameter Weibull distribution is given by (Evans et al. 1993 [DIRS 112115], Chapter 41):

$$
C D F(x)=1-\exp \left(-\left(\frac{x}{\alpha}\right)^{\beta}\right)
$$

See Section 6.3.4 for a discussion of waste package general corrosion and Section 6.4.7 for discussion of implementation. 
These inputs are appropriate for their intended use because they were developed for this purpose and provide a reasonable estimate of the general corrosion behavior of Alloy 22 subjected to the exposure conditions in the repository.

DTN: MO0409MWDUGCMW.000 [DIRS 171714] contains the file Base Case GC Rate CDF.xls that contains the Weibull scale (identified as $\mathrm{s}=8.88$ ) and Weibull shape (identified as $\mathrm{b}=1.62$ ) parameters.

These general corrosion rates are applied to the Alloy 22 waste package outer barrier surfaces when the exposure temperature is $60^{\circ} \mathrm{C}(333.15 \mathrm{~K})$. The variation in the primary general corrosion rate distribution used for the Alloy 22 waste package outer barrier is entirely due to variability on the surface of the waste packages (BSC 2004 [DIRS 169984], Section 6.4.3) (i.e., the general corrosion rate distribution is used in the IWPD analysis. As discussed in General Corrosion and Localized Corrosion of Waste Package Outer Barrier (BSC 2004 [DIRS 169984], Section 6.4.3), the uncertainty in the general corrosion rate is contained in its temperature-dependent terms presented in the next section.

\subsubsection{Temperature Dependence of Alloy 22 General Corrosion}

The Alloy 22 general corrosion rate is considered a function of exposure temperature. The temperature dependence follows an Arrhenius relationship, i.e.:

$$
R=\exp \left[C_{o}-\frac{C_{1}}{T}\right]
$$

where

$$
\begin{aligned}
& R=\text { general-corrosion rate } \\
& T=\text { temperature (Kelvin) } \\
& C_{o}=\text { intercept term } \\
& C_{1}=\text { slope term (Kelvin) }
\end{aligned}
$$

The intercept term $\left(C_{o}\right)$ is determined from the relationship between Equations 1 and 2 evaluated when the exposure temperature is $60^{\circ} \mathrm{C}(333.15 \mathrm{~K})$. The variation in the general corrosion rate intercept term is entirely due to variability. Also, see Section 6.3 .4 for a discussion of the Alloy 22 general corrosion model and Section 6.4.7 for discussion of implementation.

The slope term $\left(C_{l}\right)$ is sampled from a truncated (at \pm 3 standard deviations) normal distribution with a mean of 3,116.47 K and a standard deviation of 296.47 K (BSC 2004 [DIRS 169984], Section 6.4.3) (DTN: MO0409MWDUGCMW.000 [DIRS 171714]). Note that the sign of the slope term in this report is negative with respect to the slope term in General Corrosion and Localized Corrosion of Waste Package Outer Barrier (BSC 2004 [DIRS 169984], Section 6.4.3) to be consistent with the input requirements of the WAPDEG. 
Table 7. General Corrosion Slope Term $\left(C_{1}\right)$ Distribution

\begin{tabular}{|l|c|c|}
\hline \multicolumn{1}{|c|}{ Input Name } & Input Value & Units \\
\hline Normal mean $^{\mathrm{a}}$ & $3,116.47$ & $\mathrm{~K}$ \\
\hline Normal standard deviation $^{\mathrm{a}}$ & 296.47 & $\mathrm{~K}$ \\
\hline Truncation $^{\mathrm{b}}$ & \pm 3 standard deviations & $\mathrm{N} / \mathrm{A}$ \\
\hline
\end{tabular}

Source: ${ }^{a}$ BSC 2004 [DIRS 169984], Section 6.4.3;

DTN: MO0409MWDUGCMW.000 [DIRS 171714].

b BSC 2004 [DIRS 169984], Section 6.4.3.

These inputs are appropriate for its intended use because they were developed for this purpose and provide a reasonable estimate of the temperature variation in the general corrosion behavior of Alloy 22 subjected to the exposure conditions in the repository.

DTN: MO0409MWDUGCMW.000 [DIRS 171714] contains a file called GC_TempDep_Reg.xls that contains the normal mean and standard deviation for the general corrosion temperature dependence slope term, $C_{1}$.

The variation in the general corrosion rate slope term is entirely due to uncertainty (BSC 2004 [DIRS 169984], Section 6.4.3). For each realization of the integrated waste package degradation analysis, a single general corrosion rate slope term is sampled and applied to the Alloy 22 waste package outer barrier surfaces to represent variation in the Alloy 22 general corrosion rate with exposure temperature. Spatial and temporal variability of the exposure temperature in the repository lead to spatial and temporal variability in Alloy 22 general corrosion rates.

\subsubsection{Weld Flaw Inputs}

The design information inputs to the integrated waste package degradation (IWPD) analysis of weld flaws in the Alloy 22 waste package outer barrier (or outer shell) closure-lid welds can be found in Analysis of Mechanisms for Early Waste Package/Drip Shield Failure (BSC 2004 [DIRS 170024]). The fraction of embedded weld flaws to propagate can be found in Stress Corrosion Cracking of the Drip Shield, the Waste Package Outer Barrier, and the Stainless Steel Structural Material (BSC 2004 [DIRS 169985], Table 8-1).

This design information was obtained from controlled sources. Weld flaws and their relation to stress corrosion cracking are discussed in Section 6.3.5.2. 
Table 8. Manufacturing Defect Analysis Inputs and Their Sources

\begin{tabular}{|c|c|c|c|}
\hline Description & Input Source & Input Value & Units \\
\hline $\begin{array}{l}\text { Fraction of embedded weld } \\
\text { flaws to propagate (Depth of } \\
\text { plate to be included for } \\
\text { embedded flaws) }\end{array}$ & $\begin{array}{l}\text { BSC } 2004 \text { [DIRS 169985], Table 8-1 } \\
\text { DTN: LL030607012251.065 } \\
\text { [DIRS 163968] }\end{array}$ & 0.25 & $\mathrm{~N} / \mathrm{A}$ \\
\hline $\begin{array}{l}\text { Fraction of weld flaws capable } \\
\text { of propagation based on } \\
\text { orientation }\end{array}$ & BSC 2004 [DIRS 170024], Table 12 & 0.008 & $\mathrm{~N} / \mathrm{A}$ \\
\hline $\begin{array}{l}\text { Characteristic weld flaw size for } \\
\text { PND (location parameter) }\end{array}$ & BSC 2004 [DIRS 170024], Table 11 & 2.5 & $\mathrm{~mm}$ \\
\hline Shape factor for PND & BSC 2004 [DIRS 170024], Table 11 & 3 & $\mathrm{~N} / \mathrm{A}$ \\
\hline $\begin{array}{l}\text { Lower limit for PND } \\
\text { (detection threshold) }\end{array}$ & BSC 2004 [DIRS 170024], Table 11 & 0.005 & $\mathrm{~N} / \mathrm{A}$ \\
\hline $\begin{array}{l}\text { Cumulative volume of sample } \\
\text { welds, } V_{f}\end{array}$ & $\begin{array}{l}\text { BSC } 2004 \text { [DIRS 170024], Appendix I, } \\
\text { p. I- } 26 \\
\text { Identified as "total volume of weld in the } \\
16 \text { specimen rings" }\end{array}$ & 18610540.3277924 & $\mathrm{~mm}^{3}$ \\
\hline Number of sample welds & $\begin{array}{l}\text { BSC } 2004 \text { [DIRS 170024], Section } \\
6.2 .1 .1 .2\end{array}$ & 16 & $\mathrm{~N} / \mathrm{A}$ \\
\hline Number of weld flaws, $n_{f}$ & BSC 2004 [DIRS 170024], Table 11 & 7 & $\mathrm{~N} / \mathrm{A}$ \\
\hline Cumulative size of weld flaws $S_{f}$ & $\begin{array}{l}\text { BSC } 2004 \text { [DIRS 170024], Appendix I, } \\
\text { p. I-3 }\end{array}$ & 31.75 & $\mathrm{~mm}$ \\
\hline Flaw size parameter & BSC 2004 [DIRS 170024], Equation 2 & $\begin{array}{l}\text { Gamma distribution with } \\
\text { a mean of } n_{f} / S_{f} \text { and a } \\
\text { standard deviation of } \\
\operatorname{sqrt}\left(n_{f}\right) / S_{f}(a)\end{array}$ & $\mathrm{mm}^{-1}$ \\
\hline Flaw density parameter & BSC 2004 [DIRS 170024], Equation 12 & $\begin{array}{l}\text { Gamma distribution with } \\
\text { a mean of }\left(\mathrm{n}_{\mathrm{f}}+1 / 2\right) / \mathrm{V}_{\mathrm{f}} \\
\text { and a standard deviation } \\
\text { of } \operatorname{sqrt}\left(\mathrm{n}_{\mathrm{f}}+1 / 2\right) / \bigvee_{\mathrm{f}} \text { (a) }\end{array}$ & $\mathrm{mm}^{-3}$ \\
\hline $\begin{array}{l}\text { CSNF waste package outer } \\
\text { closure lid weld volume }\end{array}$ & BSC 2003 [DIRS 164610], Table 19 & $1,350,189$ & $\mathrm{~mm}^{3}$ \\
\hline $\begin{array}{l}\text { CSNF waste package middle } \\
\text { closure lid weld volume }\end{array}$ & BSC 2003 [DIRS 164610], Table 18 & 490,478 & $\mathrm{~mm}^{3}$ \\
\hline $\begin{array}{l}\text { CDSP waste package outer } \\
\text { closure lid weld volume }\end{array}$ & BSC 2003 [DIRS 164610], Table 19 & $1,753,091$ & $\mathrm{~mm}^{3}$ \\
\hline $\begin{array}{l}\text { CDSP waste package middle } \\
\text { closure lid weld volume }\end{array}$ & BSC 2003 [DIRS 164610], Table 18 & 639,901 & $\mathrm{~mm}^{3}$ \\
\hline Weld Thickness $(t h)$ & $\begin{array}{l}\text { BSC } 2001 \text { [DIRS 157812]; BSC } 2001 \\
\text { [DIRS 157817]; and BSC } 2001 \\
\text { [DIRS 157818], Sheet } 3 \text { of } 3\end{array}$ & $\begin{array}{l}25 \text { for outer closure lid } \\
10 \text { for middle closure lid } \\
\text { (same for CSNF and } \\
\text { CDSP waste packages) }\end{array}$ & $\mathrm{mm}$ \\
\hline
\end{tabular}

NOTE: ${ }^{a}$ Equations 2 and 12 in BSC 2004 [DIRS 170024] are probability density functions of gamma distributions (Evans et al. [DIRS 112115], Section 18.

\subsubsection{Stress and Stress Intensity Factor Profile Inputs}

Inputs to this analysis include stress and stress intensity factor profiles (stress or stress intensity factor versus depth) and slip dissolution parameters appropriate for both the outer closure and middle closure lids of the waste package outer barrier. Table 9 summarizes these inputs, their 
sources, data tracking numbers (DTNs), and table numbers. Most of these parameters can be found in Stress Corrosion Cracking of the Drip Shield, the Waste Package Outer Barrier, and the Stainless Steel Structural Material (BSC 2004 [DIRS 169985], Tables 8-1, 8-2, and 8-3).

Table 9. Stress and Stress Intensity Factor Profile Inputs and Their Sources

\begin{tabular}{|l|l|l|}
\hline \multicolumn{1}{|c|}{ Input Name } & \multicolumn{1}{|c|}{ Input Source } & \multicolumn{1}{c|}{ Input Value } \\
\hline Stress Profile Equation & $\begin{array}{l}\text { BSC 2004 [DIRS 169985], Table 8-1 } \\
\text { DTN: LL030607012251.065 [DIRS 163968] }\end{array}$ & Equation 3 \\
\hline Stress Profile Coefficients & $\begin{array}{l}\text { BSC 2004 [DIRS 169985], Table 8-1 } \\
\text { DTN: LL030607012251.065 [DIRS 163968] }\end{array}$ & See Table 10 \\
\hline Stress Intensity Factor Profiles & $\begin{array}{l}\text { BSC 2004 [DIRS 169985], Table 8-2 and } \\
\text { Table 8-3 } \\
\text { DTN: LL030607012251.065 [DIRS 163968] }\end{array}$ & See Table 11 \\
\hline $\begin{array}{l}\text { Yield strength, YS } \\
\text { (various temperatures) }\end{array}$ & DTN: MO0003RIB00071.000 [DIRS 148850] & $\begin{array}{l}338 \mathrm{MPa} \text { at 366 K } \\
\text { 283 MPa at 477 K }\end{array}$ \\
\hline $\begin{array}{l}\text { Stress variation with angle } \\
\text { Stress intensity factor variation } \\
\text { with angle }\end{array}$ & $\begin{array}{l}\text { BSC 2004 [DIRS 169985], Table 8-1 } \\
\text { DTN: LL030607012251.065 [DIRS 163968] }\end{array}$ & Equation 4 \\
\hline $\begin{array}{l}\text { Uncertain scaling factor for } \\
\text { stress and stress intensity } \\
\text { factor profiles, } z\end{array}$ & $\begin{array}{l}\text { BSC 2004 [DIRS 169985], Table 8-1 } \\
\text { DTN: LL030607012251.065 [DIRS 163968] }\end{array}$ & $\begin{array}{l}\text { Equation 5 } \\
\text { standard deviation (sd) of } \\
\text { 5\% of YS }\end{array}$ \\
\hline
\end{tabular}

These inputs are qualified.

The hoop stress ( $\sigma$ in $\mathrm{MPa})$ as a function of depth $(x$ in $\mathrm{mm})$ in the closure weld regions of the Alloy 22 waste package outer barrier is given by a third-order polynomial equation of the form (BSC 2004 [DIRS 169985], Table 8-1; DTN: LL030607012251.065 [DIRS 163968]):

$$
\sigma(x, 0)=A_{0}+A_{1} \cdot x+A_{2} \cdot x^{2}+A_{3} \cdot x^{3}
$$

where the values of the coefficient(s) $\left(A_{i}\right)$ are given in Table 10. The variation in the stress profile with depth is variability. The second argument in the stress function is used to represent angular variation as discussed later in this section.

Table 10. Stress Coefficients Used in the IWPD Analysis for the Outer and Middle Closure Lids of Waste Package Outer Barrier in Metric Units (i.e., stress in MPa)

\begin{tabular}{|l|c|c|l|}
\hline Stress Coefficient & $\begin{array}{c}\text { Outer Closure Lid } \\
\text { Laser Peened }\end{array}$ & $\begin{array}{c}\text { Middle Closure Lid } \\
\text { As-Welded }\end{array}$ & \multicolumn{1}{|c|}{ Units } \\
\hline $\mathrm{A}_{0}$ & -292.607 & 219.908 & $\mathrm{MPa}$ \\
\hline $\mathrm{A}_{1}$ & 178.277 & 56.494 & $\mathrm{MPa} / \mathrm{mm}$ \\
\hline $\mathrm{A}_{2}$ & -14.135 & -20.848 & $\mathrm{MPa} / \mathrm{mm}^{2}$ \\
\hline $\mathrm{A}_{3}$ & 0.320 & 1.083 & $\mathrm{MPa} / \mathrm{mm}^{3}$ \\
\hline
\end{tabular}

Source: BSC 2004 [DIRS 169985], Table 8-1;

DTN: LL030607012251.065 [DIRS 163968]). 
Table 11 lists the stress intensity factor versus depth profiles for the outer and middle closure lids of the Alloy 22 waste package outer barrier. The stress intensity factor is a scale factor defining the magnitude of the crack tip stress field. The variation in the stress intensity factor profile with depth is variability. As these are the results of intermediate calculations, as many digits as possible are retained to avoid round-off errors.

Table 11. Stress Intensity Factor $\left(\mathrm{K}_{\mathrm{l}}\right)$ Vs. Depth Tables (due to Sz Hoop Stress) for the Outer and Middle Closure-Lids of Waste Package Outer Barrier

\begin{tabular}{|c|c|c|c|}
\hline \multicolumn{2}{|c|}{ Outer Closure Lid } & \multicolumn{2}{|c|}{ Middle Closure Lid } \\
\hline $\mathrm{K}_{\left(\mathrm{MPa} \cdot \mathrm{m}^{1 / 2}\right)^{\mathrm{a}}}$ & $\begin{array}{l}\text { Depth } \\
(\mathrm{mm})^{\mathrm{b}}\end{array}$ & $\underset{\left(\mathrm{MPa}_{\mathrm{l}} \mathrm{K}^{1 / 2}\right)^{\mathrm{c}}}{\left(\mathrm{C}^{2}\right.}$ & $\begin{array}{l}\text { Depth } \\
(\mathrm{mm})^{\mathrm{d}}\end{array}$ \\
\hline-5.6943 & 0.3988 & 7.5754 & 0.1593 \\
\hline-6.4965 & 0.8001 & 10.9665 & 0.3203 \\
\hline-6.1528 & 1.1989 & 13.7144 & 0.4797 \\
\hline-5.1372 & 1.6002 & 16.1330 & 0.6407 \\
\hline-3.6697 & 1.9990 & 18.3358 & 0.8000 \\
\hline-1.8824 & 2.4003 & 20.3775 & 0.9593 \\
\hline 0.1212 & 2.7991 & 22.3816 & 1.1203 \\
\hline 2.2821 & 3.2004 & 24.3197 & 1.2797 \\
\hline 4.5533 & 3.5992 & 26.1726 & 1.4407 \\
\hline 6.8939 & 3.9980 & 27.9459 & 1.6000 \\
\hline 9.2702 & 4.3993 & 29.6433 & 1.7593 \\
\hline 11.6543 & 4.7981 & 31.2668 & 1.9203 \\
\hline 14.0165 & 5.1994 & 32.8922 & 2.0797 \\
\hline 16.3364 & 5.5982 & 34.5292 & 2.2407 \\
\hline 18.6024 & 5.9995 & 36.1060 & 2.4000 \\
\hline 20.8003 & 6.3983 & 37.6220 & 2.5593 \\
\hline 22.9177 & 6.7970 & 39.0762 & 2.7203 \\
\hline 24.9441 & 7.1984 & 40.4676 & 2.8797 \\
\hline 26.9023 & 7.5971 & 41.8264 & 3.0407 \\
\hline 28.8612 & 7.9985 & 43.2168 & 3.2000 \\
\hline 30.7287 & 8.3972 & 44.5479 & 3.3593 \\
\hline 32.5008 & 8.7986 & 45.8181 & 3.5203 \\
\hline 34.1745 & 9.1973 & 47.0265 & 3.6797 \\
\hline 35.7479 & 9.5987 & 48.1718 & 3.8407 \\
\hline 37.2200 & 9.9974 & 49.2531 & 4.0000 \\
\hline 38.4530 & 10.3962 & 50.3451 & 4.1593 \\
\hline 39.5674 & 10.7975 & 51.3729 & 4.3203 \\
\hline 40.5636 & 11.1963 & 52.3351 & 4.4797 \\
\hline 41.4432 & 11.5976 & 53.2313 & 4.6407 \\
\hline 42.2086 & 11.9964 & 54.0602 & 4.8000 \\
\hline 42.8627 & 12.3977 & 54.8214 & 4.9593 \\
\hline 43.4439 & 12.7965 & 55.4811 & 5.1203 \\
\hline 43.9342 & 13.1978 & 56.0586 & 5.2797 \\
\hline 44.3269 & 13.5966 & 56.5637 & 5.4407 \\
\hline 44.6272 & 13.9954 & 56.9965 & 5.6000 \\
\hline
\end{tabular}


Table 11. Stress Intensity Factor $\left(K_{1}\right)$ Vs. Depth Tables (due to Sz Hoop Stress) for the Outer and Middle Closure-Lids of Waste Package Outer Barrier (Continued)

\begin{tabular}{|c|c|c|c|}
\hline \multicolumn{2}{|c|}{ Outer Closure Lid } & \multicolumn{2}{c|}{ Middle Closure Lid } \\
\hline $\begin{array}{c}\mathbf{K}_{\mathbf{I}} \\
\left(\mathbf{M P a}^{\mathbf{1} / \mathbf{2}}\right)^{\mathbf{a}}\end{array}$ & $\begin{array}{c}\text { Depth } \\
\mathbf{( m m}^{\mathbf{b}}\end{array}$ & $\begin{array}{c}\mathbf{K}_{\mathbf{I}} \\
\left.\mathbf{( M P a}^{\mathbf{1} / \mathbf{2}}\right)^{\mathbf{c}}\end{array}$ & $\begin{array}{c}\text { Depth } \\
(\mathbf{m m})^{\mathbf{d}}\end{array}$ \\
\hline 44.8409 & 14.3967 & 57.3567 & 5.7593 \\
\hline 44.9743 & 14.7955 & 57.6444 & 5.9203 \\
\hline 45.0329 & 15.1968 & 57.7587 & 6.0797 \\
\hline 45.0208 & 15.5956 & 57.6946 & 6.2407 \\
\hline 44.9464 & 15.9969 & 57.5522 & 6.4000 \\
\hline 44.8182 & 16.3957 & 57.3322 & 6.5593 \\
\hline 44.6449 & 16.7945 & 57.0353 & 6.7203 \\
\hline 44.4361 & 17.1958 & 56.6626 & 6.8797 \\
\hline 44.2112 & 17.5946 & 56.1419 & 7.0407 \\
\hline 43.9968 & 17.9959 & 55.3276 & 7.2000 \\
\hline 43.7750 & 18.3947 & 54.4422 & 7.3593 \\
\hline 43.5578 & 18.7960 & 53.4878 & 7.5203 \\
\hline 43.3569 & 19.1948 & 54.6294 & 7.6797 \\
\hline 43.1853 & 19.5961 & 56.2191 & 7.8407 \\
\hline 43.0560 & 19.9949 & 57.7865 & 8.0000 \\
\hline
\end{tabular}

Source: ${ }^{a}$ BSC 2004 [DIRS 169985], Table 8-3, Column 5 labeled SIF due to Sz MPa-m ${ }^{0.5}$; DTN: LL030607012251.065 [DIRS 163968].

b BSC 2004 [DIRS 169985], Table 8-3, Column 1; DTN: LL030607012251.065 [DIRS 163968].

c BSC 2004 [DIRS 169985], Table 8-2, Column 5 labeled SIF due to Sz MPa-m ${ }^{0.5}$.

d BSC 2004 [DIRS 169985], Table 8-2, Column 1; DTN: LL030607012251.065 [DIRS 163968].

The variation in the stress profile with depth is due to variability. The provided hoop stress state was determined to vary with angle $(\theta)$ around the circumference of the Alloy 22 waste package outer and middle closure-lid welds ( $\theta=0$ point arbitrarily chosen) according to the following functional form (BSC 2004 [DIRS 169985], Table 8-1; DTN: LL030607012251.065 [DIRS 163968]):

$$
\sigma(x, \theta)=\sigma(x, 0)-(17.236893) \times(1-\cos (\theta))
$$


Note that $\sigma(x, 0)$ (defined in Equation 3$)$ uses the stress coefficients $\left(A_{i}\right)$ defined in Table 10 with $x$ (in $\mathrm{mm}$ ). Based on the angular stress variation in Equation 4, the stress intensity factor variation with angle is given by (BSC 2004 [DIRS 169985], Table 8-1; DTN: LL030607012251.065 [DIRS 163968]):

$$
K_{I}(x, \theta)=K_{I}(x) \times\left(\frac{\sigma(\text { Thck, } \theta)}{\sigma(\text { Thck, } 0)}\right)
$$

where Thck is the lid thickness and $K_{I}(x)$ is given by the values in Table 11. The variation of the stress and stress intensity factor profiles with angle is due to variability (BSC 2004 [DIRS 169985], Section 6.4.5).

The uncertainty in the stress and stress intensity factor profiles is introduced through a scaling factor, $z$. The scaling factor, $z$, which is sampled from a normal distribution with a mean of zero and a standard deviation of 5 percent of the yield strength, YS, with an upper-bound of 15 percent of the YS and a lower-bound of -15 percent of the YS (BSC 2004 [DIRS 169985], Table 8-1).

The stress relation, accounting for uncertainty, is given by:

$$
\sigma_{u}(x, \theta, z)=\sigma(x, \theta) \times\left(\frac{\sigma(\text { Thck, } \theta)+z}{\sigma(\text { Thck, } \theta)}\right)
$$

and the stress intensity factor relation is given by:

$$
K_{I u}(x, \theta, z)=K_{I}(x, \theta) \times\left(\frac{\sigma(\text { Thck, } \theta)+z}{\sigma(\text { Thck, } \theta)}\right)=K_{I}(x, 0) \times\left(\frac{\sigma(\text { Thck, } \theta)+z}{\sigma(\text { Thck, } 0)}\right)
$$

The inputs discussed in this section is appropriate for their intended use because they were developed for this purpose and provide a reasonable estimate of the stress and stress intensity factor profiles for the outer and middle closure lids of waste package outer barrier.

The uncertainty treatment of these inputs is encompassed in the parameter, $z$, sampled once per realization of the integrated waste package degradation analysis for each closure lid (i.e., a different value of $z$ is sampled for each lid in a given realization).

The stress and stress intensity factor profiles for the waste package outer barrier closure lids are technical product output obtained from controlled and confirmed sources.

\subsubsection{Slip Dissolution Inputs}

The slip dissolution model for stress corrosion cracking uses a threshold stress, a threshold stress intensity factor, an incipient crack size, and crack growth rate parameters (functions of $n$, the repassivation slope). These inputs and their sources are listed in Table 12. 
Table 12. Slip Dissolution Inputs Used in the IWPD Analysis and Their Sources

\begin{tabular}{|c|c|c|}
\hline Input Name & Input Value & Units \\
\hline Threshold stress & $0.9 \times Y S$ at $473 \mathrm{~K}^{\mathrm{a}}$ & $\mathrm{MPa}$ \\
\hline Incipient crack size & $0.05^{a}$ & $\mathrm{~mm}$ \\
\hline Fraction of embedded weld flaws to propagate & $0.25^{a}$ & $\mathrm{~N} / \mathrm{A}$ \\
\hline Threshold stress intensity factor, $K_{I S C C}$ & Equation $8^{a}$ & $\mathrm{MPa} \mathrm{m}^{1 / 2}$ \\
\hline Repassivation slope, $n$ & $\begin{array}{l}\text { Truncated normal (at } \pm 2 \text { sd) with } \\
\text { a mean of } 1.304 \text { and sd of } 0.16^{\text {a }}\end{array}$ & $\mathrm{N} / \mathrm{A}$ \\
\hline Distance between through-wall cracks & "the plate thickness"b & $\mathrm{mm}$ \\
\hline
\end{tabular}

Source: ${ }^{a}$ BSC 2004 [DIRS 169985], Table 8-1 DTN: LL030607012251.065 [DIRS 163968].

b BSC 2004 [DIRS 169985], Section 6.5.1.

The threshold stress is defined as the minimum stress at which cracks initiate on a "smooth" surface. This report refers to these as incipient cracks (to distinguish them from weld flaws), which typically form at local surface defects, such as grain boundary junctions and surface roughness. Incipient cracks are $0.05 \mathrm{~mm}$ long (BSC 2004 [DIRS 169985], Table 8-1).

Weld flaws are already nucleated and, thus, do not require a stress threshold to nucleate. However, most weld flaws are embedded within the material and, therefore, not exposed to the environment. As general corrosion proceeds, some initially embedded weld flaws will be exposed to the environment (BSC 2004 [DIRS 169985], Section 6.2.2) while others are "corroded away." This evolution of the number of defects is not considered in detail. A conservative approach is used (BSC 2004 [DIRS 169985], Section 6.2.2), in which the fraction of weld flaws embedded within the outer one fourth of the weld thickness are sites for crack propagation by the slip-dissolution mechanism.

If the stress intensity factor at the crack tip is below the threshold stress intensity factor, no crack growth will occur. The threshold stress intensity factor, $K_{I S C C}$, is given as a function of the repassivation slope, $n$ and $V_{g c}$ (which equals $7.23 \mathrm{~nm} / \mathrm{yr}$ and is expressed in units of mm/sec for use in Equation 8) (BSC 2004 [DIRS 169985], Table 8-1):

$$
K_{I S C C}=\left(\frac{V_{g c}}{\bar{A}}\right)^{1 / \bar{n}}
$$

$\bar{A}$ and $\bar{n}$ are functions of $n$, as discussed below. The threshold stress intensity factor is applied to both incipient cracks and weld flaws. The variations in the threshold stress and stress intensity factor distributions are entirely due to uncertainty. The thresholds are sampled once per realization of the IWPD analysis (i.e., the same value of these thresholds is used for each lid in a given realization). 
Once crack growth initiates, the crack(s) grow at a velocity given by (BSC 2004 [DIRS 169985], Table 8-1) (DTN: LL030607012251.065 [DIRS 163968]):

$$
V_{t}=\bar{A}\left(K_{I}\right)^{\bar{n}}
$$

where $V_{t}$ is the crack growth rate in $\mathrm{mm} / \mathrm{sec}$, and $K_{I}$ is the stress intensity factor in $\mathrm{MPa}(\mathrm{m})^{1 / 2}$. Parameters, $\bar{A}$ and $\bar{n}$, in the above equation are expressed in terms of the repassivation slope, $n$, as follows:

$$
\begin{gathered}
\bar{A}=7.8 \times 10^{-2} n^{3.6}\left(4.1 \times 10^{-14}\right)^{n} \\
\bar{n}=4 n
\end{gathered}
$$

In the IWPD analysis, the parameter $n$ is represented by a truncated normal distribution (at $\pm 2 \mathrm{sd}$ ) with a mean of 1.304 , and an sd of 0.16 . The variation in the repassivation slope, $n$, is entirely due to uncertainty. The repassivation slope is sampled once per realization of the IWPD analysis (i.e., the same value of $n$ is used for each lid in a given realization).

Analyses presented in Stress Corrosion Cracking of the Drip Shield, the Waste Package Outer Barrier, and the Stainless Steel Structural Material (BSC 2004 [DIRS 169985], Section 6.5.1), indicate that the distance between two neighboring cracks must be greater than the plate thickness for the stress (and stress intensity factor) profile to be of sufficient magnitude to propagate a crack through-wall. This information is used in Section 6.3.2.1 to determine the crack density used in the IWPD analysis.

The inputs discussed in this section are appropriate for their intended use because they were developed for this purpose and provide reasonable estimates of the stress corrosion crack growth characteristics for the outer and middle closure lids of the Alloy 22 waste package outer barrier. The slip dissolution parameters for the waste package outer barrier closure lids are technical product output information obtained from controlled and confirmed sources.

\subsubsection{Waste Package Outer Barrier Microbially Influenced Corrosion Inputs}

The treatment of microbially influenced corrosion (MIC) of the Alloy 22 waste package outer barrier requires a threshold relative humidity $(\mathrm{RH})$ for microbial activity and a general corrosion rate multiplier representing the effect of microbial activity. These inputs and their sources are listed in Table 13.

Table 13. Waste Package Outer Barrier Microbially Influenced Corrosion Inputs and Their Sources

\begin{tabular}{|l|l|l|l|}
\hline \multicolumn{1}{|c|}{ Input Name } & \multicolumn{1}{|c|}{ Input Source } & \multicolumn{1}{c|}{ Input Value } & \multicolumn{1}{c|}{ Units } \\
\hline MIC Threshold RH & $\begin{array}{l}\text { BSC 2004 [DIRS 169984], Section 6.4.5 } \\
\text { DTN: MO0409MWDUGCMW.000 [DIRS 171714] }\end{array}$ & 0.9 & fraction \\
\hline $\begin{array}{l}\text { General Corrosion } \\
\begin{array}{l}\text { Rate MIC } \\
\text { Enhancement Factor }\end{array}\end{array}$ & $\begin{array}{l}\text { BSC 2004 [DIRS 169984], Section 6.4.5 } \\
\text { DTN: MO0409MWDUGCMW.000 [DIRS 171714] }\end{array}$ & $\begin{array}{l}\text { Uniform over the range } \\
(1,2)\end{array}$ & N/A \\
\hline
\end{tabular}


According to General Corrosion and Localized Corrosion of Waste Package Outer Barrier (BSC 2004 [DIRS 169984], Section 6.4.5; DTN: MO0409MWDUGCMW.000 [DIRS 171714]), general corrosion rates should be enhanced due to the effect of MIC when the relative humidity exceeds 90 percent. The value for the threshold RH above which MIC takes place is fixed (i.e., no uncertainty or variability).

The general corrosion rate of the waste package outer barrier is enhanced due to MIC by a factor between 1 and 2 (i.e., no enhancement up to the general corrosion rate being doubled) (BSC 2004 [DIRS 169984], Section 6.4.5; DTN: MO0409MWDUGCMW.000 [DIRS 171714]). Thus, the general corrosion rate enhancement factor is sampled from a uniform distribution with an upper-bound of 2 and a lower-bound of 1 . The general corrosion rate enhancement factor is applied to the entire waste package surface (BSC 2004 [DIRS 169984], Section 6.4.5; DTN: MO0409MWDUGCMW.000 [DIRS 171714]). The variation in the general corrosion rate MIC enhancement factor is entirely due to uncertainty (BSC 2004 [DIRS 169984], Section 6.4.5).

The parameters discussed in this section are appropriate for their intended use because they were developed for this purpose and provide a reasonable estimate of the affects of microbial action on the waste package outer barrier. The parameters are technical product output obtained from controlled and confirmed sources.

\subsubsection{Waste Package Early Failure Analysis Inputs}

Several mechanisms that could result in early failure of the waste package were considered in Analysis of Mechanisms for Early Waste Package/Drip Shield Failure (BSC 2004 [DIRS 170024]). It was determined that improper heat treatment, improper stress mitigation, and mishandling of the waste package could have adverse consequences on waste package performance (BSC 2004 [DIRS 170024], Section 6.4.8). The probabilities of occurrence for these three mechanisms were combined to yield an overall probability of waste package early failure. The number of waste packages affected per realization is given by a Poisson distribution with an uncertain intensity. These values and their sources are summarized in Table 14.

Table 14. Waste Package Early Failure Inputs and Their Sources

\begin{tabular}{|l|l|l|l|}
\hline \multicolumn{1}{|c|}{ Input Name } & \multicolumn{1}{|c|}{ Input Source } & \multicolumn{1}{c|}{ Input Value } & \multicolumn{1}{c|}{ Units } \\
\hline $\begin{array}{l}\text { Evaluation Probability per } \\
\begin{array}{l}\text { WP (Uncertain Poisson } \\
\text { Intensity) }\end{array}\end{array}$ & $\begin{array}{l}\text { BSC 2004 [DIRS 170024], } \\
\text { Section 7, Table 22 }\end{array}$ & $\begin{array}{l}\text { Log normal distribution with a } \\
\text { median of 7.2 } \times 10^{-6} \text { and an error } \\
\text { factor of 15, truncated at an upper } \\
\text { value of 7.44213 } \times 10^{-3}\end{array}$ & $\begin{array}{l}\text { per waste } \\
\text { package }\end{array}$ \\
\hline $\begin{array}{l}\text { Number of Early Failed WP } \\
\text { per Realization }\end{array}$ & $\begin{array}{l}\text { BSC 2004 [DIRS 170024], } \\
\text { Section 7, Table 22 }\end{array}$ & $\begin{array}{l}\text { Poisson Distribution with intensity } \\
\text { given above multiplied by number } \\
\text { of waste packages considered. }\end{array}$ & $\begin{array}{l}\text { number of waste } \\
\text { packages per } \\
\text { realization }\end{array}$ \\
\hline
\end{tabular}

The "Evaluation Probability per WP" distribution is sampled once per realization (i.e., it is an uncertainty distribution). The sampled value is then multiplied by the number of waste packages per realization to give the intensity for the Poisson distribution for the number of early failed waste packages per realization. The Poisson distribution is sampled once per realization to give the number of affected waste packages in the realization. In this representation, variation in the 
number of early failed waste packages is expressed as variability deriving from a discrete Poisson distribution with an uncertain intensity parameter. The uncertain intensity parameter is the product of the uncertain rate of waste package failures (log normally distributed) and the number of waste packages in a realization. Also, see Section 6.3.8 for further discussion of early failure and Section 6.4.12 for discussion of implementation (including a discussion of a marginal distribution that incorporates uncertainty).

The following recommendations are made in Analysis of Mechanisms for Early Waste Package/Drip Shield Failure (BSC 2004 [DIRS 170024], Section 6.4.8) for evaluating the consequences of early failure of the Alloy 22 waste package outer barrier:

- A failure of the waste package outer barrier shell and outer and middle closure lids should be assumed

- The affected waste packages should be assumed to fail immediately upon initiation of degradation processes

- The entire waste package surface area should be considered affected by improper heat treatment

- The materials of the entire affected area should be assumed lost upon failure of the waste packages because the affected area will be subjected to stress corrosion cracking and highly enhanced localized and general corrosion.

The inputs are technical product output information obtained from controlled and confirmed sources.

\subsection{CRITERIA}

The technical work plan for this activity (BSC 2004 [DIRS 171583], Table 3-1) has identified the following acceptance criteria (AC) based on the requirements mentioned in Project Requirements Document (PRD) (Canori and Leitner 2003 [DIRS 166275]) and Yucca Mountain Review Plan, Final Report (NRC 2003 [DIRS 163274]):

1. System Description and Demonstration of Multiple Barriers (NRC 2003 [DIRS 163274], Section 2.2.1.1.3; Canori and Leitner 2003 [DIRS 166275], PRD-002/T-014, PRD-002/T-016)

Specific requirements involve identification of multiple barriers (natural and engineered), describing the capabilities of these barriers to isolate waste, and providing technical bases for capabilities descriptions consistent with the postclosure performance objectives. To comply with these requirements, the following acceptance criteria are identified in the technical work plan (BSC 2004 [DIRS 171583], Table 3-1):

- AC1: Identification of Barriers is Adequate

- AC2: Description of Barrier Capability to Isolate Waste is Acceptable 
- AC3: Technical Basis for Barrier Capability is Adequately Presented.

2. Degradation of Engineered Barriers (NRC 2003 [DIRS 163274], Section 2.2.1.3.1.3; Canori and Leitner 2003 [DIRS 166275], PRD-002/T-015)

Specific requirements include describing deterioration or degradation of engineered barriers and modeling degradation processes using data for performance assessment, including total system performance assessment (TSPA). Consideration of uncertainties and variabilities in model parameters and alternative conceptual models are also required. To fulfill these requirements, the following acceptance criteria are identified in the technical work plan (BSC 2004 [DIRS 171583], Table 3-1):

- AC1: System Description and Model Integration are Adequate

- AC2: Data are Sufficient for Model Justification

- AC3: Data Uncertainty is Characterized and Propagated Through the Model Abstraction

- AC4: Model Uncertainty is Characterized and Propagated Through the Model Abstraction

- AC5: Model Abstraction Output is Supported by Objective Comparisons.

The Yucca Mountain Review Plan Criteria are addressed in Section 7.3.

\subsection{CODES AND STANDARDS}

The process of implementing these models is consistent with the methodology described in the ASTM Standard Practice C-1174 for prediction of the long-term behavior of EBS components in a geologic repository (ASTM C 1174-97 [DIRS 105725]). 


\section{ASSUMPTIONS}

None of the following assumptions requires any further confirmation in addition to the rationale provided below prior to the use of the parameters developed in this document.

\subsection{RELATIVE HUMIDITY THRESHOLD}

Assumption: It is conservatively assumed that no relative humidity threshold for the initiation of corrosion processes exists (e.g., corrosion is allowed to occur at any exposure relative humidity).

Rationale: The relative humidity threshold is the relative humidity below which water will not form on a clean metal surface and electrochemical processes will not occur (ASM International 1987 [DIRS 133378], p. 82). For clean metal surfaces, the relative humidity must exceed about 60 percent before a thin film of moisture will form on the metal surface, providing an electrolyte for ionic current transfer (ASM International 1987 [DIRS 133378], p. 82). Cleanliness, corrosion product build-up, and hygroscopic salts or contaminants can cause water absorption at lower relative humidities (ASM International 1987 [DIRS 133378], p. 80). General Corrosion and Localized Corrosion of Waste Package Outer Barrier (BSC 2004 [DIRS 169984], Assumption 5.1) and General Corrosion and Localized Corrosion of the Drip Shield (BSC 2004 [DIRS 169845], Section 5.2) assume the existence of a relative humidity threshold for the initiation of corrosion processes. The assumption that no relative humidity threshold for the initiation of corrosion processes exists is conservative because use of a relative humidity threshold would delay the corrosion initiation start time.

Confirmation Status: This assumption is appropriate for its intended use and is conservative. On this basis, this assumption requires no further confirmation.

Use in Analysis: This assumption is used throughout this report.

\subsection{CORROSION BEHAVIOR OF THE WELD REGIONS}

Assumption: The general corrosion and localized corrosion behavior of the weld metal does not significantly differ from the general corrosion and localized corrosion behavior of the Alloy 22 base material.

Rationale: This assumption is consistent with Waste Package Operations Fabrication Process Report (Plinski 2001 [DIRS 156800], Section 6.3), which states, "Filler metal material shall be selected to be compatible with the base material." This assumption is also consistent with analyses in General Corrosion and Localized Corrosion of Waste Package Outer Barrier (BSC 2004 [DIRS 169984], Sections 6.4.3 and 6.4.4) in which it was found that welded regions had similar general and localized corrosion behavior as the base metal.

Confirmation Status: This assumption is consistent with the current state of knowledge and is appropriate for its intended use; therefore, no further confirmation is required.

Use in Analysis: This assumption is used throughout this document in the integrated waste package degradation analysis using parameters appropriate for Alloy 22 in the weld regions. 


\subsection{CORROSION BEHAVIOR OF THE OUTER LID CLOSURE WELD REGION}

Assumption: The corrosion behavior of the stress-mitigated (laser-peened) outer lid closure weld region does not significantly differ from the corrosion behavior of a closure lid weld region that has not undergone stress mitigation.

Rationale: Laser peening involves the use of a laser pulse that induces a shock wave within the material being peened resulting in the formation of a compressive surface layer. Laser peening causes less surface damage than conventional shot peening (Chen et al. 2002 [DIRS 165441]) particularly because in laser peening no physical contact is made with the part to be peened. Comparisons of the corrosion rates (measured by the polarization resistance technique in simulated acidified water at $90^{\circ} \mathrm{C}$ and potentiodynamic polarization curves) of unmitigated and laser-peened Alloy 22 samples have shown that laser peened samples exhibited lower corrosion rates than unmitigated samples (Chen et al. 2002 [DIRS 165441], Figure 9). In addition, laserpeened samples exhibited lower passive current densities (in potentiodynamic polarization tests) than unmitigated samples (Chen et al. 2002 [DIRS 165441], Figure 10). The potentiodynamic polarization curves did not show the initiation of localized corrosion before the transpassive potential was reached. Conservatively, no credit is taken in this report for the increased resistance to corrosion processes imparted by the laser peening process. This assumption is consistent with assumptions made in General Corrosion and Localized Corrosion of Waste Package Outer Barrier (BSC 2004 [DIRS 169984], Assumption 5.6).

Confirmation Status: This is a conservative assumption and does not require further confirmation.

Use in Analysis: This assumption is used throughout this report. 


\section{SCIENTIFIC ANALYSIS DISCUSSION}

This section provides analysis objectives for the waste package and drip shield degradation in the integrated waste package degradation (IWPD) analysis. The implementation of the models and analyses for the degradation processes considered are described. The IWPD analysis results are discussed in terms of a set of profiles for waste package and drip shield failure and average number of penetrations as a function of time. The results of all analyses documented in this report are tracked by output DTN: MO0310MWDWAPAN.002.

The IWPD analysis itself (Section 6.4), not the resultant curves from the IWPD analysis presented in Section 6.5 (which are for illustrative purposes), is used directly in total system performance assessment (TSPA). The IWPD analysis simulates general corrosion and stress corrosion cracking of the waste package outer barrier and general corrosion of the drip shield. Analysis of localized corrosion is not included in the IWPD analysis. The outputs of this report are inputs and methodologies used by TSPA to evaluate waste package and drip shield degradation as a function of exposure time under exposure conditions anticipated in the repository.

\subsection{ANALYSIS OBJECTIVES}

The License Application (LA) waste package design consists of two layers: an Alloy 22 outer barrier and a Stainless Steel Type 316 inner vessel (BSC 2003 [DIRS 165406]). A drip shield with Titanium Grade 7 water diversion plates will be placed over the waste package (BSC 2004 [DIRS 168489]). The space between the drip shield and the emplacement drift is open for air circulation and there is no backfill material used. Although the stainless steel inner vessel provides structural stability to the Alloy 22 outer barrier, no other performance credit is taken for the waste package inner vessel. The waste package outer barrier has two Alloy 22 closure lids (referred to as the waste package outer barrier outer and middle closure lids). The Stainless Steel Type 316 waste package inner vessel has one Stainless Steel Type 316 closure lid (referred to as the waste package inner vessel closure lid). The waste package outer barrier closure lids are welded to the waste package outer barrier and the waste package inner vessel closure lid is welded to the waste package inner vessel after the waste form (spent nuclear fuel or high-level waste glass, or both) is loaded.

The drip shield and waste package are subject to various degradation processes including general corrosion and stress corrosion cracking. The Integrated Waste Package Degradation (IWPD) analysis developed in this technical product is used directly in total system performance assessment (TSPA) analysis to evaluate degradation of the drip shields and waste packages with time. In addition to the drip shield and waste package design inputs discussed above, the primary inputs to the IWPD analysis are documented in the reports summarized below:

- General Corrosion and Localized Corrosion of the Drip Shield (BSC 2004 [DIRS 169845])

- General corrosion inputs for the Titanium Grade 7 drip shield (Section 4.1.2). The general corrosion treatment for the Titanium Grade 7 drip shield includes an uncertain distribution of general corrosion rates. 
- General Corrosion and Localized Corrosion of Waste Package Outer Barrier (BSC 2004 [DIRS 169984])

- General corrosion inputs for the Alloy 22 waste package outer barrier (Section 4.1.3). The general corrosion treatment for the Alloy 22 waste package outer barrier includes a variability distribution of general corrosion rates applicable at $60^{\circ} \mathrm{C}$ and an uncertain distribution for an Arrhenius-type temperature dependence.

- An uncertain distribution for a general corrosion rate multiplier to represent the effect of MIC on general corrosion (Section 4.1.7).

- Stress Corrosion Cracking of the Drip Shield, the Waste Package Outer Barrier, and the Stainless Steel Structural Material (BSC 2004 [DIRS 169985])

- Stress and stress intensity factor profiles for the closure weld regions of the Alloy 22 waste package outer barrier (Section 4.1.5). These inputs include an angular variability treatment and an uncertainty treatment.

- Slip dissolution inputs such as stress and stress intensity factor thresholds for the closure weld regions of the Alloy 22 waste package outer barrier and stress corrosion crack growth velocity inputs (Section 4.1.6). These inputs are 100 percent uncertain.

- An assessment of the area of the Alloy 22 waste package outer barrier subject to stress corrosion cracking. This input is neither uncertain nor variable.

- Analysis of Mechanisms for Early Waste Package/Drip Shield Failure (BSC 2004 [DIRS 170024])

- Inputs for the number and size of weld flaws (Section 4.1.4)

- Inputs for the mechanisms of early failure and their consequences (Section 4.1.8).

The IWPD analysis uses a stochastic simulation approach and provides a description of the variation of waste package and drip shield degradation as a function of time for specific design and thermal-hydrologic exposure conditions. The objectives of the IWPD analysis are:

- To provide a representation of waste package degradation processes in the repository;

- To capture the effects of uncertainty and variability both in exposure conditions and degradation processes over a geologic time scale.

The TSPA-LA waste package degradation analysis simulates the behavior of a few hundred waste packages (Section 6.4). Effects of spatial and temporal variations in the exposure conditions over the repository are simulated by explicitly incorporating exposure condition histories into the analysis (representative thermal hydrologic histories are used in the present 
analysis (Section 6.4.5), but repository-relevant thermal hydrologic histories are used in TSPA). In addition, potentially variable corrosion processes within a single waste package are represented by dividing the waste package surface into subareas called "patches" and stochastically sampling the degradation parameter values for each patch. The use of patches explicitly represents the variability in degradation processes within a single waste package at a given time.

In the TSPA-LA, uncertainty in waste package degradation is analyzed with multiple realizations of the IWPD analysis. For each realization, values are sampled for the uncertain degradation parameters and passed to the IWPD analysis. Each realization is a complete IWPD analysis simulation of a given number of waste packages explicitly considering variability in the degradation processes. Accordingly, each of the IWPD analysis outputs (i.e., the fraction of the total number of waste packages and drip shields failed versus time and of the average number of patch and crack penetrations per failed waste package (or drip shield)) are reported as a group of "degradation profile curves" (resulting from the multiple realizations) representing the potential range of the output parameters. For example, the waste package failure time profiles are reported with a group of curves representing the cumulative probability of waste package failures as a function of time. The outputs of this report are inputs and methodologies, which are used by TSPA to evaluate waste package and drip shield degradation as a function of exposure time under exposure conditions anticipated in the repository.

\subsubsection{Alternative Scientific Approaches and Computational Methods Considered}

The integrated waste package degradation (IWPD) analysis documented in this report uses the WAPDEG software (BSC 2002 [DIRS 161240]). The WAPDEG software (BSC 2002 [DIRS 161240]) was developed specifically for the purpose of implementing the scientific approaches and computational methods specified in documents supporting this analysis (BSC 2004 [DIRS 169845]; BSC 2004 [DIRS 169984]; BSC 2004 [DIRS 169985]; BSC 2004 [DIRS 170024]). This scientific approaches or technical methods, or both, as well as computational methods to be used are specified in documents supporting this analysis (BSC 2004 [DIRS 169845]; BSC 2004 [DIRS 169984]; BSC 2004 [DIRS 169985]; BSC 2004 [DIRS 170024]) and justification would be required in order to deviate from these specifications. Alternative conceptual models (i.e., alternative scientific approaches or technical methods, or both) and computational methods were considered, as appropriate, during the development of the documents supporting this analysis. The reader is referred to those documents for further details on the alternative scientific approaches or technical methods considered that were not used and the rationale for not selecting them (BSC 2004 [DIRS 169845]; BSC 2004 [DIRS 169984]; BSC 2004 [DIRS 169985]; BSC 2004 [DIRS 170024]).

Other software or computational methods similar to those used exist. For example, the Electric Power Research Institute (EPRI) has used its Integrated Multiple Assumptions and Release Code (IMARC) model to evaluate repository performance (EPRI 2002 [DIRS 158069]). Also, the Nuclear Regulatory Commission (NRC) has used its Total-system Performance Assessment (TPA) code to evaluate repository performance (Codell et al. 2001 [DIRS 164795]). The EPRI IMARC uses a logic tree methodology and should be used as a high-level analysis tool rather than a performance assessment code that can be used to incorporate uncertainties in all phases of the analysis (EPRI 2002 [DIRS 158069], Section 9.1). For this reason, the EPRI IMARC was 
not selected for use in this analysis. The NRC TPA code evaluates the performance of a prototypical waste package for each repository subarea (Codell et al. 2001 [DIRS 164795], Section 2.2.3). The NRC TPA code assumes that when this prototypical waste package fails, all waste packages in the repository subarea are failed (Codell et al. 2001 [DIRS 164795], Section 2.2.3). In this respect, the NRC TPA code is not as sophisticated as the WAPDEG code which can simulate several waste packages, to represent variability, in each repository subarea (Section 6.1). For this reason, the NRC TPA code was not selected for use in this analysis. Also, neither the EPRI IMARC nor the NRC TPA code is readily available for use on the project. Furthermore, the WAPDEG software (BSC 2002 [DIRS 161240]) was developed specifically to implement the scientific approaches and computational methods used in evaluating drip shield and waste package performance for the project. On this basis, the WAPDEG software (BSC 2002 [DIRS 161240]) was selected for use in this analysis.

\subsection{FEATURES, EVENTS, AND PROCESSES INCLUDED IN ANALYSIS}

The development of a comprehensive list of features, events, and processes (FEPs) potentially relevant to postclosure performance of the Yucca Mountain repository is an ongoing, iterative process based on site-specific information, design, and regulations. To support TSPA-LA, the FEP list was re-evaluated in accordance with The Enhanced Plan for Features, Events, and Processes (FEPs) at Yucca Mountain (BSC 2002 [DIRS 158966], Section 3.2). Table 15 provides a list of FEPs included in this report and provides specific references to sections within this report where the FEPs are discussed. No FEPs are excluded by the analyses in this report. See also DTN: MO0407SEPFEPLA.000 [DIRS 170760] for a description of these FEPs and FEPs Screening of Processes and Issues in Drip Shield and Waste Package Degradation (BSC 2004 [DIRS 169997]) for a complete list of all FEPs related to waste package and drip shield degradation.

Table 15. Included FEPs

\begin{tabular}{|c|l|l|}
\hline \multicolumn{1}{|c|}{ FEP No. } & \multicolumn{1}{|c|}{ FEP Name } & \multicolumn{1}{|c|}{ Section Where Disposition is Described } \\
\hline $2.1 .03 .01 .0 \mathrm{~A}$ & General corrosion of waste packages & 6.3 .4 and 6.4.7; BSC 2004 [DIRS 169984] \\
\hline $2.1 .03 .01 .0 \mathrm{~B}$ & General corrosion of drip shields & 6.3 .3 and 6.4.6; BSC 2004 [DIRS 169845] \\
\hline $2.1 .03 .02 .0 \mathrm{~A}$ & Stress corrosion cracking (SCC) of waste packages & 6.3 .5 and 6.4.10; BSC 2004 [DIRS 169985] \\
\hline 2.1.03.05.0A & $\begin{array}{l}\text { Microbially influenced corrosion (MIC) of waste } \\
\text { packages }\end{array}$ & 6.3 .6 and 6.4.11; BSC 2004 [DIRS 169984] \\
\hline 2.1.03.08.0A & Early failure of waste packages & 6.3 .8 and 6.4.12; BSC 2004 [DIRS 170024] \\
\hline 2.1.03.11.0A & Physical form of waste package and drip shield & 6.3 .2 \\
\hline
\end{tabular}

\subsection{DESCRIPTION OF INTEGRATED WASTE PACKAGE DEGRADATION ANALYSIS}

The License Application (LA) waste package design consists of two layers: an Alloy 22 waste package outer barrier and a Stainless Steel Type 316 waste package inner vessel (BSC 2003 [DIRS 165406]). The highly corrosion-resistant Alloy 22 waste package outer barrier is responsible for the long waste package lifetime. In this report, the only performance credit taken for the Stainless Steel Type 316 inner vessel is for the structural support it provides to the waste package outer barrier before waste package breach. Although the waste package inner vessel would also provide some performance for waste containment and potentially act as a barrier to 
radionuclide transport after waste package outer barrier breach, the potential performance of this barrier is far less than that of the more corrosion resistant Alloy 22 waste package outer barrier. For this reason, the corrosion performance of the waste package inner vessel is conservatively ignored in this report. The waste package outer barrier has two Alloy 22 closure lids. The waste package closure lids are welded to the waste package outer barrier after the waste form (spent nuclear fuel or high-level waste glass, or both) is loaded. A drip shield with Titanium Grade 7 water diversion plates will be placed over the waste package (BSC 2004 [DIRS 168489]). The space between the drip shield and the emplacement drift is open for air circulation and there is no backfill material used.

Over the emplacement period, the drip shield and waste package are potentially subject to various degradation processes including general corrosion and stress corrosion cracking. The IWPD analysis itself (Section 6.4), not the resultant curves from the IWPD analysis presented in Section 6.5 (which are for illustrative purposes), is used directly in total system performance assessment (TSPA). The outputs of this report are inputs and methodologies used by TSPA to evaluate waste package and drip shield degradation as a function of exposure time under exposure conditions anticipated in the repository.

The IWPD analysis makes use of the WAPDEG software. In WAPDEG, corrosion functional forms and events are specified to apply to specific "water conditions" (BSC 2002 [DIRS 162606], Section 3.2.3). For example, in WAPDEG, a general or localized corrosion functional form is specified to apply to a specific barrier and water condition. Events, such as stress corrosion cracking or microbially influenced corrosion, apply to a specific barrier; however, they may apply to multiple water conditions. Using this input design, the effects of an event can be identical under different water conditions. In the implementation discussed in this report, the water condition on the outside of the drip shield differs from that on the underside of the drip shield and the waste package surface before drip shield failure. Upon drip shield failure, the waste package is exposed to the water condition previously on the outside surface of the drip shield and the waste package general corrosion functional form appropriate for the new water condition is applied.

\subsubsection{Drip Shield Design}

The only drip shield degradation process in the Integrated Waste Package Degradation (IWPD) analysis is general corrosion (Section 6.3.3). General corrosion is analyzed separately for the drip shield outer and inner surfaces. The drip shield outer surface uses a different general corrosion rate (Section 6.3.3) than the drip shield inner surface. As will be discussed in Section 6.3.3, the variation in the general corrosion rate of the drip shield is considered to be only due to uncertainty (i.e., there is no variability in the general corrosion rate on the inner and outer surfaces of the drip shield). For these reasons, unlike the waste packages, each drip shield is analyzed as a single entity. The waste package surface is analyzed as being composed of several subareas referred to as patches (Section 6.3.2) in order to represent spatial variation in degradation processes on the waste package surfaces.

The drip shield plate thickness (Table 3) is used directly in the input to WAPDEG (Section 6.4.6). WAPDEG does not require the drip shield surface area; it is only necessary that the number of drip shield patches (i.e., one) be specified. 


\subsubsection{Waste Package Design}

In the Integrated Waste Package Degradation (IWPD) analysis, the waste package surface is divided into subareas referred to as patches (Figure 1), which are used to simulate variability across the barrier surfaces. It is at the patch-level that the degradation modes are applied (e.g., each patch might have a different general corrosion rate, crack growth threshold, etc.). The IWPD analysis outputs the fraction of drip shield and waste package failures versus time and the average (per failed drip shield or waste package) number of pit, crack, and patch penetrations for each drip shield or waste package, or both versus time.

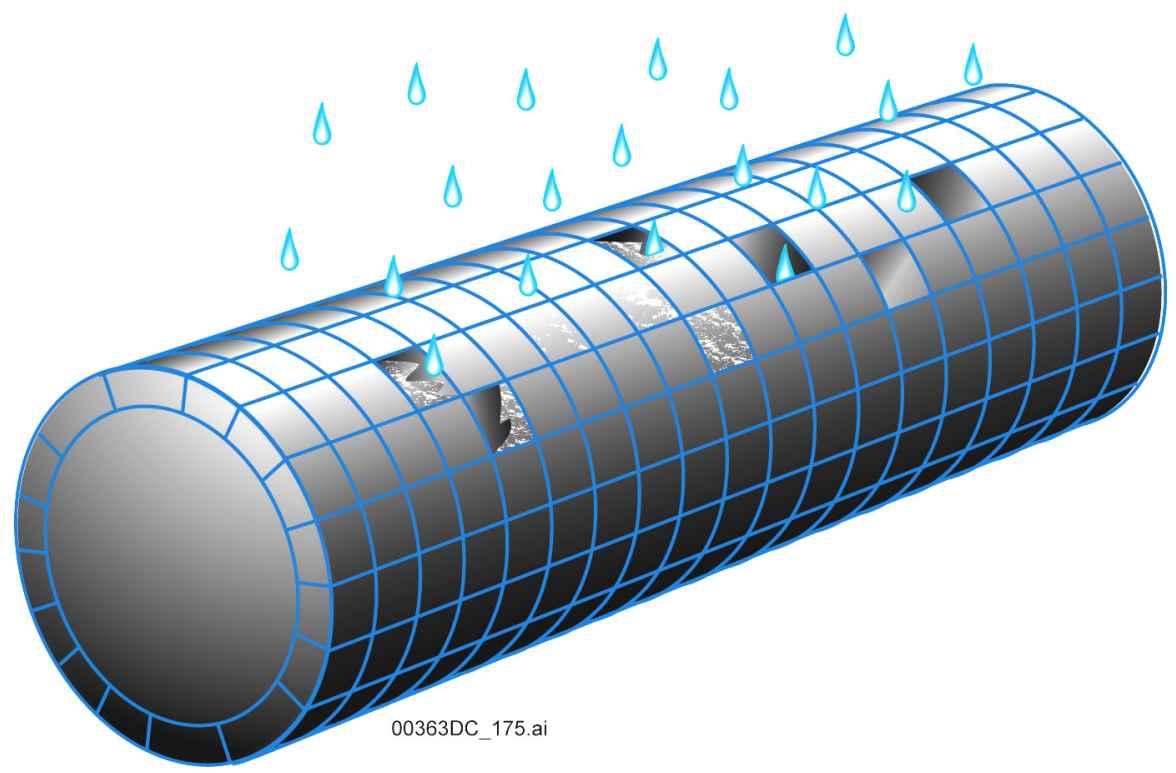

Figure 1. Schematic Representation of Waste Package Patches

As discussed in Section 4.1.1, two nominal waste package configurations are analyzed in this report. This treatment is consistent with the approach used in the TSPA-SR Model (CRWMS M\&O 2000 [DIRS 153246], Table 4.1-1). The first waste package configuration is referred to as the commercial spent nuclear fuel (CSNF) waste package configuration (CRWMS M\&O 2000 [DIRS 153246], Table 4.1-1) for which the 21-PWR waste package configuration parameters are used (BSC 2001 [DIRS 157812]). The 21-PWR waste package configuration is an appropriate representation of the CSNF waste package configuration since the 21-PWR waste package configuration is the most common waste package configuration in the repository (BSC 2003 [DIRS 163855], Table 11). Using the waste package configuration parameters listed in Table 3, the CSNF waste package configuration surface area is

$$
\text { CSNF WP Surface Area }=\pi \cdot(1,564 \mathrm{~mm}) \times(4,775 \mathrm{~mm})=2.346 \times 10^{7} \mathrm{~mm}^{2}
$$

Note that the surface area of the closure lids was not considered. Because the CSNF waste package surface area is primarily used to determine the fraction of waste package surface area subjected to stress corrosion cracking (later in this section), it is conservative and appropriate to ignore the closure lid surface area in determining the total waste package surface area. 
The second waste package configuration analyzed is the codisposal (CDSP) waste package configuration (CRWMS M\&O 2000 [DIRS 153246], Table 4.1-1) whose length is considered to be the average length of the $5 \mathrm{HLW} / 1$ DOE SNF long (BSC 2001 [DIRS 157818]) and short (BSC 2001 [DIRS 157817]) waste package configurations (which have roughly equal populations in the inventory). The $5 \mathrm{HLW} / 1$ DOE SNF (codisposal) long and short waste package configurations are appropriate representations of the CDSP waste package configuration since these are the most common high-level waste (HLW) waste package configurations in the repository (BSC 2003 [DIRS 163855], Table 11). Again using the waste package configuration parameters listed in Table 3, the CDSP waste package surface area is:

$$
\text { CDSP WP Surface Area }=\pi \cdot(2,030 \mathrm{~mm}) \times\left(\frac{(3,200+4,827)}{2} \mathrm{~mm}\right)=2.560 \times 10^{7} \mathrm{~mm}^{2}
$$

The 5 HLW/1 DOE SNF long (BSC 2001 [DIRS 157818]) and short (BSC 2001 [DIRS 157817]) waste package configurations both have the same waste package outer barrier outer diameter $(2,030 \mathrm{~mm})$ as shown in Table 3 .

The general corrosion model used for the waste package is based on weight-loss measurements for samples exposed in the LTCTF (BSC 2004 [DIRS 169984], Section 6.4.3). For the waste package outer barrier, samples with the crevice geometry were used to generate the general corrosion rate distribution (applied at $60^{\circ} \mathrm{C}$ ). The crevice geometry samples have nominal dimensions of 2 in. $\times 2$ in. $\times 1 / 8$ in. and a 0.312 -in. diameter hole in the center for sample mounting (BSC 2004 [DIRS 169984], Section 6.4.3). Therefore, the exposed surface area, $A$, for a crevice geometry sample is calculated as follows:

$$
A=2 a b+2 b c+2 a c-\left(\frac{\pi d^{2}}{2}\right)+\pi d c
$$

where $a$ is the length of the specimen, $b$ is the width of the specimen, $c$ is the thickness of the specimen, and $d$ is diameter of hole. Using the above-mentioned dimensions, the exposed surface area for a crevice sample (converted to $\mathrm{mm}^{2}$ ) is $5,787 \mathrm{~mm}^{2}$. The IWPD analysis uses a patch size of about four (4) times this area $\left(23,150 \mathrm{~mm}^{2}\right)$. Therefore, the CSNF waste packages are composed of 1,014 patches and the CDSP waste packages composed of 1,106 patches. In Section 6.3.4, the general corrosion rate distribution applied to the waste package outer barrier is modified to reflect this change in scale between the smaller crevice geometry sample size and the patch size.

Effectively, the waste package outer barrier is composed of two different regions; the closure lid region and the shell region. The waste package outer barrier shell region thickness, $20 \mathrm{~mm}$ for the CSNF waste package configuration and $25 \mathrm{~mm}$ for the CDSP waste package configuration (Table 3), is used indirectly in the formulation of inputs to the WAPDEG software. CSNF and CDSP waste package configurations have similar closure-lid configurations. The waste package outer barrier outer closure lid thickness (and weld thickness) is $25 \mathrm{~mm}$ for CSNF and CDSP waste package configurations (Table 8). The waste package outer barrier middle closure lid thickness (and weld thickness) is $10 \mathrm{~mm}$ (Table 8). These thicknesses are used as direct inputs to WAPDEG. WAPDEG does not analyze the waste package outer barrier closure lid and the shell 
regions independently. Both waste package outer barrier regions are analyzed as being composed of two layers (Figure 2); the outer analyzed layer is $25 \mathrm{~mm}$ thick and the inner analyzed layer is $10 \mathrm{~mm}$ thick. Use of two layers is straightforward for analysis of the closure lid region of the waste package outer barrier. For the waste package outer barrier shell region, the general corrosion rate used for the analyzed outer layer is very large $\left(\sim 10^{10} \mathrm{~mm} / \mathrm{yr}\right)$ effectively leading to instantaneous penetration. Therefore, the waste package outer barrier shell region of the analyzed outer layer does not contribute to waste package performance. The general corrosion rate used for the waste package outer barrier shell region of the analyzed inner layer of the CSNF waste package configuration is decreased by a factor of $20 \mathrm{~mm} / 10 \mathrm{~mm}=2$ (i.e., multiplied by a factor of 0.5). In this way, the analyzed 10-mm inner layer for the waste package outer barrier shell region "behaves" (in the analysis) like a 20-mm layer. Similarly, the general corrosion rate used for the waste package outer barrier shell region of the analyzed inner layer of the CDSP waste package configuration is decreased by a factor of $25 \mathrm{~mm} / 10 \mathrm{~mm}=2.5$ (i.e., multiplied by a factor of 0.4 ). In this way, the analyzed 10-mm inner layer behaves (in the analysis) like a 25-mm layer.

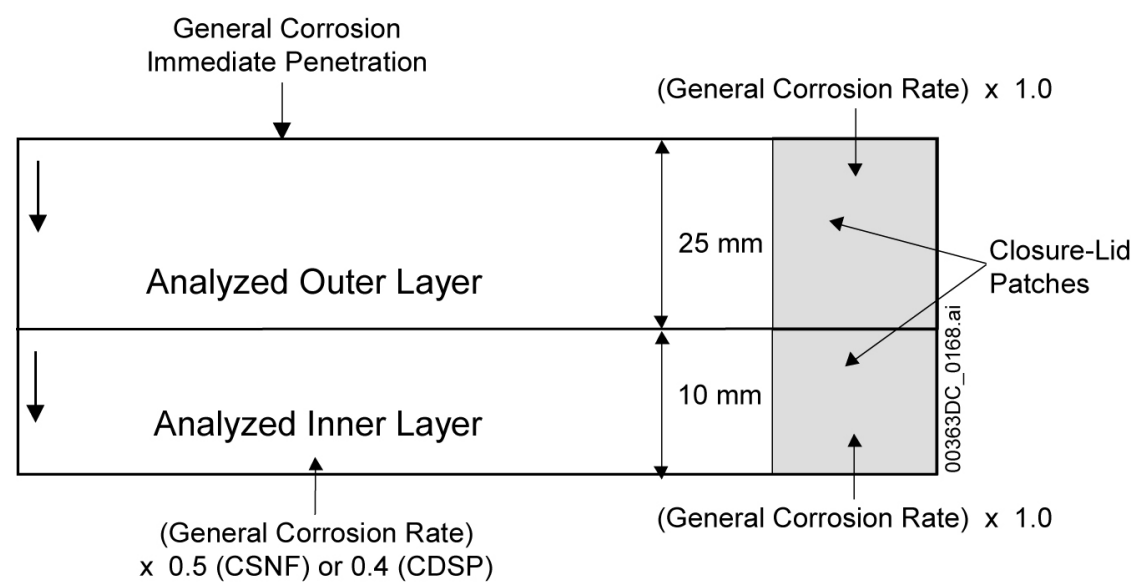

Figure 2. Schematic of Waste Package Configuration in IWPD Analysis to Implement Stress Corrosion Cracking of Dual Closure Lids of Waste Package Outer Barrier

\subsubsection{Stress Corrosion Cracking Patches}

The Integrated Waste Package Degradation (IWPD) analysis subjects a fraction of the waste package surface to stress corrosion cracking. This area fraction is the same as the fraction of the total surface area represented by the closure-lid patches identified in Figure 2 (the bulk of the closure lid is not analyzed, only the closure lid weld region). As mentioned above, the area of a waste package patch is $23,150 \mathrm{~mm}^{2}$. Making the reasonable analysis assumption that the patches are square, the length of one side of a patch is about $152 \mathrm{~mm}$.

The closure-lid weld region is represented as a cylinder, one-patch side wide and with the same radius as the waste package. This results in the fraction of area represented by the closure weld region for CSNF waste packages being:

$$
\frac{\text { Closure-Lid Weld Region Area }}{\text { WP Surface Area }}=\frac{\pi(1,564 \mathrm{~mm})(152 \mathrm{~mm})}{2.346 \times 10^{7} \mathrm{~mm}^{2}} \approx 0.032
$$


or about 32 patches. For CDSP waste packages the fraction of area represented by the closure weld region is:

$$
\frac{\text { Closure-Lid Weld Region Area }}{\text { WP Surface Area }}=\frac{\pi(2,030 \mathrm{~mm})(152 \mathrm{~mm})}{2.560 \times 10^{7} \mathrm{~mm}^{2}} \approx 0.038
$$

or about 42 patches.

Analyses presented in Stress Corrosion Cracking of the Drip Shield, the Waste Package Outer Barrier, and the Stainless Steel Structural Material (BSC 2004 [DIRS 169985], Section 6.5.1), indicate the distance between two neighboring cracks must be greater than the plate thickness for the stress (and stress intensity factor) profile to be of sufficient magnitude to propagate a crack through-wall. Therefore, for the waste package outer barrier outer closure-lid (25-mm thick (Table 8)), and again making the analysis assumption that the patches are square (side length about $150 \mathrm{~mm}$ ), about six cracks per patch are able to propagate through-wall. For the waste package outer barrier middle closure-lid (10-mm thick (Table 8)), about 15 cracks per patch are able to propagate through-wall. WAPDEG propagates cracks on a patch until the first crack penetrates, then ceases crack propagation for any remaining cracks. If, for example, 32 patches are subject to crack growth and all fail by cracking, only 32 crack penetrations (the first crack to penetrate on each patch) will be reported, regardless of how many cracks per patch were considered. Therefore, it is appropriate (and conservative) to multiply the number of crack penetrations reported by WAPDEG by the number of cracks per patch to get a measure of the total number of cracks (Section 6.4.10).

\subsubsection{Drip Shield General Corrosion Model Discussion}

Details of the general corrosion rate distributions used for the drip shield are given in General Corrosion and Localized Corrosion of the Drip Shield (BSC 2004 [DIRS 169845], Section 6.5.5) and are tracked with DTN: MO0408MWDGLCDS.002 [DIRS 171486]. Also, see Section 4.1.2 for a discussion of the drip shield general corrosion inputs and Section 6.4.6 for discussion of implementation.

The drip shield outer surface is exposed to a more complicated chemistry and geometry than the drip shield inner surface because dust and/or mineral films (from evaporation of dripping water) form crevices on the drip shield outer surfaces. In contrast, the drip shield inner surfaces will not be exposed to dripping water or significant dust film formation (BSC 2004 [DIRS 169845], Section 6.5.5). Therefore, the general corrosion of the inner surface and the outer surface of the drip shield are analyzed by using different sets of corrosion data (BSC 2004 [DIRS 169845], Section 6.5.5). The general corrosion rate cumulative distribution function applicable to the under side of the drip shield is shown in Table 4 . The general corrosion rate cumulative distribution function applicable to the top side of the drip shield is shown in Table 5.

For each realization of the Integrated Waste Package Degradation analysis, a single general corrosion rate is sampled from each general corrosion rate distribution and applied to all drip shields. The variation in these inputs is entirely due to uncertainty (BSC 2004 [DIRS 169845], Section 6.5.5). Using this approach, all drip shields in the repository fail by general corrosion at the same time for a given realization. 
The maximum general corrosion rate for the cumulative distribution function applied to the under side of the drip shield (Table 4) is approximately $1.13 \times 10^{-4} \mathrm{~mm} / \mathrm{yr}$ and the maximum general corrosion rate for the cumulative distribution function applied to the top side of the drip shield (Table 5) is approximately $3.20 \times 10^{-4} \mathrm{~mm} / \mathrm{yr}$. Therefore, the earliest possible drip shield failure by general corrosion is about 35,000 years.

\subsubsection{Waste Package Outer Barrier General Corrosion Model Discussion}

Details of the general corrosion rate distributions used for the Alloy 22 waste package outer barrier are given in General Corrosion and Localized Corrosion of Waste Package Outer Barrier (BSC 2004 [DIRS 169984], Section 6.4.3). Also, see Section 4.1.3 for a discussion of the waste package outer barrier general corrosion inputs and Section 6.4.7 for discussion of implementation. The Alloy 22 general corrosion rate is a function of exposure temperature. The temperature dependence follows an Arrhenius relationship:

$$
R=\exp \left[C_{o}-\frac{C_{1}}{T}\right]
$$

where

$$
\begin{aligned}
& R=\text { general-corrosion rate } \\
& T=\text { temperature (Kelvin) } \\
& C_{o}=\text { intercept term } \\
& C_{1}=\text { slope term (Kelvin) }
\end{aligned}
$$

as discussed in General Corrosion and Localized Corrosion of Waste Package Outer Barrier (BSC 2004 [DIRS 169984], Section 6.4.3). The sign of the slope term in this report is negative with respect to the slope term in General Corrosion and Localized Corrosion of Waste Package Outer Barrier (BSC 2004 [DIRS 169984], Section 6.4.3) to be consistent with the input requirements of WAPDEG. The slope term, $C_{l}$, is normally distributed with a mean of 3,116.47 K and a standard deviation of 296.47 K (BSC 2004 [DIRS 169984], Section 6.4.3; DTN: MO0409MWDUGCMW.000 [DIRS 171714]).

The intercept term, $C_{o}$, is determined from the general corrosion rate distribution derived from the weight loss of the 5-year crevice geometry samples exposed in the LTCTF (BSC 2004 [DIRS 169984], Section 6.4.3) and the value of the slope term, $C_{l}$. The general corrosion rate distribution derived from the weight loss of the 5-year crevice geometry samples exposed in the LTCTF represents the distribution of long-term general corrosion rates of the waste package outer barrier at $60^{\circ} \mathrm{C}(333.15 \mathrm{~K})$. Therefore:

$$
\ln \left(R_{o}\right)=C_{o}-\frac{C_{1}}{333.15 \mathrm{~K}}
$$

or

$$
C_{o}=\ln \left(R_{o}\right)+\frac{C_{1}}{333.15 \mathrm{~K}}
$$


where $R_{o}$ is the general corrosion rate distribution from the 5-year exposed crevice geometry samples. Substituting for $C_{o}$ in Equation 17,

$$
R=\exp \left[\ln \left(R_{o}\right)+C_{1}\left(\frac{1}{333.15 \mathrm{~K}}-\frac{1}{T}\right)\right]
$$

General Corrosion and Localized Corrosion of Waste Package Outer Barrier (BSC 2004 [DIRS 169984], Section 6.4.3) states that $R_{o}$ is given by a Weibull distribution (Equation 1) $(\alpha=8.88 \mathrm{~nm} / \mathrm{yr}, \beta=1.62$, and $\theta=0)$ (Table 6). This is a two-parameter Weibull distribution (since the location parameter, $\theta$, is zero) with $\alpha$ being the scale parameter and $\beta$ the shape parameter. As discussed in Section 6.3.2, the patch area used to analyze the waste packages is four times the area of the crevice geometry sample size used to determine the $R_{o}$ distribution. Therefore, the general corrosion rates used in the IWPD analysis are adjusted to account for the effects of this change of scale (Aziz 1956 [DIRS 159379]; Shibata 1996 [DIRS 119589]). The method employed to accomplish this change in scale corresponds to using the highest of four sampled corrosion rates (from the two-parameter Weibull distribution) to analyze general corrosion of the waste package patch. This approach is conservative and appropriate for this application. The approach is conservative because it is probable that not all four samples from the Weibull distribution will have the highest rate, therefore, a more realistic representation of the overall general corrosion rate would be the average of the four sampled corrosion rates. However, this approach would not account for the fact that one fourth of the patch has the maximum of the four sampled corrosion rates. On this basis, the proposed approach is conservative and appropriate for this application.

Mathematically stated, if $C D F(x)$ is the cumulative probability distribution, then the probability that $x$ will be the largest amongst $n$ observations is $[C D F(x)]^{n}$ (Aziz 1956 [DIRS 159379]; Shibata 1996 [DIRS 119589]). In this context, $n$ can be called the size factor. The effect of this method is to shift the median general corrosion rate to higher values and to decrease the probability of sampling lower general corrosion rates. This can be seen in Figure 3 where the original distribution for $R_{o}$ is plotted along with the distribution resulting from a size factor of 4 .

The variation in $R_{o}$ is entirely due to variability (i.e., a cumulative distribution function for $\ln \left(R_{o}\right)$ is used in the Integrated Waste Package Degradation (IWPD) analysis). General Corrosion and Localized Corrosion of Waste Package Outer Barrier (BSC 2004 [DIRS 169984], Section 6.4.3) states that $C_{l}$ is given by a truncated (at $\pm 3 \mathrm{sds}$ ) normal distribution with a mean of $3,116.47 \mathrm{~K}$ and a standard deviation of $296.47 \mathrm{~K}$ (Table 7). The variation in the general corrosion rate slope term, $C_{l}$, is entirely due to uncertainty. For each realization of the IWPD analysis, a single general corrosion rate slope term is sampled and applied to the Alloy 22 waste package outer barrier surfaces. Spatial and temporal variability in the waste package surface temperatures in the repository lead to spatial and temporal variability in the general corrosion rate of the Alloy 22 waste package outer barrier. 


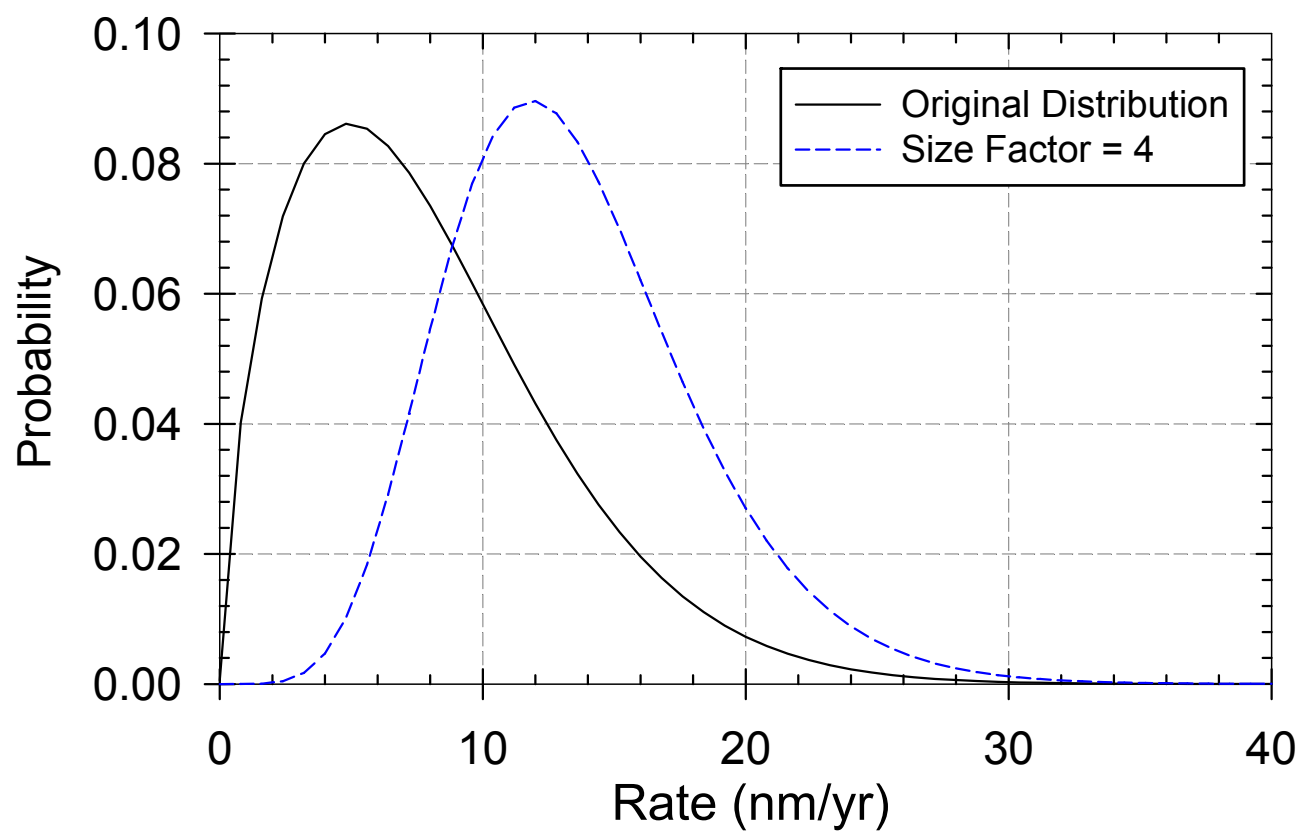

Source DTN: MO0409MWDUGCMW.000 [DIRS 171714].

Output DTN: MO0310MWDWAPAN.002.

Figure 3. Effect of Scaling General Corrosion Distribution by a Size Factor of Four

\subsubsection{Waste Package Stress Corrosion Cracking Model Discussion}

Weld residual stresses are a potential driving force for stress corrosion cracking. All regions of the waste package (including fabrication welds), except the waste package outer barrier closure-lid weld regions, are stress relief annealed before the waste packages are loaded with waste (Plinski 2001 [DIRS 156800], Section 8.1.7), and, thus, do not develop residual stress/stress intensity factors high enough for stress corrosion cracking to occur (BSC 2004 [DIRS 169985], Section 6.4.2). Stress corrosion cracking of the waste package outer barrier closure lid weld regions is analyzed in this report. Analyses of the potential for stress corrosion cracking due to seismic-induced loading and rockfalls are not discussed in this report.

A dual closure-lid design (Figure 4) for the Alloy 22 waste package outer barrier (or outer shell) is used for license application (Bokhari 2003 [DIRS 162429]). The outer closure lid is 25-mm thick and the middle closure lid is 10-mm thick (Bokhari 2003 [DIRS 162429]). The primary differences in closure lid design to be used for license application with respect to the closure lid design used in site recommendation are (a) the full penetration stainless steel lid weld will be replaced with a spread ring and seal weld; (b) the outer closure lid extension is eliminated; (c) the outer closure lid mitigation method will be laser peening instead of induction annealing; and (d) no laser peening will be applied to the middle closure lid (Bokhari 2003 [DIRS 162429]). The effects of the peening method applied to the outer closure lid are accounted for in the stress and stress intensity factor profiles discussed in the next section. 


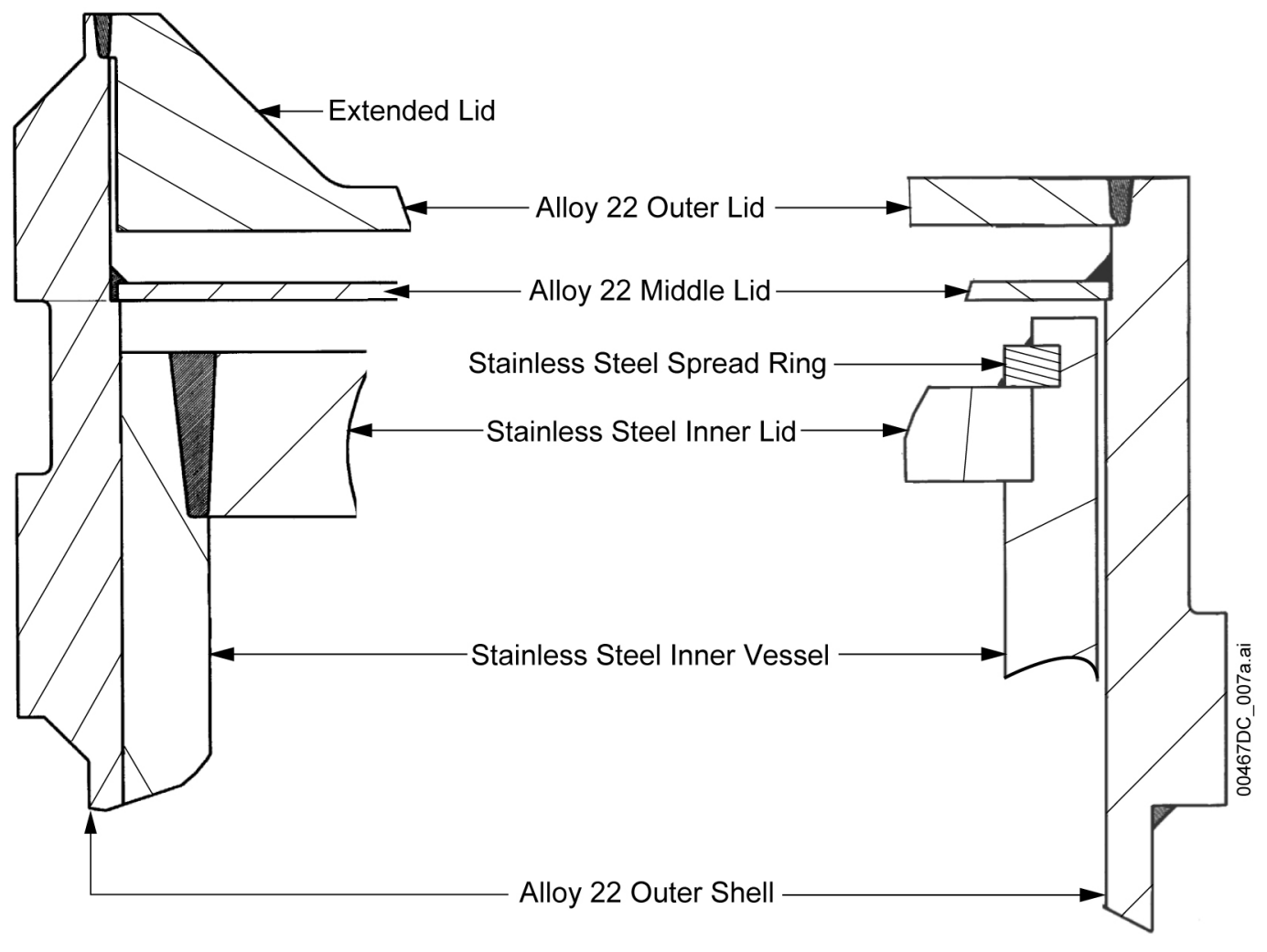

Site Recommendation Design

License Application Design

Figure 4. Schematic of the Dual Closure Lids of Waste Package Outer Barrier

One can see in Figure 4 that there is a physical separation between the two lids. Thus, any stress corrosion cracks initiated in the outer closure lid stop after penetrating it, and then the middle closure-lid welds are subject to the external environment and the potential for stress corrosion crack initiation and growth.

\subsubsection{Stress and Stress Intensity Factor Profiles}

Inputs to this analysis include stress and stress intensity factor profiles (stress or stress intensity factor versus depth) appropriate for both the outer closure and middle closure lids of the waste package outer barrier. Table 9 summarizes these inputs and their sources. These inputs can be found in Stress Corrosion Cracking of the Drip Shield, the Waste Package Outer Barrier, and the Stainless Steel Structural Material (BSC 2004 [DIRS 169985]).

In Stress Corrosion Cracking of the Drip Shield, the Waste Package Outer Barrier, and the Stainless Steel Structural Material (BSC 2004 [DIRS 169985], Section 6.2.2), it is concluded that the hoop stress, which promotes radially oriented crack growth, is the dominant component of stress in the waste package outer barrier closure lid weld regions. On this basis, only the hoop stress profiles are considered further in this report. 
The hoop stress $(\sigma$ in $\mathrm{MPa})$ as a function of depth $(x$ in $\mathrm{mm})$ in the closure weld regions of the Alloy 22 waste package outer barrier is given by a third order polynomial equation of the form (BSC 2004 [DIRS 169985], Table 8-1; DTN: LL030607012251.065 [DIRS 163968]):

$$
\sigma(x, 0)=A_{0}+A_{1} \times x+A_{2} \times x^{2}+A_{3} \times x^{3}
$$

where the values of the coefficients $\left(A_{i}\right.$ 's) used in the Integrated Waste Package Degradation (IWPD) analysis are given in Table 10. The second argument in the stress function is used to represent angular variation $(\theta=0$ arbitrarily chosen) around the circumference of the Alloy 22 waste package outer and middle closure-lid weld regions. The angular variation is included using the following functional form (BSC 2004 [DIRS 169985], Section 6.4.5, Table 8-1; DTN: LL030607012251.065 [DIRS 163968]):

$$
\sigma(x, \theta)=\sigma(x, 0)-(17.236893) \times(1-\cos (\theta))
$$

Note that $\sigma(x, 0)$ (defined in Equation 21) uses the stress coefficients $\left(A_{i}\right)$ defined in Table 10 with $x$ in units of $\mathrm{mm}$. Based on the angular stress variation in Equation 22, the stress intensity factor variation with angle is given by (BSC 2004 [DIRS 169985], Section 6.4.5, Table 8-1; DTN: LL030607012251.065 [DIRS 163968]):

$$
K_{I}(x, \theta)=K_{I}(x) \times\left(\frac{\sigma(\text { Thck, } \theta)}{\sigma(\text { Thck, } 0)}\right)
$$

where Thck is taken to be the maximum depth value given in Table 11 and $K_{I}(x)$ is given by the values in Table 11. The variation of the stress and stress intensity factor profiles with angle is due to variability (BSC 2004 [DIRS 169985], Section 6.4.5).

The uncertainty in the stress and stress intensity factor profiles is introduced through a scaling factor, $z$. The scaling factor, $z$, which is sampled from a normal distribution with a mean of zero and a standard deviation of 5 percent of the yield strength, YS, has an upper-bound of 15 percent of the YS and a lower-bound of -15 percent of the YS (BSC 2004 [DIRS 169985], Section 6.4.5). The numerical value of the yield strength, YS, used in these calculations is the yield strength at $473 \mathrm{~K}$ (Table 12). The value of YS (285 MPa) is obtained by linear interpolation between the values of the yield strength at $366 \mathrm{~K}(338 \mathrm{MPa})$ and $477 \mathrm{~K}(283 \mathrm{MPa})$ (Table 9), i.e.:

$$
\mathrm{YS}=338 \mathrm{MPa}+\left(\frac{473 \mathrm{~K}-366 \mathrm{~K}}{477 \mathrm{~K}-366 \mathrm{~K}}\right) \times(283 \mathrm{MPa}-338 \mathrm{MPa})=285 \mathrm{MPa}
$$


The stress relation, accounting for uncertainty, is given by:

$$
\sigma_{u}(x, \theta, z)=\sigma(x, \theta) \times\left(\frac{\sigma(\text { Thck, } \theta)+z}{\sigma(\text { Thck, }, \theta)}\right)
$$

and the stress intensity factor relation is given by:

$$
K_{I u}(x, \theta, z)=K_{I}(x, \theta) \times\left(\frac{\sigma(\text { Thck, } \theta)+z}{\sigma(\text { Thck, } \theta)}\right)=K_{I}(x, 0) \times\left(\frac{\sigma(\text { Thck, } \theta)+z}{\sigma(\text { Thck, } 0)}\right)
$$

The uncertainty treatment of these inputs is encompassed in the parameter $z$, which is sampled once per realization of the Integrated Waste Package Degradation analysis for each closure lid (i.e., a different value of $z$ is sampled for each lid in a given realization).

\subsubsection{Weld Flaws}

Flaws in the closure-lid welds are likely sites for stress corrosion cracking initiation. Weld flaws are generally larger than other surface defects and are conservatively considered to maintain their depth relative to the advancing general corrosion front (i.e., they are not removed by general corrosion processes). Therefore, the characteristics of weld flaws in the closure welds are important inputs to the waste package stress corrosion cracking analysis. As discussed earlier, residual stress analyses showed that the hoop stress is the dominant stress driving crack growth; thus, only radially oriented weld flaws are potential sites for stress corrosion cracking initiation.

This section lists the design information inputs to the integrated waste package degradation (IWPD) analysis of weld flaws for the Alloy 22 waste package outer barrier (or outer shell) closure-lid welds.

The probability of nondetection, $P_{N D}$, of weld flaws of length $x$ using a nondestructive evaluation (NDE) technique is (BSC 2004 [DIRS 170024], Section 6.2.1.2.1, Equation 21):

$$
P_{N D}(x)=\varepsilon+\frac{1}{2}(1-\varepsilon) \operatorname{erfc}\left(v \times \ln \left(\frac{x}{b}\right)\right)=\frac{\varepsilon+1}{2}+\frac{\varepsilon-1}{2} \operatorname{erf}\left(v \times \ln \left(\frac{x}{b}\right)\right)
$$

The parameters in Equation 27 are identified in Table 16 and correspond to inputs in Table 8.

Table 16. Probability of Nondetection Inputs Used in the IWPD Analysis and Their Sources

\begin{tabular}{|l|c|c|}
\hline \multicolumn{1}{|c|}{ Input Name } & Input Value & Units \\
\hline $\begin{array}{l}\text { Lower limit of probability of } \\
\text { nondetection, } \varepsilon\end{array}$ & 0.005 & $\mathrm{~N} / \mathrm{A}$ \\
\hline Characteristic flaw size, $b$ & 2.5 & $\mathrm{~mm}$ \\
\hline Shape factor, $v$ & 3 & $\mathrm{~N} / \mathrm{A}$ \\
\hline
\end{tabular}

Source: BSC 2004 [DIRS 170024], Table 11.

Table 17 lists the inputs to the IWPD analysis of weld flaws for the Alloy 22 waste package outer barrier closure-lid welds. 
Table 17. Weld Flaw Analysis Inputs Used in the IWPD Analysis and Their Sources

\begin{tabular}{|c|c|c|c|}
\hline $\begin{array}{l}\text { Input } \\
\text { Name }\end{array}$ & $\begin{array}{l}\text { Input } \\
\text { Source }\end{array}$ & Input Value & Units \\
\hline $\begin{array}{l}\text { CSNF WP outer closure } \\
\text { lid weld volume }(V)\end{array}$ & BSC 2003 [DIRS 164610], Table 19 & 1350189 & $\mathrm{~mm}^{3}$ \\
\hline $\begin{array}{l}\text { CSNF WP middle closure } \\
\text { lid weld volume }(V)\end{array}$ & BSC 2003 [DIRS 164610], Table 18 & 490478 & $\mathrm{~mm}^{3}$ \\
\hline $\begin{array}{l}\text { CDSP WP outer closure } \\
\text { lid weld volume }(\mathrm{V})\end{array}$ & BSC 2003 [DIRS 164610], Table 19 & 1753091 & $\mathrm{~mm}^{3}$ \\
\hline $\begin{array}{l}\text { CDSP WP middle closure } \\
\text { lid weld volume }(V)\end{array}$ & BSC 2003 [DIRS 164610], Table 18 & 639901 & $\mathrm{~mm}^{3}$ \\
\hline Weld Thickness $(t h)$ & $\begin{array}{l}\text { BSC } 2001 \text { [DIRS 157812], BSC } 2001 \\
\text { [DIRS 157817], and BSC } 2001 \\
\text { [DIRS 157818], Sheet } 3 \text { of } 3\end{array}$ & $\begin{array}{l}25 \text { for outer closure lid } \\
10 \text { for middle closure lid }\end{array}$ & $\mathrm{mm}$ \\
\hline Number of sample welds & $\begin{array}{l}\text { BSC } 2004 \text { [DIRS 170024], Section } \\
6.2 .1 .1 .2\end{array}$ & 16 & $\mathrm{~N} / \mathrm{A}$ \\
\hline Number of weld flaws $\left(n_{f}\right)$ & BSC 2004 [DIRS 170024], Table 11 & 7 & $\mathrm{~N} / \mathrm{A}$ \\
\hline $\begin{array}{l}\text { Cumulative size of weld } \\
\text { flaws }\left(S_{f}\right)\end{array}$ & $\begin{array}{l}\text { BSC } 2004 \text { [DIRS 170024], Appendix I, } \\
\text { p. I-3 }\end{array}$ & 31.75 & $\mathrm{~mm}$ \\
\hline $\begin{array}{l}\text { Cumulative volume of } \\
\text { sample welds, } V_{f}\end{array}$ & $\begin{array}{l}\text { BSC } 2004 \text { [DIRS 170024], Appendix I, } \\
\text { p. I-26 } \\
\text { Identified as "total volume of weld in the } \\
16 \text { specimen rings" }\end{array}$ & 18610540.3277924 & $\mathrm{~mm}^{3}$ \\
\hline $\begin{array}{l}\text { Flaw size distribution } \\
\text { parameter }\left(\lambda_{s}\right)\end{array}$ & BSC 2004 [DIRS 170024], Equation 2 & $\begin{array}{l}\text { Gamma distribution with a mean of } \\
n_{f} / S_{f} \text { and a standard deviation of } \\
\operatorname{sqrt}\left(n_{f}\right) / S_{f}\end{array}$ & $\mathrm{~mm}^{-1}$ \\
\hline $\begin{array}{l}\text { Flaw count distribution } \\
\text { parameter }\left(\lambda_{c}\right)\end{array}$ & BSC 2004 [DIRS 170024], Equation 12 & $\begin{array}{l}\text { Gamma distribution with a mean of } \\
\left(n_{f}+1 / 2\right) / V_{f} \text { and a standard } \\
\text { deviation of } \operatorname{sqrt}\left(n_{f}+1 / 2\right) / V_{f}\end{array}$ & $\mathrm{~mm}^{-3}$ \\
\hline $\begin{array}{l}\text { Fraction of radial-oriented } \\
\text { flaws }\left(F_{r}\right)\end{array}$ & BSC 2004 [DIRS 170024], Table 12 & 0.008 & $\mathrm{~N} / \mathrm{A}$ \\
\hline $\begin{array}{l}\text { Fraction of plate to be } \\
\text { included for propagating } \\
\text { embedded flaws }(F \psi)\end{array}$ & BSC 2004 [DIRS 169985], Table 8-1 & 0.25 & $\mathrm{~N} / \mathrm{A}$ \\
\hline
\end{tabular}

Weld flaw sizes follow an exponential distribution of parameter $\lambda_{s}$ normalized to the weld thickness (BSC 2004 [DIRS 170024], Attachment I). The flaw size probability density function is shown below:

$$
f_{s}(x)=\frac{\lambda_{s} \exp \left(-\lambda_{s} \cdot x\right)}{1-\exp \left(-\lambda_{s} t h\right)}
$$

The flaw size distribution parameter (representing uncertainty), $\lambda_{s}$, is gamma distributed with shape parameter $n_{f}$, and scale parameter, $1 / S_{f}$. 
The fraction of nondetected defects remaining in the weld after inspection is given by the integration of the two functions above (Equations 27 and 28):

$$
F_{n r}(t h)=\int_{0}^{t h} P_{N D}(u) f_{s}(u) d u
$$

While the postinspection weld flaw sizes is given by the cumulative distribution function:

$$
G(x)=\frac{\int_{0}^{x} P_{N D}(u) f_{s}(u) d u}{F_{n r}(t h)}
$$

The distribution for the number of defects before any inspection or repair follows a Poisson distribution with parameter $\lambda_{c}$. The flaw count distribution parameter (representing epistemic uncertainty), $\lambda_{c}$, is gamma distributed with shape parameter, $\left(n_{f}+1 / 2\right)$, and scale parameter, $1 / \mathrm{V}_{f}$.

The distribution for the number of defects that remain after inspection is Poisson distributed with parameter $\lambda$ (count per closure weld given volume, $V$, and thickness, $t h$ ), given by the product below (Equation 31). This expression contains the fraction of weld flaws that are radially oriented, $F_{r}$, the fraction of embedded weld flaws able to propagate, $F_{\psi}$, and the fraction of nondetected defects, $F_{n r}(t h)$ :

$$
\lambda=F_{r} \times F_{\psi} \times F_{n r}(t h) \times\left(V \times \lambda_{c}\right)
$$

The various weld volumes, $V$, and thicknesses, $t h$, are as given for each of the four closure lid types (Table 17).

In summary, variation for weld flaw sizes is expressed as variability at the waste package level given by the truncated exponential probability density function in Equation 28, with an uncertain parameter, $\lambda_{s}$, sampled for each realization. The variation in the number of weld flaws is expressed as variability at the waste package level given by a Poisson distribution, with an uncertain parameter $\lambda$ (count per closure weld) given by Equation 31 . This parameter in turn is a function of parameters, $\lambda_{s}$ (from the fraction of nondetected flaws, $F_{n r}(t h)$ term), and $\lambda_{c}$, which are sampled as uncertain for each realization.

\subsubsection{Slip Dissolution Mechanism}

The Slip Dissolution Mechanism for stress corrosion cracking (BSC 2004 [DIRS 169985], Section 6.3) requires a threshold stress, a stress intensity factor threshold, an incipient crack size, and crack growth rate parameters (which are functions of $n$, the repassivation slope). These inputs and their sources are listed in Table 12.

The threshold stress is defined as the minimum stress at which cracks initiate on a "smooth" surface. This analysis refers to these as incipient cracks (to distinguish them from weld flaws) and typically form at local surface defects such as grain boundary junctions and surface roughness. Incipient cracks are considered to be $0.05 \mathrm{~mm}$ in length at the time of their 
nucleation (BSC 2004 [DIRS 169985], Table 8-1). The threshold stress is 90 percent of the yield strength (Table 12). Incipient cracks nucleate when general corrosion has penetrated to the depth at which the stress profile (Section 6.3.5.1) exceeds the threshold stress.

Weld flaws are already nucleated and, thus, do not require a stress threshold to nucleate. However, most weld flaws are embedded within the material and, therefore, not exposed to the environment. As general corrosion proceeds, some initially embedded weld flaws will be exposed to the environment (BSC 2004 [DIRS 169985], Section 6.2.2) while others are "corroded away." This evolution of the number of defects is not considered in detail. It has been recommended that a conservative approach is to consider the fraction of weld flaws embedded within the outer one-fourth of the weld thickness (BSC 2004 [DIRS 169985], Section 6.2.2) to be capable of propagation by the slip-dissolution mechanism. As discussed in Section 6.3.5.2, only 0.8 percent of weld flaws are capable of propagation based on their orientation with respect to the dominant stress components.

Stress corrosion crack growth can occur when the stress intensity factor at the tip of the incipient crack or weld flaw exceeds or is equal to a threshold stress intensity factor. The depth of the tip is the sum of the general corrosion depth and the crack or weld flaw depth. The stress intensity factor at this depth is determined from the stress intensity factor profile (Section 6.3.5.1). The threshold stress intensity factor, $K_{I S C C}$, is given as a function of the repassivation slope, $n$ and $V_{g c}$ (which equals $7.23 \mathrm{~nm} / \mathrm{yr}$ or $7.23 \times 10^{-6} \mathrm{~mm} / \mathrm{yr}$ ) (BSC 2004 [DIRS 169985], Section 6.3.5):

$$
K_{I S C C}=\left(\frac{7.23 \times 10^{-6} \frac{\mathrm{mm}}{\mathrm{yr}}}{\bar{A}}\right)^{1 / \bar{n}}
$$

$\bar{A}$ and $\bar{n}$ are functions of $n$, as discussed below. The threshold stress intensity factor is applied to both incipient cracks and weld flaws. It should be noted that parameter $\bar{A}$, and the equations using $\bar{A}$ are converted from units of $\mathrm{mm} / \mathrm{s}$ (as expressed in Section 4.1.6) to $\mathrm{mm} / \mathrm{yr}$ in this Section in order to be consistent with their use in the IWPD analysis.

Once crack growth initiates the crack(s) grow at a velocity given by (BSC 2004 [DIRS 169985], Table 8-1; DTN: LL030607012251.065 [DIRS 163968]):

$$
V_{t}=\bar{A}\left(K_{I}\right)^{\bar{n}}
$$

where $V_{t}$ is the crack growth rate in $\mathrm{mm} / \mathrm{yr}$, and $K_{I}$ is the stress intensity factor in $\mathrm{MPa}(\mathrm{m})^{1 / 2}$. Parameters, $\bar{A}$ and $\bar{n}$, in the above equation are expressed in terms of the repassivation slope, $n$, as follows.

$$
\begin{gathered}
\bar{A}=7.8 \times 10^{-2} n^{3.6}\left(4.1 \times 10^{-14}\right)^{n} \times\left[\left(60 \frac{\mathrm{s}}{\mathrm{min}}\right)\left(60 \frac{\mathrm{min}}{\mathrm{hr}}\right)\left(24 \frac{\mathrm{hr}}{\mathrm{day}}\right)\left(365.25 \frac{\mathrm{day}}{\mathrm{yr}}\right)\right] \\
\bar{n}=4 n
\end{gathered}
$$


In the IWPD analysis, the parameter $n$ is represented by a truncated normal distribution (at \pm 2 standard deviations (sds)) with a mean of 1.304, a sd of 0.16 (Table 12). The variation in the repassivation slope, $n$, is entirely due to uncertainty. The repassivation slope is sampled once per realization of the IWPD analysis (i.e., the same value of $n$ is used for each lid in a given realization).

The variations in the threshold stress and threshold stress intensity factor (through its dependence on $n$ ) distributions are entirely due to uncertainty. The thresholds are sampled once per realization of the IWPD analysis (i.e., the same value of these thresholds are used for each lid in a given realization).

\subsubsection{Waste Package Microbially Influenced Corrosion}

Analyses conducted in General Corrosion and Localized Corrosion of Waste Package Outer Barrier (BSC 2004 [DIRS 169984], Section 6.4.5) evaluate the effects of microbially influenced corrosion (MIC) on corrosion of the waste package outer barrier. It is concluded in that report that the effect of MIC is adequately represented by a multiplier applied to the general corrosion rate of the waste package outer barrier (BSC 2004 [DIRS 169984], Section 6.4.5), i.e.:

$$
C R_{M I C}=C R_{s t} \times f_{M I C}
$$

where $C R_{M I C}$ is the general corrosion rate in presence of microorganisms, $C R_{s t}$ is the general corrosion rate of the alloy in absence of MIC, and $f_{M I C}$ is the MIC factor. The MIC factor, $f_{M I C}$, is uniformly distributed between 1 and 2 . The variation in $f_{M I C}$, is entirely due to uncertainty (BSC 2004 [DIRS 169984], Section 6.4.5; DTN: MO0409MWDUGCMW.000 [DIRS 171714]). The MIC factor is applied to the waste package outer barrier general corrosion rate when the relative humidity (a measure of water activity) at the waste package outer barrier surface is above 90 percent. See Section 6.4.11 for implementation of MIC in the IWPD analysis.

\subsubsection{Inside-Out Degradation}

When a waste package fails, the IWPD analysis initiates corrosion degradation of the waste package inner surface (inside-out corrosion). The inside-out corrosion analysis includes general corrosion of the Alloy 22 waste-package outer barrier. The inside-out corrosion could cause penetrations by general corrosion in addition to those by outside-in corrosion. WAPDEG (BSC 2002 [DIRS 162606], Section 3.1) inside-out general corrosion initiates on the next time step after the time of the waste package failure. The in-package water condition is considered to be the same as the water condition initially on the outside of the drip shield. Since the drip shields life span is shorter than the waste packages (Section 6.5), the water condition initially on the outside of the drip shield is employed for the water condition contacting the waste package inner and outer surfaces at the time of waste package failure. Similar to the outside-in general corrosion rates, the inside-out corrosion rates are modified for the analyzed waste package configuration (Figure 2) and for patch scaling effects (Section 6.3.4). Inside-out stress corrosion cracking is not simulated since it would be of negligible consequence to waste package performance either because the waste package has already been breached by the much larger patch penetrations (due to general corrosion) or because the patches susceptible to stress corrosion cracking have already breached. 


\subsubsection{Waste Package Early Failure Analysis}

Analysis of Mechanisms for Early Waste Package/Drip Shield Failure (BSC 2004 [DIRS 170024], Section 6.1.6) identified several general types of manufacturing defects including weld flaws, base metal flaws, improper weld material, improper base metal, improper heat treatment, improper weld-flux material, poor weld-joint design, contamination, mislocated welds, missing welds, handling damage, and administrative or operational error. Weld flaws in waste package welds have been discussed in Sections 4.1.4 and 6.3.5 in relation to their effect on stress corrosion cracking.

Of the types of manufacturing defects identified, only improper heat treatment and handling damage (including improper laser peening) were carried forward for analysis and were considered together, because they share the same consequence of increasing the susceptibility of the waste package to stress corrosion cracking (BSC 2004 [DIRS 170024], Section 7). Improper heat treatment is, by far, the dominant process in terms of probability (BSC 2004 [DIRS 170024], Section 7). Improper heat treatment and handling damage (including improper laser peening) shall be collectively referred to as "waste package early failure" for the remainder of this report.

Variation in the number of early failed waste packages is expressed as variability deriving from a discrete Poisson distribution with an uncertain intensity parameter. The uncertain intensity parameter is the product of the uncertain rate of waste package failures (log normally distributed) and the number of waste packages in a realization. As summarized in Table 14 in Section 4.1.8, the Poisson intensity is sampled from a log normal distribution with a median of $7.2 \times 10^{-6}$ and an error factor of 15 (BSC 2004 [DIRS 170024], Section 7, Table 22).

These inputs need to be adjusted to conform to the input requirements of GoldSim (GoldSim Technology Group 2002 [DIRS 160643], Appendix B) for log normal distributions. First, note that the median is equal to the geometric mean for log normal distributions (Evans et al. 1993 [DIRS 112115], Chapter 25). Second, according to Analysis of Mechanisms for Early Waste Package/Drip Shield Failure (BSC 2004 [DIRS 170024], Section 6.2.2), the shape parameter, $\sigma_{k}$, is related to the error factor by:

$$
\sigma_{k}=\frac{\ln (E F)}{1.645}=\ln \left(E F^{1 / 1.645}\right)
$$

The shape parameter is the standard deviation in log space (Evans et al. 1993 [DIRS 112115], Chapter 25). Therefore, the geometric standard deviation of the log normal distribution is given by (GoldSim Technology Group 2002 [DIRS 160643], Appendix B):

$$
e^{\sigma_{k}}=E F^{1 / 1.645}
$$

The input parameters for GoldSim are as summarized in Table 18. 
Table 18. Waste Package Early Failure Inputs to the GoldSim Software

\begin{tabular}{|l|l|l|l|}
\hline \multicolumn{1}{|c|}{ Input Name } & \multicolumn{1}{|c|}{ Input Source } & \multicolumn{1}{c|}{ Input Value } & \multicolumn{1}{c|}{ Units } \\
\hline $\begin{array}{l}\text { Evaluation probability per } \\
\begin{array}{l}\text { Waste Package (Uncertain } \\
\text { Poisson intensity) }\end{array}\end{array}$ & Section 6.3.8 & $\begin{array}{l}\text { Log normal distribution with a } \\
\text { geometric mean of } 7.2 \times 10^{-6} \text { and a } \\
\text { geometric sd of } 15^{(1 / 1.645)} \text { truncated at } \\
\text { an upper-bound of } 7.44213 \times 10^{-3}\end{array}$ & per Waste Package \\
\hline $\begin{array}{l}\text { Number of Early Failed } \\
\begin{array}{l}\text { Waste Package per } \\
\text { realization }\end{array}\end{array}$ & $\begin{array}{l}\text { BSC 2004 [DIRS } \\
\text { 170024], Section 7, } \\
\text { Table 22 }\end{array}$ & $\begin{array}{l}\text { Poisson Distribution with intensity } \\
\text { given above multiplied by number of } \\
\text { waste packages considered. }\end{array}$ & $\begin{array}{l}\text { \# Waste } \\
\text { Package/Realization }\end{array}$ \\
\hline
\end{tabular}

While the failure mechanisms are expected to result in enhanced probability of stress corrosion cracking, the waste packages are treated as failed upon initiation of corrosion processes. The following recommendations are made in Analysis of Mechanisms for Early Waste Package/Drip Shield Failure (BSC 2004 [DIRS 170024], Section 6.4.8) for evaluating the effects of waste package early failure:

- A failure of the waste package outer barrier shell and outer and middle closure lids should be assumed

- The affected waste packages should fail immediately upon initiation of degradation processes

- The entire waste package surface area should be considered affected by improper heat treatment

- The materials of the entire affected area should be assumed lost upon failure of the waste packages because the affected area could be subjected to stress corrosion cracking and enhanced localized and general corrosion.

\subsection{INTEGRATED WASTE PACKAGE DEGRADATION ANALYSIS FORMULATION}

The IWPD analysis makes use of several software packages. These are listed in Section 3. WAPDEG is a dynamic-link library (DLL), which is used to analyze the variability in waste package degradation. GoldSim is used to pass input to WAPDEG and is responsible for treating the uncertainty in WAPDEG inputs. GoldSim also calls several other DLLs that are used to implement uncertainty in various inputs to WAPDEG. These include the SCCD DLL, for the treatment of uncertainty in stress and stress intensity factor profiles, and the CWD DLL, for the treatment of uncertainty in the number and size of closure lid weld (manufacturing) defects. Throughout this section, reference will be made to various parts of the GoldSim input file as well as to the various input files, parameters, and parameter distributions used in waste package degradation analysis.

\subsubsection{GoldSim Implementation Overview}

In this section, a brief overview of a GoldSim input file that calls the WAPDEG software is presented. A more detailed description of the GoldSim software can be found in GoldSim 
Graphical Simulation Environment: User's Guide (GoldSim Technology Group 2002 [DIRS 160643]). GoldSim is a graphical simulation environment, used in this report to prepare an input file for the WAPDEG software. A typical GoldSim simulation contains multiple realizations. Each realization is equally likely, and represents one particular sampling of the uncertain parameters.

The GoldSim graphical elements used to develop an input data set for WAPDEG are illustrated in Figure 5.
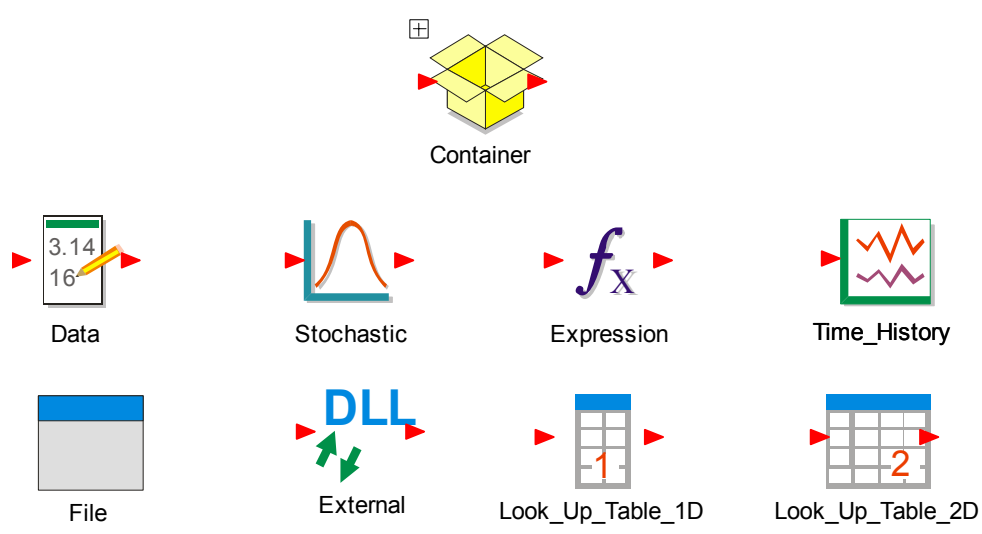

Output DTN: MO0310MWDWAPAN.002.

Figure 5. Graphical Elements Used in the GoldSim

Container elements are similar to subdirectories on a hard disk in that other graphical elements reside within them. Data elements are fixed values (or vectors of values). Stochastic elements define distributions, which are typically sampled once per realization. Expression elements are used to evaluate expressions (e.g., to multiply a data element by a stochastic value). Time_History elements are used to graph results (e.g., the contents of a Look_Up_Table_1D element). File elements contain the file names that will be passed to the simulation runs. The corresponding files must be present in the master directory. External elements are used to call external dynamic link libraries (DLLs), such as WAPDEG. Look_Up_Table_1D and Look_Up_Table_2D elements are typically used to store tables of input values or output values associated with external elements.

A schematic of a portion of the GoldSim input file, which calls WAPDEG, is shown in Figure 6. 

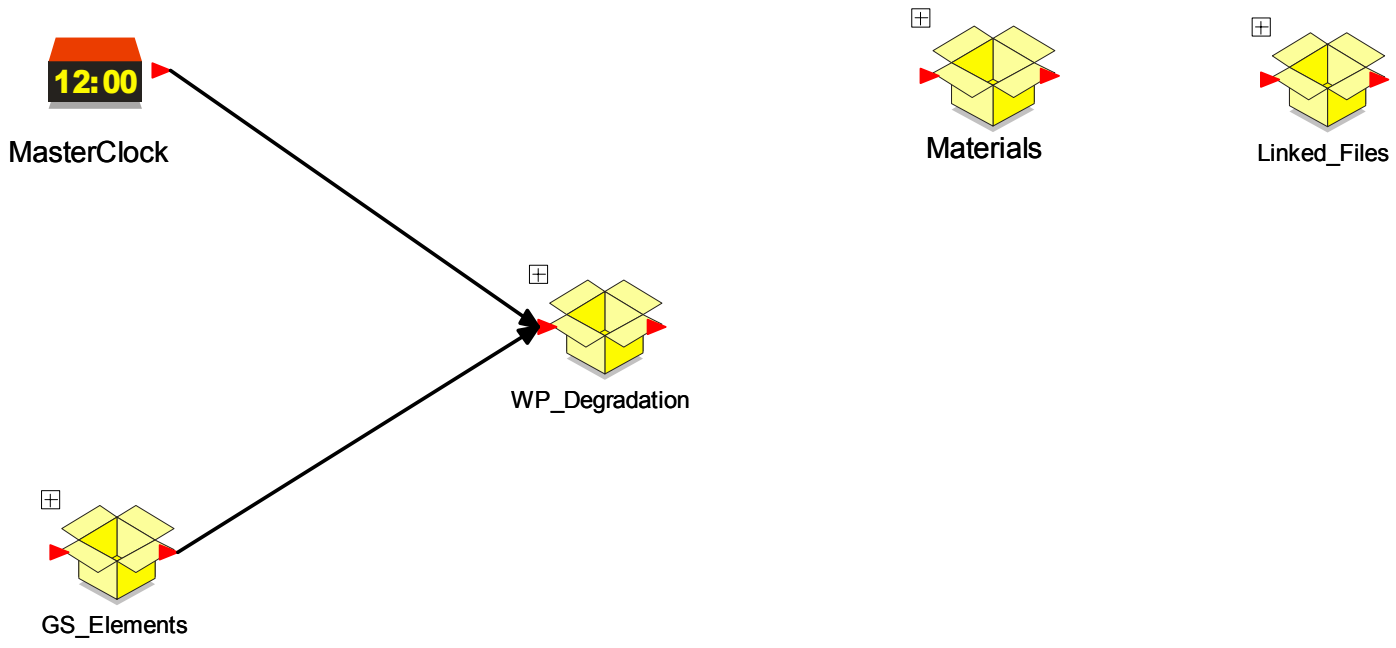

Output DTN: MO0310MWDWAPAN.002.

Figure 6. GoldSim File Calling the WAPDEG

Figure 6 is a screen capture of the top-level view of the GoldSim input file used in this analysis. The MasterClock is a built-in GoldSim element, which contains GoldSim-specific input parameters. The only GoldSim-specific parameters that impact the analysis results are the random seed used and the number of realizations.

The materials container element is a built-in GoldSim element, which is not used in this analysis. The contents of the Linked_Files container element are shown in Figure 7.

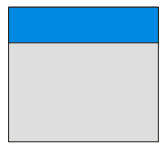

WAP_File

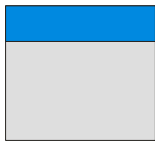

WDhist

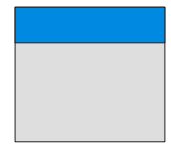

WDKlinO

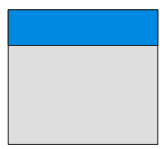

LnRo

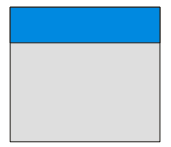

WDKlinM

Output DTN: MO0310MWDWAPAN.002.

Figure 7. Contents of the Linked_Files Container Element

The file elements within the Linked_Files container element are linked to file names. For instance the WAP_File element is linked to the file "WD4DLL.WAP," a required file for the execution of WAPDEG.

The contents of the GS_Elements container element are shown in Figure 8. These elements contain global parameters that are defined within the GoldSim input file but are used by WAPDEG. 


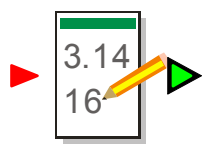

Number_DS_Patches

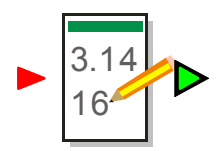

SimTime

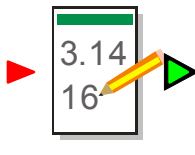

NumBins
BinStart

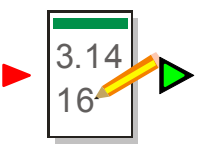

Output DTN: MO0310MWDWAPAN.002.

Figure 8. Contents of the GS_Elements Container Element

The contents of the WP_Degradation container element will be discussed later in this document, in relation to specific degradation modes.

\subsubsection{WAPDEG-GoldSim Interface Overview}

GoldSim interacts with the WAPDEG DLL through an external element. The TSPA-LA file will typically call the WAPDEG DLL several times per GoldSim realization. The exact number of calls will depend on the scenario class being run. A graphical representation of the interface between the GoldSim software and the WAPDEG DLL is shown in Figure 9, for simulation of CSNF waste package degradation (the interface and input for CDSP waste package degradation are almost identical to those for CSNF waste package degradation, differences will be mentioned when appropriate throughout this section). 


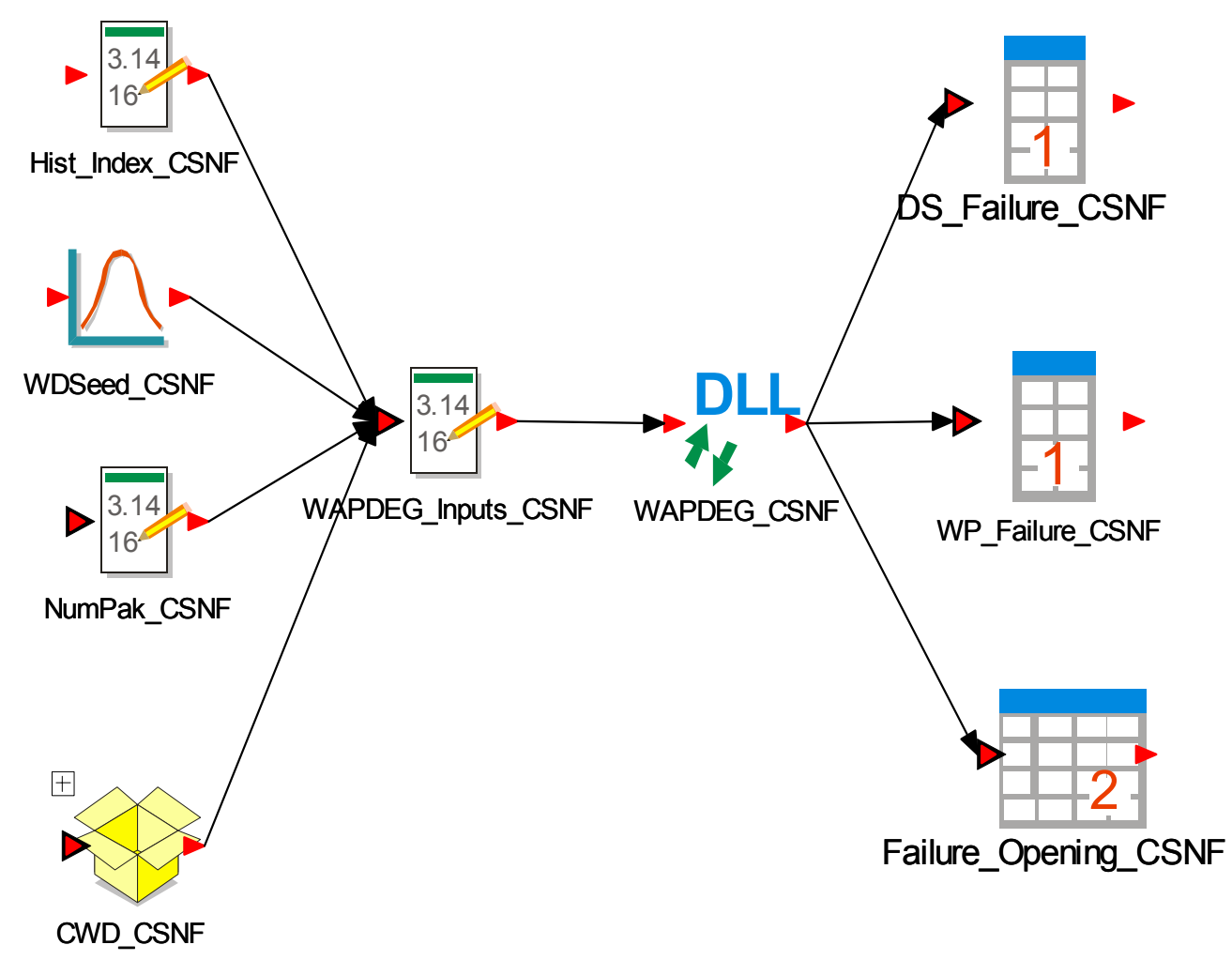

Output DTN: MO0310MWDWAPAN.002.

NOTE: These are the contents of the IWPD_CSNF Container Element as depicted in Figure 10.

Figure 9. Interface Between the GoldSim Software and the WAPDEG DLL for CSNF Waste Packages

At each call, the WAPDEG DLL, represented by the external element WAPDEG_CSNF, is passed a vector of 2,000 real numbers, via a vector data element, WAPDEG_Inputs_C $\bar{C}$ SNF. The values in the WAPDEG input vector specify degradation modes and degradation parameters.

The contents of the WAPDEG input vector are reproduced in Appendix I (Table I-1) and will be discussed in more detail in the following sections. All values in the WAPDEG input vector are real numbers. Those that do not change, and are not defined by other TSPA-LA components, are explicitly stated. The rest are represented by variable names, defined in the TSPA-LA itself. Certain parameters in the WAPDEG input vector reproduced in Appendix I (Table I-1) depend on the waste package configuration (CSNF or CDSP) being simulated. The values for the CSNF waste package configuration are shown first, with the corresponding CDSP waste package configuration value given afterwards in brackets.

Since only real numbers are passed between the GoldSim input file and the WAPDEG DLL, and since some of the degradation parameters are represented by distributions and tables, stored in text files, an additional communication mechanism is needed. GoldSim and WAPDEG share a "file index" file, WD4DLL.WAP. The contents of this file, for a typical TSPA-LA input file, are listed in Table 19. Note that the line numbers and the column headings in Table 19 are not part of the WD4DLL.WAP file, but are included for clarity. 
Table 19. Contents of WD4DLL.WAP File

\begin{tabular}{|c|l|}
\hline Line & \multicolumn{1}{|c|}{ File Name } \\
\hline 1 & WDenv_00_07wheader.ou \\
\hline 2 & WDenv_00wh.ou \\
\hline 3 & EMPTY \\
\hline 4 & WDKlinO.fil \\
\hline 5 & WDKlinM.fil \\
\hline 6 & WDKISCCO.fil \\
\hline 7 & WDStressO.fil \\
\hline 8 & WDKISCCM.fil \\
\hline 9 & WDStressM.fil \\
\hline 10 & WDCWDNDO_CSNF.cdf \\
\hline 11 & WDCWDSizeO_CSNF.cdf \\
\hline 12 & WDCWDNDM_CSNF.cdf \\
\hline 13 & WDCWDSizeM_CSNF.cdf \\
\hline 14 & WDCWDNDO_CDSP.cdf \\
\hline 15 & WDCWDSizeO_CDSP.cdf \\
\hline 16 & WDCWDNDM_CDSP.cdf \\
\hline 17 & WDCWDSizeM_CDSP.cdf \\
\hline 18 & WDInRGC.cdf \\
\hline
\end{tabular}

Using the WD4DLL.WAP file, GoldSim and WAPDEG can share file indices (line numbers in the WD4DLL.WAP file) in place of actual file names. The 2,000 real numbers and the contents of the files identified in the WD4DLL.WAP file are the only inputs to the WAPDEG DLL.

In the TSPA-LA, the drip shield and waste package degradation processes are discretized at the spatial bin/fuel type level. The repository is divided into five spatially defined bins. Each bin contains a different number of waste packages and is subject to different environment conditions. There are two different major types of waste package configurations, designated as commercial spent nuclear fuel (CSNF) and codisposal (CDSP) waste packages.

Figure 9 shows four input links to the WAPDEG_Inputs_CSNF vector. These are all a function of the fuel type and/or thermal history and environment variables. The data element, NumPak_CSNF, defines the number of CSNF waste packages in the bin. The data element, Hist_Index_CSNF, contains the file index linking the file containing the waste package thermal histories to a line number and file name in the WD4DLL.WAP file. WDSeed_CSNF is a stochastic element characterized by a uniform distribution between 1 and $2^{31}-1$ (the maximum positive 32-bit integer). WDSeed_CSNF is used to generate a different integer for each WAPDEG DLL call, to seed the random number generator within WAPDEG. The container element, CWD_CSNF, holds some of the parameters required for the calculation of the weld flaw probability for the closure lids. Weld flaws are discussed in Section 6.3.5.2 and the WAPDEG implementation is described in Section 6.4.8.

Figure 9 also illustrates the output produced by the WAPDEG DLL. There are two one-dimensional table elements and one two-dimensional table element linked to the WAPDEG_CSNF external element. The DS_Failure_CSNF element receives a one-dimensional 
table of drip shield first failure times. The WP_Failure_CSNF element receives a onedimensional table of waste package first failure times. The waste package first failure time is defined to be the first penetration by any mechanism (patch, pit, or crack) of the waste package inner layer (in this analysis, there are no pit penetration since localized corrosion is not simulated and there will be no crack penetrations of the drip shield since stress corrosion cracking of the drip shield is not simulated). The format of both of these tables is similar; the first column containing the drip shield or waste package first failure times in years (sorted in increasing order) and the second column containing the cumulative fraction of drip shields or waste packages failed. The Failure_Opening_CSNF element receives a two dimensional table containing 33 columns. The number of rows is determined by the input parameter "NumBins." The column contents are explained in Table 20. Note that waste package failure (for the purposes of averaging) is defined as any penetration (patch, pit, or crack) of the waste package layer 2 (the analyzed inner layer in Figure 2). If there are penetrations of layer 1 (the analyzed outer layer in Figure 2) of a waste package, but no waste package failures (penetrations of layer 2), the corresponding average number of patch, pit, or crack failures being reported is set to zero.

Table 20. Column Contents of the Failure_Opening_CSNF Element

\begin{tabular}{|c|c|}
\hline $\begin{array}{l}\text { Column } \\
\text { Number }\end{array}$ & Contents \\
\hline 1 & average number of patch failures (per failed drip shield) on the drip shield top \\
\hline 2 & average number of pit failures (per failed drip shield) on the drip shield top \\
\hline 3 & average number of crack failures (per failed drip shield) on the drip shield top \\
\hline 4 & average number of patch failures (per failed drip shield) on the drip shield side \\
\hline 5 & average number of pit failures (per failed drip shield) on the drip shield side \\
\hline 6 & average number of crack failures (per failed drip shield) on the drip shield side \\
\hline 7 & the cumulative fraction of first patch failures on the drip shield (top and side) \\
\hline 8 & the cumulative fraction of first pit failures on the drip shield (top and side) \\
\hline 9 & the cumulative fraction of first crack failures on the drip shield (top and side) \\
\hline 10 & average number of patch failures (per failed waste package) on the waste package layer 1 top \\
\hline 11 & average number of pit failures (per failed waste package) on the waste package layer 1 top \\
\hline 12 & average number of crack failures (per failed waste package) on the waste package layer 1 top \\
\hline 13 & average number of patch failures (per failed waste package) on the waste package layer 1 side \\
\hline 14 & average number of pit failures (per failed waste package) on the waste package layer 1 side \\
\hline 15 & average number of crack failures (per failed waste package) on the waste package layer 1 side \\
\hline 16 & average number of patch failures (per failed waste package) on the waste package layer 1 bottom \\
\hline 17 & average number of pit failures (per failed waste package) on the waste package layer 1 bottom \\
\hline 18 & average number of crack failures (per failed waste package) on the waste package layer 1 bottom \\
\hline 19 & the cumulative fraction of first patch failures on the waste package layer 1 (top, side, and bottom) \\
\hline 20 & the cumulative fraction of first pit failures on the waste package layer 1 (top, side, and bottom) \\
\hline 21 & the cumulative fraction of first crack failures on the waste package layer 1 (top, side, and bottom) \\
\hline 22 & average number of patch failures (per failed waste package) on the waste package layer 2 top \\
\hline 23 & average number of pit failures (per failed waste package) on the waste package layer 2 top \\
\hline 24 & average number of crack failures (per failed waste package) on the waste package layer 2 top \\
\hline 25 & average number of patch failures (per failed waste package) on the waste package layer 2 side \\
\hline 26 & average number of pit failures (per failed waste package) on the waste package layer 2 side \\
\hline 27 & average number of crack failures (per failed waste package) on the waste package layer 2 side \\
\hline
\end{tabular}


Table 20. Column Contents of the Failure_Opening_CSNF Element (Continued)

\begin{tabular}{|c|l|}
\hline $\begin{array}{c}\text { Column } \\
\text { Number }\end{array}$ & \multicolumn{1}{c|}{ Contents } \\
\hline 28 & average number of patch failures (per failed waste package) on the waste package layer 2 bottom \\
\hline 29 & average number of pit failures (per failed waste package) on the waste package layer 2 bottom \\
\hline 30 & average number of crack failures (per failed waste package) on the waste package layer 2 bottom \\
\hline 31 & the cumulative fraction of first patch failures on the waste package layer 2 (top, side, and bottom) \\
\hline 32 & the cumulative fraction of first pit failures on the waste package layer 2 (top, side, and bottom) \\
\hline 33 & the cumulative fraction of first crack failures on the waste package layer 2 (top, side, and bottom) \\
\hline
\end{tabular}

There are additional input links to the WAPDEG_Inputs_CSNF vector. Some of these are in the global parameter container, GS_Elements, and were discussed in Section 6.4.1. The implementation of degradation due to general corrosion of Alloy 22 and Titanium Grade 7, and for stress corrosion cracking of Alloy 22 is done in separate container elements. These are shown in Figure 10 (WP_Degradation Container) and discussed in the following sections.

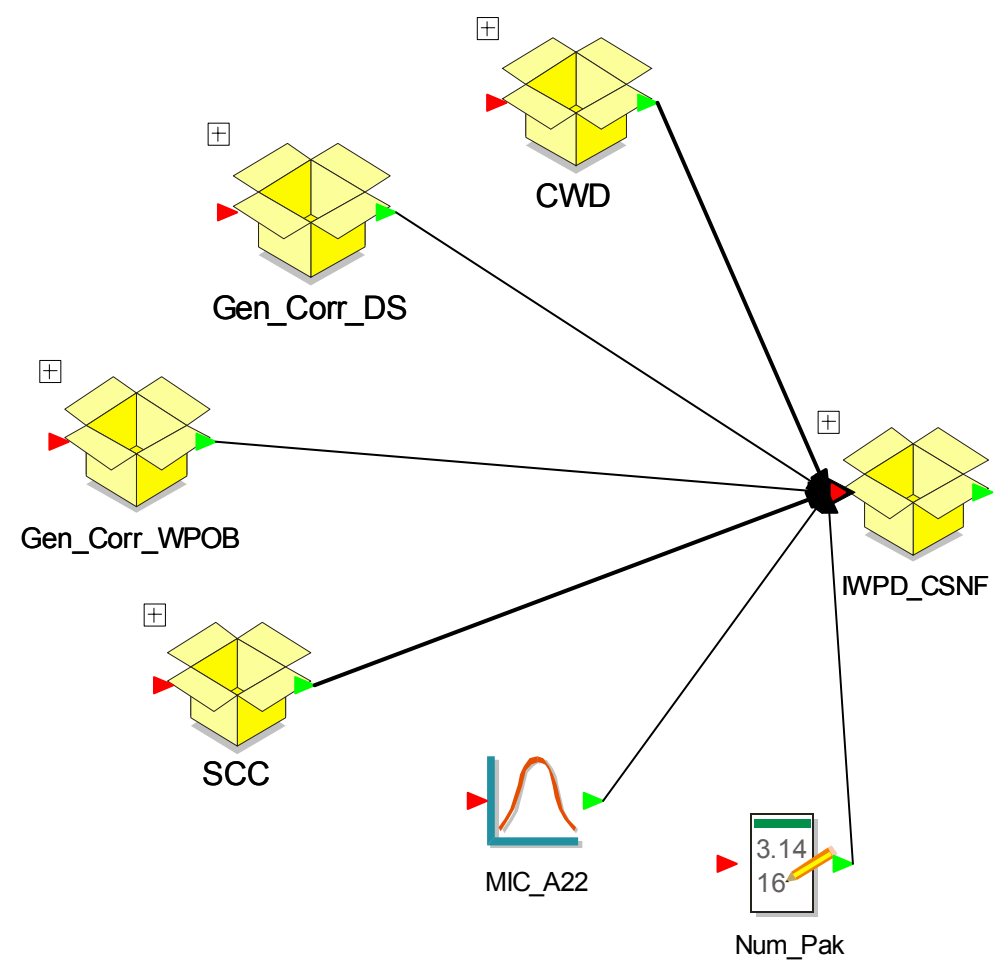

Output DTN: MO0310MWDWAPAN.002.

Figure 10. Other Input Links to IWPD_CSNF (contents of the WP_Degradation Container)

\subsubsection{Number of Patches and Number Waste Package-Drip Shields Design Input}

The drip shield plate thickness is used directly in the input to the WAPDEG DLL (see line 40 of Table I-1). WAPDEG does not require the drip shield surface area, only the number of drip shield patches need be specified. Since the variation in the general corrosion rate of the drip shield is considered to be due only to uncertainty (Section 6.3.3) each drip shield is analyzed using one patch (see line 52 of Table I-1). 
In Section 6.3.2 the CSNF and CDSP waste package surface areas and patch sizes were calculated. The number of waste package patches was determined to be 1,014 for CSNF waste packages and 1,106 for CDSP waste packages (Section 6.3.2). This data is entered on line 29 of Table I-1.

Note that WAPDEG can calculate the number of patches by dividing the waste package surface area entered by the patch area entered. When the number of patches is pre-calculated, as above, the result is entered as the surface area parameter (with value equal to the number of patches in $\mathrm{mm}^{2}$ ), and the patch area is entered with the value " 1 " (see lines 32 to 36 and lines 54 to 58 of Table I-1).

The drip shield and waste container surface areas are also divided into fractions. The drip shield has a top and side fraction. The top fraction is defined in line 53 of the WAPDEG input vector. The waste package has a top, bottom and side fraction. The top fraction and bottom fractions are entered on lines 30 and 31, respectively, of the WAPDEG input vector. The fraction assigned to side patches is obtained by subtracting the data entered for the other fraction(s) from one. The fraction assigned to side patches of the waste container is identified with the closure lid region for analysis purposes.

In the TSPA Model, the drip shield and waste package degradation processes are simulated at the spatial bin/fuel type level. The number of IWPD analysis simulations per TSPA Model realization depends on the scenario class being run. The WAPDEG software runs twice for each of the five spatially fixed bins, once for the CSNF waste packages in that bin and once for CDSP waste packages. If the spatially fixed bin contains fewer than 500 drip shield-waste package pairs, all CSNF and CDSP drip shield-waste package pairs in the bin should be simulated. If the bin contains more than 500 drip shield-waste package pairs, then only up to $500 \mathrm{CSNF}$ and 500 CDSP drip shield-waste package pairs should be simulated. The impact of this is analyzed in the sensitivity studies in Section 6.5.4.

\subsubsection{Waste Package Design Input}

As discussed in Section 6.3.2, the dual Alloy 22 lid design for the waste package outer barrier requires that outer barrier be analyzed as two layers. The outer analyzed layer is $25-\mathrm{mm}$ thick (the thickness of the outer closure lid) and the inner analyzed layer is 10-mm thick (the thickness of the middle closure lid). The WAPDEG input vector defines these two layer thicknesses in lines 4 and 17 of Table I-1.

In addition, each layer is analyzed as being composed of two different regions, the closure lid region and the shell region. The closure lid thicknesses (both outer and middle) are the same for CSNF and CDSP waste packages, but the thickness of the shell region is different $(20 \mathrm{~mm}$ for the CSNF waste package, $25 \mathrm{~mm}$ for the CDSP waste package). WAPDEG assigns a fraction of the total waste package surface area to top and bottom surfaces. The side fraction is obtained by subtracting the sum of the top and bottom fractions from one. This area assignment, for the waste package outer barrier, is done in lines 30 and 31 of the WAPDEG input vector (Table I-1). The top and bottom area fractions are associated with the shell region and the side fraction is associated with the closure lid region. The fractions are not the same for both waste package 
types. The area fraction assigned to "side" (closure lid) patches is calculated to be $0.032(0.038$ for CDSP waste packages) in Section 6.3.2.1.

The two-layer implementation of the waste package outer barrier also requires that the general corrosion rate be adjusted. The general corrosion rate applied to the outer layer is set to a large value. The general corrosion rate applied to the inner layer is modified by the ratio of the inner to outer shell layer thicknesses. The effect of this adjustment to general corrosion rate is then removed, for the closure lid regions only. Thus, the original general corrosion rate is applied to both closure lids. However, the outer layer shell region degrades immediately and the inner layer shell region degrades at the correct rate for the $20-\mathrm{mm}$ (or $25-\mathrm{mm}$ ) waste package outer barrier shell.

The two-layer implementation of the waste package outer barrier in the WAPDEG software is done in two places. First, the error term in the general linear functional form, used to analyze general corrosion (BSC 2002 [DIRS 162606], Section 4.2.6.5) of the layers, is changed. The second change is to modify the multipliers used in the stress corrosion cracking slip dissolution event used to analyze stress corrosion cracking degradation (BSC 2002 [DIRS 162606], Section 4.2.7.5) of the closure lid regions.

The general linear functional form (BSC 2002 [DIRS 162606], Section 4.2.6.5), in its most general form, is given by:

$$
D=\exp \left(c_{0}+\sum_{j=1}^{N} c_{j} E_{j}+\varepsilon\right) \exp \left(-\frac{Q}{T}\right) t^{n}
$$

where

$$
\begin{aligned}
D & =\text { corrosion depth }(\mathrm{mm}) \\
N & =\text { number of terms } \\
c_{0} & =\text { constant } \\
\mathrm{c}_{j} & =\text { the } j^{\text {th }} \text { coefficient } \\
E_{j} & =\text { the } j^{\text {th }} \text { exposure condition } \\
\varepsilon & =\text { error term } \\
Q & =\text { activation energy } \\
T & =\text { temperature }(\mathrm{K}) \\
n & =\text { time exponent }
\end{aligned}
$$

The general linear functional form is used by WAPDEG to implement the general corrosion model. The general linear functional form defined by Equation 39 includes a constant term, $N$; terms that depend on exposure conditions; as well as an error term, $\varepsilon$. The general corrosion functional form presented in Equations 17 through 20 (Section 6.3.4) does not require the full generality of Equation 39. The particular form used in the implementation involves a constant term, the activation energy term, and the error term. This implementation is discussed in more detail in Section 6.4.7. The discussion in this section is limited to an explanation of how the error term, $\varepsilon$, is used to implement the two-layer waste package outer barrier analyzed.

The outer layer error term is set to the natural $\log$ of $10^{14}$ in lines 111 to 115 and lines 210 to 214 of the WAPDEG input vector. The error term that applies to the inner layer is set to the natural 
$\log$ of the ratio of 10 to 20 (or the natural $\log$ of the ratio of 10 to 25 for CDSP waste packages). The inner layer error term is defined in lines 150 to 154 and lines 249 to 253 of the WAPDEG input vector.

Inspection of the functional form in Equation 39 shows that setting the error term, $\varepsilon$, to a large value effectively causes instantaneous penetration of the outer layer. Using the error term for the inner layer to modify the corrosion rate by the ratio of thicknesses causes the inner layer to degrade at the correct rate for the waste package outer barrier shell region.

The closure lid region stress corrosion cracking degradation is implemented in the WAPDEG input vector using a slip dissolution event (BSC 2002 [DIRS 162606], Section 4.2.7.5). As noted above, the closure lid region of the waste package is identified with the side fraction of the surface area. To maintain the original general corrosion rate in the closure lid region, the effect of the multipliers (imposed by adjusting the error term) is removed in the closure lid region only (i.e., for side patches only).

The input data for the slip dissolution event is contained in lines 331 to 408 of Table I-1, for the outer layer. Examination of lines 337 to 339 of Table I-1 shows that only side patches are impacted by this event data. Examination of line 395 to 406 shows that one of the event effects is to accelerate the general corrosion rate by a factor of $1.00 \times 10^{-14}$, which cancels the large multiplier on the general corrosion rate for the closure lid region (side patches).

The input data for the Slip Dissolution event for the inner layer is contained in lines 409 to 486 of Table I-1, for the inner layer. Examination of lines 415 to 417 shows that only side patches are impacted by this event data. Examination of line 473 to 484 shows that one of the event effects is to accelerate the general corrosion rate by a factor of $20 / 10=2$ (or $25 / 10=2.5$ for CDSP waste packages) This cancels the previously added multiplier on the general corrosion rate.

\subsubsection{Waste Package and Drip Shield Exposure Conditions Implementation}

The exposure condition inputs to the IWPD analysis are representative temperature and relative humidity histories and not the actual thermal hydrologic histories used in TSPA. The representative thermal hydrologic history files are produced to allow the IWPD analysis to be exercised in this report. Analysis outputs presented in Section 6.5 using these inputs are for illustrative purposes only and do not represent output for use in TSPA nor should they be used to evaluate repository performance.

Temperature response is interpolated (on a logarithmic time scale) from a peak temperature at 70 years to a background temperature of $21^{\circ} \mathrm{C}$ at one hundred thousand years. To study the system response to differing decay rates, a power term in the interpolation is used. The temperature as a function of time is given by:

$$
T(t)=T_{o}+\left(21^{\circ} \mathrm{C}-T_{o}\right)\left(\frac{\ln \left(\frac{t}{70 \mathrm{yr}}\right)}{\ln \left(\frac{10^{5} \mathrm{yr}}{70 \mathrm{yr}}\right)}\right)^{a}, \quad 70 \mathrm{yr} \leq t \leq 10^{5} \mathrm{yr}
$$


The peak temperature is given by $T_{o}$ and the decay term is $a$. Peak temperature values of $160^{\circ} \mathrm{C}$ and $220^{\circ} \mathrm{C}$ and decay term values of 0.4 and 0.8 are evaluated. Schematic temperature-versustime profiles using a peak temperature of $220^{\circ} \mathrm{C}$ are shown in Figure 11.

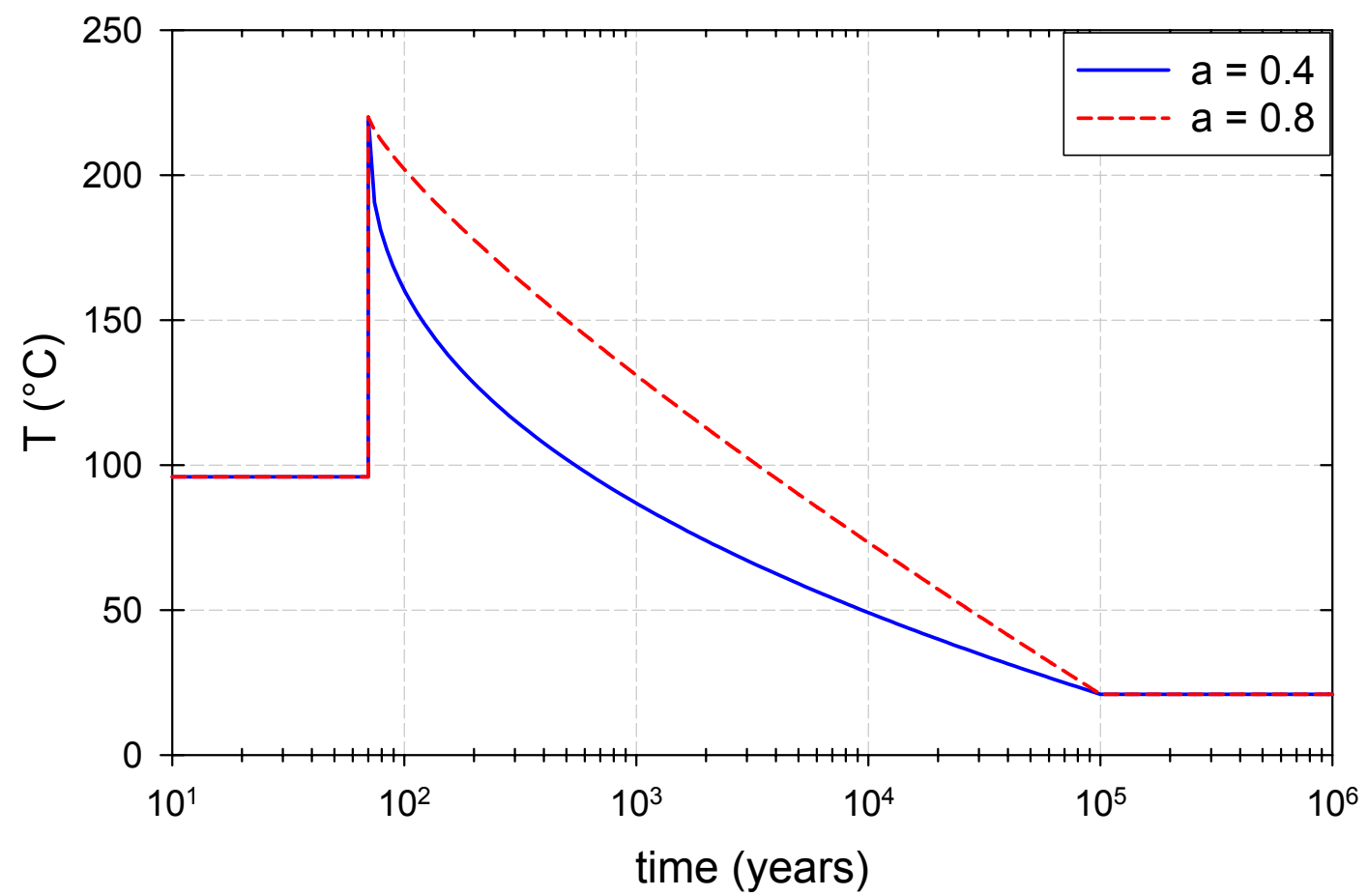

Output DTN: MO0310MWDWAPAN.002.

Figure 11. Schematic Temperature Versus Time Profiles for a Peak Temperature of $220^{\circ} \mathrm{C}$ and Decay Terms of 0.4 and 0.8

The relative humidity is given by a logistic function of temperature. At low temperature, the fractional RH will reach a limit of one, and at high temperatures, the relative humidity limit will be set at 0.08 . The midpoint transition temperature between these limits is set at a temperature of $100^{\circ} \mathrm{C}$. The fractional relative humidity as a function of temperature is given by:

$$
\mathrm{RH}(T)=0.08+\frac{(1.00-0.08)}{1+\left(\frac{T}{100.0^{\circ} C}\right)^{b}}
$$

The scaling term, $b$, is varied to change the rate at which relative humidity, $\mathrm{RH}$, varies with temperature. Scaling term values of 4 and 8 are evaluated. Schematic relative humidity versus time profiles using a peak temperature of $220^{\circ} \mathrm{C}$, a decay term of 0.4 , and scale terms of 4 and 8 are shown in Figure 12. 


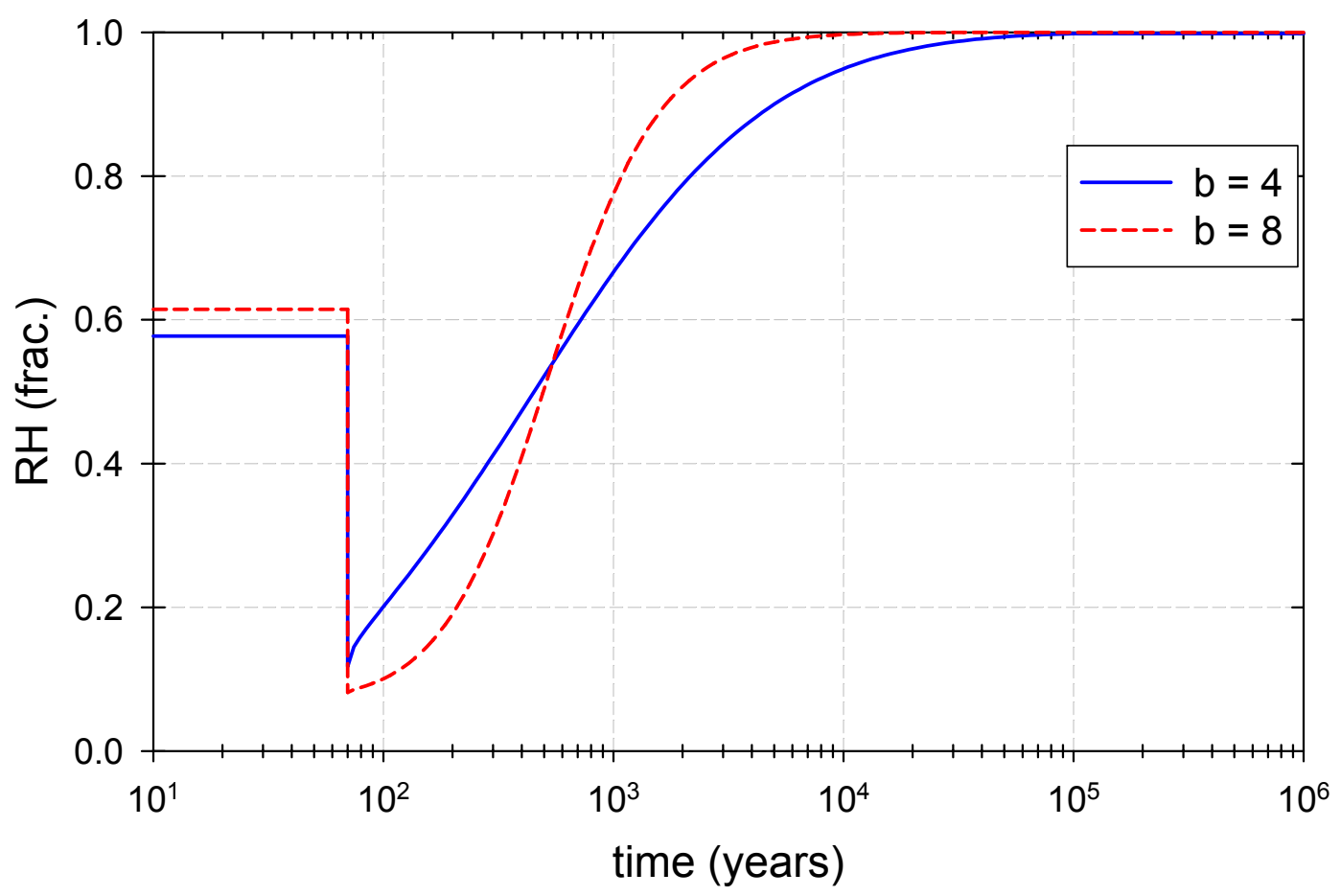

Output DTN: MO0310MWDWAPAN.002.

Figure 12. Schematic Relative Humidity Versus Time Profiles for a Peak Temperature of $220^{\circ} \mathrm{C}$, Decay Term of 0.4 , and Scale Terms of 4 and 8

In this way, a total of eight different thermal hydrologic histories is created; one for each unique combination of the three factors $T_{o}, a$, and $b$. These combinations are summarized in Table 21 .

Table 21. Combinations of Peak Temperature, $T_{0}$, Decay Term, $a$, and Scaling Term, $b$, Used to Create Representative Thermal Hydrologic Histories

\begin{tabular}{|c|c|c|}
\hline $\begin{array}{c}\boldsymbol{T}_{\mathbf{o}} \\
{ }^{\circ} \mathbf{C}\end{array}$ & $\mathbf{a}$ & $\mathbf{b}$ \\
\hline 160 & 0.4 & 4 \\
\hline 160 & 0.4 & 8 \\
\hline 160 & 0.8 & 4 \\
\hline 160 & 0.8 & 8 \\
\hline 220 & 0.4 & 4 \\
\hline 220 & 0.4 & 8 \\
\hline 220 & 0.8 & 4 \\
\hline 220 & 0.8 & 8 \\
\hline
\end{tabular}

All eight thermal hydrologic histories were copied to one exposure file used in the IWPD analysis simulations documented in this report. Each thermal hydrologic history represents the behavior of one-eighth $(0.125)$ of the drip shields and waste packages simulated.

The eight different thermal hydrologic histories were created and combined in one exposure file (WDenv_00_07wheader.ou), to use in the IWPD analysis simulations documented in this report. 
Each thermal hydrologic history is considered to represent the behavior of 1/8 (0.125) of the drip shields and waste packages simulated. The format of the thermal hydrology input file conforms to the WAPDEG table format (BSC 2002 [DIRS 162606], Section 4.2.4). The first few lines of the first and second set of exposure histories are shown below:

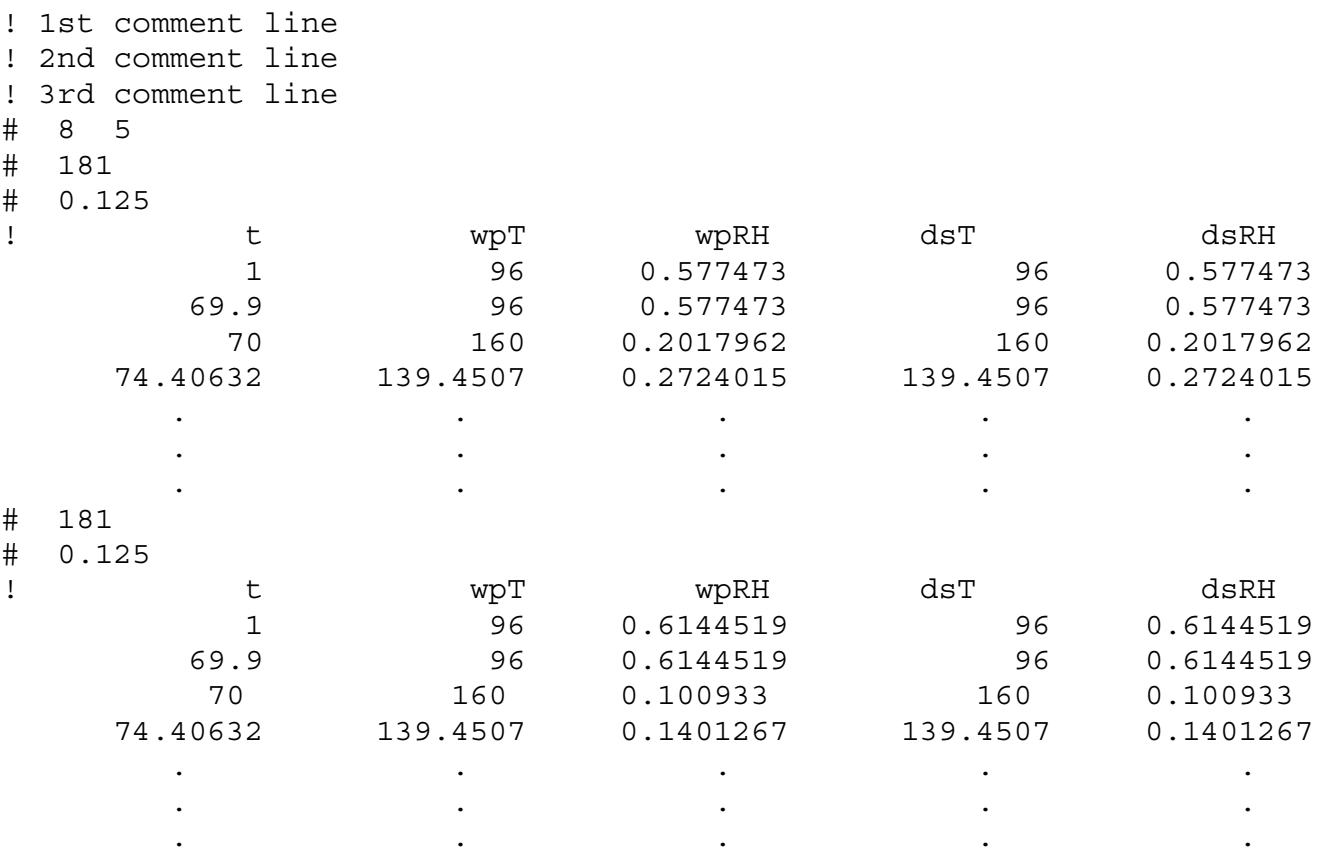

The first three lines in the example file (beginning with exclamation points) are comment lines. The user can enter as many comment lines as desired. The WAPDEG software ignores these lines. The user can enter comments designed to enhance traceability and uniquely identify the exposure history file. The next line (\# 8 5 $)$ is a header line which indicates that the exposure history file contains 8 exposure histories each with five columns. The next line (\# 181) is a header line which indicates that the first exposure history contains 181 rows of exposure data. This is followed by (\# 0.125) a header line containing the fraction of waste packages to which the exposure history applies (1/8 in this case). The next line again begins with an exclamation point and is a comment line, typically used for column labels. Only one comment line is allowed in this position. The header lines are followed by exposure data, typically consisting of the time, temperature, and relative humidity on the drip shield and waste container surfaces. The next exposure history is preceded by two header lines indicating that it consists of 181 rows and applies to $1 / 8$ of the drip shield waste package pairs.

The WAPDEG input vector (see line 67 of Table I-1) specifies the file index corresponding to the exposure conditions file to be used. In the TSPA-LA, the exposure conditions will vary with spatial bin and fuel type.

Water conditions (BSC 2002 [DIRS 162606], Sections 3.2.3, 4.2.5.6, 4.2.5.7, and 4.2.5.8) are the mechanism used in WAPDEG to apply corrosion processes to the waste container barriers. The IWPD analysis defines two water conditions. The first, identified by the numerical label " 1 ," corresponds to the environment under the drip shield and is referred to as the "DSInside" water 
condition. The second, identified by the numerical label "2," corresponds to the environment above the drip shield and is referred to as the "DSOutside" water condition.

The water condition that applies to the outer (top) surface of the drip shield is defined in the drip sequence data. A drip sequence (BSC 2002 [DIRS 162606], Sections 3.2.2 and 4.2.5.6) is made up of one or more phases, where each phase lasts a specified length of time and is characterized by a constant water contact condition. In the TSPA-LA, only one drip sequence, with one phase, is defined. Lines 68 to 85 of the WAPDEG input vector in Table I-1 define the drip sequence. The water condition number corresponding to this drip sequence is " 2 " ("DSOutside" water). The drip sequence initially applies to all patches (top and side) on the outer (top) surface of the drip shield. When a drip shield patch penetrates, the drip sequence water condition is transferred to the patches of the underlying waste package outer barrier. Since the drip shield is analyzed with only one patch, when the drip shield fails, all patches of the outer layer of the underlying waste package become subject to the drip sequence water condition ("DSOutside" water).

The water condition that applies to the inner (bottom) surface of the drip shield is defined by the "Drip Shield Initial Water Condition" (BSC 2002 [DIRS 162606], Section 4.2.5.4). For the TSPA-LA, the water condition in effect for the drip shield inner (bottom) surface is specified in line 65 of the WAPDEG input vector to be condition "1" ("DSInside" water condition).

\subsubsection{Drip Shield General Corrosion Implementation}

General corrosion is the only drip shield degradation process analyzed by integrated waste package degradation (IWPD) analysis (Section 6.3.3). Two cumulative distribution functions were developed for general corrosion of Titanium Grade 7 (Section 4.1.2), one each applicable to the inner surface of the drip shield (Table 4) and for the outer surface (Table 5). These cumulative distribution functions are reproduced in the stochastic elements WDDSOInGC and WDDSOutGC, which are inputs to the WAPDEG DLL (Figure 13).

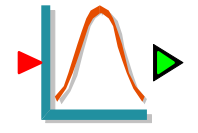

WDDSOutGC

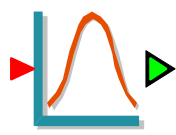

WDDSInGC

Output DTN: MO0310MWDWAPAN.002.

Figure 13. Contents of the Gen_Corr_DS Container Element

General corrosion of the drip shield is implemented in WAPDEG using the Power Law functional form (BSC 2002 [DIRS 162606], Section 4.2.6.6). The Power Law functional form has the general representation:

$$
D=B t^{n}
$$

where

$$
\begin{aligned}
D & =\text { corrosion depth }(\mathrm{mm}) \\
B & =\text { Pre-exponent }\left(\mathrm{mm} / \mathrm{yr}^{n}\right) \\
t & =\text { time }(\mathrm{yr}) \\
n & =\text { time exponent }
\end{aligned}
$$


In the current analysis, the time exponent, $n$, is one.

In WAPDEG, every general corrosion functional form is associated with a single water condition and barrier. Therefore, two implementations of the Power Law functional form are required to define the two possible states of drip shield general corrosion.

The Power Law functional form data is defined in the WAPDEG input vector in lines 165 to 185 ("DSInside" water) and lines 264 to 284 ("DSOutside" water). The $B$ term in Equation 42 is input to WAPDEG as a sampled value from the stochastic WDDSInGC, for the drip shield inner surface and as a sampled value from the stochastic WDDSOutGC, for the drip shield outer surface.

The exponent, $n$, of the time term, $t$, in Equation 42 is set to one (lines 180 to 184 and lines 279 to 283$)$.

Note that "inside-out" corrosion of the drip shield proceeds with the water condition defined by the "Drip Shield Initial Water Condition." The water condition defined on line 288 applies only to "inside-out" corrosion of the waste package outer barrier layers (BSC 2002 [DIRS 162606], Sections 4.2.5.4 and 4.2.5.10).

Uncertainty in the general corrosion of titanium is captured by the two stochastics WDDSOutGC and WDDSInGC. These stochastics are sampled once for every TSPA-LA realization and apply to all drip shields.

\subsubsection{Waste Package Outer Barrier General Corrosion Implementation}

The functional form for the general corrosion rate of the waste package outer barrier is presented in Equation 20 (Section 6.3.4) The rate of general corrosion of the Alloy 22 waste package outer barrier is a function of exposure temperature, with the temperature dependence following an Arrhenius relationship (Section 6.3.4, Equation 17).

General corrosion of Alloy 22 is implemented in WAPDEG using the general linear functional form (BSC 2002 [DIRS 162606], Section 4.2.6.5). The most general form of the general linear functional form is given by Equation 39 (Section 6.4.4). The specific form used for the TSPA-LA implementation of the Alloy 22 corrosion rate is:

$$
D=\exp \left(\ln \left(R_{o}\right)+\frac{C_{1}}{333.15}+\varepsilon\right) \exp \left(-\frac{C_{1}}{T}\right) t^{n}
$$

where $D$ is corrosion depth $(\mathrm{mm}), t$ is time $(\mathrm{yr})$, and $T$ is exposure temperature $(\mathrm{K})$. This implementation involves a constant term $\left(\ln \left(R_{o}\right)+C_{1} / 333.15\right)$, the activation energy term $\left(C_{1}\right)$, and an error term, $\varepsilon$. The constant term has two components, $\ln \left(R_{o}\right)$ and $C_{1} / 333.15 . \ln \left(R_{o}\right)$ is sampled from the (natural logarithm of the) general corrosion rate distribution adjusted for the change of scale (Section 6.3.4). $C_{1}$ is normally distributed with a mean of $3,116.47 \mathrm{~K}$ and a standard deviation of $296.47 \mathrm{~K}$. The derivation of these two parameters is described in more detail in Section 6.3.4. The error term, $\varepsilon$, is used to adjust the corrosion rate for the dual lid design. This adjustment is required because the lids and outer shell are of different thicknesses. 
In WAPDEG, every general corrosion functional form is associated with a single water condition and barrier. "DSInside" and "DSOutside" water conditions can potentially contact the waste package outer barrier. The same general corrosion rate functional form is applied to all surfaces of the waste package outer barrier. Therefore, four almost identical implementations of the general linear functional form are defined, one for each combination of layer and water condition. These four definitions differ only in the error term data.

The general linear functional form data is defined in the WAPDEG input vector in lines 90 to 125 (WPOB outer layer, "DSInside" water), lines 129 to 164 (waste package outer barrier inner layer, "DSInside" water), lines 189 to 224 (waste package outer barrier outer layer, "DSOutside" water), and lines 228 to 263 (WPOB inner layer, "DSOutside" water). Since the same general corrosion functional form applies to both layers and water conditions, these data sections contain essentially the same information. Therefore, only the first (lines 90 to 125) will be discussed in detail.

The first two terms of the general linear functional form specification are defined in lines 100 to $104\left(\ln \left(R_{\mathrm{o}}\right)\right.$ and lines 105 to $110\left(C_{1} / 333.15\right)$, respectively. The $\ln \left(R_{\mathrm{o}}\right)$ term in Equation 43 is input to WAPDEG as a cumulative distribution functions. Line 101 of the WAPDEG input vector specifies the file index for this cumulative distribution function (line 18 in Table 19). The $C_{1}$ term is given by a normal distribution with mean of $3,116.47 \mathrm{~K}$ and a standard deviation of $296.47 \mathrm{~K}$ truncated at \pm 3 standard deviations (Table 7). This normal distribution is defined in the stochastic element C1_GenCorr_A22 (lines 116 to 120). The related term, $C_{1} / 333.15$, is given by the expression element, C1divTo_GenCorr_A22 (Figure 14). The exponent, $n$, of the time term, $t$, in Equation 43 is one (lines 121 to 125). The function of the error term, $\varepsilon$, is explained in Section 6.4.4.

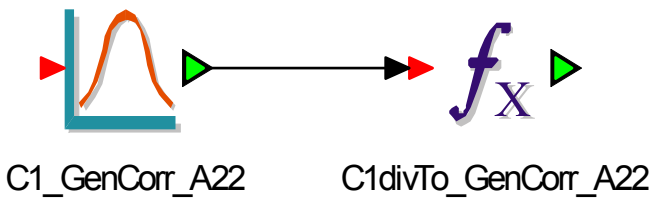

Output DTN: MO0310MWDWAPAN.002.

Figure 14. Contents of the Gen_Corr_WPOB Container Element

Uncertainty in the general corrosion of Alloy 22 is captured by the stochastic C1_GenCorr_A22. This stochastic is sampled once for every TSPA-LA realization and applies to all waste package outer barrier layers.

Variability in the general corrosion of Alloy 22 is represented by the implementation of the $\ln \left(R_{0}\right)$ cumulative distribution functions. The barrier variance sharing for the cumulative distribution function is set to zero (lines 95 to 99 ). The cumulative distribution function is sampled once, therefore, for every patch of each waste package outer barrier. Each patch on the waste package outer barrier surface will have a different corrosion rate. This captures the variation in the general corrosion rate over the waste package surface. 
Variability in the general corrosion of Alloy 22 is also expressed in Equation 43 through the exposure temperature variable, which varies spatially and temporally, according to the thermal hydrologic history files.

\subsubsection{Weld Flaw Implementation}

Weld flaws in waste package closure lid welds are the only manufacturing defects identified as having the potential to affect waste package performance (Section 6.3.8). The weld flaws in the closure lid welds are likely sites for stress corrosion cracking initiation, and are, therefore, part of the IWPD analysis of stress corrosion cracking (Section 6.3.5.2).

Stress corrosion cracking is implemented in WAPDEG by the use of a slip dissolution event (BSC 2002 [DIRS 162606], Sections 3.3.2.1.1 and 4.2.7.5). The slip dissolution event will be described in more detail in Section 6.4.10. When a slip dissolution event includes defect (weld) flaws, the weld flaw density, and size distribution are defined by a manufacturing defects event (BSC 2002 [DIRS 162606], Sections 3.3.2.1 and 4.2.7.2).

In WAPDEG, a corrosion-affecting event can apply to one barrier and one or more water conditions and can have effects specific to that event, as well as generic effects. The manufacturing defects event has only one specific effect, to introduce manufacturing defects onto patches.

A separate manufacturing defects event must be defined for the outer and middle closure lids. The closure lids can potentially be subject to both exposure conditions; therefore, both water conditions ("DSInside" and "DSOutside" water) are defined. Two manufacturing defect events are defined in lines 291 to 310 (outer closure lid) and lines 311 to 330 (middle closure lid) of the WAPDEG input vector (Table I-1). The inputs to the manufacturing defects event consist of a probability that a barrier has manufacturing defects, a distribution for the number of manufacturing defects per barrier (defect density), and a defect size distribution.

In the TSPA-LA, the defect probability, and the defect density and size distributions are calculated by the CWD DLL (Figure 9 and Figure 10).

CWD computes the cumulative probability of a manufacturing defect based on the probability for the nondetection of weld flaws. Inputs to this calculation are the weld thickness, the weld volume, the defect fraction considered, a detection threshold, a characteristic flaw size, a shape factor, a defect count parameter, and a defect size parameter. The details of this calculation are provided in Section 6.3.5.2.

The global input parameters to CWD DLL are held in the container element CWD (Figure 15). The weld thickness is given by the data elements Thickness_OL and Thickness_ML (for the outer and middle closure lids). The defect fraction considered is calculated in the expression element, Defect_Frac, as the product of the fraction of defects capable of propagation based on orientation (Defect_Frac_Orientation) and the fraction of embedded manufacturing defects to propagate (Defect_Frac_Embedded). The detection threshold is defined in the data element Detection_Thresh_PND. The characteristic flaw size and shape factor are defined in the data elements Location_PND and Shape_PND, respectively. The defect count parameter is given by a gamma distribution defined in the stochastic element Defect_Count_Param. The defect size 
parameter is given by a gamma distribution defined in the stochastic element Defect_Size_Param. The values of all of these parameters are taken from Table 8.

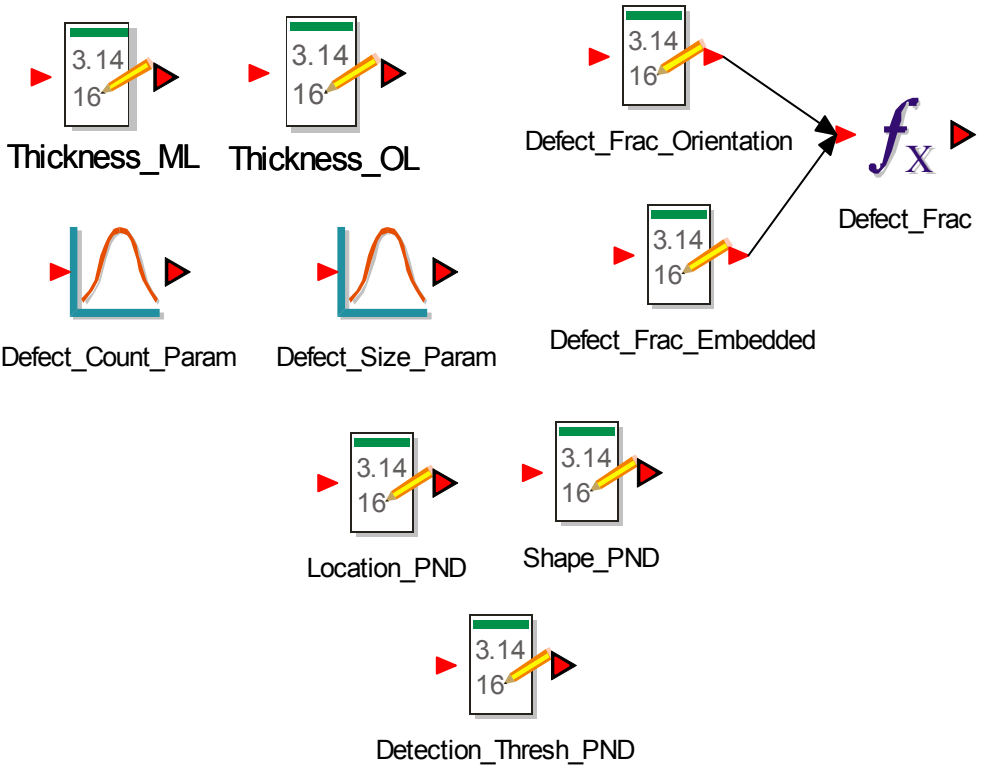

Output DTN: MO0310MWDWAPAN.002.

Figure 15. Contents of the CWD Container Element (Global CWD DLL Inputs)
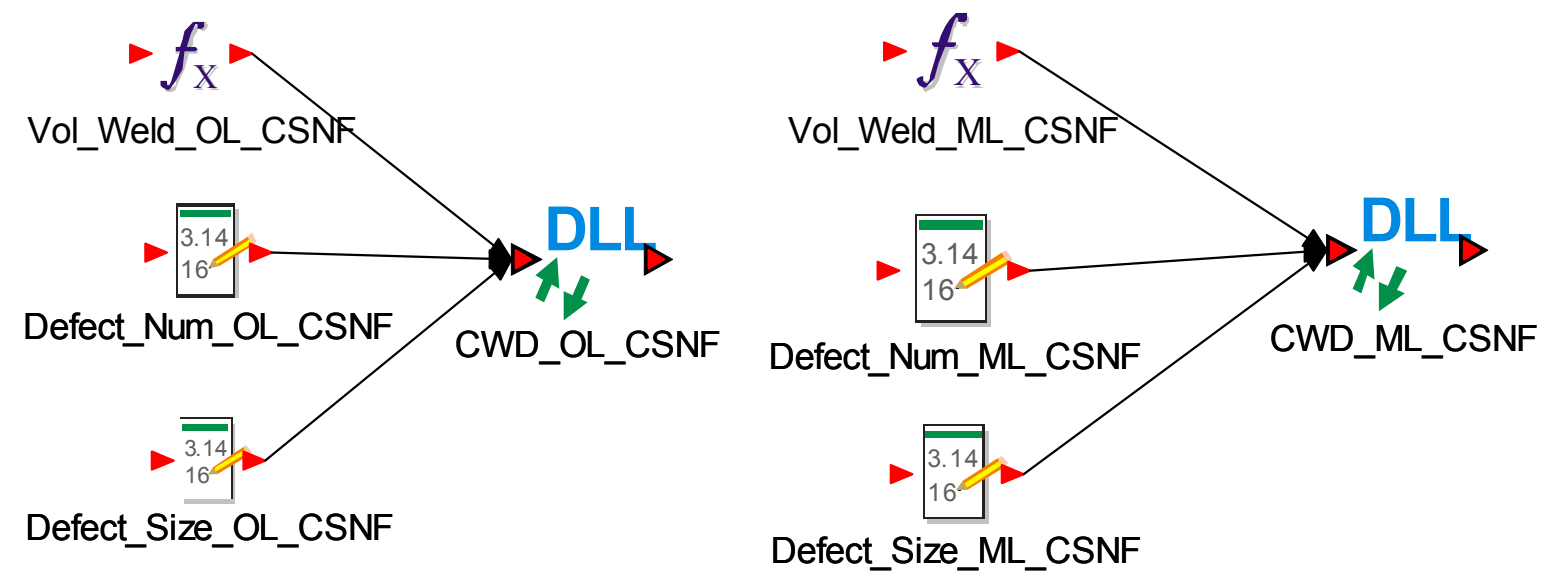

Output DTN: MO0310MWDWAPAN.002.

Figure 16. Contents of the CWD_CSNF Container Element

The local input parameters to the CWD DLL are held in the container CWD CSNF (CWD_CDSP). The contents of the CWD_CSNF container element are shown in Figure 16. The input parameter, weld volume (Vol_Weld_OL_CSNF and Vol_Weld_ML_CSNF in Figure 16), is not globally defined, but depends on the waste package type. The values for both waste package types and both lids are provided in Table 8 .

The output of CWD consists of two tables, and the probability of the occurrence of at least one defect per waste package. The four data elements, Defect_Num_OL_CSNF, Defect_Size_OL_CSNF, Defect_Num_ML_CSNF, and Defect_Size_ML_CSNF contain the file 
indices for CWD output tables. These output tables contain distributions for the density and size of weld flaws, on the outer and middle closure lids. The CWD outputs are direct inputs to the manufacturing defects event in WAPDEG.

The probability of at least one weld flaw is input at lines 296 and 316 of the WAPDEG input vector (Table I-1), for the outer and middle closure lids, respectively. The file indices corresponding to the number of flaws distribution are input at lines 297 to 301 and lines 317 to 321 of the WAPDEG input vector (Table I-1), for the outer and middle closure lids, respectively. The file indices corresponding to the flaw size distribution are input at lines 302 to 306 and lines 322 to 326 of the WAPDEG input vector (Table I-1), for the outer and middle closure lids, respectively.

Uncertainty is inherent in the calculation of the probability of at least one weld flaw, via the probability for nondetection (PND) function. The calculation of this function uses the parameters Detection_Thresh_PND, Location_PND, and Shape_PND. Uncertainty in the weld flaw density and size is represented by the uncertain parameters (Defect_Count_Param and Defect_Size_Param) that form components of the calculation of the density and size distributions.

Spatial variability in the weld flaw density and size results from the density and size distributions, which form the input to the manufacturing defects event. These distributions are sampled once for each layer of each waste package. They are then randomly distributed to stress corrosion cracking patches on the waste package outer barrier layers (BSC 2002 [DIRS 162606], Section 4.2.7.2).

\subsubsection{Stress and Stress Intensity Factor Profile Implementation}

The dominant component of stress in the waste package outer barrier closure lid weld regions has been determined to be hoop stress, which promotes radially oriented crack growth. The stress and stress intensity factor profiles are part of a slip dissolution event (BSC 2002 [DIRS 162606], Section 3.3.2.1.1 and Section 4.2.7.5). The slip dissolution event will be described in more detail in Section 6.4.10. The part of the event data that pertains to the stress and stress intensity factor will be discussed here.

The slip dissolution event requires as input, a stress intensity factor, $K_{I}$, versus depth table, and a stress versus depth table. In the TSPA-LA, these tables are produced by the SCCD DLL (Figure 10). In particular, the SCCD software calculates the variation in stress and stress intensity versus depth and angle. Inputs to this calculation are four coefficients used to calculate the stress versus depth, the sine of the fracture angle, the number of angles to be calculated, the yield strength, the yield strength scaling factor, and the angular amplitude of the stress variation. Also required is an uncertain deviation from median yield strength range and a table of stress intensity versus depth. The details of this calculation are given in the SMR for the SCCD software. 


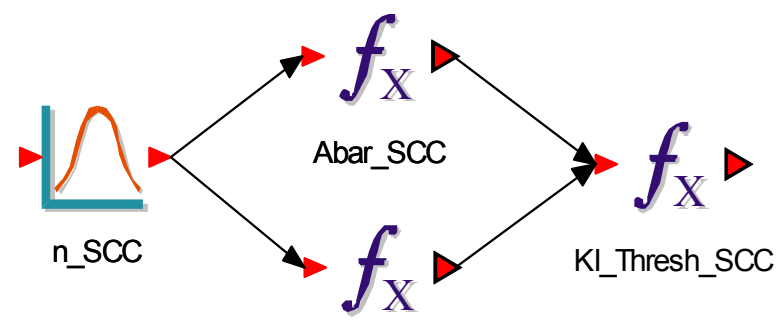

nbar_SCC



Output DTN: MO0310MWDWAPAN.002.

Figure 17. Contents of the SCC Container Element

The input parameters to the SCCD DLL are held in the container element SCC (Figure 17). The global parameter, yield strength, is defined in Table 9 and input via the data element Yield_Strength_A22. The remaining input parameters are barrier-dependent, and are defined for the outer and middle closure lids in the container elements SCC_Outer_Lid and SCC_Middle_Lid. The contents of the container element SCC_Outer_Lid are shown in Figure 18. The contents of the corresponding container for the middle lid are entirely analogous.

The four coefficients are defined in Table 10, for both lids. The outer lid values are stored in data elements A0_OL, A1_OL, A2_OL, and A3_OL. The sine of the fracture angle is defined in the data element sinf_OL. This value is always one, since only radial cracks are considered. The number of angles for which the calculation will be performed is set in the data element Num_Angles_OL. The yield strength scaling factor, fys_OL, is defined in Section 6.3.5.1 to be 15 percent of the yield strength. The angular amplitude of the stress variation, amp_OL, is defined in Equation 4 (17.236893). The input table of stress intensity factor versus depth is defined in Table 11. The WD4DLL.WAP file index for this table is contained in the data element KI_inp_OL.

Uncertainty in the stress and stress intensity factor profiles is included via an uncertainty scaling factor, $z$, given by

$$
z=\left(\frac{z_{-} O L \times \text { Yield_Strength_A22×fys_OL }}{3}\right)
$$

z_OL represents the uncertain variation away from the median value and is sampled from a truncated normal distribution with a mean of zero, a standard deviation of one, and is truncated at 
three standard deviations. The uncertainty scaling factor, $z$, then has standard deviation given by 5 percent of yield strength (since fys_OL $=0.15$ ), as specified in Table 9 .

Two implementations of the uncertainty are possible, according to the value in the data element, Model_Number_OL. Details of the two uncertainty implementations are given in the SMR for the SCCD software.

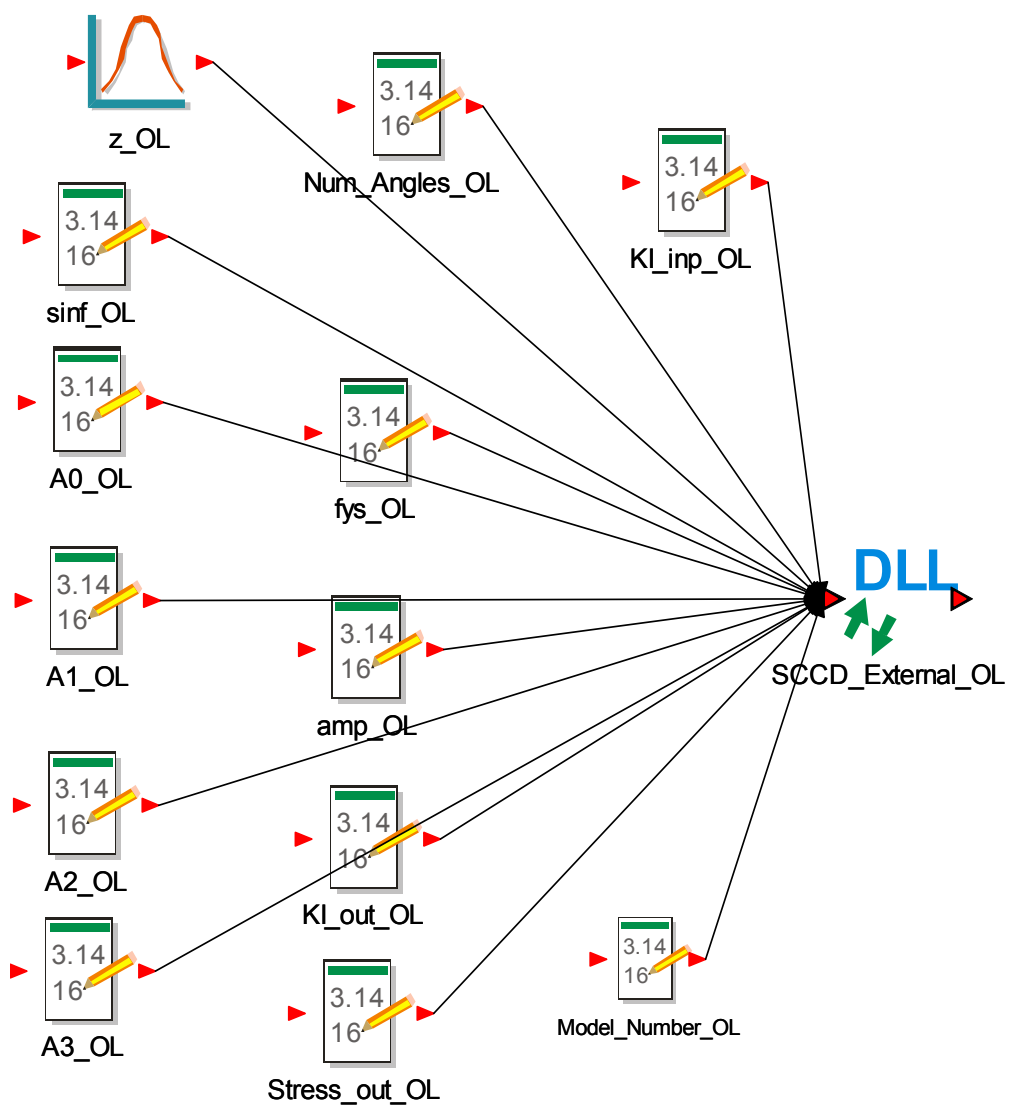

Output DTN: MO0310MWDWAPAN.002.

Figure 18. Contents of SCC_Outer_Lid Container Element

Outputs of the SCCD DLL are stress and stress intensity tables, as a function of depth, calculated at a number of angles (equally spaced and in the range 0 to $\pi$ radians, inclusive). The two data elements, Stress_out_OL and KI_out_OL contain the file indices for the SCCD output tables. The SCCD outputs are direct inputs to the slip dissolution event in WAPDEG.

The WD4DLL.WAP file indices corresponding to the tables of stress intensity-versus-depth and stress-versus-depth tables are input at lines 340 and 341 and lines 418 and 419 of the WAPDEG input vector (Table I-1), for the outer and middle closure lids, respectively.

\subsubsection{Slip Dissolution Implementation}

Stress corrosion cracking is implemented in WAPDEG by the use of a slip dissolution event (BSC 2002 [DIRS 162606], Sections 3.3.2.1.1 and 4.2.7.5). In WAPDEG, cracking can be 
initiated at incipient cracks or weld flaws, or both. Stress corrosion cracking due to both incipient cracks and weld flaws is analyzed using the slip dissolution event.

In WAPDEG, a corrosion-affecting event can apply to one barrier and one or more water conditions and can have effects specific to that event, as well as generic effects. The slip dissolution event has one specific effect, to initiate stress corrosion cracking.

A separate slip dissolution event must be defined for each closure lid (outer and middle). The closure lids can potentially be subject to both DSInside and DSOutside exposure conditions; therefore, both water conditions are included. The two slip dissolution events are defined in lines 331 to 408 (outer closure lid) and lines 409 to 486 (middle closure lid) of the WAPDEG input vector (Table I-1). Incipient cracks are automatically included in the event, but weld flaws must be specifically included (lines 336 and 414 of the WAPDEG input vector). Note that the event is restricted to apply only to side patches (closure lid region), by the data entered at lines 337 to 339 and lines 415 to 417 .

Using this event, cracks, once initiated, grow at a rate given by:

$$
V=\bar{A}\left(K_{I}\right)^{\bar{n}}
$$

where

$$
\begin{aligned}
V & =\text { crack velocity } \\
\bar{A} & =\text { Pre-exponential factor } \\
K_{I} & =\text { Stress intensity factor } \\
\bar{n} & =\text { Repassivation rate (or slope) }
\end{aligned}
$$

The crack growth parameters ( $\bar{A}$ and $\bar{n})$ are defined by Equations 10 and 11 (Section 4.1.6) and by the repassivation slope in Table 12. They are input to the WAPDEG input vector at lines 352 to 361 and at lines 430 to 439 . The parameters Abar_SCC and nbar_SCC correspond to the TSPA-LA expression elements of the same name, in the SCC container element (Figure 17). Abar_SCC and nbar_SCC are a function of the repassivation slope, n_SCC. The repassivation slope is sampled from the stochastic element, n_SCC, defined by a truncated normal distribution (at \pm 2 sds), with a mean of 1.304 and a standard deviation of 0.16 (Table 12).

The number of incipient cracks per patch is defined in the barrier definition data of the WAPDEG input vector. This definition is found in lines 11 to 15 , for the outer closure lid and lines 24 to 28 for the middle closure lid. The incipient crack densities are six cracks per patch and 15 cracks per patch, respectively (Section 6.3.5). The number of weld flaws per patch (defect flaw density) is defined by the manufacturing defects event for each closure lid (Section 6.4.8). The stress corrosion cracking slip dissolution event requires data for incipient crack size. The incipient crack size, defined in Table 12, is input at lines 362 to 366 and at lines 440 to lines 444 of the WAPDEG input vector.

The slip dissolution event also requires both a stress threshold or a stress intensity factor threshold or both, for crack growth initiation. These thresholds are defined separately for incipient cracks and weld flaws. The values of stress threshold and stress intensity factor threshold are defined in Table 12. They are contained in the expression elements 
Stress_Thresh_SCC and KI_Thresh_SCC. The thresholds for the incipient cracks are defined in lines $\overline{3} 73$ to $38 \overline{8}$ and in lines 451 to 460 of the WAPDEG input vector. The thresholds for the weld flaws are entered in lines 383 to 392 and lines 461 to 470 of the WAPDEG input vector. Note that both the incipient cracks and weld flaws use the same stress intensity factor threshold. However, the defect (weld) flaws do not require a stress threshold to nucleate (Section 4.1.6) and, therefore, a relatively large negative number $(-600)$ is input as the stress threshold.

Uncertainty in the crack growth and in the stress intensity factor threshold is represented by the uncertainty in the repassivation slope. The repassivation slope is sampled by the stochastic element n_SCC, once every realization. The stress and stress intensity factor tables, produced by the SCCD DLL, include uncertainty due to the use of a scaling factor that describes the deviation from the median stress/stress intensity profile. This scaling factor is sampled by the stochastic element z_OL, once every realization. Uncertainty in the probability of occurrence and the density and size distributions for weld flaws is included via the stochastic elements (Defect_Count_Param and Defect_Size_Param) that form part of the CWD calculation (Section 6.4.8). Note that there is no uncertainty associated with the density and size distribution of the incipient cracks. These are explicitly defined at lines 12, 25, 363, and 441.

Spatial variability is included in the crack growth analysis via the stress versus depth and stress intensity factor versus depth tables. A new set of tables is calculated for every realization. The tables are sampled for every patch that is subject to stress corrosion cracking. Spatial variability in the density and size of the weld flaws is also included, as described in Section 6.4.8.

\subsubsection{Waste Package Outer Barrier Microbially Influenced Corrosion Implementation}

The effect of microbially influenced corrosion (MIC) on the general corrosion of the waste package outer barrier is described in Section 6.3.6. Equation 36 defines a MIC general corrosion rate enhancement factor, $f_{M I C}$. The MIC general corrosion rate enhancement factor is applied to the waste package outer barrier general corrosion rate when the relative humidity at the waste package outer barrier surface is above 90 percent.

MIC is analyzed by the use of a MIC event (BSC 2002 [DIRS 162606], Section 4.2.7.10). The WAPDEG input vector defines two MIC events, one for the outer layer (lines 487 to 520 of Table I-1) and one for the inner layer (lines 521 to 554 of Table I-1).

In both cases, the MIC general corrosion rate enhancement factor is applied to the entire surface area (lines 492 and 526 of Table I-1). The threshold relative humidity for initiation of MIC is entered as a fraction (i.e., 0.9) (Table 13) in lines 499 to 503 and lines 533 to 537 of Table I-1.

The MIC general corrosion rate enhancement factor is input to WAPDEG as a sampled value from the stochastic MIC_A22 (Figure 10). This stochastic is defined to be uniformly distributed between 1 and 2 (Table 13). It is entered in lines 514 to 518 of the WAPDEG input vector, for the outer layer, and in lines 548 to 552, for the inner layer. The same value is used for both layers. 
Uncertainty in the MIC general corrosion rate enhancement factor is represented by the stochastic element MIC_A22. There is no variability in the MIC general corrosion rate enhancement factor (the factor is applied to the whole waste package outer barrier surface area).

\subsubsection{Implementation of Early Failure of Waste Packages}

The early failure implementation consists of specifying the number of waste packages to be considered as potentially subject to early failure and the distribution for the failure rate per waste package. The distribution for the failure rate was discussed in Sections 4.1.8 and 6.3.8. A sample GoldSim implementation is shown in Figure 19.

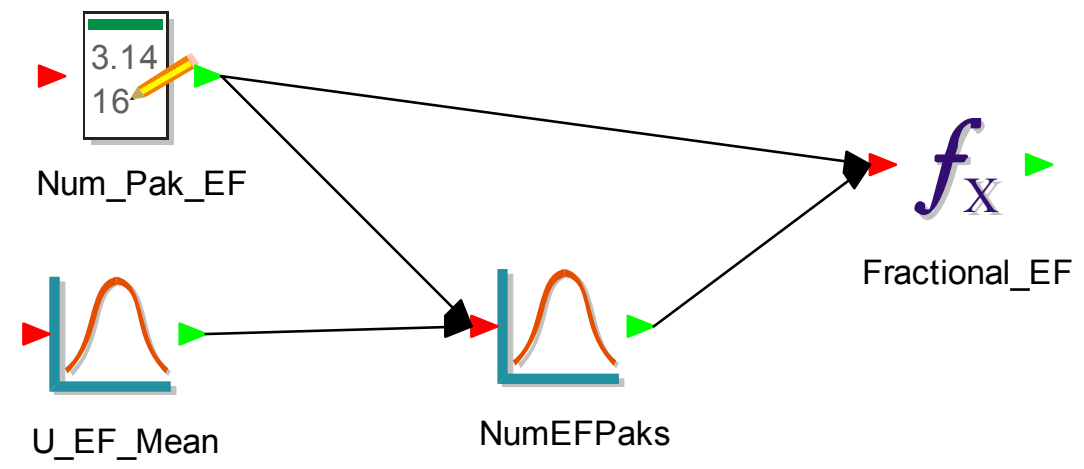

Output DTN: MO0310MWDWAPAN.002.

Figure 19. Example GoldSim Implementation to Determine the Fraction of Early Failed Waste Packages

The values used in the GoldSim elements in Figure 19 are summarized in Table 22.

Table 22. Waste Package Early Failure Parameters and Their Sources

\begin{tabular}{|c|c|c|c|}
\hline Parameter Name & Parameter Source & Parameter Value & Units \\
\hline $\begin{array}{l}\text { Num_Pak_EF } \\
\text { Number of Waste Packages } \\
\text { considered }\end{array}$ & $\begin{array}{l}\text { This is a TSPA parameter } \\
\text { to be specified by TSPA } \\
\text { Model at runtime }\end{array}$ & $\begin{array}{l}\text { e.g., } 11,184 \text { (representative } \\
\text { value, see discussion under } \\
\text { Parameter Source) }\end{array}$ & $\mathrm{N} / \mathrm{A}$ \\
\hline $\begin{array}{l}\text { U_EF_Mean } \\
\text { Evaluation probability per } \\
\text { Waste Package (Uncertain } \\
\text { Poisson intensity) }\end{array}$ & This report (Section 6.3.8) & $\begin{array}{l}\text { Log normal distribution with a } \\
\text { geometric mean of } 7.2 \times 10^{-6} \text { and } \\
\text { a geometric sd of } 15^{(1 / 1 / 1.645)} \\
\text { truncated at an upper-bound of } \\
7.44213 \times 10^{-3}\end{array}$ & $\begin{array}{l}\text { per waste } \\
\text { package }\end{array}$ \\
\hline $\begin{array}{l}\text { NumEFPaks } \\
\text { Number of Early Failed } \\
\text { Waste Package in the } \\
\text { realization }\end{array}$ & $\begin{array}{l}\text { BSC } 2004 \text { [DIRS 170024], } \\
\text { Section } 7 \text {, Table } 22\end{array}$ & $\begin{array}{l}\text { Poisson Distribution with } \\
\text { intensity } \\
\text { Num_Pak_EF*U_EF_Mean }\end{array}$ & $\begin{array}{l}\text { Number of waste } \\
\text { packages per } \\
\text { realization }\end{array}$ \\
\hline $\begin{array}{l}\text { Fractional_EF } \\
\text { Fraction of Early Failed } \\
\text { Waste Package in the } \\
\text { realization }\end{array}$ & This report (This section) & NumEFPaks/Num_Pak_EF & $\begin{array}{l}\text { fraction of waste } \\
\text { packages per } \\
\text { realization }\end{array}$ \\
\hline
\end{tabular}

The value of Num_Pak_EF should be chosen appropriately for the purpose of the study. For example, if one wanted to know how many (or what fraction of) waste packages will undergo early failure in a given realization, one should set Num_Pak_EF equal to the total number of wate packages (i.e., 11,184) (Section 4.1.1). Alternatively, if one wanted to know how many 
CDSP waste packages will undergo early failure in a given realiztion, one should set Num_Pak_EF equal to the total number of CDSP waste packages (i.e., 3,412) (Section 4.1.1). Three types of waste packages are considered; CDSP, CSNF with zirconium-based cladding on the waste form, and CSNF with stainless steel-based cladding on the waste form. The separation of CSNF waste package configurations is made for the purposes of incorporating differences in waste form degradation.

A marginal distribution for the number of early failed waste packages which incorporates the uncertainty variation is analysed here. This is evaluated by integrating the Poisson probability density function with the rate of early failure probability density function (given by the $\log$ normal distribution) over their given ranges. This integration results in the marginal distribution for number of early failed waste packages given the total number of waste packages $(N=11,184)$. The integral is numerically evaluated over its domain from zero to the truncated upper-bound. The log normal probability density function is also adjusted to its truncated upperbound representation so that the probability density function integrates to one over its effective range. This upper-bound is chosen so that it is as large as any of the rate values from the Monte Carlo study to which the log normal was fitted. The marginal distribution integral is represented below, where $f(x)$ and $F(x)$ are the probability density function and cumulative distribution function of the lognormal distribution, $N$ is the population of packages considered, and $n$ is the count of early failed waste packages.

$$
p(n)=\int_{0}^{\lambda_{m}}(\lambda N)^{n} \times \frac{\exp (-\lambda N)}{n !} \times \frac{f(\lambda)}{F\left(\lambda_{m}\right)} \times d \lambda
$$

The discrete probability density function, $p(n)$, evaluated for values of $n=0,1,2, \ldots$, gives the probability of $n$ packages being failed early. The integral upper-bound, represented by $\lambda_{m}$, is $7.44213 \times 10^{-3}$ for numerically evaluating the marginal distribution.

Evaluating this marginal probability density function for various values of $n$ provides the following results. Only 17 percent of the realizations have early failures, 83 percent of realizations have no early failed waste packages (Table 23). Realizations with only one early failure account for 11.4 percent of realizations and 3 percent of realizations have two early failed waste packages. This leaves 2.6 percent of the remaining realizations having three or more failed waste packages.

Table 23. Early Failure Waste Package Unconditional Probability Values

\begin{tabular}{|c|c|}
\hline $\begin{array}{c}\mathbf{n} \\
\text { (Number of Waste } \\
\text { Packages) }\end{array}$ & $\mathbf{p}(\mathbf{n})$ \\
\hline 0 & 0.830177156 \\
\hline 1 & 0.114170546 \\
\hline 2 & 0.029481907 \\
\hline$\geq 3$ & 0.026170391 \\
\hline
\end{tabular}

Output DTN: MO0310MWDWAPAN.002.

A second probability density function is derived from the probability density function (Equation 46) given that at least one waste package has undergone early failure by renormalizing 
the probabilities associated with having at least one early failed waste package. This second probability density functions called a conditional distribution (i.e., conditional on the fact that at least one failure has occurred). For purposes of constructing a probability density function table, a maximum value of $n=n_{m}$ is chosen such that having a value of $n$ larger can be neglected. The maximum count value chosen $\left(n_{m}=111\right)$ is the count associated with the mean plus three standard deviations. The probability of all count values larger than $n_{m}$ is small, $1.7 \times 10^{-9}$. The conditional probability density function, $p c(n)$, is given below by normalizing the individual probabilities of failure $(p(n))$ by the sum of the probabilities $(p(i))$ for $i=1,2, \ldots, n_{m}$ (Equation 47). Values for this probability density function are in Table 41.

$$
p c(n)=\frac{p(n)}{\sum_{i=1}^{n_{m}} p(i)}, \quad\left(n=1,2, \ldots, n_{m}\right)
$$

The distributions above can be sampled directly for unconditional or conditional counts of early failed waste packages, respectively. If it is then required to partition this count between differing package types this may be done by expressing the count as a sample from a multinomial distribution. The parameters for the multinomial distribution would be $n$ and the probabilities of each waste package type, where these probabilities are given by the ratio of the number of packages in the repository for that type $\left(N_{i}\right.$, such that $\left.N=\Sigma N_{i}\right)$ to the total of number of all package types (i.e., $N$ ). To generate a multinomial distribution, a simple way is to work with the marginals since they are binomials. The generation is done sequentially. Each succeeding conditional marginal is a binomial. As an example, an implementation for three (waste form) waste package types would be performed as in Table 24 .

Table 24. Multinomial Sampling Algorithm (Three Waste Package Types)

\begin{tabular}{|l|}
\hline 1. Sample a value for $n$. \\
\hline 2. Sample $n_{1}$ as a $\operatorname{Binomial}\left(n, p=N_{1} / N\right)$. \\
\hline 3. Sample $n_{2}$ as a $\operatorname{Binomial}\left(n-n_{1}, p=N_{2} /\left(N-N_{1}\right)\right)$. \\
\hline 4. Sample $n_{3}$ as a $\operatorname{Binomial}\left(n-n_{1}-n_{2}, p=N_{3} /\left(N-N_{1}-N_{2}\right)=1\right)$. That is $n_{3}=n-n_{1}-n_{2}$. \\
\hline
\end{tabular}

While the analysis above provides counts of early failed waste packages, the effect and time of an early failure are presented in the discussion that follows.

While the failure mechanisms are expected to result in enhanced probability of stress corrosion cracking, the waste packages are treated as failed upon initiation of corrosion processes. The following recommendations are made in Analysis of Mechanisms for Early Waste Package/Drip Shield Failure (BSC 2004 [DIRS 170024], Section 6.4.8) for evaluating waste package early failure:

- A failure of the waste package outer barrier shell and outer and middle closure lids should be assumed

- The affected waste packages should be assumed to fail immediately upon initiation of degradation processes 
- The entire waste package surface area should be considered affected by improper heat treatment

- The materials of the entire affected area should be assumed lost upon failure of the waste packages, because the affected area could be subjected to stress corrosion cracking and enhanced localized and general corrosion.

An example GoldSim implementation which determines the number and failure time of early failed waste packages is shown in Figure 20.

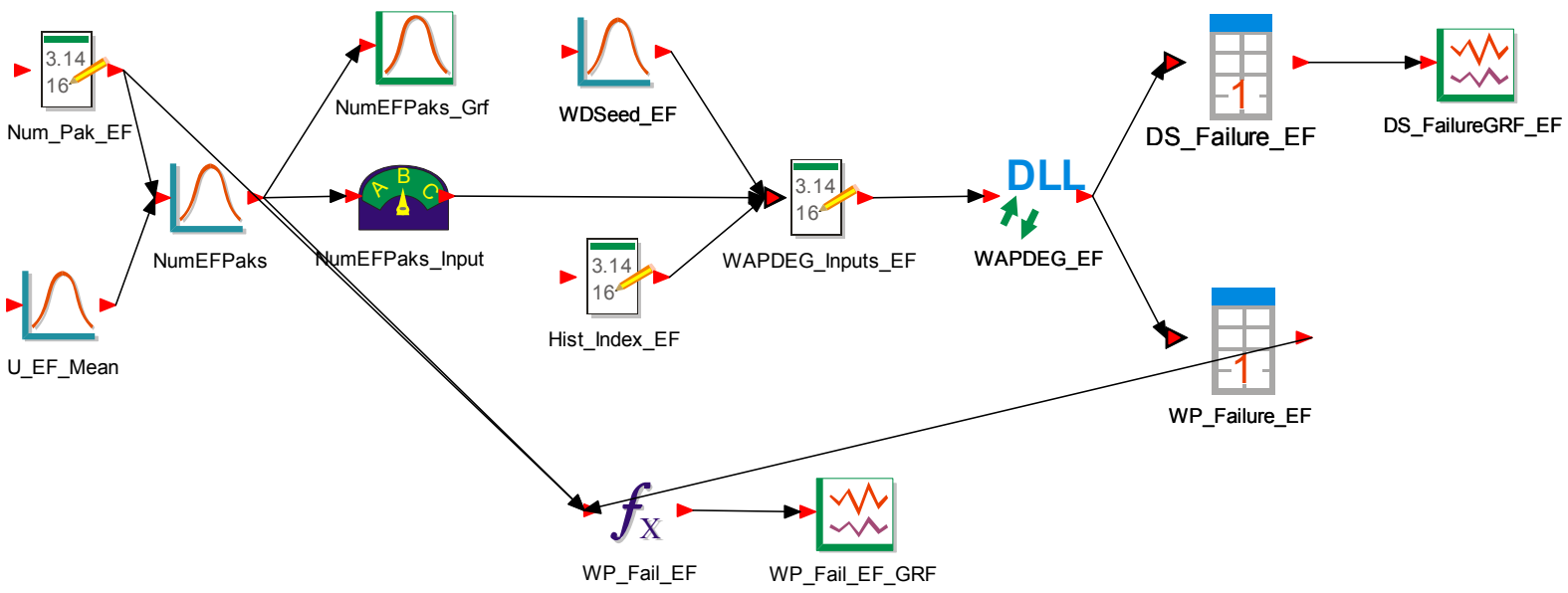

Output DTN: MO0310MWDWAPAN.002.

Figure 20. Example GoldSim Implementation to Determine the Number and Failure Time of Early Failed Waste Packages

It is expected that not all of this implementation will be used; it is provided to guide the implementation of the early failure analysis in TSPA. The parameters Num_Pak_EF, U_EF_Mean, and NumEFPaks are familiar from the previous figure. The element labeled NumEFPaks_GRF is merely a graphical element used to show the user a plot of the number of early failed waste packages per realization. It has no effect on the results of the calculation and can be removed. The element labeled NumEFPaks_Input is a switch element whose contents are shown in Figure 21. 


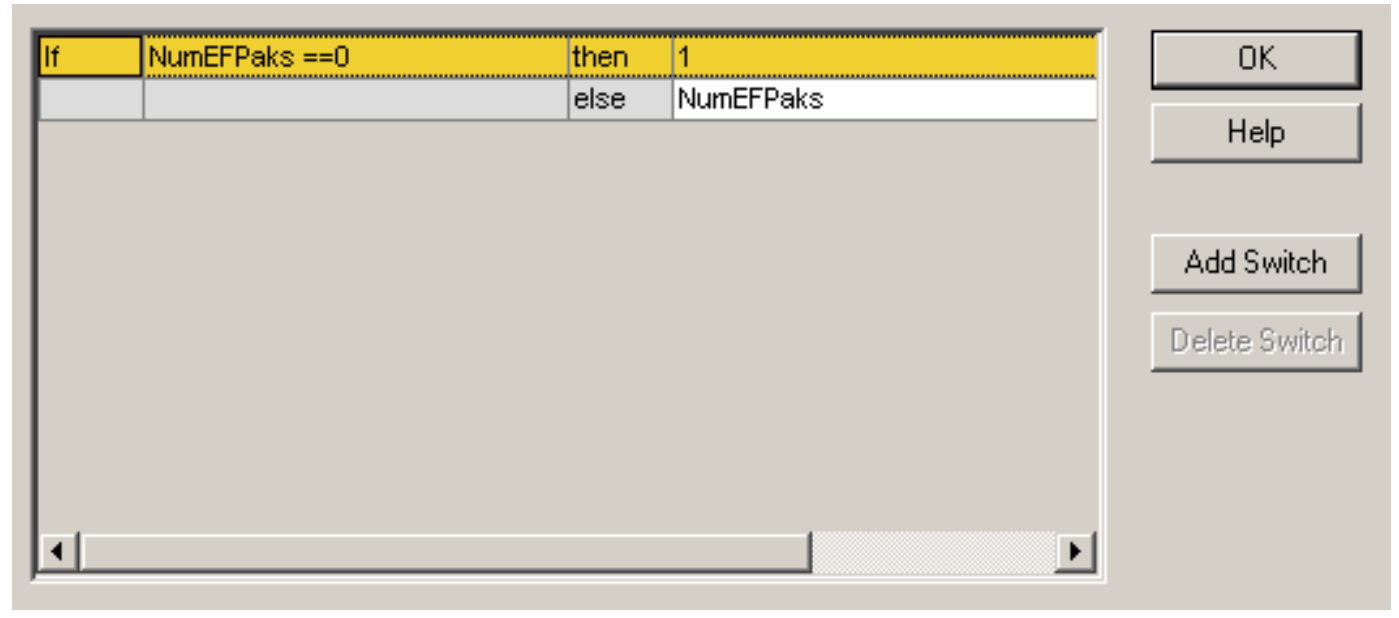

Output DTN: MO0310MWDWAPAN.002.

Figure 21. Contents of NumEFPaks_Input Element

The effect of this element is clear; if the number of sampled waste packages subject to early failure is zero, then the number of waste packages analyzed by WAPDEG is set to one; if the number of sampled waste packages subject to early failure is one or more, then the number of waste packages analyzed by WAPDEG is unchanged. This is done so that WAPDEG is not called with zero waste packages (which would result in an error).

The element WDSeed_EF provides WAPDEG with a seed value (through the WAPDEG_Inputs_EF element). Similarly, the Hist_Index_EF provides WAPDEG with the file index for the thermal hydrologic history file index (the line number in the WD4DLL.WAP file) to be used (through the WAPDEG_Inputs_EF element). The contents of the WAPDEG_Inputs_EF element are shown in Table 25.

Table 25. Contents of the WAPDEG_Inputs_EF Element

\begin{tabular}{|c|c|l|l|}
\hline Row & Value & \multicolumn{1}{|c|}{ Input Description } & Comments/Units \\
\hline 1 & Realization & Realization Number & \\
\hline 2 & 1 & Number of Barriers & \\
\hline 3 & 1 & Barrier Type & A22 OB \\
\hline 4 & 25 & Barrier Thickness & $\mathrm{mm}$ \\
\hline 5 & 0.75 & Barrier Mechanical Failure Fraction & fraction \\
\hline 6 & 1,000 & Barrier Pit Density Distribution Index & Fixed \\
\hline 7 & 0 & Parameter1 & /mm² \\
\hline 8 & 0 & Parameter 2 & \\
\hline 9 & 0 & Parameter 3 & \\
\hline 10 & 0 & Parameter 4 & Fixed \\
\hline 11 & 1,000 & Barrier Crack Density Distribution Index & \\
\hline 12 & 0 & Parameter1 & \\
\hline 13 & 0 & Parameter 2 & $\mathrm{mm} 2$ \\
\hline 14 & 0 & Parameter 3 & \\
\hline 15 & 0 & Parameter 4 & \\
\hline 16 & 1 & Waste Container Surface Area & \\
\hline
\end{tabular}


Table 25. Contents of the WAPDEG_Inputs_EF Element (Continued)

\begin{tabular}{|c|c|c|c|}
\hline Row & Value & Input Description & Comments/Units \\
\hline 17 & 1 & Waste Container Top Fraction & fraction \\
\hline 18 & 0 & Waste Container Bottom Fraction & fraction \\
\hline 19 & 1,000 & Waste Container Patch Size Distribution Index & Fixed \\
\hline 20 & 1 & Parameter1 & $\mathrm{mm}^{\wedge} 2$ \\
\hline 21 & 0 & Parameter 2 & \\
\hline 22 & 0 & Parameter 3 & \\
\hline 23 & 0 & Parameter 4 & \\
\hline 24 & -1 & Apply Size Boolean & TRUE \\
\hline 25 & -1 & Drip Shield Present Boolean & TRUE \\
\hline 26 & 3 & Drip Shield Type & Ti7 DS \\
\hline 27 & 15 & Drip Shield Thickness & $\mathrm{mm}$ \\
\hline 28 & 0.75 & Drip Shield Mechanical Failure Fraction & fraction \\
\hline 29 & 1,000 & Drip Shield Pit Density Distribution Index & Fixed \\
\hline 30 & 0 & Parameter1 & $/ \mathrm{mm}^{\wedge} 2$ \\
\hline 31 & 0 & Parameter 2 & \\
\hline 32 & 0 & Parameter 3 & \\
\hline 33 & 0 & Parameter 4 & \\
\hline 34 & 1,000 & Drip Shield Crack Density Distribution Index & Fixed \\
\hline 35 & 0 & Parameter1 & $/ \mathrm{mm}^{\wedge} 2$ \\
\hline 36 & 0 & Parameter 2 & \\
\hline 37 & 0 & Parameter 3 & \\
\hline 38 & 0 & Parameter 4 & \\
\hline 39 & Number_DS_Patches & Drip Shield Surface Area & $\mathrm{mm}^{\wedge} 2$ \\
\hline 40 & 1 & Drip Shield Top Fraction & fraction \\
\hline 41 & 1,000 & Drip Shield Patch Size Distribution Index & Fixed \\
\hline 42 & 1 & Parameter1 & $\mathrm{mm}^{\wedge} 2$ \\
\hline 43 & 0 & Parameter 2 & \\
\hline 44 & 0 & Parameter 3 & \\
\hline 45 & 0 & Parameter 4 & \\
\hline 46 & -1 & Drip Shield Apply Size Boolean & TRUE \\
\hline 47 & 1,000 & Drip Shield Fractional Area Affected Distribution Index & Fixed \\
\hline 48 & 1 & Parameter1 & fraction \\
\hline 49 & 0 & Parameter 2 & \\
\hline 50 & 0 & Parameter 3 & \\
\hline 51 & 0 & Parameter 4 & \\
\hline 52 & 1 & Initial Water Condition under drip shield & DSInside \\
\hline 53 & NumEFPaks_Input & Total Number of Waste Packages & \\
\hline 54 & Hist_Index_EF & Index Number of $\mathrm{T} / \mathrm{H}$ File to Read & \\
\hline 55 & 1 & Number of Drip Sequences & \\
\hline 56 & 1 & Number of Phases - Drip Sequence \#1 & \\
\hline 57 & 1,000 & $\begin{array}{l}\text { Fraction of Top Patches Subject to Sequence Distribution } \\
\text { Number }\end{array}$ & Fixed \\
\hline 58 & 1 & Parameter1 & fraction \\
\hline
\end{tabular}


Table 25. Contents of the WAPDEG_Inputs_EF Element (Continued)

\begin{tabular}{|c|c|c|c|}
\hline Row & Value & Input Description & Comments/Units \\
\hline 59 & 0 & Parameter 2 & \\
\hline 60 & 0 & Parameter 3 & \\
\hline 61 & 0 & Parameter 4 & \\
\hline 62 & 1,000 & $\begin{array}{l}\text { Fraction of Side Patches Subject to Sequence Distribution } \\
\text { Number }\end{array}$ & Fixed \\
\hline 63 & 1 & Parameter1 & fraction \\
\hline 64 & 0 & Parameter 2 & \\
\hline 65 & 0 & Parameter 3 & \\
\hline 66 & 0 & Parameter 4 & \\
\hline 67 & 1,000 & $\begin{array}{l}\text { Fraction of Bottom Patches Subject to Sequence } \\
\text { Distribution Number }\end{array}$ & Fixed \\
\hline 68 & 1 & Parameter1 & fraction \\
\hline 69 & 0 & Parameter 2 & \\
\hline 70 & 0 & Parameter 3 & \\
\hline 71 & 0 & Parameter 4 & \\
\hline 72 & 2 & Water Condition for Last Phase & DSOutside \\
\hline 73 & 4 & Number of Corrosion Functional Forms & \\
\hline 74 & 1 & Water Condition Index Number & DSInside \\
\hline 75 & 1 & Corrosion Mechanism Index $(1,2$, or 3$)$ & General \\
\hline 76 & 1 & Layer Composition Index & $\mathrm{A} 22 \mathrm{OB}$ \\
\hline 77 & 6 & Functional Form Index & Power Law \\
\hline 78 & 2 & Number of Levels for Variance Sharing & \\
\hline 79 & 1,000 & Barrier Variance Sharing Distribution Index & Fixed \\
\hline 80 & 1 & Parameter1 & fraction \\
\hline 81 & 0 & Parameter 2 & \\
\hline 82 & 0 & Parameter 3 & \\
\hline 83 & 0 & Parameter 4 & \\
\hline 84 & 1,000 & B term distribution & Fixed \\
\hline 85 & $1.00 E+14$ & Parameter1 & \\
\hline 86 & 0 & Parameter 2 & \\
\hline 87 & 0 & Parameter 3 & \\
\hline 88 & 0 & Parameter 4 & \\
\hline 89 & 1,000 & n term distribution & Fixed \\
\hline 90 & 1 & Parameter1 & \\
\hline 91 & 0 & Parameter 2 & \\
\hline 92 & 0 & Parameter 3 & \\
\hline 93 & 0 & Parameter 4 & \\
\hline 94 & 0 & Sample Type & \\
\hline 95 & 1 & Water Condition Index & DSInside \\
\hline 96 & 1 & Corrosion Mechanism Index $(1,2$, or 3$)$ & General \\
\hline 97 & 3 & Layer Composition Index & Ti7 DS \\
\hline 98 & 6 & Functional Form Index $-\mathrm{D}=\mathrm{B}^{\star} \mathrm{t}^{\wedge} \mathrm{n}$ & Power Law \\
\hline 99 & 2 & Number of Levels for Variance Sharing & \\
\hline
\end{tabular}


Table 25. Contents of the WAPDEG_Inputs_EF Element (Continued)

\begin{tabular}{|c|c|c|c|}
\hline Row & Value & Input Description & Comments/Units \\
\hline 100 & 1,000 & Barrier Variance Sharing Distribution Index & Fixed \\
\hline 101 & 1 & Parameter1 & fraction \\
\hline 102 & 0 & Parameter 2 & \\
\hline 103 & 0 & Parameter 3 & \\
\hline 104 & 0 & Parameter 4 & \\
\hline 105 & 1,000 & B Distribution Index & Fixed \\
\hline 106 & WDDSInGC & Parameter1 & $\mathrm{mm} / \mathrm{yr}$ \\
\hline 107 & 0 & Parameter 2 & \\
\hline 108 & 0 & Parameter 3 & \\
\hline 109 & 0 & Parameter 4 & \\
\hline 110 & 1,000 & n Distribution Index & Fixed \\
\hline 111 & 1 & Parameter1 & \\
\hline 112 & 0 & Parameter 2 & \\
\hline 113 & 0 & Parameter 3 & \\
\hline 114 & 0 & Parameter 4 & \\
\hline 115 & 0 & Sample Type & \\
\hline 116 & 2 & Water Condition Index & DSOutside \\
\hline 117 & 1 & Corrosion Mechanism Index (1, 2, or 3$)$ & General \\
\hline 118 & 1 & Layer Composition Index & A22 OB \\
\hline 119 & 6 & Functional Form Index & Power Law \\
\hline 120 & 2 & Number of Levels for Variance Sharing & \\
\hline 121 & 1,000 & Barrier Variance Sharing Distribution Index & Fixed \\
\hline 122 & 1 & Parameter1 & fraction \\
\hline 123 & 0 & Parameter 2 & \\
\hline 124 & 0 & Parameter 3 & \\
\hline 125 & 0 & Parameter 4 & \\
\hline 126 & 1,000 & B term distribution & Fixed \\
\hline 127 & $1.00 \mathrm{E}+14$ & Parameter1 & \\
\hline 128 & 0 & Parameter 2 & \\
\hline 129 & 0 & Parameter 3 & \\
\hline 130 & 0 & Parameter 4 & \\
\hline 131 & 1,000 & n term distribution & Fixed \\
\hline 132 & 1 & Parameter1 & \\
\hline 133 & 0 & Parameter 2 & \\
\hline 134 & 0 & Parameter 3 & \\
\hline 135 & 0 & Parameter 4 & \\
\hline 136 & 0 & Sample Type & \\
\hline 137 & 2 & Water Condition Index & DSOutside \\
\hline 138 & 1 & Corrosion Mechanism Index $(1,2$, or 3$)$ & General \\
\hline 139 & 3 & Layer Composition Index & Ti7 DS \\
\hline 140 & 6 & Functional Form Index $-\mathrm{D}=\mathrm{B}^{*} \mathrm{t}^{\wedge} \mathrm{n}$ & Power Law \\
\hline 141 & 2 & Number of Levels for Variance Sharing & \\
\hline 142 & 1,000 & Barrier Variance Sharing Distribution Index & Fixed \\
\hline
\end{tabular}


Table 25. Contents of the WAPDEG_Inputs_EF Element (Continued)

\begin{tabular}{|c|c|c|c|}
\hline Row & Value & Input Description & Comments/Units \\
\hline 143 & 1 & Parameter1 & \\
\hline 144 & 0 & Parameter 2 & \\
\hline 145 & 0 & Parameter 3 & \\
\hline 146 & 0 & Parameter 4 & \\
\hline 147 & 1,000 & B Distribution Index & Fixed \\
\hline 148 & WDDSOutGC & Parameter1 & $\mathrm{mm} / \mathrm{yr}$ \\
\hline 149 & 0 & Parameter 2 & \\
\hline 150 & 0 & Parameter 3 & \\
\hline 151 & 0 & Parameter 4 & \\
\hline 152 & 1,000 & n Distribution Index & Fixed \\
\hline 153 & 1 & Parameter1 & \\
\hline 154 & 0 & Parameter 2 & \\
\hline 155 & 0 & Parameter 3 & \\
\hline 156 & 0 & Parameter 4 & \\
\hline 157 & 0 & Sample Type & \\
\hline 158 & 0 & Number of General Thresholds & \\
\hline 159 & 0 & Number of Pit Temperature Thresholds & \\
\hline 160 & -1 & Inside Out Corrosion Logical & TRUE \\
\hline 161 & 2 & Water Condition for Inside Out Corrosion & DSOutside \\
\hline 162 & 0 & Interface Corrosion Logical & FALSE \\
\hline 163 & 0 & Number of Events & \\
\hline 164 & WDSeed_EF & Seed for the random number generator & \\
\hline 165 & NumBins & Number of bins for reporting penetrations with time & \\
\hline 166 & BinStart & Bin Start Time & \\
\hline 167 & 0 & Number of summary times for reporting penetrations & \\
\hline 168 & 0 & Do Subset of Total Package Logical & FALSE \\
\hline 169 & 1 & Number of First Package & \\
\hline 170 & 1 & Number of Last Package & \\
\hline 171 & SimTime & Simulation Time & \\
\hline 172 & 11 & Number of Output files & \\
\hline 173 & 0 & Generate OUT file logical & \\
\hline 174 & 0 & Generate AUX file logical & \\
\hline 175 & 0 & Generate PIT file logical & \\
\hline 176 & 0 & Generate CRK file logical & \\
\hline 177 & 0 & Generate PAT file logical & \\
\hline 178 & 0 & Generate THK file logical & \\
\hline 179 & 0 & Generate EVN file logical & \\
\hline 180 & 0 & Generate DET file logical & \\
\hline 181 & 0 & Generate INA file logical & \\
\hline 182 & 0 & Generate OUA file logical & \\
\hline 183 & 0 & Generate PDZ file logical & \\
\hline
\end{tabular}

Output DTN: MO0310MWDWAPAN.002. 
This WAPDEG input vector is much simplified compared to the nominal WAPDEG input vector. The WAPDEG_Inputs_EF vector contains input for analyzing NumEFPaks_Input number of drip shield-waste package pairs. The drip shield is analyzed with the same general corrosion rates used in the nominal IWPD analysis (lines 106 and 147 in Table 25). A very high $\left(10^{14} \mathrm{~mm} / \mathrm{yr}\right.$ general corrosion rate is chosen for the single-barrier waste package (line 126 of Table 25) resulting in immediate failure of the entire waste package barrier upon initiation of degradation. The DS_Failure_EF and WP_Failure_EF elements contain the output of the WAPDEG software. The WP_Fail_EF element contains WP_Failure_EF* (NumEFPaks/Num_Pak_EF), which is zero when NumEFPaks is zero and gives the fraction of early failed waste packages failed versus time. The WP_Fail_EF_GRF element is a graph element, which has no effect on the simulation results.

\subsection{BASE-CASE ANALYSIS RESULTS}

\subsubsection{Overview}

The previous sections of this report have documented the inputs to the integrated waste package degradation (IWPD) nominal-case analysis. In this section, the results of a representative IWPD analysis for waste package and drip shield degradation are presented. Waste package early failure is not included in the representative analysis presented in this section. The information in this section is provided only as a demonstration of an example set of analysis outputs. The waste package and drip shield degradation analyses to be presented in this section are for 300 realizations of the IWPD analysis to account for the uncertainty analysis of the uncertain simulation parameters. Each IWPD analysis realization corresponds to a complete IWPD analysis run to represent the variability in the degradation processes for a given number of waste package and drip shield pairs. Sensitivities using other choices of number of waste package and drip shield pairs are discussed in the next section.

The input parameters and their values were discussed in Section 6.4. Further specification of analysis inputs and recommendations for implementation can be found in Section 7.1. The IWPD analysis results (i.e., fraction of drip shields and waste packages failed versus time and the number of crack and patch penetrations per failed drip shield or waste package versus time) are reported as a group of "degradation profile curves" that represent the potential range of the output parameters.

The analysis results are presented for the upper- and lower-bounds, mean, and $95^{\text {th }}, 75^{\text {th }}, 25^{\text {th }}$, and $5^{\text {th }}$ percentiles as a function of time for the following output parameters:

- Waste package first breach (or failure)

- Drip shield first breach (or failure)

- Waste package first crack penetration

- Waste package first patch penetration

- Waste package number of crack penetrations per failed waste package

- Waste package number of patch penetrations per failed waste package

- Drip shield number of patch penetrations per failed drip shield 
Note that localized corrosion is not analyzed in this report. Also, stress corrosion cracking of the drip shield is not analyzed; thus, no crack penetration failures for the drip shield are calculated. Therefore, for the drip shield, the first patch penetration versus time profile is equivalent to the first breach versus time profile.

The upper- and lower-bounds, mean, and $95^{\text {th }}, 75^{\text {th }}, 25^{\text {th }}$, and $5^{\text {th }}$ percentile curves do not correspond to single realizations. They are summary statistics related to consideration of all 300 realizations. In the bullets below, the origin of the upper- and lower-bound, mean, and $95^{\text {th }}, 75^{\text {th }}$, $25^{\text {th }}$, and $5^{\text {th }}$ percentile curves for first breach of the waste package are discussed. Similar wording (not included for the sake of brevity) applies to the origins of the drip shield first breach curves, waste package first crack penetration curves, etc.

- At each time, the upper-bound curve shows the realization with the greatest fraction of waste packages failed calculated in any one of the 300 realizations. This may not be the same realization at each point in time. The upper-bound curve becomes nonzero at the time of failure of first waste package in all of the 300 realizations.

- At each time, the $95^{\text {th }}$-percentile curve shows the realization with the $285^{\text {th }}$ greatest fraction of waste packages failed (i.e., $3 \times 95=285$ realizations out of 300 have smaller fraction of waste packages failed calculated in any one of the 300 realizations. This may not be the same realization at each point in time. The $95^{\text {th }}$-percentile curve becomes nonzero at the time when at least $3 \times 5=15$ realizations have at least one waste package failure.

- At each time, the $75^{\text {th }}$-percentile curve shows the realization calculated in any one of the 300 realizations with the $225^{\text {th }}$ greatest fraction of waste packages failed (i.e., $3 \times 75=225$ realizations out of 300 have smaller fraction of waste packages failed). This may not be the same realization at each point in time. The $75^{\text {th }}$-percentile curve becomes nonzero at the time when at least $3 \times 25=75$ realizations have at least one waste package failure.

- At each time, the $25^{\text {th }}$-percentile curve shows the realization calculated in any one of the 300 realizations with the $75^{\text {th }}$ greatest fraction of waste packages failed (i.e., $3 \times 25=75$ realizations out of 300 have smaller fraction of waste packages failed). This may not be the same realization at each point in time. The $25^{\text {th }}$-percentile curve becomes nonzero at the time when at least $3 \times 75=225$ realizations have at least one waste package failure.

- At each time, the $5^{\text {th }}$-percentile curve shows the realization calculated in any one of the 300 realizations with the $15^{\text {th }}$ greatest fraction of waste packages failed (i.e., $3 \times 5=15$ realizations out of 300 have smaller fraction of waste packages failed). This may not be the same realization at each point in time. The $5^{\text {th }}$-percentile curve becomes nonzero at the time when at least $3 \times 95=285$ realizations have at least one waste package failure.

- At each time, the mean curve shows the mean of all the fractions of waste packages failed in all of the 300 realizations. The mean curve becomes nonzero at the time of failure of first waste package in all of the 300 realizations. 


\subsubsection{Commercial Spent Nuclear Fuel Integrated Waste Package Degradation Analysis Base-Case Results}

The commercial spent nuclear fuel (CSNF) waste packages are simulated using 1,014 patches (Section 6.3.2). The CSNF waste package outer barrier shell thickness is $20 \mathrm{~mm}$ (Section 4.1.1).

Figure 22 shows the upper- and lower-bounds, mean, and $95^{\text {th }}, 75^{\text {th }}, 25^{\text {th }}$, and $5^{\text {th }}$ percentile confidence intervals of the first breach profile for CSNF waste packages versus time. The upperbound profile, which is the upper extreme of the probable range of the first breach time, indicates that the earliest possible first breach time for a waste package is about 120,000 years. Note that the estimated earliest possible first breach time has a very low probability. It can be shown by comparing with the upper-bound profile in Figure 24 (showing the first crack breach profiles of waste packages with time) that the first breach is by stress corrosion crack penetration (Figure 24 and Figure 25). The median estimate (50 percent of waste packages failed) of the first breach time of the upper-bound profile is about 310,000 years. The median estimate of the first breach time of the mean profile is about 1.06 million years. The time to fail 10 percent of waste packages for the upper-bound and mean profiles is about 230,000 and 320,000 years, respectively.

Figure 23 shows the first breach profiles of CSNF drip shields with time. Because stress corrosion cracking and localized corrosion of the drip shields are not analyzed in this report, the first breach profiles shown in the figure are all by general corrosion only. Both the upper and under sides of the drip shield are exposed to the exposure conditions in the emplacement drift and are subject to general corrosion. Thus, in the analysis, the general corrosion rate for the drip shields is sampled twice independently, once for the upper side and the once for the under side. There is no variability in drip shield failure times. This is shown in the failure profiles in that the fraction of failed drip shields rises quickly from zero to one. For the upper-bound drip shield failure profile, the drip shields fail at about 47,500 years. For the $95^{\text {th }}$-percentile profile, the drip shields fail at about 92,500 years. The median estimate of the first breach time of the mean profile is about 310,000 years. Note that the lower-bound curve for drip shield breach is not shown in Figure 23 because the lower-bound breach curve lies beyond 10 million years. The lower-bound entry is left in the graph legend for consistency with the other figures in this report. Because the drip shields are analyzed with one patch, the entire surface of a failed drip shield fails at one time.

Figure 24 and Figure 25 show respectively the first crack penetration and patch penetration profiles of the CSNF waste packages with time. The first crack breach times of the upper-bound and $95^{\text {th }}$-percentile profiles are about 120,000 and 240,000 years, respectively (Figure 24), and the first patch breach times of the upper-bound and $95^{\text {th }}$-percentile profiles are about 480,000 and 560,000 years, respectively (Figure 25). Comparison of the first crack and patch breach profiles with the first breach profiles in Figure 22 indicates that the initial breach (or failure) of the waste packages is generally by stress corrosion crack penetration in the Alloy 22 waste package outer barrier middle closure lid welds. For the $75^{\text {th }}$-percentile profiles in the figures, the first crack and patch penetration times are about 360,000 and 840,000 years, respectively.

Figure 26 shows the profile for the average number of crack penetrations per failed CSNF waste package. As discussed for Figure 24, the upper-bound and $95^{\text {th }}$-percentile profiles show the first 
crack penetration at about 120,000 and 240,000 years, respectively. The mean profile never develops more than about 382 cracks.

Figure 27 presents the profile for the average number of patch openings per failed waste package. For the upper-bound profile, which again represents an extremely low probability case, the average first patch breach occurs at about 480,000 years (Figure 25), and about 10 patches on average (about 1 percent of the waste package surface area) are breached by 825,000 years. For the mean profile, there will be only about 2.5 patch openings (on average) in each of the failed waste packages by 1 million years.

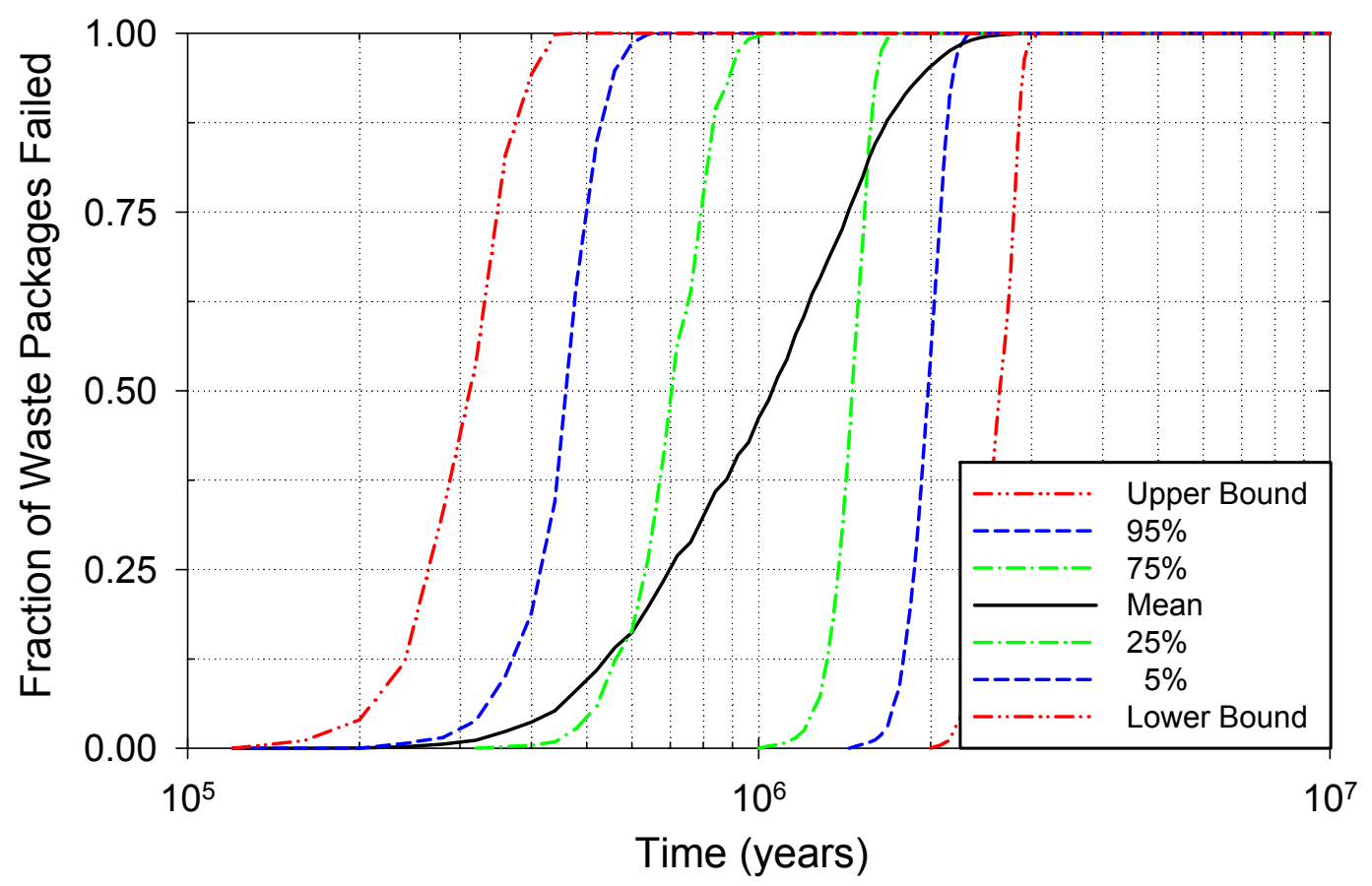

Output DTN: MO0310MWDWAPAN.002.

Figure 22. The Upper- and Lower-Bounds, Mean, and $95^{\text {th }}, 75^{\text {th }}, 25^{\text {th }}$, and $5^{\text {th }}$ Percentile Confidence Intervals of the First Breach Profile of CSNF Waste Packages With Time for the IWPD Analysis 


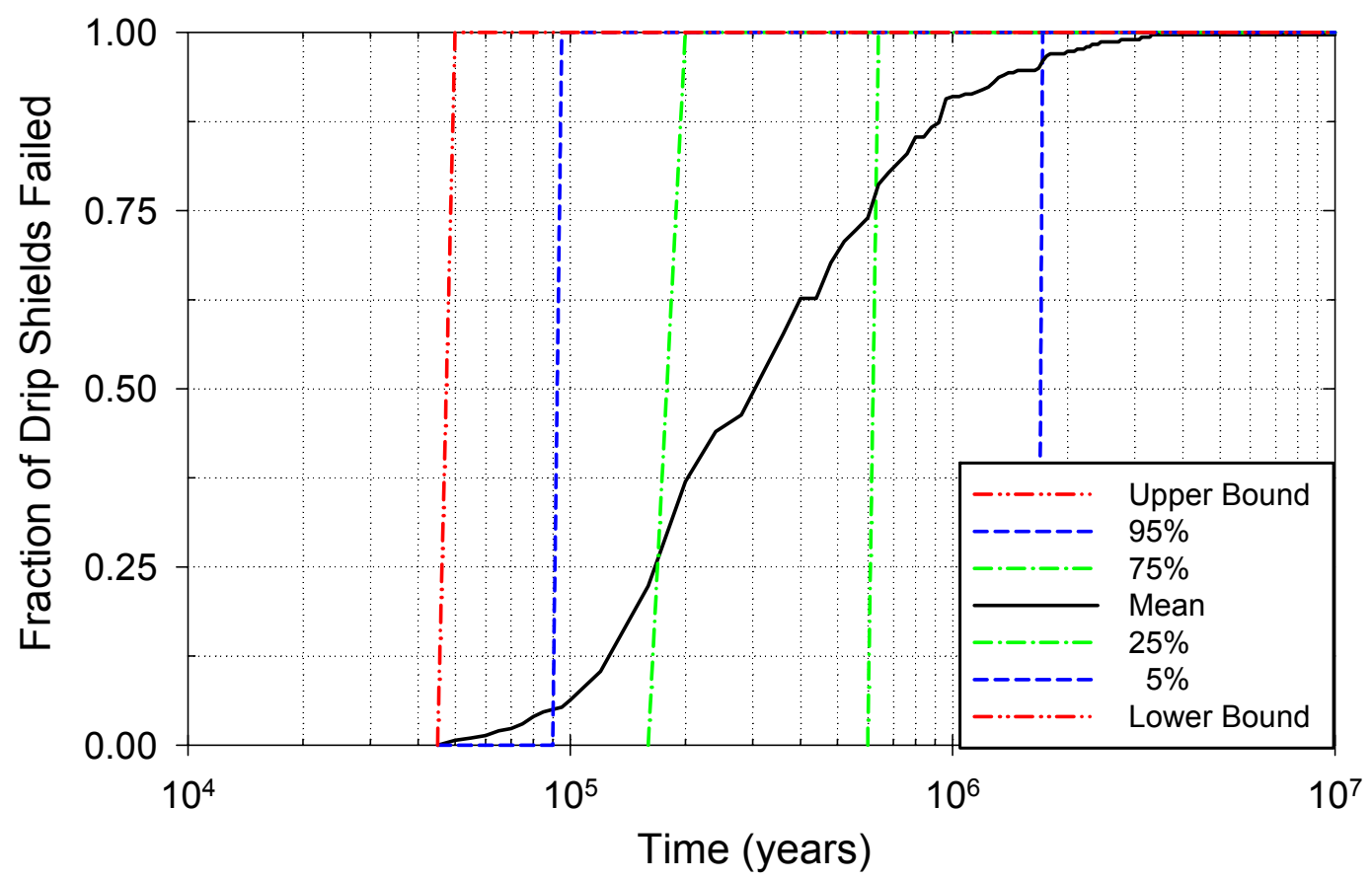

Output DTN: MO0310MWDWAPAN.002.

Note: The lower-bound curve for drip shield breach is not shown because the lower-bound breach curve lies beyond 10 million years

Figure 23. The Upper-Bound, Mean, and $95^{\text {th }}, 75^{\text {th }}, 25^{\text {th }}$, and $5^{\text {th }}$ Percentile Confidence Intervals of the First Breach Profile of CSNF Drip Shields With Time for the IWPD Analysis

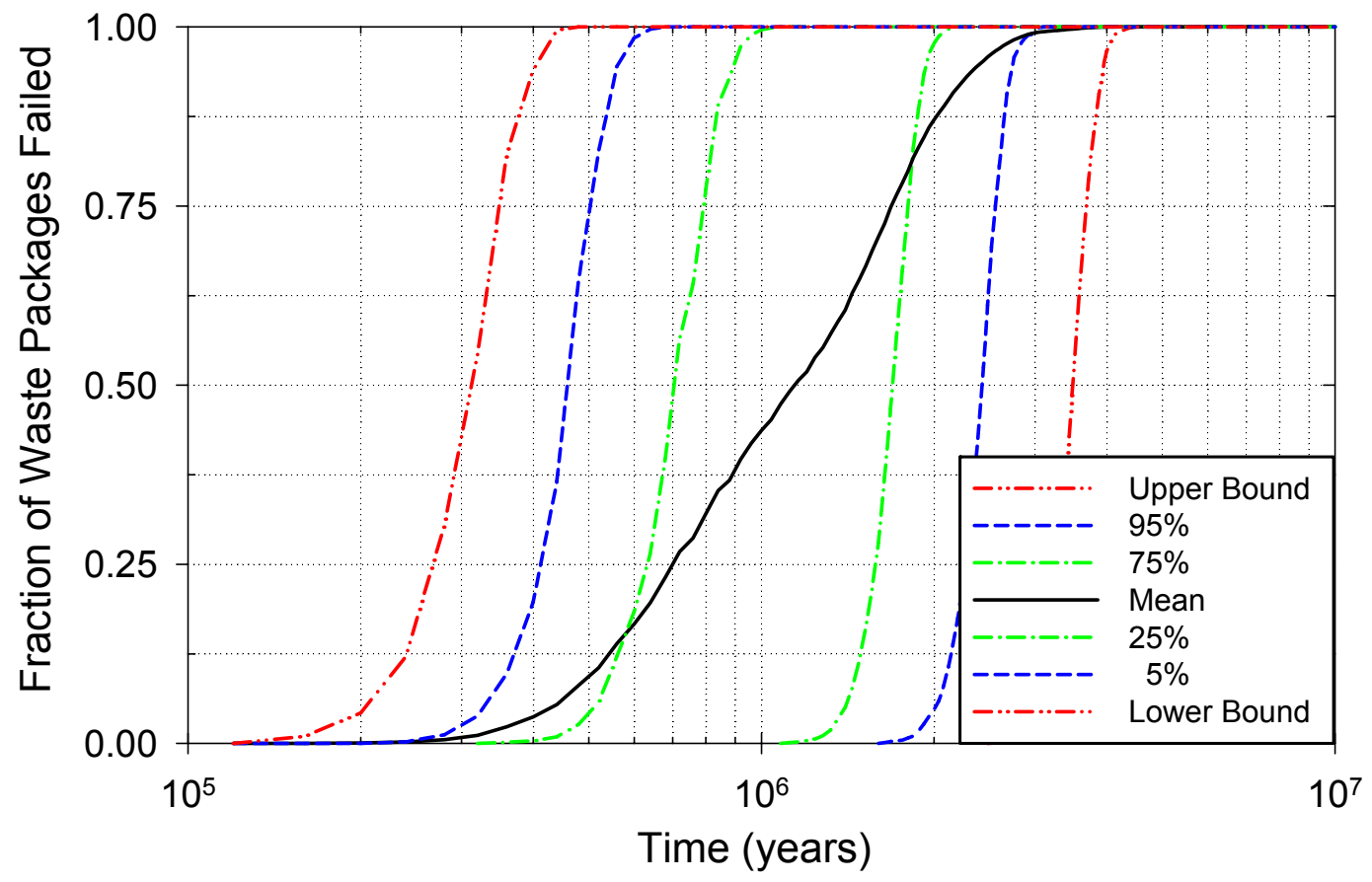

Output DTN: MO0310MWDWAPAN.002.

Figure 24. The Upper- and Lower-Bounds, Mean, and $95^{\text {th }}, 75^{\text {th }}, 25^{\text {th }}$, and $5^{\text {th }}$ Percentile Confidence Intervals of the First Crack Breach Profile of CSNF Waste Packages With Time for the IWPD Analysis 


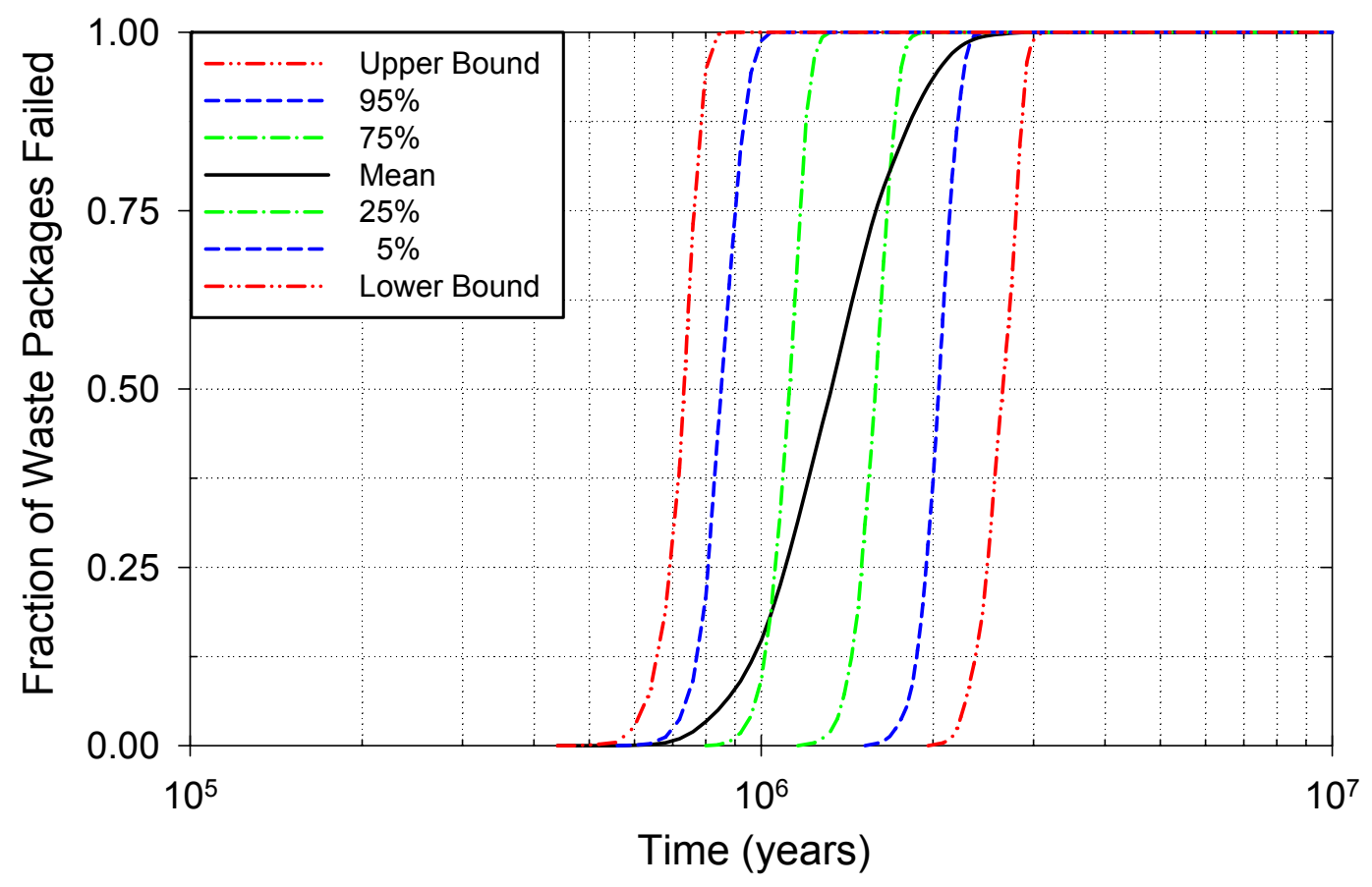

Output DTN: MO0310MWDWAPAN.002.

Figure 25. The Upper- and Lower-Bounds, Mean, and $95^{\text {th }}, 75^{\text {th }}, 25^{\text {th }}$, and $5^{\text {th }}$ Percentile Confidence Intervals of the First Patch Breach Profile of CSNF Waste Packages With Time for the IWPD Analysis

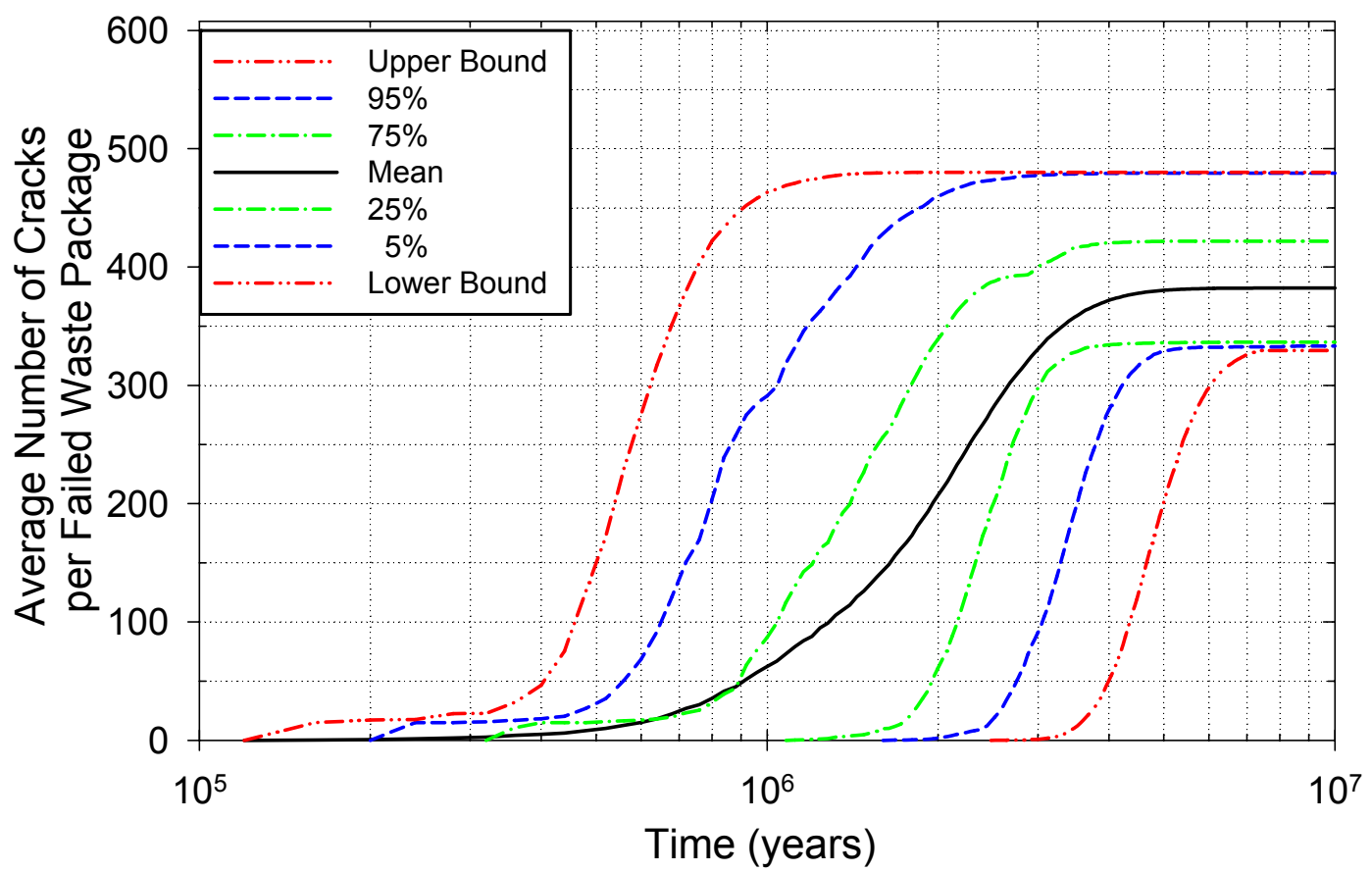

Output DTN: MO0310MWDWAPAN.002.

Figure 26. The Upper- and Lower-Bounds, Mean, and $95^{\text {th }}, 75^{\text {th }}, 25^{\text {th }}$, and $5^{\text {th }}$ Percentile Confidence Intervals of the Average Number of Crack Penetrations per Failed CSNF Waste Package Profile With Time for the IWPD Analysis 


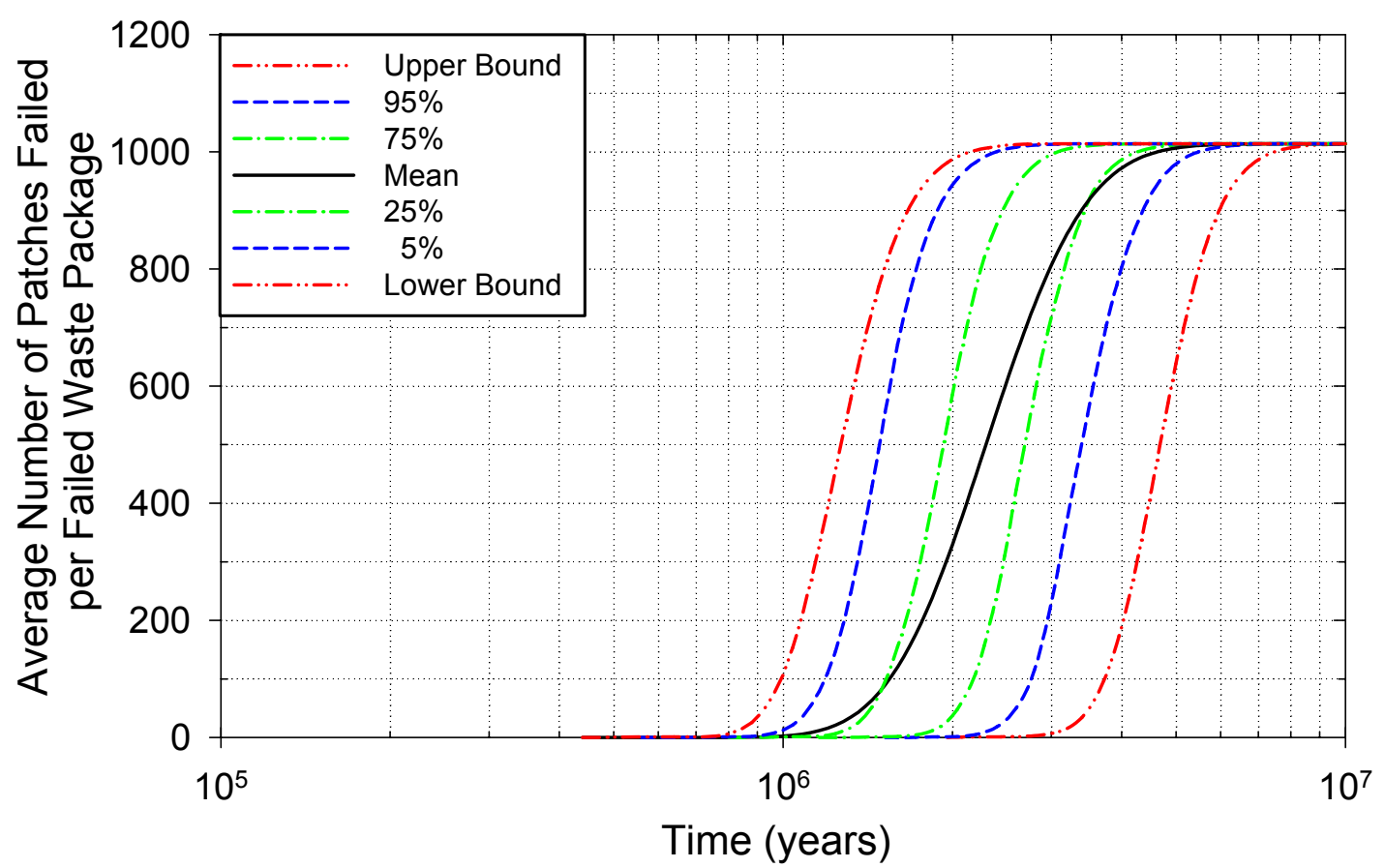

Output DTN: MO0310MWDWAPAN.002.

Figure 27. The Upper- and Lower-Bounds, Mean, and $95^{\text {th }}, 75^{\text {th }}, 25^{\text {th }}$, and $5^{\text {th }}$ Percentile Confidence Intervals of the Average Number of Patch Penetrations per Failed CSNF Waste Package Profile With Time for the IWPD Analysis

\subsubsection{Codisposal Waste Package Integrated Waste Package Degradation Analysis Base- Case Results}

The codisposal (CDSP) waste packages are simulated using 1,106 patches (Section 6.3.2). The CDSP waste package outer barrier shell thickness is $25 \mathrm{~mm}$ (Section 4.1.1).

Figure 28 shows the upper- and lower-bounds, mean, and $95^{\text {th }}, 75^{\text {th }}, 25^{\text {th }}$, and $5^{\text {th }}$ percentile confidence intervals of the first breach profile for CDSP waste packages versus time. The upperbound profile, which is the upper extreme of the probable range of the first breach time, indicates that the earliest possible first breach time for a waste package is about 120,000 years. The estimated earliest possible first breach time has a very low probability. It can be shown by comparing with the upper-bound profile in Figure 30 (showing the first crack breach profiles of waste packages with time) that the first breach is by stress corrosion crack penetration (see the discussion of the results in Figure 30 and Figure 31 later in this section). The median estimate (50 percent of waste packages failed) of the first breach time of the upper-bound profile is about 310,000 years. The median estimate of the first breach time of the mean profile is about 1.12 million years. The time to fail 10 percent of waste packages for the upper-bound and mean profiles is about 220,000 and 485,000 years, respectively.

Figure 29 shows the first breach profiles of CDSP drip shields with time. Because stress corrosion cracking and localized corrosion of the drip shields are not analyzed in this report, the first breach profiles shown in the figure are all by general corrosion only. Both the upper and under sides of the drip shield are exposed to the exposure conditions in the emplacement drift 
and are subject to general corrosion. Thus, in the analysis, the general corrosion rate for the drip shields is sampled twice independently, once for the upper side and the once for the under side. There is no variability in drip shield failure times. This is shown in the failure profiles in that the fraction of failed drip shields rises quickly from zero to one. For the upper-bound drip shield failure profile, the drip shields all fail at about 47,500 years. For the $95^{\text {th }}$-percentile profile, the drip shields all fail at about 92,500 years. The median estimate of the first breach time of the mean profile is about 310,000 years. Note that the lower-bound curve for drip shield breach is not shown in Figure 29 because the lower-bound breach curve lies beyond 10 million years. The lower-bound entry is left in the graph legend for consistency with the other figures in this report. Because the drip shields are analyzed with one patch, the entire surface of a failed drip shield fails at one time. Note that the CSNF and CDSP drip shield failure curves are identical since there is no difference between the drip shields for the two waste package types.

Figure 30 and Figure 31 show, respectively, the first crack penetration and patch penetration profiles of the CDSP waste packages with time. The first crack breach times of the upper-bound and $95^{\text {th }}$-percentile profiles are about 120,000 and 200,000 years respectively (Figure 30), and the first patch breach times of the upper- and $95^{\text {th }}$-percentile profiles are about 560,000 and 720,000 years, respectively (Figure 31 ). Comparison of the first crack and patch breach profiles with the first breach profiles in Figure 28 indicates that the initial breach (or failure) of the waste packages is generally by stress corrosion cracking crack penetration in the Alloy 22 waste package outer barrier middle closure lid welds. For the $75^{\text {th }}$-percentile profiles in the figures, the first crack and patch penetration times are about 360,000 and 920,000 years, respectively.

Figure 32 shows the profile for the average number of crack penetrations per failed CDSP waste package. As discussed for Figure 30, the upper-bound and $95^{\text {th }}$-percentile profiles show the first crack penetration at about 120,000 and 200,000 years, respectively. The mean profile never develops more than about 522 cracks.

Figure 33 presents the profile for the average number of patch openings per failed waste package. For the upper-bound profile, which again represents an extremely low probability case, the first patch breach occurs at about 560,000 years (Figure 31), and about 13 patches (on average) (about 1 percent of the waste package surface area) are breached by 1 million years. For the mean profile, there will be only about 0.28 of a patch opening (on average) in each of the failed waste packages by 1 million years. 


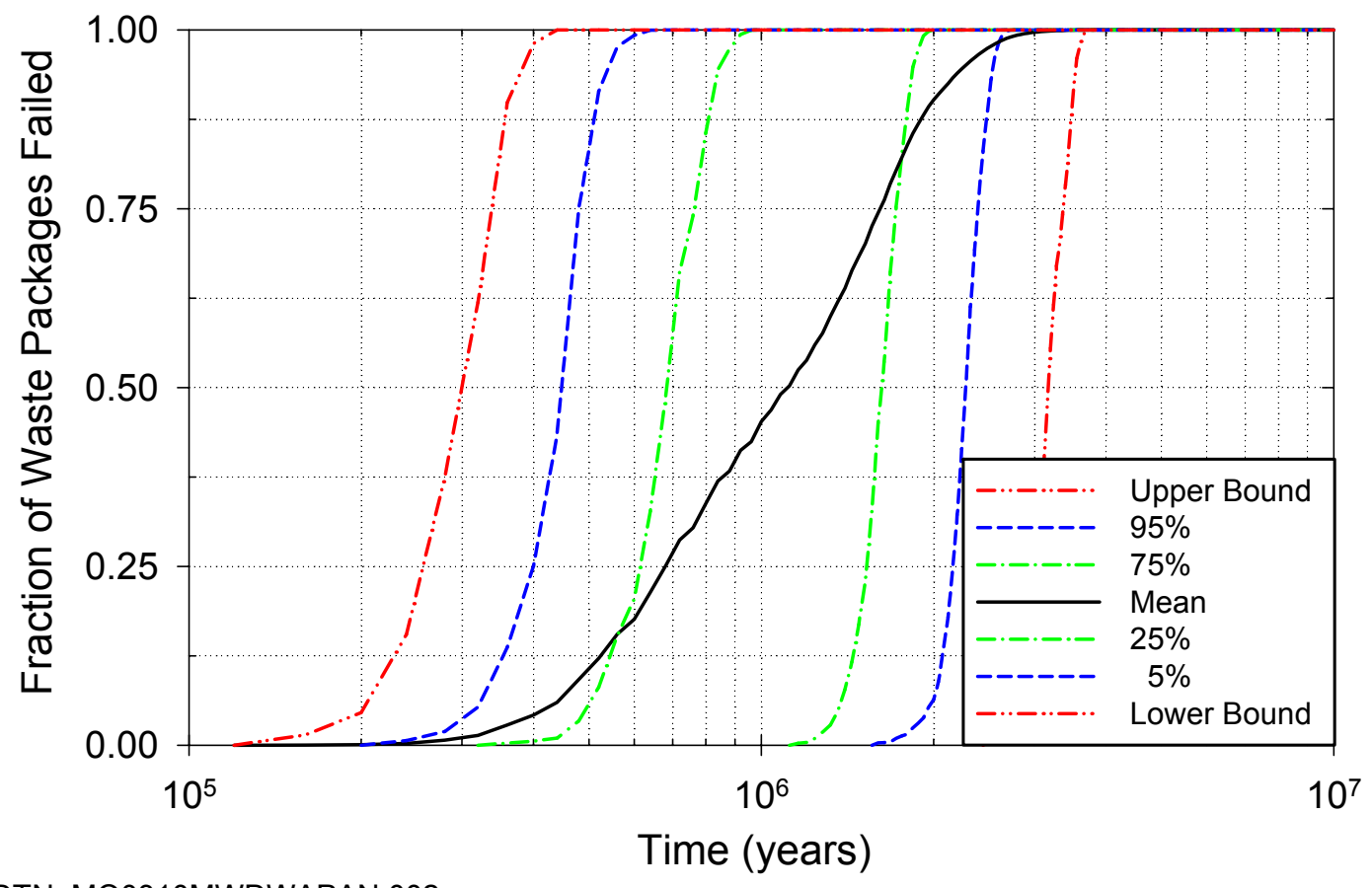

Output DTN: MO0310MWDWAPAN.002.

Figure 28. The Upper- and Lower-Bounds, Mean, and $95^{\text {th }}, 75^{\text {th }}, 25^{\text {th }}$, and $5^{\text {th }}$ Percentile Confidence Intervals of the First Breach Profile of CDSP Waste Packages With Time for the IWPD Analysis

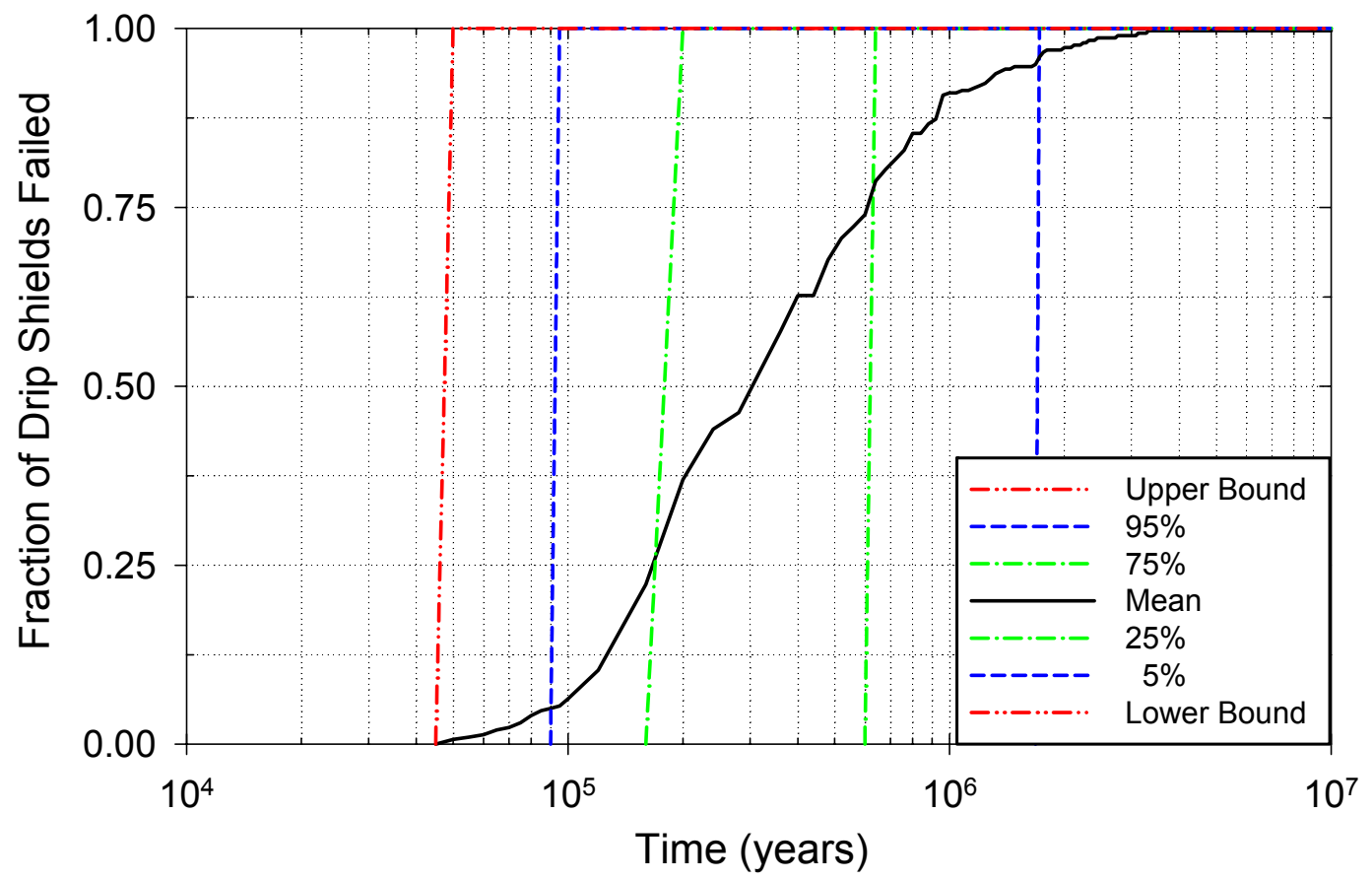

Output DTN: MO0310MWDWAPAN.002.

NOTE: The lower-bound curve for drip shield breach is not shown because the lower-bound breach curve lies beyond 10 million years.

Figure 29. The Upper-Bound, Mean, and $95^{\text {th }}, 75^{\text {th }}, 25^{\text {th }}$, and $5^{\text {th }}$ Percentile Confidence Intervals of the First Breach Profile of CDSP Drip Shields With Time for the IWPD Analysis 


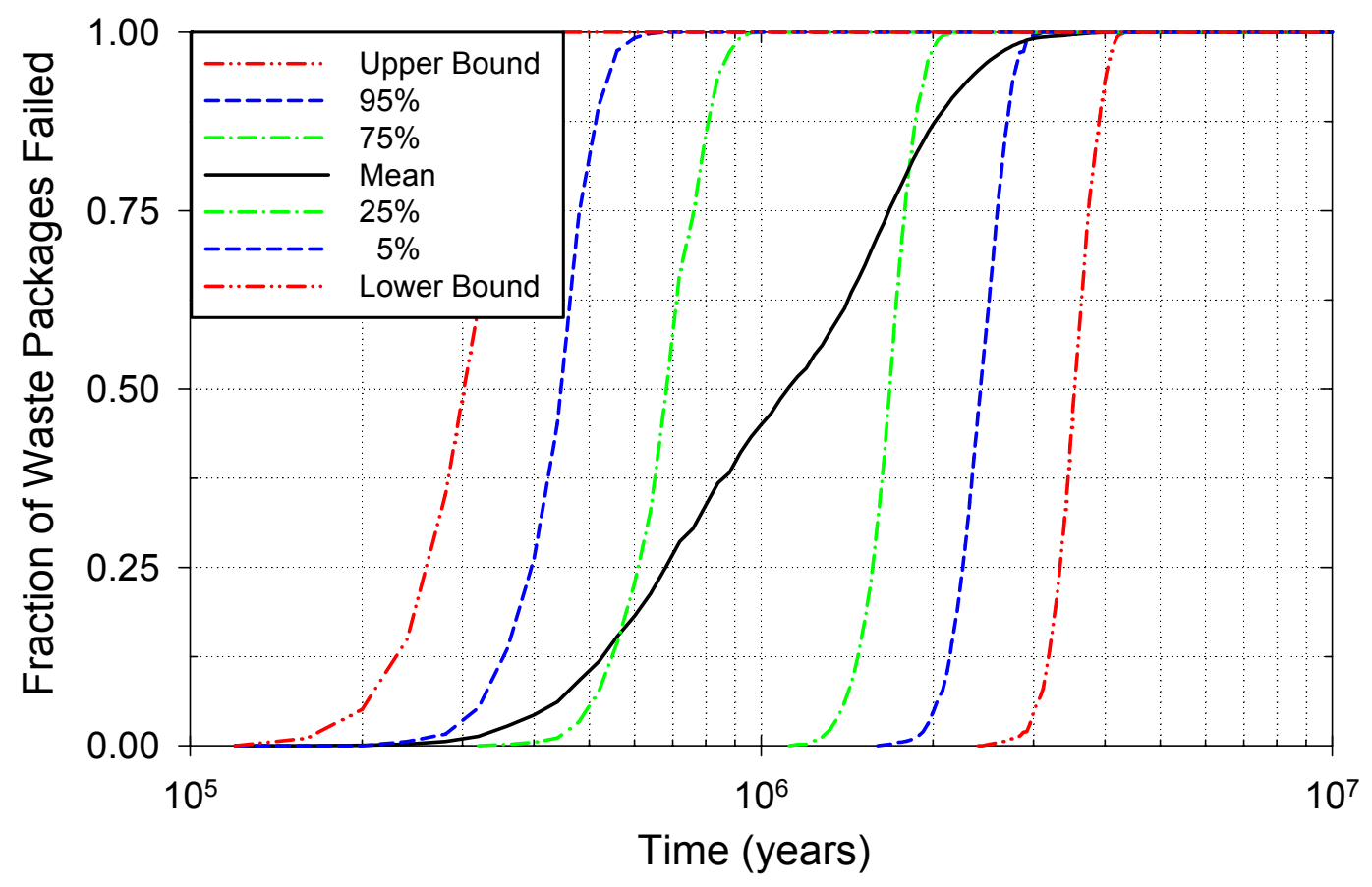

Output DTN: MO0310MWDWAPAN.002.

Figure 30. The Upper- and Lower-Bounds, Mean, and $95^{\text {th }}, 75^{\text {th }}, 25^{\text {th }}$, and $5^{\text {th }}$ Percentile Confidence Intervals of the First Crack Breach Profile of CDSP Waste Packages With Time for the IWPD Analysis



Output DTN: MO0310MWDWAPAN.002.

Figure 31. The Upper- and Lower-Bounds, Mean, and $95^{\text {th }}, 75^{\text {th }}, 25^{\text {th }}$, and $5^{\text {th }}$ Percentile Confidence Intervals of the First Patch Breach Profile of CDSP Waste Packages With Time for the IWPD Analysis 


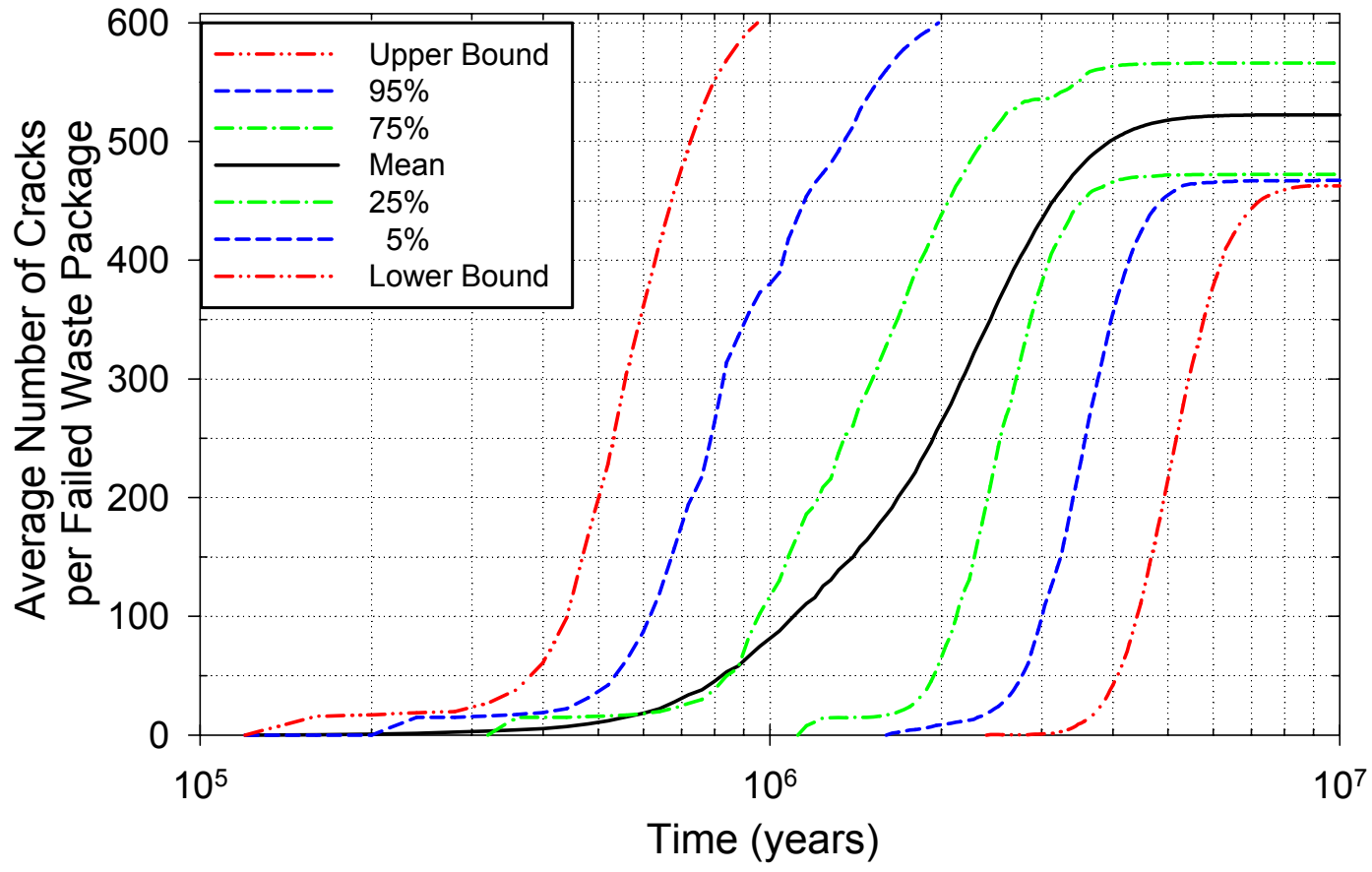

Output DTN: MO0310MWDWAPAN.002.

Figure 32. The Upper- and Lower-Bounds, Mean, and $95^{\text {th }}, 75^{\text {th }}, 25^{\text {th }}$, and $5^{\text {th }}$ Percentile Confidence Intervals of the Average Number of Crack Penetrations per Failed CDSP Waste Package Profile With Time for the IWPD Analysis

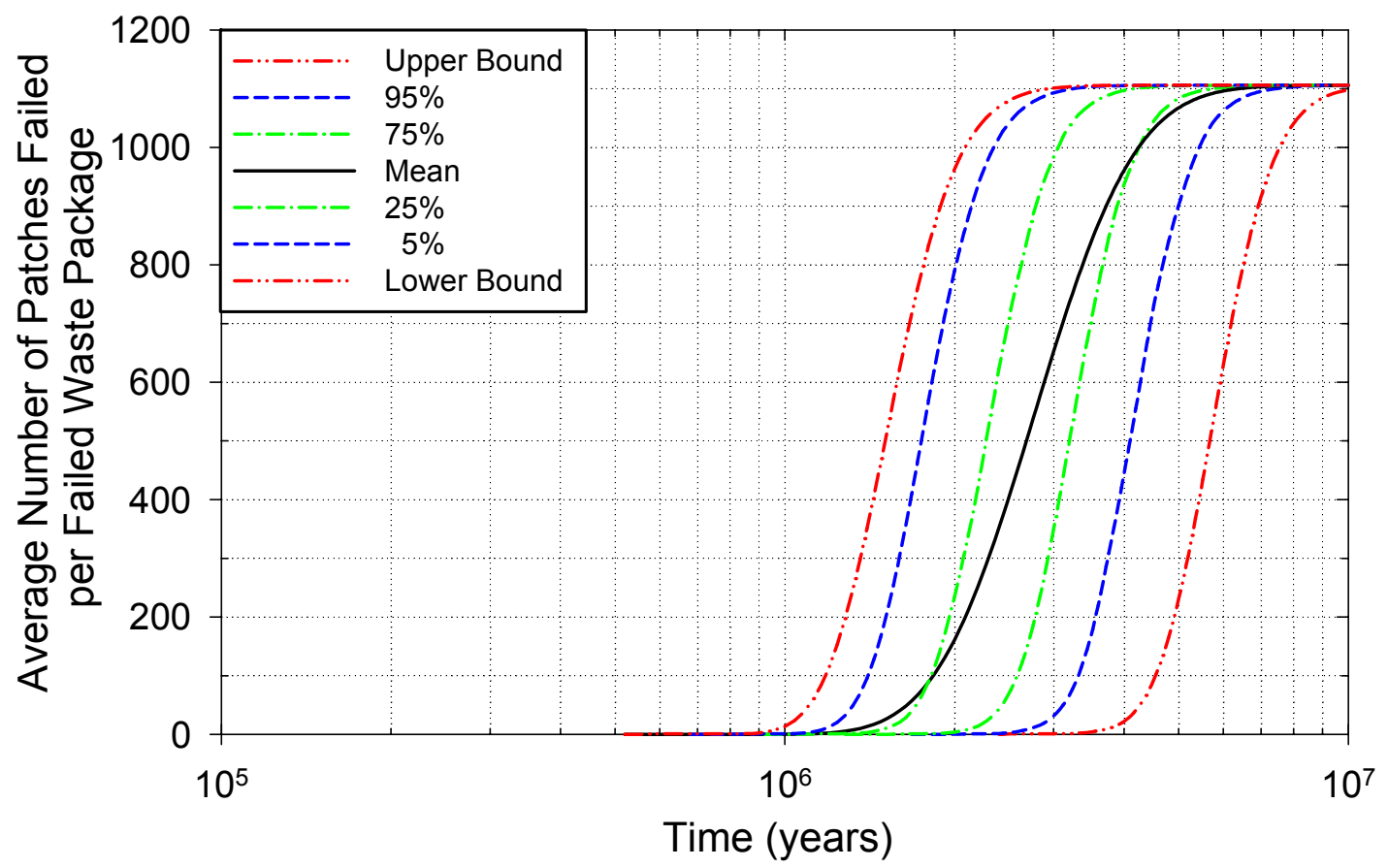

Output DTN: MO0310MWDWAPAN.002.

Figure 33. The Upper- and Lower-Bounds, Mean, and $95^{\text {th }}, 75^{\text {th }}, 25^{\text {th }}$, and $5^{\text {th }}$ Percentile Confidence Intervals of the Average Number of Patch Penetrations per Failed CDSP Waste Package Profile With Time for the IWPD Analysis 


\subsubsection{Number of Drip Shield and Waste Package Pairs Sensitivity Study}

A sensitivity study using various numbers of waste package and drip shield pairs was conducted to determine the appropriate number of waste package and drip shield pairs to use in nominal simulations. Simulations with various numbers of waste package and drip shield patches are not necessary since the analyses in this report have developed a technical basis for the particular choice of the number of patches used in nominal integrated waste package degradation (IWPD) analysis simulations (Section 6.3.4).

The IWPD analysis was executed with 250, 500, 1,000, and 3,400 drip shield and waste package pairs. The mean and $95^{\text {th }}$ percentile waste package first failure curves are shown in Figure 34 for all cases. Figure 34 shows that the IWPD analysis results are not very sensitive to the number of drip shield and waste package pairs simulated over the range investigated. However, it should be noted that the TSPA will use thermal hydrologic history files which differ from those used in these analyses. On this basis, it is recommended that the TSPA use the lesser of the number of drip shield-waste package pairs to be simulated and 500 drip shield-waste package pairs. This choice is obviously appropriate when less than 500 drip shield-waste package pairs are to be simulated and balances the need for accuracy with the need for reasonable execution time when more than 500 drip shield-waste package pairs are to be simulated. In the TSPA, the drip shield and waste package degradation processes will be simulated at the spatial bin/fuel type level. The number of IWPD analysis simulations per TSPA realization depends on the scenario class being run. The IWPD analysis is evaluated twice for each of the five spatially fixed bins, once for the CSNF waste packages in that bin and once for CDSP waste packages. If the spatially fixed bin contains fewer than 500 drip shield-waste package pairs, all CSNF and CDSP drip shield-waste package pairs in the bin should be simulated. If the bin contains more than 500 drip shieldwaste package pairs, then only 500 CSNF and 500 CDSP drip shield-waste package pairs need to be simulated. 


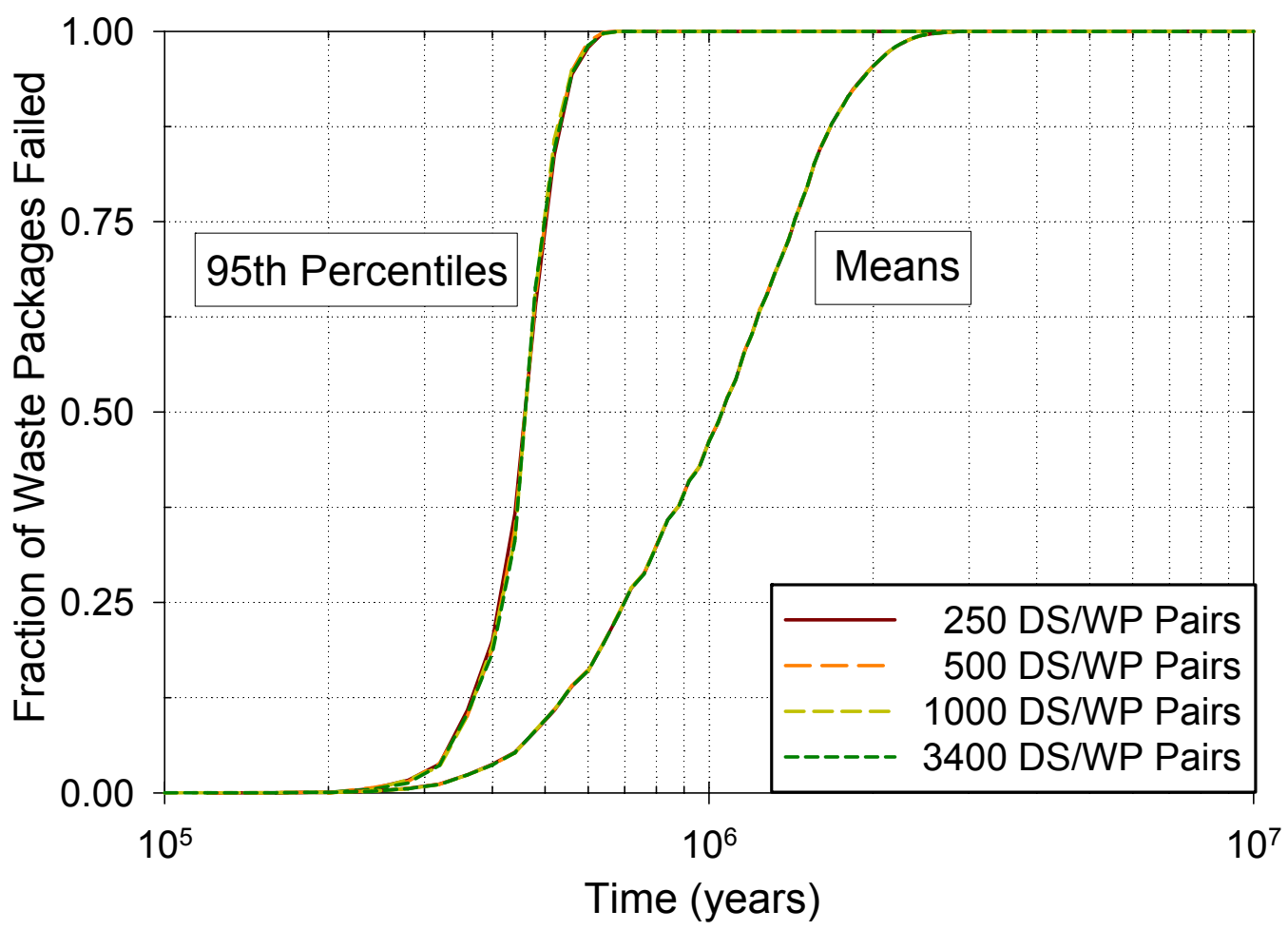

Output DTN: MO0310MWDWAPAN.002.

Figure 34. The 95th Percentile Confidence Intervals and Means Using 250, 500, 1,000, and 3,400 Drip Shield-Waste Package Pairs of the First Breach of CSNF Waste Package Profile With Time for the IWPD Analysis

\subsection{SUMMARY OF BARRIER ANALYSIS}

The reader should note that the results of the analyses documented in Section 6.5 are for illustrative purposes only. The drip shield and waste package degradation profiles presented in this Section 6.5 result from the use of representative thermal hydrologic history files (Section 6.4.5) produced to allow the IWPD analysis to be exercised in this report. The drip shield and waste package degradation profiles, which will be generated in TSPA, will make use of the thermal hydrologic history files appropriate for the repository. Nonetheless, the drip shield and waste package degradation profiles presented in this Section 6.5 provide evidence that the IWPD analysis implementation functions properly.

The effects of igneous and seismic events and localized corrosion on drip shield and waste package performance were not evaluated in this report. 


\section{CONCLUSIONS}

\subsection{ANALYSIS OUTPUTS}

The results of all outputs documented in this report are tracked by DTN: MO0310MWDWAPAN.002. All distributions sampled within GoldSim are uncertainty distributions and all distributions sampled within the WAPDEG DLL are variability distributions.

\subsubsection{Developed Outputs}

The outputs discussed in this section are inputs to the TSPA integrated waste package degradation (IWPD) analysis implementation.

\subsubsection{Nominal Integrated Waste Package Degradation Analysis Outputs}

Since the integrated waste package degradation (IWPD) analysis is implemented directly in the TSPA, the inputs to the IWPD analysis are also inputs to the TSPA. For example, the files identified in the Linked_Files container element (Figure 7), are inputs to the IWPD analysis and must accompany the TSPA Model if the IWPD analysis is to be run properly within the TSPA. Therefore, the files identified in the Linked_Files container element (Figure 7) would also be documented in the TSPA documentation since they serve as inputs to the IWPD analysis component of the larger TSPA Model. The primary outputs of this report are the WAPDEG input vector (Table I-1) and the external input files that must accompany the IWPD analysis GoldSim implementation (Appendix II). In addition, the contents of the IWPD analysis GoldSim implementation are outputs of this report.

The elements in the Linked_Files container element (Figure 7) and their values are listed in Table 26.

Table 26. Contents of Linked_Files Container

\begin{tabular}{|l|l|l|}
\hline \multicolumn{1}{|c|}{ Element Name } & \multicolumn{1}{|c|}{ Description } & \multicolumn{1}{c|}{ Value } \\
\hline WAP_File & List of filenames & WD4DLL.WAP (Appendix II) \\
\hline WDKlinO & Stress intensity vs depth for outer lid & WDKlinO.fil (Appendix II) \\
\hline WDKlinM & Stress intensity vs depth for middle lid & WDKlinM.fil (Appendix II) \\
WDhist & List of T/RH files & $\begin{array}{l}\text { WDenv_00_07wheader.ou } \\
\text { (it is expected that TSPA will generate } \\
\text { their own list of T/RH files) }\end{array}$ \\
\hline LnRo & $\begin{array}{l}\text { Cumulative distribution function for the natural } \\
\text { logarithm of the general corrosion rate for Alloy 22 }\end{array}$ & WDInRGC.cdf (Appendix II) \\
\hline
\end{tabular}

The elements in the GS_Elements container element (Figure 8) and their values are listed in Table 27. 
Table 27. Contents of GS_Elements Container

\begin{tabular}{|l|l|l|}
\hline \multicolumn{1}{|c|}{ Element Name } & \multicolumn{1}{c|}{ Description } & \multicolumn{1}{c|}{ Value } \\
\hline Number_DS_Patches & Number of patches per drip shield & 1 \\
\hline SimTime & Length of Simulation (years) & $1.0 \mathrm{E} 7$ \\
\hline BinStart & Start time for bins (years) & 1,000 \\
\hline NumBins & Number of log-spaced time bins in WAPDEG tables & 300 \\
\hline Cracks_per_Patch_Factor & Number of cracks per patch for middle lid & 15 \\
\hline
\end{tabular}

The GoldSim elements, which do not vary with waste package configuration (i.e., CSNF or CDSP), are treated in separate container elements as illustrated in Figure 10. The elements in Figure 10 and their values are listed in Table 28.

Table 28. Contents of WP_Degradation Container

\begin{tabular}{|l|l|l|}
\hline \multicolumn{1}{|c|}{ Element Name } & \multicolumn{1}{|c|}{ Description } & \multicolumn{1}{c|}{ Value } \\
\hline MIC_A22 & MIC general corrosion enhancement factor & $\begin{array}{l}\text { Uniform between } 1 \\
\text { and 2 }\end{array}$ \\
\hline Gen_Corr_DS (Container) & General corrosion of the Drip Shield & Table 29 \\
\hline $\begin{array}{l}\text { Gen_Corr_WPOB } \\
\text { (Container) }\end{array}$ & General corrosion of the waste package outer barrier & Table 30 \\
\hline CWD (Container) & Closure Weld Defect treatment & Table 31 \\
\hline SCC (Container) & SCC Inputs & Table 32 \\
\hline IWPD_CSNF (Container) & Inputs for CSNF Waste Package analysis & Table 35 \\
\hline $\begin{array}{l}\text { IWPD_CDSP (Container) } \\
\text { (not shown in Figure 10) }\end{array}$ & Inputs for CDSP Waste Package analysis & Table 36 \\
\hline
\end{tabular}

NOTE: See Figure 10

The elements in the Gen_Corr_DS container element (Figure 13) and their values are listed in Table 35 .

Table 29. Contents of the Gen_Corr_DS Container Element

\begin{tabular}{|l|l|l|}
\hline \multicolumn{1}{|c|}{$\begin{array}{c}\text { Element } \\
\text { Name }\end{array}$} & \multicolumn{1}{|c|}{ Description } & Value \\
\hline WDDSOutGC & Outside surface general corrosion rate for Drip Shield & Cumulative distribution function in Table 5 \\
\hline WDDSInGC & Inside surface general corrosion rate for Drip Shield & Cumulative distribution function in Table 4 \\
\hline
\end{tabular}

The elements in the Gen_Corr_WPOB container element (Figure 14) and their values are listed in Table 30.

Table 30. Contents of the Gen_Corr_WPOB Container Element

\begin{tabular}{|l|l|l|}
\hline \multicolumn{1}{|c|}{ Element Name } & \multicolumn{1}{c|}{ Description } & \multicolumn{1}{c|}{ Value } \\
\hline C1_GenCorr_A22 & $\begin{array}{l}\text { Slope term for T-dependent Alloy 22 } \\
\text { general corrosion }\end{array}$ & Table 7 \\
\hline C1divTo_GenCorr_A22 & $\begin{array}{l}\text { Constant term (per realization) for Alloy } \\
\text { 22 general corrosion rate }\end{array}$ & C1_GenCorr_A22/333.15 \\
\hline
\end{tabular}


The elements in the CWD container element (Figure 15) and their values are listed in Table 31.

Table 31. Contents of the CWD Container Element

\begin{tabular}{|l|l|l|}
\hline \multicolumn{1}{|c|}{ Element Name } & \multicolumn{1}{|c|}{ Description } & \multicolumn{1}{c|}{ Value } \\
\hline Thickness_ML & Middle lid thickness (mm) (CWD input) & 10 \\
\hline Thickness_OL & Outer lid thickness (mm) (CWD input) & 25 \\
\hline Defect_Count_Param & $\begin{array}{l}\text { Flaw density parameter (flaws per mm }{ }^{3} \\
\text { of weld) (CWD input) }\end{array}$ & $\begin{array}{l}\text { Gamma distribution with a mean } \\
\text { of 7.5/18610540.3277924 and a } \\
\text { standard deviation of } \\
\text { sqrt(7.5)/18610540.3277924 }\end{array}$ \\
\hline Defect_Size_Param & Flaw size parameter (1/mm) (CWD input) & $\begin{array}{l}\text { Gamma distribution with a mean } \\
\text { of } 7 / 31.75 \text { and a standard } \\
\text { deviation of sqrt(7)/31.75 }\end{array}$ \\
\hline Location_PND & $\begin{array}{l}\text { Characteristic flaw size for NDE PND } \\
\text { (mm) (CWD input) }\end{array}$ & 2.5 \\
\hline Shape_PND & $\begin{array}{l}\text { Shape factor for probability of } \\
\text { nondetection (CWD input) }\end{array}$ & 3 \\
\hline Detection_Thresh_PND & $\begin{array}{l}\text { Lower limit for NDE probability of } \\
\text { nondetection (CWD input) }\end{array}$ & 0.005 \\
\hline Defect_Frac_Orientation & $\begin{array}{l}\text { Fraction of defects capable of } \\
\text { propagation based on orientation }\end{array}$ & 0.008 \\
\hline Defect_Frac_Embedded & $\begin{array}{l}\text { Fraction of embedded manufacturing } \\
\text { defect flaws to propagate }\end{array}$ & 0.25 \\
\hline Defect_Frac & $\begin{array}{l}\text { Fraction of defects capable of } \\
\text { propagation (CWD input) }\end{array}$ & $\begin{array}{l}\text { Defect_Frac_Embedded*Defect_ } \\
\text { Frac_Orientation }\end{array}$ \\
\hline
\end{tabular}

The elements in the SCC container element (Figure 17) and their values are listed in Table 32.

Table 32. Contents of the SCC Container Element

\begin{tabular}{|l|l|l|}
\hline \multicolumn{1}{|c|}{ Element Name } & \multicolumn{1}{|c|}{ Description } & \multicolumn{1}{c|}{ Value } \\
\hline n_SCC & $\begin{array}{l}\text { Stress corrosion cracking growth rate } \\
\text { exponent (repassivation rate) }\end{array}$ & $\begin{array}{l}\text { Truncated normal (at } \pm 2 \text { sd) with a } \\
\text { mean of } 1.304 \text { and sd of } 0.16 .\end{array}$ \\
\hline Abar_SCC & $\begin{array}{l}\text { Stress corrosion cracking growth rate } \\
\text { pre-exponent }\end{array}$ & $\begin{array}{l}(7.8 \mathrm{E}-2)^{*}\left((\mathrm{n} \text { SSCC })^{\wedge} 3.6\right)^{*} \\
\left((4.1 \mathrm{E}-14)^{\wedge}(\mathrm{n} \text { SCC })\right) \\
{ }^{*} 60^{*} 60^{*} 24^{*} 365.25\end{array}$ \\
\hline nbar_SCC & $4^{*} \mathrm{n}$ & $4^{*} \mathrm{n}$ SCC \\
\hline KI_Thresh_SCC & Stress Intensity Factor Threshold & $(7.23 \mathrm{E}-06 / \text { Abar_SCC })^{\wedge}(1 / \mathrm{nbar}$ SCC) \\
\hline Yield_Strength_A22 & Yield Strength of Alloy 22 (MPa) & 285 \\
\hline Stress_Thresh_SCC & $\begin{array}{l}\text { Stress threshold for stress corrosion } \\
\text { cracking nucleation (MPa) }\end{array}$ & $0.9^{*}$ Yield_Strength_A22 \\
\hline $\begin{array}{l}\text { SCC_Outer_Lid } \\
\text { (Container) }\end{array}$ & $\begin{array}{l}\text { Stress corrosion cracking Inputs for } \\
\text { Outer Lid }\end{array}$ & Table 33 \\
\hline $\begin{array}{l}\text { SCC_Middle_Lid } \\
\text { (Container) }\end{array}$ & $\begin{array}{l}\text { Stress corrosion cracking Inputs for } \\
\text { Middle Lid }\end{array}$ & Table 34 \\
\hline
\end{tabular}

The elements in the SCC_Outer_Lid container element (Figure 18) and their values are listed in Table 33. 
Table 33. Contents of the SCC_Outer_Lid Container Element

\begin{tabular}{|c|c|c|}
\hline Element Name & Description & Value \\
\hline z_OL & $\begin{array}{l}\text { Uncertain deviation from median yield } \\
\text { strength range for outer lid (SCCD input) }\end{array}$ & $\begin{array}{l}\text { Truncated normal (at } \pm 3 \mathrm{sd} \text { ) with a } \\
\text { mean of } 0 \text { and sd of } 1\end{array}$ \\
\hline Num_Angles_OL & $\begin{array}{l}\text { Number of angles at which stress } \\
\text { intensity factor will be evaluated for outer } \\
\text { lid (SCCD input) }\end{array}$ & 5 \\
\hline KI_inp_OL & $\begin{array}{l}\text { Line number in WD4DLL.WAP file of the } \\
\text { stress intensity factor (KI) versus depth } \\
\text { profiles for the outer lid (WDKlinO.fil) } \\
\text { (SCCD input) }\end{array}$ & 4 \\
\hline sinf_OL & $\begin{array}{l}\text { Sine of the angle of projection that the } \\
\text { crack path makes with the outer lid } \\
\text { normal (SCCD input) }\end{array}$ & 1 \\
\hline $\mathrm{A} 0 \_\mathrm{OL}$ & Outer lid stress coefficient (SCCD input) & -292.607 \\
\hline A1_OL & Outer lid stress coefficient (SCCD input) & 178.277 \\
\hline $\mathrm{A} 2 \_\mathrm{OL}$ & Outer lid stress coefficient (SCCD input) & -14.135 \\
\hline A3_OL & Outer lid stress coefficient (SCCD input) & 0.320 \\
\hline fys_OL & $\begin{array}{l}\text { Outer lid yield strength scaling factor } \\
\text { (SCCD input) }\end{array}$ & 0.15 \\
\hline amp_OL & $\begin{array}{l}\text { Amplitude of the stress variation with } \\
\text { angle, for the outer lid (SCCD input) }\end{array}$ & 17.236893 \\
\hline KI_out_OL & $\begin{array}{l}\text { Line number in WD4DLL.WAP file of the } \\
\text { filename outer lid KI vs depth profile } \\
\text { (SCCD output, WAPDEG input) }\end{array}$ & 6 \\
\hline Stress_out_OL & $\begin{array}{l}\text { Line number in WD4DLL.WAP file of the } \\
\text { filename for outer lid stress vs depth } \\
\text { profile (SCCD output, WAPDEG input) }\end{array}$ & 7 \\
\hline Model_Number_OL & $\begin{array}{l}\text { SCC uncertainty model number for outer } \\
\text { lid (SCCD input) }\end{array}$ & 1 \\
\hline
\end{tabular}

The elements in the SCC_Middle_Lid container element and their values are listed in Table 34. 
Table 34. Contents of the SCC_Middle_Lid Container Element

\begin{tabular}{|c|c|c|}
\hline Element Name & Description & Value \\
\hline z_ML & $\begin{array}{l}\text { Uncertain deviation from median yield } \\
\text { strength range for middle lid (SCCD input) }\end{array}$ & $\begin{array}{l}\text { Truncated normal (at } \pm 3 \mathrm{sd} \text { ) with a } \\
\text { mean of } 0 \text { and sd of } 1\end{array}$ \\
\hline Num_Angles_ML & $\begin{array}{l}\text { Number of angles at which stress intensity } \\
\text { factor will be evaluated for middle lid } \\
\text { (SCCD input) }\end{array}$ & 5 \\
\hline KI_inp_ML & $\begin{array}{l}\text { Line number in WD4DLL.WAP file of the } \\
\text { stress intensity factor (KI) versus depth } \\
\text { profiles for the middle lid (WDKlinO.fil) } \\
\text { (SCCD input) }\end{array}$ & 5 \\
\hline sinf_ML & $\begin{array}{l}\text { Sine of the angle of projection that the } \\
\text { crack path makes with the middle lid } \\
\text { normal (SCCD input) }\end{array}$ & 1 \\
\hline $\mathrm{A} 0 \_\mathrm{ML}$ & Middle lid stress coefficient (SCCD input) & 219.908 \\
\hline A1_ML & Middle lid stress coefficient (SCCD input) & 56.494 \\
\hline $\mathrm{A} 2 \_\mathrm{ML}$ & Middle lid stress coefficient (SCCD input) & -20.848 \\
\hline A3_ML & Middle lid stress coefficient (SCCD input) & 1.083 \\
\hline fys_ML & $\begin{array}{l}\text { Middle lid yield strength scaling factor } \\
\text { (SCCD input) }\end{array}$ & 0.15 \\
\hline amp_ML & $\begin{array}{l}\text { Amplitude of the stress variation with } \\
\text { angle, for the middle lid (SCCD input) }\end{array}$ & 17.236893 \\
\hline KI_out_ML & $\begin{array}{l}\text { Line number in WD4DLL.WAP file of the } \\
\text { filename outer lid KI vs depth profile } \\
\text { (SCCD output, WAPDEG input) }\end{array}$ & 8 \\
\hline Stress_out_ML & $\begin{array}{l}\text { Line number in WD4DLL.WAP file of the } \\
\text { filename for middle lid stress vs depth } \\
\text { profile (SCCD output, WAPDEG input) }\end{array}$ & 9 \\
\hline Model_Number_ML & $\begin{array}{l}\text { SCC uncertainty model number for middle } \\
\text { lid (SCCD input) }\end{array}$ & 1 \\
\hline
\end{tabular}

The elements in the IWPD_CSNF container element (Figure 9) and their values are listed in Table 35.

Table 35. Contents of IWPD_CSNF Container

\begin{tabular}{|c|c|c|}
\hline Element Name & Description & Value \\
\hline Hist_Index_CSNF & $\begin{array}{l}\text { Line number in WD4DLL.WAP file of the } \\
\text { filename for the thermal hydrologic and } \\
\text { chemistry time history file }\end{array}$ & 1 \\
\hline WDSeed_CSNF & WAPDEG Seed CSNF & $\begin{array}{l}\text { Uniform between } 1 \\
\text { and } 2^{31}-1\end{array}$ \\
\hline NumPak_CSNF & Number of CSNF waste packages & $\begin{array}{l}\text { Expected to be set } \\
\text { by TSPA }\end{array}$ \\
\hline CWD_CSNF (Container) & $\begin{array}{l}\text { Closure weld defects treatment for CSNF } \\
\text { Waste Packages }\end{array}$ & See Table 37 \\
\hline WAPDEG_Inputs_CSNF & Input vector to WAPDEG.DLL CSNF & $\begin{array}{l}\text { See Appendix I, } \\
\text { Table I-1 }\end{array}$ \\
\hline
\end{tabular}

The elements in the IWPD_CDSP container element and their values are listed in Table 36. 
Table 36. Contents of IWPD_CDSP Container Element

\begin{tabular}{|l|l|l|}
\hline \multicolumn{1}{|c|}{ Element Name } & \multicolumn{1}{c|}{ Description } & \multicolumn{1}{c|}{ Value } \\
\hline Hist_Index_CDSP & $\begin{array}{l}\text { Line number in WD4DLL.WAP file of the } \\
\text { filename for the thermal hydrologic and } \\
\text { chemistry time history file }\end{array}$ & 1 \\
\hline WDSeed_CDSP & WAPDEG Seed CDSP & $\begin{array}{l}\text { Uniform between } 1 \\
\text { and } 2^{31}-1\end{array}$ \\
\hline NumPak_CDSP & Number of CDSP waste packages & $\begin{array}{l}\text { Expected to be set } \\
\text { by TSPA }\end{array}$ \\
\hline CWD_CDSP (Container) & Closure weld defects treatment for CDSP & See Table 38 \\
\hline WAPDEG_Inputs_CDSP & Input vector to WAPDEG.DLL CDSP & $\begin{array}{l}\text { See Appendix I, } \\
\text { Table I-1 }\end{array}$ \\
\hline
\end{tabular}

The elements in the CWD_CSNF container element (Figure 16) and their values are listed in Table 37.

Table 37. Contents of CWD_CSNF Container Element

\begin{tabular}{|l|l|l|}
\hline \multicolumn{1}{|c|}{ Element Name } & \multicolumn{1}{|c|}{ Description } & \multicolumn{1}{|c|}{ Value } \\
\hline Vol_Weld_OL_CSNF & $\begin{array}{l}\text { Volume of outer lid weld for CSNF Waste } \\
\text { Packages (CWD input) }\left(\mathrm{mm}^{3}\right)\end{array}$ & $1,350,189$ \\
\hline Defect_Num_OL_CSNF & $\begin{array}{l}\text { Line number in WD4DLL.WAP file of the filename } \\
\text { for CDF of the number of outer lid manufacturing } \\
\text { defect flaws for CSNF Waste Packages (CWD } \\
\text { output) }\end{array}$ & 10 \\
\hline Defect_Size_OL_CSNF & $\begin{array}{l}\text { Line number in WD4DLL.WAP file of the filename } \\
\text { for CDF of the length of outer lid manufacturing } \\
\text { defect flaws for CSNF Waste Packages (CWD } \\
\text { output) }\end{array}$ & 11 \\
\hline Vol_Weld_ML_CSNF & $\begin{array}{l}\text { Volume of middle lid weld for CSNF Waste } \\
\text { Packages (CWD input) (mm }{ }^{3} \text { ) }\end{array}$ & 490,478 \\
\hline Defect_Num_ML_CSNF & $\begin{array}{l}\text { Line number in WD4DLL.WAP file of the filename } \\
\text { for CDF of the number of middle lid manufacturing } \\
\text { defect flaws for CSNF Waste Packages (CWD } \\
\text { output) }\end{array}$ & 12 \\
\hline Defect_Size_ML_CSNF & $\begin{array}{l}\text { Line number in WD4DLL.WAP file of the filename } \\
\text { for CDF of the length of middle lid manufacturing } \\
\text { defect flaws for CSNF Waste Packages (CWD } \\
\text { output) }\end{array}$ & 13 \\
\hline
\end{tabular}

The elements in the CWD_CDSP container element and their values are listed in Table 38. 
Table 38. Contents of CWD_CDSP Container Element

\begin{tabular}{|l|l|l|}
\hline \multicolumn{1}{|c|}{ Element Name } & \multicolumn{1}{|c|}{ Description } & \multicolumn{1}{|c|}{ Value } \\
\hline Vol_Weld_OL_CDSP & $\begin{array}{l}\text { Volume of outer lid weld for CDSP Waste } \\
\text { Packages (CWD input) (mm^3) }\end{array}$ & $1,753,091$ \\
\hline Defect_Num_OL_CDSP & $\begin{array}{l}\text { Line number in WD4DLL.WAP file of the } \\
\text { filename for CDF of the number of outer } \\
\text { lid manufacturing defect flaws for CDSP } \\
\text { Waste Packages (CWD output) }\end{array}$ & 14 \\
\hline Defect_Size_OL_CDSP & $\begin{array}{l}\text { Line number in WD4DLL.WAP file of the } \\
\text { filename for CDF of the length of outer lid } \\
\text { manufacturing defect flaws for CDSP } \\
\text { Waste Packages (CWD output) }\end{array}$ & 15 \\
\hline Vol_Weld_ML_CDSP & $\begin{array}{l}\text { Volume of middle lid weld for CDSP } \\
\text { Waste Packages (CWD input) (mm }{ }^{3} \text { ) }\end{array}$ & 639,901 \\
\hline Defect_Num_ML_CDSP & $\begin{array}{l}\text { Line number in WD4DLL.WAP file of the } \\
\text { filename for CDF of the number of } \\
\text { middle lid manufacturing defect flaws for } \\
\text { CDSP Waste Packages (CWD output) }\end{array}$ & 16 \\
\hline Defect_Size_ML_CDSP & $\begin{array}{l}\text { Line number in WD4DLL.WAP file of the } \\
\text { filename for CDF of the length of middle } \\
\text { lid manufacturing defect flaws for CDSP } \\
\text { Waste Packages (CWD output) }\end{array}$ & 17 \\
\hline
\end{tabular}

It is recommended that the WAPDEG DLL be called twice (i.e., once each for CSNF and for CDSP waste packages) for each region of the repository (i.e., each unique set of thermal hydrologic history files) to be simulated. The input to the WAPDEG DLL consists of the elements in the IWPD_CSNF (Figure 9) (or IWPD_CDSP) container element and the external files created by calls to the CWD DLL (for outer lid of CSNF waste packages: WDCWDNDO_CSNF.cdf and WDCWDSizeO_CSNF.cdf; for middle lid of CSNF waste packages: WDCWDNDM_CSNF.cdf and WDCWDSizeM_CSNF.cdf; for outer lid of CDSP waste packages: WDCWDNDO_CDSP.cdf and WDCWDS̄izeO_CDSP.cdf; for middle lid of CDSP waste packages: WDCWDNDM_CDSP.cdf and WDCWDSizeM_CDSP.cdf) and SCCD DLL (for outer lid: WDKISCCO.fil and WDStressO.fil; for middle lid: WDKISCCM.fil and WDStressM.fil).

\subsubsection{Waste Package Early Failure Analysis Outputs}

An implementation of the waste package early failure analysis involves the full uncertainty and variability specification as outlined in Section 4.1.8 and developed in Section 6.3.8. Alternatively, use of the marginal probability distribution, developed in Section 6.4.12, allows results to be used in a conditional or stratified approach, which allows for computational efficiencies. 
Table 39. Waste Package Early Failure Parameters and Their Sources

\begin{tabular}{|c|c|c|c|}
\hline Parameter Name & Parameter Source & Parameter Value & Units \\
\hline $\begin{array}{l}\text { Num_Pak_EF } \\
\text { Number of packages } \\
\text { considered }\end{array}$ & $\begin{array}{l}\text { This is a TSPA parameter to } \\
\text { be specified by TSPA at } \\
\text { runtime }\end{array}$ & $\begin{array}{l}\text { e.g., } 11,184 \text { (representative } \\
\text { value, see discussion under } \\
\text { Parameter Source) }\end{array}$ & $\mathrm{N} / \mathrm{A}$ \\
\hline $\begin{array}{l}\text { U_EF_Mean } \\
\text { Evaluation probability per } \\
\text { WP (Uncertain Poisson } \\
\text { intensity) }\end{array}$ & This report (Section 6.3.8) & $\begin{array}{l}\text { Log normal distribution with a } \\
\text { geometric mean of } 7.2 \times 10^{-6} \\
\text { and a geometric sd of } 15^{(1 / 1.645)} \\
\text { truncated at an upper-bound of } \\
7.44213 \times 10^{-3}\end{array}$ & $\begin{array}{l}\text { per Waste } \\
\text { Package }\end{array}$ \\
\hline $\begin{array}{l}\text { NumEFPaks } \\
\text { Number of Early Failed WP } \\
\text { in the realization }\end{array}$ & $\begin{array}{l}\text { BSC } 2004 \text { [DIRS 170024], } \\
\text { Section } 7, \text { Table } 22\end{array}$ & $\begin{array}{l}\text { Poisson distribution with } \\
\text { intensity } \\
\text { Num_Pak_EF*U_EF_Mean }\end{array}$ & $\begin{array}{l}\text { number of waste } \\
\text { packages per } \\
\text { realization }\end{array}$ \\
\hline $\begin{array}{l}\text { Fractional_EF } \\
\text { Fraction of Early Failed WP } \\
\text { in the realization }\end{array}$ & This report (Section 6.4.12) & NumEFPaks/Num_Pak_EF & $\begin{array}{l}\text { fraction of waste } \\
\text { packages per } \\
\text { realization }\end{array}$ \\
\hline
\end{tabular}

Table 40. Early Failure Waste Package Unconditional Probability Values

\begin{tabular}{|c|c|}
\hline $\begin{array}{c}\mathbf{n} \\
\text { (Number of Waste } \\
\text { Packages) }\end{array}$ & $\mathbf{p}(\mathbf{n})$ \\
\hline 0 & 0.830177156 \\
\hline 1 & 0.114170546 \\
\hline 2 & 0.029481907 \\
\hline$\geq 3$ & 0.026170391 \\
\hline
\end{tabular}

Table 41. Early Failure Waste Package Conditional Probability Density Function

\begin{tabular}{|c|c|}
\hline Conditional Probability & $\begin{array}{c}\text { Number of Waste } \\
\text { Packages }\end{array}$ \\
\hline $6.72292043249447 \mathrm{E}-01$ & 1 \\
\hline $1.73603896475176 \mathrm{E}-01$ & 2 \\
\hline $6.62102251738378 \mathrm{E}-02$ & 3 \\
\hline $3.16781457051218 \mathrm{E}-02$ & 4 \\
\hline $1.74664265480460 \mathrm{E}-02$ & 5 \\
\hline $1.05986309693713 \mathrm{E}-02$ & 6 \\
\hline $6.88874646926455 \mathrm{E}-03$ & 7 \\
\hline $4.71473222137090 \mathrm{E}-03$ & 8 \\
\hline $3.35923480253975 \mathrm{E}-03$ & 9 \\
\hline $2.47181818957650 \mathrm{E}-03$ & 10 \\
\hline $1.86749677986347 \mathrm{E}-03$ & 11 \\
\hline $1.44237040765972 \mathrm{E}-03$ & 12 \\
\hline $1.13503969252866 \mathrm{E}-03$ & 13 \\
\hline $9.07649803289940 \mathrm{E}-04$ & 14 \\
\hline $7.36008651370934 \mathrm{E}-04$ & 15 \\
\hline $6.04171817640069 \mathrm{E}-04$ & 16 \\
\hline $5.01345905459817 \mathrm{E}-04$ & 17 \\
\hline $4.20051218756154 \mathrm{E}-04$ & 18 \\
\hline $3.54995977674767 \mathrm{E}-04$ & 19 \\
\hline
\end{tabular}


Table 41. Early Failure Waste Package Conditional Probability Density Function (Continued)

\begin{tabular}{|c|c|}
\hline Conditional Probability & $\begin{array}{c}\text { Number of Waste } \\
\text { Packages }\end{array}$ \\
\hline $3.02366678546451 E-04$ & 20 \\
\hline 2.59369367847244E-04 & 21 \\
\hline 2.23926363184013E-04 & 22 \\
\hline 1.94471645187147E-04 & 23 \\
\hline 1.69810267359572E-04 & 24 \\
\hline 1.49020132777530E-04 & 25 \\
\hline 1.31382319712795E-04 & 26 \\
\hline 1.16330965064662E-04 & 27 \\
\hline $1.03416750621992 E-04$ & 28 \\
\hline 9.22799833021864E-05 & 29 \\
\hline 8.26305297934502E-05 & 30 \\
\hline 7.42327072291007E-05 & 31 \\
\hline 6.68937973539920E-05 & 32 \\
\hline 6.04552375285604E-05 & 33 \\
\hline 5.47858084815550E-05 & 34 \\
\hline 4.97763250833152E-05 & 35 \\
\hline 4.53354681692636E-05 & 36 \\
\hline 4.13864895817636E-05 & 37 \\
\hline 3.78645905269958E-05 & 38 \\
\hline 3.47148228178331E-05 & 39 \\
\hline 3.18903989250389E-05 & 40 \\
\hline $2.93513236906451 \mathrm{E}-05$ & 41 \\
\hline 2.70632806669899E-05 & 42 \\
\hline 2.49967211722396E-05 & 43 \\
\hline 2.31261156125399E-05 & 44 \\
\hline 2.14293353591146E-05 & 45 \\
\hline 1.98871401733203E-05 & 46 \\
\hline 1.84827513472259E-05 & 47 \\
\hline 1.72014947430197E-05 & 48 \\
\hline $1.60305010475418 \mathrm{E}-05$ & 49 \\
\hline $1.49584530155581 \mathrm{E}-05$ & 50 \\
\hline 1.39753714138465E-05 & 51 \\
\hline 1.30724329177318E-05 & 52 \\
\hline 1.22418144452487E-05 & 53 \\
\hline 1.14765594142005E-05 & 54 \\
\hline 1.07704622310122E-05 & 55 \\
\hline 1.01179680120012E-05 & 56 \\
\hline 9.51408513147726E-06 & 57 \\
\hline 8.95430871137521E-06 & 58 \\
\hline 8.43455362935730E-06 & 59 \\
\hline 7.95109603336955E-06 & 60 \\
\hline 7.50052270944795E-06 & 61 \\
\hline
\end{tabular}


Table 41. Early Failure Waste Package Conditional Probability Density Function (Continued)

\begin{tabular}{|c|c|}
\hline Conditional Probability & $\begin{array}{c}\text { Number of Waste } \\
\text { Packages }\end{array}$ \\
\hline 7.07968794836482E-06 & 62 \\
\hline 6.68567778292314E-06 & 63 \\
\hline 6.31578160673403E-06 & 64 \\
\hline 5.96747122389443E-06 & 65 \\
\hline 5.63838730892199E-06 & 66 \\
\hline 5.32633307799113E-06 & 67 \\
\hline 5.02927469761981E-06 & 68 \\
\hline $4.74534760973451 \mathrm{E}-06$ & 69 \\
\hline 4.47286756875376E-06 & 70 \\
\hline 4.21034481259677E-06 & 71 \\
\hline 3.95649947572606E-06 & 72 \\
\hline 3.71027614758051E-06 & 73 \\
\hline 3.47085542520984E-06 & 74 \\
\hline 3.23766043150573E-06 & 75 \\
\hline 3.01035657795550E-06 & 76 \\
\hline 2.78884332947732E-06 & 77 \\
\hline $2.57323734345134 \mathrm{E}-06$ & 78 \\
\hline $2.36384705234588 \mathrm{E}-06$ & 79 \\
\hline $2.16113947409198 \mathrm{E}-06$ & 80 \\
\hline $1.96570069703811 \mathrm{E}-06$ & 81 \\
\hline 1.77819203158221E-06 & 82 \\
\hline $1.59930419528470 \mathrm{E}-06$ & 83 \\
\hline $1.42971206779268 \mathrm{E}-06$ & 84 \\
\hline 1.27003250396409E-06 & 85 \\
\hline 1.12078743904329E-06 & 86 \\
\hline 9.82374090487728E-07 & 87 \\
\hline $8.55043505290756 \mathrm{E}-07$ & 88 \\
\hline 7.38888077500076E-07 & 89 \\
\hline 6.33838028935228E-07 & 90 \\
\hline 5.39666263494115E-07 & 91 \\
\hline 4.56000518554527E-07 & 92 \\
\hline 3.82341378459289E-07 & 93 \\
\hline 3.18084501625250E-07 & 94 \\
\hline $2.62545345353809 \mathrm{E}-07$ & 95 \\
\hline 2.14984738019739E-07 & 96 \\
\hline 1.74633823455080 E-07 & 97 \\
\hline $1.40717156867760 \mathrm{E}-07$ & 98 \\
\hline 1.12473032823898E-07 & 99 \\
\hline 8.91704420953614E-08 & 100 \\
\hline 7.01223580113182E-08 & 101 \\
\hline 5.46953228642639E-08 & 102 \\
\hline 4.23155263966068E-08 & 103 \\
\hline
\end{tabular}


Table 41. Early Failure Waste Package Conditional Probability Density Function (Continued)

\begin{tabular}{|c|c|}
\hline Conditional Probability & $\begin{array}{c}\text { Number of Waste } \\
\text { Packages }\end{array}$ \\
\hline $3.24717339289036 \mathrm{E}-08$ & 104 \\
\hline $2.47155300757037 \mathrm{E}-08$ & 105 \\
\hline $1.86593991019425 \mathrm{E}-08$ & 106 \\
\hline $1.39731722870978 \mathrm{E}-08$ & 107 \\
\hline $1.03793457798317 \mathrm{E}-08$ & 108 \\
\hline $7.64771967930777 \mathrm{E}-09$ & 109 \\
\hline $5.58974043798139 \mathrm{E}-09$ & 110 \\
\hline $4.05285294051235 \mathrm{E}-09$ & 111 \\
\hline
\end{tabular}

\subsection{SUMMARY}

A nominal case analysis of degradation of drip shield and waste package in the Yucca Mountain repository was presented, incorporating the data and analyses of the individual degradation processes documented in the companion process-level reports (BSC 2004 [DIRS 169985]; BSC 2004 [DIRS 169984]; BSC 2004 [DIRS 169845]). The IWPD analysis was conducted to provide the TSPA with inputs and methodologies, which are used to evaluate waste package and drip shield degradation as a function of exposure time under exposure conditions anticipated in the repository.

It should be noted that the results of the analyses documented in Section 6.5 are for illustrative purposes only. The drip shield and waste package degradation profiles presented in Section 6.5 result from the use of representative thermal hydrologic history files (Section 6.4.5) produced to allow the IWPD analysis to be exercised in this report. The drip shield and waste package degradation profiles, which will be used in the TSPA-LA will make use of the thermal hydrologic history files appropriate for the repository. The drip shield and waste package degradation profiles presented in this Section 6.5 provide evidence that the IWPD analysis implementation functions properly.

The waste package and drip shield degradation analyses documented in this report have shown that based on the current general corrosion and stress corrosion cracking analysis, neither the drip shields nor the waste packages fail within the regulatory time period (10,000 years). The effects of igneous and seismic events and localized corrosion on drip shield and waste package performance were not evaluated in this report. Both the drip shield and waste package degrade by general corrosion at very low passive dissolution rates. The current experimental data and detailed process-level analyses, upon which the IWPD Analyses are based, are consistent with this conclusion. With the exception of early failure processes (Section 6.3.8), only the closurelid welds of the waste package, for which complete stress mitigation may not be possible, are subject to rapidly penetrating corrosion modes under repository conditions (BSC 2004 [DIRS 169985]). Because of potential residual stresses, the closure-lid welds would be subject to stress corrosion cracking.

A dual closure-lid design for the waste package outer barrier is used, and stress mitigation techniques is used on the outer closure lid weld region. The analyses in this report show that the hoop stress (driving radial cracks) is the dominant stress in the closure-lid welds that causes 
stress corrosion cracking failure of waste package. The analyses also show that stress mitigation techniques achieve a substantial stress relief for the closure-lid welds (BSC 2004 [DIRS 169985]).

\subsection{YUCCA MOUNTAIN REVIEW PLAN CRITERIA}

Yucca Mountain Review Plan, Final Report (YMRP) (NRC 2003 [DIRS 163274]) contains Acceptance Criteria that are intended to establish the basis for the review of the material contained in the License Application. As this report serves, in part, as the basis for the License Application, it is important to show how the information contained herein addresses each of the applicable YMRP Acceptance Criteria.

The drip shield limits the water contacting the waste package and the water available for advective transport through the waste package and drift invert. The waste package limits the water contacting the waste form. Therefore, the drip shield and waste package must help meet criteria specific to Technical Work Plan For: Regulatory Integration Modeling and Analysis of the Waste Form and Waste Package (BSC 2004 [DIRS 171583]), which has identified acceptance criteria (AC) based on the requirements mentioned in Project Requirements Document (Canori and Leitner 2003 [DIRS 166275]) and Yucca Mountain Review Plan, Final Report (NRC 2003 [DIRS 163274]).

\subsubsection{System Description and Demonstration of Multiple Barriers}

For the Yucca Mountain Review Plan criterion entitled System Description and Demonstration of Multiple Barriers (NRC 2003 [DIRS 163274], Section 2.2.1.1.3; Canori and Leitner 2003 [DIRS 166275], PRD-002/T-014, PRD-002/T-016), the acceptance criteria (AC) AC1, AC2, and AC3 do not apply because the purpose of this report is not to describe the performance of the barriers but to describe the analysis process as used by TSPA-LA. The barriers are adequately identified and described in Sections 4.1, 6.1, and 6.3.

\subsubsection{Degradation of Engineered Barriers}

For the Yucca Mountain Review Plan criterion entitled Degradation of Engineered Barriers (NRC 2003 [DIRS 163274], Section 2.2.1.3.1.3; Canori and Leitner 2003 [DIRS 166275], PRD-002/T-015), the following acceptance criteria (AC) were addressed:

\section{AC 1 - System Description and Model Integration are Adequate}

(1) TSPA adequately incorporates important design features, physical phenomena and couplings and uses consistent assumptions throughout the degradation of engineered barriers abstraction process;

(2) Abstraction uses assumptions, technical bases, data and models that are appropriate and consistent with [those used] in other abstractions.

(3) The descriptions of the engineered barriers, design features, degradation processes, physical phenomena, and couplings that may affect the degradation of the engineered barriers are adequate. 
(4) Initial and boundary conditions are propagated consistently throughout the abstraction process.

(5) Sufficient technical basis for the inclusion and exclusion of FEPs are provided;

(6) Adequate technical bases are provided, for selecting the design criteria, that mitigate any potential impact of in-package criticality on repository performance, including considering all features, events, and processes that may increase the reactivity of the system inside the waste package.

(7) Guidance in NUREG 1297 and NUREG 1298 [re: Expert Elicitation] are followed.

The drip shield and waste package barriers that this report addresses are described in Sections 4.1 and 6.6. This report documents how important design features, physical phenomena and couplings, and consistent assumptions are incorporated throughout the degradation of engineered barriers analysis process are incorporated into the total system performance. assessment. Adequate description of the engineered barriers, design features, physical phenomena and couplings are addressed in Section 6.3. Assumptions used are identified in Section 5 and are consistent with those used in other abstractions. A description of how these elements are incorporated into the total system performance assessment is presented in Section 6.4 and analyses of (illustrative) results are presented in Section 6.5. The models and analyses used in this report are implemented in a manner consistent with their sources (BSC 2004 [DIRS 169845]; BSC 2004 [DIRS 169984]; BSC 2004 [DIRS 169985]; BSC 2004 [DIRS 170024]) and all initial and boundary conditions identified in these sources as described in Section 6.3.

The features, events, and processes (FEPs) treated in this report are identified in Section 6.2. Sufficient technical basis for the inclusion of FEPs are provided in Section 6.3 as part of the conceptual discussion for drip shield and waste package degradation. See also DTN: MO0407SEPFEPLA.000 [DIRS 170760] for a description of these FEPs and FEPs Screening of Processes and Issues in Drip Shield and Waste Package Degradation (BSC 2004 [DIRS 169997]) for a complete list of all FEPs related to waste package and drip shield degradation.

Those sections of the acceptance criterion that relate to the selection of design criteria are not applicable to this report because design criteria are not selected in this report. Those sections of the acceptance criterion that relate to the use of expert elicitation are not applicable to this report because expert elicitation was not used in this report.

\section{AC 2 - Data Are Sufficient for Model Justification}

(1) Parameters used to evaluate the degradation of EBS are adequately justified;

(2) Sufficient data have been collected to establish initial and boundary conditions; 
(3) Data on the degradation of the engineered barriers (e.g. - general and localized corrosion, microbially induced corrosion, galvanic interactions, hydrogen embrittlement and phase stability) are based on laboratory measurements, site-specific field measurements, industrial and/or natural analogs and tests designed to replicate anticipated conditions. As appropriate, sensitivity or uncertainty analyses are provided and are shown to be adequate.

(4) Degradation models for the applicable processes are adequate. For example, general and localized corrosion, microbially induced corrosion, galvanic interactions, hydrogen embrittlement and phase stability are given appropriate consideration and treatment.

The data used in the IWPD analysis are adequately justified in Section 4.1. The models and analyses used in this report (BSC 2004 [DIRS 169845]; BSC 2004 [DIRS 169984]; BSC 2004 [DIRS 169985]; BSC 2004 [DIRS 170024]) were developed based on laboratory measurements, site-specific field measurements, industrial and/or natural analogs and tests designed to replicate anticipated conditions sufficient to establish initial and boundary conditions. The degradation models for applicable processes are validated for their intended use (this analysis) in their respective reports. These data were sufficient to develop the integrated waste package degradation (IWPD) analysis described in Sections 6.3 and 6.4. The data and parameters result from activities conducted under a quality assurance program. On this basis, the data used are sufficient for justification of the IWPD analysis.

\section{AC 3 - Data Uncertainty is Characterized and Propagated Through The Model Abstraction}

(1) Models use parameter values, assumed ranges, probability distributions and/or bounding assumptions that are technically defensible, reasonably account for uncertainties and variabilities, and do not result in under-representation of the risk estimate.

(2) Appropriate parameters, based on techniques that may include laboratory experiments, field measurements, and industrial analogs are used.

(3) Assumed range of values and probability distributions for parameters used in conceptual and process-level models are not likely to underestimate the actual degradation and failure of engineered barriers.

(4) Appropriate methods of NDE of fabricated-engineered barriers are used to assess the type, size and location of fabrication defects that may lead to premature failure of engineered barriers.

(5) Where sufficient data do not exist, the definition of parameter values and conceptual models is based on appropriate use of other sources, such as expert elicitation.

The models and analyses used in this report (BSC 2004 [DIRS 169845]; BSC 2004 [DIRS 169984]; BSC 2004 [DIRS 169985]; BSC 2004 [DIRS 170024]) were developed based 
on laboratory measurements, industrial and/or natural analogs and tests designed to replicate anticipated conditions. The degradation models for applicable processes are validated for their intended use (this analysis) in their respective reports. The models used in this analysis make use of parameter values, assumed ranges, probability distributions or bounding assumptions that are technically defensible, reasonably account for uncertainties and variabilities, and do not result in under-representation of the risk estimate. The uncertainties in the parameter ranges and uncertainty distributions in the models used in this report are discussed in Sections 4.1 and 6.3. The uncertainty distributions are implemented in Section 6.4. The effect of uncertainty on (illustrative) analysis results are presented in Section 6.5.

The uncertainty treatments in this analysis do not result in under-representation of the risk estimate. The rationale for this statement is discussed below:

- The analysis does not make use of a relative humidity threshold for corrosion initiation (i.e., corrosion is allowed to occur at any exposure relative humidity) although a relative humidity threshold for corrosion initiation clearly exists (ASM International 1987 [DIRS 133378, p. 82). Use of a relative humidity threshold would delay the start time for corrosion processes.

- In this report (Section 6.3), the only performance credit taken for the Stainless Steel Type 316 inner vessel is for the structural support it provides to the waste package outer barrier before waste package breach. Although the waste package inner vessel would also provide some performance for waste containment and potentially act as a barrier to radionuclide transport after waste package outer barrier breach, the potential performance of this barrier is far less than that of the more corrosion resistant Alloy 22 waste package outer barrier. For this reason, the corrosion performance of the waste package inner vessel is conservatively ignored in this report.

- The general corrosion rate of the waste package outer barrier (at a given temperature) is time independent. This is conservative (will not result in an under-representation of the risk estimate) because the general corrosion rates of the waste package outer barrier decrease with time (BSC 2004 [DIRS 169984], Section 7.2.1).

- The general corrosion rates used for the waste package outer barrier are derived from weight loss measurements of creviced geometry specimens which showed a higher distribution of corrosion rates than did the weight loss geometry specimens (BSC 2004 [DIRS 169984], Section 6.4.3). This is conservative because it is unlikely that the entire waste package surface has a creviced geometry.

- In Section 6.3.4, the waste package outer barrier general corrosion rates are conservatively adjusted for the change of scale between a creviced geometry specimen and the patch size (which is about four times larger than the creviced geometry specimen size) used in this analysis. The technique used is equivalent to using the highest of four sampled values for the overall patch general corrosion rate.

On these bases, the uncertainty treatments in this analysis do not result in under-representation of the risk estimate. 
Those sections of the acceptance criterion that relate to NDE of fabricated engineered barriers are not applicable to this report because no analyses of nondestructive examination of fabricated engineered barriers were analyzed in this report. Those sections of the acceptance criterion that relate to the use of other sources, such as expert elicitation, are not applicable to this report because no other sources were used in the creation of this report.

\section{AC 4 - Model Uncertainty is Characterized and Propagated Through the Model Abstraction}

(1) Alternative modeling approaches are considered and are consistent with available data and current scientific understanding.

(2) Consideration of conceptual model uncertainty is consistent with available site characterization data, laboratory experiments, . . . and the treatment of uncertainty does not result in under-estimation of the risk estimate.

(3) Alternative modeling approaches, consistent with available data and current scientific understanding, are used and the modeling results are evaluated using tests that are sensitive to the processes modeled.

Conceptual model uncertainty was adequately considered in the models used in this report (BSC 2004 [DIRS 169845]; BSC 2004 [DIRS 169984]; BSC 2004 [DIRS 169985]). Objective evidence of this is their approval in accordance with the applicable procedures under which they were produced. The uncertainty treatments in these reports are inputs to this report, meaning that the uncertainty treatments are implemented within the IWPD analysis (Sections 4.1 and 6.3). On this basis model uncertainty is appropriately characterized and propagated through the IWPD analysis. As discussed in acceptance criterion 3, these uncertainty treatments do not result in underestimation of the risk estimate.

Those sections of the acceptance criterion that relate to consideration of alternative conceptual models are not applicable to this report because no analyses of alternative conceptual models were undertaken in this report.

\section{AC 5 - Model Abstraction Output Is Supported By Objective Comparisons}

(1) Models implemented in this total system performance assessment abstraction provide results consistent with output from detailed process-level models and or empirical observations (laboratory and field testing, and/or natural analogs).

(2) Numerical corrosion models used to calculate the lifetime of the engineered barriers are adequate representations, considering the associated uncertainties in long term behavior, range of conditions (including residual stresses) and the variability in fabrication processes.

(3) Evidence is sufficient to show that models will not underestimate the actual degradation and failure of engineered barriers. 
(4) Mathematical degradation models are based on the same environmental parameters, material factors, assumptions and approximations shown to be appropriate for closely analogous applications.

(5) Accepted and well documented procedures are used to construct and test the numerical models that simulate the EBS chemical environment and degradation of EBS;

(6) Sensitivity analyses or bounding analyses are provided to support the abstraction of the degradation of engineered barriers.

The models used in the IWPD analysis, including their uncertainty treatments, are listed in Section 4.1. The uncertainty treatments are inputs to this report meaning that the uncertainty treatments are implemented within the IWPD analysis consistent with the process or abstraction models feeding this report (BSC 2004 [DIRS 169845]; BSC 2004 [DIRS 169984]; BSC 2004 [DIRS 169985]). Numerical corrosion models used to calculate the lifetime of the engineered barriers are adequate representations, considering the associated uncertainties in long term behavior, range of conditions (including residual stresses) and the variability in fabrication processes. Objective evidence of this is the approval of the process or abstraction models feeding this report in accordance with the applicable procedures under which they were produced. Sufficient evidence to show that models will not underestimate the actual degradation and failure of engineered barriers is provided in the response to acceptance criterion 3 .

One input (the waste package outer barrier general corrosion rate distribution) was manipulated in this report using a technique evident from standard scientific practices, approaches, or methods. The IWPD analysis makes use of a patch size which is about four times the size of the creviced geometry specimens used to generate the distribution of rates used to analyze general corrosion of the waste package outer barrier (Section 6.3.4). In this instance, a comparison was made between the input general corrosion rate distribution and that resulting from the methodology (Figure 3). The results of that comparison are that the implementation methodology is conservative and does not result in underestimation of the risk estimate. The models used in the IWPD analysis are discussed in Sections 6.3 and 6.4. Illustrative analysis results are presented in Section 6.5. On this basis, analysis output is supported by objective comparisons (where necessary) in this report. 


\section{INTENTIONALLY LEFT BLANK}




\section{INPUTS AND REFERENCES}

\subsection{DOCUMENTS CITED}

133378 ASM International. 1987. Corrosion. Volume 13 of ASM Handbook. Formerly 9th Edition, Metals Handbook. Materials Park, Ohio: ASM International. TIC: 240704.

159379 Aziz, P.M. 1956. "Application of the Statistical Theory of Extreme Values to the Analysis of Maximum Pit Depth Data for Aluminum.” Corrosion, 12, (10), 35-46. Houston, Texas: National Association of Corrosion Engineers. TIC: 241560.

162429 Bokhari, S.A. 2003. "Approved Baseline Change Proposal (BCP) YMP-2003-005, Design Changes to Site Recommendation (SR) Waste Package." Memorandum from S.A. Bokhari (DOE) to W.J. Arthur, III (OCRWM/CCB), R.A. Milner (OCRWM/CCB), and R.D. Brown (OCRWM/CCB), January 30, 2003, with attachments. ACC: MOL.20030508.0040.

157817 BSC (Bechtel SAIC Company) 2001. Repository Design, Waste Package Project 5 DHLW/DOE SNF - Short Waste Package, Sheet 1 of 3, Sheet 2 of 3, and Sheet 3 of 3. DWG-DDC-ME-000001 REV A. Las Vegas, Nevada: Bechtel SAIC Company. ACC: MOL.20020102.0183.

157818 BSC 2001. Repository Design, Waste Package Project 5 DHLW/DOE SNF - Long Waste Package, Sheet 1 of 3, Sheet 2 of 3, and Sheet 3 of 3. DWG-DDC-ME-000002 REV A. Las Vegas, Nevada: Bechtel SAIC Company. ACC: MOL.20020102.0184.

157812 BSC 2001. Repository Design, Waste Package, Project 21-PWR Waste Package with Absorber Plates, Sheet 1 of 3, Sheet 2 of 3, and Sheet 3 of 3. DWG-UDC-ME-000001 REV A. Las Vegas, Nevada: Bechtel SAIC Company. ACC: MOL.20020102.0174.

158966 BSC 2002. The Enhanced Plan for Features, Events, and Processes (FEPs) at Yucca Mountain. TDR-WIS-PA-000005 REV 00. Las Vegas, Nevada: Bechtel SAIC Company. ACC: MOL.20020417.0385.

162606 BSC 2002. Users' Manual for WAPDEG 4.07. SDN: 10000-UM-4.07-00. Las Vegas, Nevada: Bechtel SAIC Company. ACC: MOL.20030409.0233; MOL.20040427.0343.

165406 BSC 2003. Design and Engineering, D\&E/PA/C IED Typical Waste Package Components Assembly 1 of 9. 800-IED-WIS0-00201-000-00C. Las Vegas, Nevada: Bechtel SAIC Company. ACC: ENG.20030917.0002.

163855 BSC 2003. Repository Design Project, RDP/PA IED Typical Waste Package Components Assembly (2). 800-IED-WIS0-00202-000-00A. Las Vegas, Nevada: Bechtel SAIC Company. ACC: ENG.20030702.0002.

164610 BSC 2003. Repository Design Project, RDP/PA IED Typical Waste Package Components Assembly (5). 800-IED-WIS0-00205-000-00B. Las Vegas, Nevada: Bechtel SAIC Company. ACC: ENG.20030811.0012. 
170024 BSC 2004. Analysis of Mechanisms for Early Waste Package/Drip Shield Failure. CAL-EBS-MD-000030 REV 00C. Las Vegas, Nevada: Bechtel SAIC Company. ACC: DOC.20040913.0006.

168489 BSC 2004. D\&E / PA/C IED Emplacement Drift Configuration and Environment. 800-IED-MGR0-00201-000-00B. Las Vegas, Nevada: Bechtel SAIC Company. ACC: ENG.20040326.0001.

169220 BSC 2004. D\&E / PA/C IED Interlocking Drip Shield and Emplacement Pallet. 800IED-WIS0-00401-000-00D. Las Vegas, Nevada: Bechtel SAIC Company. ACC: ENG.20040503.0018.

169997 BSC 2004. FEPs Screening of Processes and Issues in Drip Shield and Waste Package Degradation. ANL-EBS-PA-000002, Rev. 03. Las Vegas, Nevada: Bechtel SAIC Company.

169845 BSC 2004. General Corrosion and Localized Corrosion of the Drip Shield. ANLEBS-MD-000004 REV 02. Las Vegas, Nevada: Bechtel SAIC Company. ACC: DOC.20040921.0002.

169984 BSC 2004. General Corrosion and Localized Corrosion of Waste Package Outer Barrier. ANL-EBS-MD-000003, Rev. 02. Las Vegas, Nevada: Bechtel SAIC Company.

168361 BSC 2004. Q-List. 000-30R-MGR0-00500-000-000 REV 00. Las Vegas, Nevada: Bechtel SAIC Company. ACC: ENG.20040721.0007.

170992 BSC 2004. Safety Classification of SSCs and Barriers. 000-00C-MGR0-01000-00000A. Las Vegas, Nevada: Bechtel SAIC Company. ACC: ENG.20040721.0005.

169985 BSC 2004. Stress Corrosion Cracking of the Drip Shield, the Waste Package Outer Barrier, and the Stainless Steel Structural Material. ANL-EBS-MD-000005, Rev. 02. Las Vegas, Nevada: Bechtel SAIC Company.

171478 BSC 2004. Technical Management Review Board (TMRB) Decision Proposal. Tracking No. TMRB-2004-066. Las Vegas, Nevada: Bechtel SAIC Company. ACC: MOL.20040902.0260.

171583 BSC 2004. Technical Work Plan For: Regulatory Integration Modeling and Analysis of the Waste Form and Waste Package. TWP-WIS-MD-000009 REV 00 ICN 01. Las Vegas, Nevada: Bechtel SAIC Company. ACC: DOC.20040910.0001.

166275 Canori, G.F. and Leitner, M.M. 2003. Project Requirements Document. TER-MGRMD-000001 REV 02. Las Vegas, Nevada: Bechtel SAIC Company. ACC: DOC.20031222.0006.

165441 Chen, H.-L.; Evans, K.J.; Hackel, L.A.; Rankin, J.E.; Yamamoto, R.M.; Demma, A.G.; Dewald, A.T.; Lee, M.J.; and Hill, M.R. 2002. Mitigation of Tensile Weld Stresses in Alloy 22 Using Laser Peening. UCRL-ID-151055. Livermore, California: Lawrence Livermore National Laboratory. ACC: MOL.20030911.0252. 
164795 Codell, R.B.; Byrne, M.R.; McCartin, T.J.; Mohanty, S.; Weldy, J.; Jarzemba, M.; Wittmeyer, G.W.; Lu, Y.; and Rice, R.W. 2001. System-Level Repository Sensitivity Analyses, Using TPA Version 3.2 Code. NUREG-1746. Washington, D.C.: U .S. Nuclear Regulatory Commission, Office of Nuclear Material Safety and Safeguards. TIC: 254763.

153246 CRWMS M\&O 2000. Total System Performance Assessment for the Site Recommendation. TDR-WIS-PA-000001 REV 00 ICN 01. Las Vegas, Nevada: CRWMS M\&O. ACC: MOL.20001220.0045.

171539 DOE (U.S. Department of Energy) 2004. Quality Assurance Requirements and Description. DOE/RW-0333P, Rev. 16. Washington, D.C.: U.S. Department of Energy, Office of Civilian Radioactive Waste Management. ACC: DOC.20040907.0002. Replacement for 171386

158069 EPRI (Electric Power Research Institute) 2002. Evaluation of the Proposed HighLevel Radioactive Waste Repository at Yucca Mountain Using Total System Performance Assessment, Phase 6. EPRI TR-1003031. Palo Alto, California: Electric Power Research Institute. TIC: 252239.

112115 Evans, M.; Hastings, N.; and Peacock, B. 1993. Statistical Distributions. 2nd Edition. New York, New York: John Wiley \& Sons. TIC: 246114.

160643 GoldSim Technology Group. 2002. GoldSim, Graphical Simulation Environment, User's Guide. Version 7.40. Redmond, Washington: Golder Associates. TIC: 253564.

163274 NRC (U.S. Nuclear Regulatory Commission) 2003. Yucca Mountain Review Plan, Final Report. NUREG-1804, Rev. 2. Washington, D.C.: U.S. Nuclear Regulatory Commission, Office of Nuclear Material Safety and Safeguards. TIC: 254568.

156800 Plinski, M.J. 2001. Waste Package Operations Fabrication Process Report. TDREBS-ND-000003 REV 02. Las Vegas, Nevada: Bechtel SAIC Company. ACC: MOL.20011003.0025.

119589 Shibata, T. 1996. "Statistical and Stochastic Approaches to Localized Corrosion." Corrosion, 52, (11), 813-830. Houston, Texas: National Association of Corrosion Engineers. TIC: 236691.

\subsection{CODES, STANDARDS, REGULATIONS, AND PROCEDURES}

AP-2.14Q, Rev. 3, ICN 0. Document Review. Washington, D.C.: U.S. Department of Energy, Office of Civilian Radioactive Waste Management.

ACC: DOC.20030827.0018.

AP-2.22Q, Rev. 1, ICN 1. Classification Analyses and Maintenance of the Q-List. Washington, D.C.: U.S. Department of Energy, Office of Civilian Radioactive Waste Management. ACC: DOC.20040714.0002. 
AP-3.15Q, Rev. 4, ICN 5. Managing Technical Product Inputs. Washington, D.C.: U.S. Department of Energy, Office of Civilian Radioactive Waste Management. ACC: DOC.20040812.0004.

AP-SIII.9Q, Rev. 2, ICN 7. Scientific Analyses. Washington, D.C.: U.S. Department of Energy, Office of Civilian Radioactive Waste Management.

ACC: DOC.20040920.0001.

AP-SIII.10Q, Rev. 2, ICN 7. Models. Washington, D.C.: U.S. Department of Energy, Office of Civilian Radioactive Waste Management. ACC: DOC.20040920.0002.

AP-SV.1Q, Rev. 1, ICN 1. Control of the Electronic Management of Information. Washington, D.C.: U.S. Department of Energy, Office of Civilian Radioactive Waste Management. ACC: DOC.20040308.0001.

105725 ASTM C 1174-97. 1998. Standard Practice for Prediction of the Long-Term Behavior of Materials, Including Waste Forms, Used in Engineered Barrier Systems (EBS) for Geological Disposal of High-Level Radioactive Waste. West Conshohocken, Pennsylvania: American Society for Testing and Materials. TIC: 246015.

LP-SI.11Q-BSC, Rev. 0, ICN 0. Software Management. Washington, D.C.: U.S. Department of Energy, Office of Civilian Radioactive Waste Management. ACC: DOC.20040225.0007.

\subsection{SOURCE DATA LISTED BY DATA TRACKING NUMBER}

163968 LL030607012251.065. Output of Stress Corrosion Cracking AMR ANL-EBS-MD000005 REV. 01 ICN 00. Submittal date: 06/20/2003.

148850 MO0003RIB00071.000. Physical and Chemical Characteristics of Alloy 22. Submittal date: 03/13/2000.

170760 MO0407SEPFEPLA.000. LA FEP List. Submittal date: 07/20/2004.

171486 MO0408MWDGLCDS.002. General Corrosion and Localized Corrosion of the Drip Shield for LA. Submittal date: 08/27/2004.

171714 MO0409MWDUGCMW.000. Updated General Corrosion Model of the Waste Package Outer Barrier. Submittal date: 09/17/2004.

\subsection{SOFTWARE CODES}

162809 Software Code: CWD. V. 2.0. PC. 10363-2.0-00.

161572 Software Code: GoldSim. V7.50.100. PC. 10344-7.50.100-00.

161757 Software Code: SCCD. V2.01. PC. 10343-2.01-00.

161240 Software Code: WAPDEG. V. 4.07. PC. 10000-4.07-00. 
APPENDIX I

CONTENTS OF WAPDEG INPUT VECTOR 


\section{INTENTIONALLY LEFT BLANK}




\section{CONTENTS OF WAPDEG INPUT VECTOR}

The contents of the WAPDEG input vector are reproduced below (Table I-1). All values in the WAPDEG input vector are real numbers. Those that do not change, and are not defined by TSPA-LA components, are explicitly stated. The rest are represented by variable names, defined in the TSPA-LA itself. Certain of the parameters in the WAPDEG input vector reproduced in Table I-1 depend on the waste package configuration (CSNF or CDSP) being simulated. In this case, the value for the CSNF waste package is shown first, with the corresponding CDSP waste package value given afterwards in brackets.

The DLL links at the end of the vector (i.e., elements 700 and 701) are used to control the calling sequence of the DLLs. Inclusion in the WAPDEG input vector assures that those DLLs are called before WAPDEG is called.

For details of construction of the WAPDEG input vector consult (BSC 2002 [DIRS 162606]).

Table I-1. Contents of WAPDEG Input Vector

\begin{tabular}{|c|c|c|c|}
\hline Row & Value & Parameter Description & Comments \\
\hline 1 & Realization & Realization Number & \\
\hline 2 & 2 & Number of Barriers & \\
\hline 3 & 1 & Barrier Type & A22 OB \\
\hline 4 & 25 & Barrier Thickness & $\mathrm{mm}$ \\
\hline 5 & 0.75 & Barrier Mechanical Failure Fraction & fraction \\
\hline 6 & 1000 & Barrier Pit Density Distribution Index & Fixed \\
\hline 7 & 0 & Parameter 1 & $/ \mathrm{mm}^{\wedge} 2$ \\
\hline 8 & 0 & Parameter 2 & \\
\hline 9 & 0 & Parameter 3 & \\
\hline 10 & 0 & Parameter 4 & \\
\hline 11 & 1000 & Barrier Crack Density Distribution Index & Fixed \\
\hline 12 & 6 & Parameter 1 & $/ \mathrm{mm}^{\wedge} 2$ \\
\hline 13 & 0 & Parameter 2 & \\
\hline 14 & 0 & Parameter 3 & \\
\hline 15 & 0 & Parameter 4 & \\
\hline 16 & 2 & Barrier Type & A22 IB \\
\hline 17 & 10 & Barrier Thickness & $\mathrm{mm}$ \\
\hline 18 & 0.75 & Barrier Mechanical Failure Fraction & fraction \\
\hline 19 & 1000 & Barrier Pit Density Distribution Index & Fixed \\
\hline 20 & 0 & Parameter 1 & $/ \mathrm{mm}^{\wedge} 2$ \\
\hline 21 & 0 & Parameter 2 & \\
\hline 22 & 0 & Parameter 3 & \\
\hline 23 & 0 & Parameter 4 & \\
\hline 24 & 1000 & Barrier Crack Density Distribution Index & Fixed \\
\hline 25 & 15 & Parameter 1 & $/ \mathrm{mm}^{\wedge} 2$ \\
\hline 26 & 0 & Parameter 2 & \\
\hline 27 & 0 & Parameter 3 & \\
\hline 28 & 0 & Parameter 4 & \\
\hline 29 & $1014(1106)$ & Waste Container Surface Area & $\mathrm{mm}^{\wedge} 2$ \\
\hline 30 & $0.484(0.481)$ & Waste Container Top Fraction & fraction \\
\hline 31 & $0.484(0.481)$ & Waste Container Bottom Fraction & fraction \\
\hline 32 & 1000 & Waste Container Patch Area Distribution Index & Fixed \\
\hline 33 & 1 & Parameter 1 & $\mathrm{~mm}^{\wedge} 2$ \\
\hline 34 & 0 & Parameter 2 & \\
\hline 35 & 0 & Parameter 3 & \\
\hline 36 & 0 & Parameter 4 & \\
\hline
\end{tabular}




\begin{tabular}{|c|c|c|c|}
\hline Row & Value & Parameter Description & Comments \\
\hline 37 & -1 & Apply Size Boolean & TRUE \\
\hline 38 & -1 & Drip Shield Present Boolean & TRUE \\
\hline 39 & 3 & Drip Shield Type & Ti7 DS \\
\hline 40 & 15 & Drip Shield Thickness & $\mathrm{mm}$ \\
\hline 41 & 0.75 & Drip Shield Mechanical Failure Fraction & fraction \\
\hline 42 & 1000 & Drip Shield Pit Density Distribution Index & Fixed \\
\hline 43 & 0 & Parameter 1 & $/ \mathrm{mm}^{\wedge} 2$ \\
\hline 44 & 0 & Parameter 2 & \\
\hline 45 & 0 & Parameter 3 & \\
\hline 46 & 0 & Parameter 4 & \\
\hline 47 & 1000 & Drip Shield Crack Density Distribution Index & Fixed \\
\hline 48 & 0 & Parameter 1 & $/ \mathrm{mm}^{\wedge} 2$ \\
\hline 49 & 0 & Parameter 2 & \\
\hline 50 & 0 & Parameter 3 & \\
\hline 51 & 0 & Parameter 4 & \\
\hline 52 & Number_DS_Patches & Drip Shield Surface Area & $\mathrm{mm}^{\wedge} 2$ \\
\hline 53 & 1 & Drip Shield Top Fraction & fraction \\
\hline 54 & 1000 & Drip Shield Patch Size Distribution Index & Fixed \\
\hline 55 & 1 & Parameter 1 & $\mathrm{~mm}^{\wedge} 2$ \\
\hline 56 & 0 & Parameter 2 & \\
\hline 57 & 0 & Parameter 3 & \\
\hline 58 & 0 & Parameter 4 & \\
\hline 59 & -1 & Drip Shield Apply Size Boolean & TRUE \\
\hline 60 & 1000 & $\begin{array}{l}\text { Drip Shield Fractional Area Affected Distribution } \\
\text { Index }\end{array}$ & Fixed \\
\hline 61 & 1 & Parameter 1 & fraction \\
\hline 62 & 0 & Parameter 2 & \\
\hline 63 & 0 & Parameter 3 & \\
\hline 64 & 0 & Parameter 4 & \\
\hline 65 & 1 & Initial Water Condition under drip shield & DSInside \\
\hline 66 & $\begin{array}{l}\text { NumPak_CSNF } \\
\text { (NumPak_CDSP) }\end{array}$ & Total Number of Waste Packages & \\
\hline 67 & $\begin{array}{l}\text { Hist_Index_CSNF } \\
\text { (Hist_Index_CDSP) }\end{array}$ & Index Number of $\mathrm{T} / \mathrm{H}$ File to Read & \\
\hline 68 & 1 & Number of Drip Sequences & \\
\hline 69 & 1 & Number of Phases - Drip Sequence \#1 & \\
\hline 70 & 1000 & $\begin{array}{l}\text { Fraction of Top Patches Subject to Sequence } \\
\text { Distribution Number }\end{array}$ & Fixed \\
\hline 71 & 1 & Parameter 1 & fraction \\
\hline 72 & 0 & Parameter 2 & \\
\hline 73 & 0 & Parameter 3 & \\
\hline 74 & 0 & Parameter 4 & \\
\hline 75 & 1000 & $\begin{array}{l}\text { Fraction of Side Patches Subject to Sequence } \\
\text { Distribution Number }\end{array}$ & Fixed \\
\hline 76 & 1 & Parameter 1 & fraction \\
\hline 77 & 0 & Parameter 2 & \\
\hline 78 & 0 & Parameter 3 & \\
\hline 79 & 0 & Parameter 4 & \\
\hline 80 & 1000 & $\begin{array}{l}\text { Fraction of Bottom Patches Subject to } \\
\text { Sequence Distribution Number }\end{array}$ & Fixed \\
\hline 81 & 1 & Parameter 1 & fraction \\
\hline 82 & 0 & Parameter 2 & \\
\hline 83 & 0 & Parameter 3 & \\
\hline 84 & 0 & Parameter 4 & \\
\hline 85 & 2 & Water Condition for Last Phase & DSOutside \\
\hline 86 & 6 & Number of Corrosion Functional Forms & \\
\hline 87 & 1 & Water Condition Index Number & DSInside \\
\hline 88 & 1 & Corrosion Mechanism Index $(1,2$, or 3$)$ & General \\
\hline
\end{tabular}


WAPDEG Analysis of Waste Package and Drip Shield Degradation

\begin{tabular}{|c|c|c|c|}
\hline Row & Value & Parameter Description & Comments \\
\hline 89 & 1 & Layer Composition Index & A22 OB \\
\hline 90 & 5 & Functional Form Index & General Linear \\
\hline 91 & 2 & Number of terms in form & \\
\hline 92 & 0 & Column number for term 1 & \\
\hline 93 & 0 & Column number for term 2 & \\
\hline 94 & 2 & Number of Levels for Variance Sharing & \\
\hline 95 & 1000 & Barrier Variance Sharing Distribution Index & Fixed \\
\hline 96 & 0 & Parameter1 & fraction \\
\hline 97 & 0 & Parameter 2 & \\
\hline 98 & 0 & Parameter 3 & \\
\hline 99 & 0 & Parameter 4 & \\
\hline 100 & 2500 & Term 1 distribution $-\ln (R)$ & File CDF \\
\hline 101 & 18 & Parameter 1 & WDInRGC.cdf \\
\hline 102 & 0 & Parameter 2 & \\
\hline 103 & 0 & Parameter 3 & \\
\hline 104 & 0 & Parameter 4 & \\
\hline 105 & 1000 & Term 2 distribution - C1/To & Fixed \\
\hline 106 & C1divTo_GenCorr_A22 & Parameter 1 & \\
\hline 107 & 0 & Parameter 2 & \\
\hline 108 & 0 & Parameter 3 & \\
\hline 109 & 0 & Parameter 4 & \\
\hline 110 & 0 & Sample Type & \\
\hline 111 & 1000 & Error Term Distribution Index & Fixed \\
\hline 112 & $3.2236191301917 \mathrm{E}+01$ & Parameter 1 & $\ln \left(10^{\wedge} 14\right)$ \\
\hline 113 & 0 & Parameter 2 & \\
\hline 114 & 0 & Parameter 3 & \\
\hline 115 & 0 & Parameter 4 & \\
\hline 116 & 1000 & Q Term Distribution Index - C1 & Fixed \\
\hline 117 & C1_GenCorr_A22 & Parameter 1 & $\mathrm{~K}$ \\
\hline 118 & 0 & Parameter 2 & \\
\hline 119 & 0 & Parameter 3 & \\
\hline 120 & 0 & Parameter 4 & \\
\hline 121 & 1000 & n Distribution Index & Fixed \\
\hline 122 & 1 & Parameter 1 & \\
\hline 123 & 0 & Parameter 2 & \\
\hline 124 & 0 & Parameter 3 & \\
\hline 125 & 0 & Parameter 4 & \\
\hline 126 & 1 & Water Condition Index Number & DSInside \\
\hline 127 & 1 & Corrosion Mechanism Index Number $(1,2$, or 3$)$ & General \\
\hline 128 & 2 & Layer Composition Index & A22 IB \\
\hline 129 & 5 & Functional Form Index & General Linear \\
\hline 130 & 2 & Number of terms in form & \\
\hline 131 & 0 & Column number for term 1 & \\
\hline 132 & 0 & Column number for term 2 & \\
\hline 133 & 2 & Number of Levels for Variance Sharing & \\
\hline 134 & 1000 & Barrier Variance Sharing Distribution Index & Fixed \\
\hline 135 & 0 & Parameter1 & fraction \\
\hline 136 & 0 & Parameter 2 & \\
\hline 137 & 0 & Parameter 3 & \\
\hline 138 & 0 & Parameter 4 & \\
\hline 139 & 2500 & Term 1 distribution $-\ln (R)$ & File CDF \\
\hline 140 & 18 & Parameter 1 & WDInRGC.cdf \\
\hline 141 & 0 & Parameter 2 & \\
\hline 142 & 0 & Parameter 3 & \\
\hline 143 & 0 & Parameter 4 & \\
\hline 144 & 1000 & Term 2 distribution - C1/To & Fixed \\
\hline 145 & C1divTo_GenCorr_A22 & Parameter 1 & \\
\hline 146 & 0 & Parameter 2 & \\
\hline
\end{tabular}


WAPDEG Analysis of Waste Package and Drip Shield Degradation

\begin{tabular}{|c|c|c|c|}
\hline Row & Value & Parameter Description & Comments \\
\hline 147 & 0 & Parameter 3 & \\
\hline 148 & 0 & Parameter 4 & \\
\hline 149 & 0 & Sample Type & \\
\hline 150 & 1000 & Error Term Distribution Index & Fixed \\
\hline 151 & $\begin{array}{c}-6.93147180559945 \mathrm{E}-01 \\
(-9.16290731874155 \mathrm{E}-01)\end{array}$ & Parameter 1 & $\begin{array}{l}\ln (10 / 20) \\
(\ln (10 / 25))\end{array}$ \\
\hline 152 & 0 & Parameter 2 & \\
\hline 153 & 0 & Parameter 3 & \\
\hline 154 & 0 & Parameter 4 & \\
\hline 155 & 1000 & Q Term Distribution Index & Fixed \\
\hline 156 & C1_GenCorr_A22 & Parameter 1 & $\mathrm{~K}$ \\
\hline 157 & 0 & Parameter 2 & \\
\hline 158 & 0 & Parameter 3 & \\
\hline 159 & 0 & Parameter 4 & \\
\hline 160 & 1000 & n Distribution Index & Fixed \\
\hline 161 & 1 & Parameter 1 & \\
\hline 162 & 0 & Parameter 2 & \\
\hline 163 & 0 & Parameter 3 & \\
\hline 164 & 0 & Parameter 4 & \\
\hline 165 & 1 & Water Condition Index & DSInside \\
\hline 166 & 1 & Corrosion Mechanism Index $(1,2$, or 3$)$ & General \\
\hline 167 & 3 & Layer Composition Index & Ti7 DS \\
\hline 168 & 6 & Functional Form Index $-\mathrm{D}=\mathrm{B}^{*} \mathrm{t}^{\wedge} \mathrm{n}$ & Power Law \\
\hline 169 & 2 & Number of Levels for Variance Sharing & \\
\hline 170 & 1000 & Barrier Variance Sharing Distribution Index & Fixed \\
\hline 171 & 1 & Parameter 1 & fraction \\
\hline 172 & 0 & Parameter 2 & \\
\hline 173 & 0 & Parameter 3 & \\
\hline 174 & 0 & Parameter 4 & \\
\hline 175 & 1000 & B Distribution Index & Fixed \\
\hline 176 & WDDSInGC & Parameter 1 & $\mathrm{~mm} / \mathrm{yr}$ \\
\hline 177 & 0 & Parameter 2 & \\
\hline 178 & 0 & Parameter 3 & \\
\hline 179 & 0 & Parameter 4 & \\
\hline 180 & 1000 & n Distribution Index & Fixed \\
\hline 181 & 1 & Parameter 1 & \\
\hline 182 & 0 & Parameter 2 & \\
\hline 183 & 0 & Parameter 3 & \\
\hline 184 & 0 & Parameter 4 & \\
\hline 185 & 0 & Sample Type & \\
\hline 186 & 2 & Water Condition Index & DSOutside \\
\hline 187 & 1 & Corrosion Mechanism Index $(1,2$, or 3$)$ & General \\
\hline 188 & 1 & Layer Composition Index & A22 OB \\
\hline 189 & 5 & Functional Form Index & General Linear \\
\hline 190 & 2 & Number of terms in form & \\
\hline 191 & 0 & Column number for term 1 & \\
\hline 192 & 0 & Column number for term 2 & \\
\hline 193 & 2 & Number of Levels for Variance Sharing & \\
\hline 194 & 1000 & Barrier Variance Sharing Distribution Index & Fixed \\
\hline 195 & 0 & Parameter1 & fraction \\
\hline 196 & 0 & Parameter 2 & \\
\hline 197 & 0 & Parameter 3 & \\
\hline 198 & 0 & Parameter 4 & \\
\hline 199 & 2500 & Term 1 distribution $-\ln (R)$ & File CDF \\
\hline 200 & 18 & Parameter 1 & WDInRGC.cdf \\
\hline 201 & 0 & Parameter 2 & \\
\hline 202 & 0 & Parameter 3 & \\
\hline 203 & 0 & Parameter 4 & \\
\hline
\end{tabular}


WAPDEG Analysis of Waste Package and Drip Shield Degradation

\begin{tabular}{|c|c|c|c|}
\hline Row & Value & Parameter Description & Comments \\
\hline 204 & 1000 & Term 2 distribution - C1/To & Fixed \\
\hline 205 & C1divTo_GenCorr_A22 & Parameter 1 & \\
\hline 206 & 0 & Parameter 2 & \\
\hline 207 & 0 & Parameter 3 & \\
\hline 208 & 0 & Parameter 4 & \\
\hline 209 & 0 & Sample Type & \\
\hline 210 & 1000 & Error Term Distribution Index & Fixed \\
\hline 211 & $3.2236191301917 \mathrm{E}+01$ & Parameter 1 & $\ln \left(10^{\wedge} 14\right)$ \\
\hline 212 & 0 & Parameter 2 & \\
\hline 213 & 0 & Parameter 3 & \\
\hline 214 & 0 & Parameter 4 & \\
\hline 215 & 1000 & Q Term Distribution Index & Fixed \\
\hline 216 & C1_GenCorr_A22 & Parameter 1 & $\mathrm{~K}$ \\
\hline 217 & 0 & Parameter 2 & \\
\hline 218 & 0 & Parameter 3 & \\
\hline 219 & 0 & Parameter 4 & \\
\hline 220 & 1000 & n Distribution Index & Fixed \\
\hline 221 & 1 & Parameter 1 & \\
\hline 222 & 0 & Parameter 2 & \\
\hline 223 & 0 & Parameter 3 & \\
\hline 224 & 0 & Parameter 4 & \\
\hline 225 & 2 & Water Condition Index Number & DSOutside \\
\hline 226 & 1 & Corrosion Mechanism Index Number $(1,2$, or 3$)$ & General \\
\hline 227 & 2 & Layer Composition Index & A22 IB \\
\hline 228 & 5 & Functional Form Index & General Linear \\
\hline 229 & 2 & Number of terms in form & \\
\hline 230 & 0 & Column number for term 1 & \\
\hline 231 & 0 & Column number for term 2 & \\
\hline 232 & 2 & Number of Levels for Variance Sharing & \\
\hline 233 & 1000 & Barrier Variance Sharing Distribution Index & Fixed \\
\hline 234 & 0 & Parameter1 & \\
\hline 235 & 0 & Parameter 2 & \\
\hline 236 & 0 & Parameter 3 & \\
\hline 237 & 0 & Parameter 4 & \\
\hline 238 & 2500 & Term 1 distribution - $\ln (\mathrm{R})$ & File CDF \\
\hline 239 & 18 & Parameter 1 & WDInRGC.cdf \\
\hline 240 & 0 & Parameter 2 & \\
\hline 241 & 0 & Parameter 3 & \\
\hline 242 & 0 & Parameter 4 & \\
\hline 243 & 1000 & Term 2 distribution - C1/To & Fixed \\
\hline 244 & C1divTo_GenCorr_A22 & Parameter 1 & \\
\hline 245 & 0 & Parameter 2 & \\
\hline 246 & 0 & Parameter 3 & \\
\hline 247 & 0 & Parameter 4 & \\
\hline 248 & 0 & Sample Type & \\
\hline 249 & 1000 & Error Term Distribution Index & Fixed \\
\hline 250 & $\begin{array}{c}-6.9314718055995 \mathrm{E}-01 \\
(-9.1629073187416 \mathrm{E}-01)\end{array}$ & Parameter 1 & $\begin{array}{l}\ln (10 / 20) \\
(\ln (10 / 25))\end{array}$ \\
\hline 251 & 0 & Parameter 2 & \\
\hline 252 & 0 & Parameter 3 & \\
\hline 253 & 0 & Parameter 4 & \\
\hline 254 & 1000 & Q Term Distribution Index & Fixed \\
\hline 255 & C1_GenCorr_A22 & Parameter 1 & $\mathrm{~K}$ \\
\hline 256 & 0 & Parameter 2 & \\
\hline 257 & 0 & Parameter 3 & \\
\hline 258 & 0 & Parameter 4 & \\
\hline 259 & 1000 & n Distribution Index & Fixed \\
\hline 260 & 1 & Parameter 1 & \\
\hline
\end{tabular}


WAPDEG Analysis of Waste Package and Drip Shield Degradation

\begin{tabular}{|c|c|c|c|}
\hline Row & Value & Parameter Description & Comments \\
\hline 261 & 0 & Parameter 2 & \\
\hline 262 & 0 & Parameter 3 & \\
\hline 263 & 0 & Parameter 4 & \\
\hline 264 & 2 & Water Condition Index & DSOutside \\
\hline 265 & 1 & Corrosion Mechanism Index $(1,2$, or 3$)$ & General \\
\hline 266 & 3 & Layer Composition Index & Ti7 DS \\
\hline 267 & 6 & Functional Form Index $-\mathrm{D}=\mathrm{B}^{\star} \mathrm{t}^{\wedge} \mathrm{n}$ & Power Law \\
\hline 268 & 2 & Number of Levels for Variance Sharing & \\
\hline 269 & 1000 & Barrier Variance Sharing Distribution Index & Fixed \\
\hline 270 & 1 & Parameter 1 & \\
\hline 271 & 0 & Parameter 2 & \\
\hline 272 & 0 & Parameter 3 & \\
\hline 273 & 0 & Parameter 4 & \\
\hline 274 & 1000 & B Distribution Index & Fixed \\
\hline 275 & WDDSOutGC & Parameter 1 & $\mathrm{~mm} / \mathrm{yr}$ \\
\hline 276 & 0 & Parameter 2 & \\
\hline 277 & 0 & Parameter 3 & \\
\hline 278 & 0 & Parameter 4 & \\
\hline 279 & 1000 & n Distribution Index & Fixed \\
\hline 280 & 1 & Parameter 1 & \\
\hline 281 & 0 & Parameter 2 & \\
\hline 282 & 0 & Parameter 3 & \\
\hline 283 & 0 & Parameter 4 & \\
\hline 284 & 0 & Sample Type & \\
\hline 285 & 0 & Number of General Thresholds & \\
\hline 286 & 0 & Number of Pit Temperature Thresholds & \\
\hline 287 & -1 & Inside Out Corrosion Logical & TRUE \\
\hline 288 & 2 & Water Condition for Inside Out Corrosion & DSOutside \\
\hline 289 & 0 & Interface Corrosion Logical & FALSE \\
\hline 290 & 6 & Number of Events & \\
\hline 291 & 2 & Manufacturing Defects Event Index & \\
\hline 292 & 1 & Barrier Type & A22 OB \\
\hline 293 & 2 & Number of Water Conditions & \\
\hline 294 & 1 & Condition Number & DSInside \\
\hline 295 & 2 & Condition Number & DSOutside \\
\hline 296 & $\begin{array}{l}\text { CWD_OL_CSNF.FlawProb } \\
\text { (CWD_OL_CDSP.FlawProb) }\end{array}$ & Probability that a Waste Package Has Defects & \\
\hline 297 & 2600 & Number of Flaws Distribution Index & \\
\hline 298 & $\begin{array}{c}10 \\
(14)\end{array}$ & Parameter 1 & $\begin{array}{l}\text { WDCWDNDO_CSNF.cdf } \\
\text { (WDCWDNDO_CDSP.cdf) }\end{array}$ \\
\hline 299 & 0 & Parameter 2 & \\
\hline 300 & 0 & Parameter 3 & \\
\hline 301 & 0 & Parameter 4 & \\
\hline 302 & 2500 & Flaw Size Distribution Index & File CDF \\
\hline 303 & $\begin{array}{c}11 \\
(15)\end{array}$ & Parameter 1 & $\begin{array}{l}\text { WDCWDSizeO_CSNF.cdf } \\
\text { (WDCWDSizeO_CDSP.cdf) }\end{array}$ \\
\hline 304 & 0 & Parameter 2 & \\
\hline 305 & 0 & Parameter 3 & \\
\hline 306 & 0 & Parameter 4 & \\
\hline 307 & 0 & Immediate Failure Flag (-1 or 0 for true or false) & FALSE \\
\hline 308 & 0 & $\begin{array}{l}\text { Number of Localized Corrosion Modes Initiated } \\
(0,1, \text { or } 2)\end{array}$ & \\
\hline 309 & 0 & $\begin{array}{l}\text { Number of Corrosion Modes Accelerated }(0,1 \text {, } \\
2, \text { or } 3)\end{array}$ & \\
\hline 310 & 0 & Number of Thresholds Reduced $(0,1$, or 2$)$ & \\
\hline 311 & 2 & Manufacturing Defects Event Index & \\
\hline 312 & 2 & Barrier Type & A22 IB \\
\hline 313 & 2 & Number of Water Conditions & \\
\hline
\end{tabular}


WAPDEG Analysis of Waste Package and Drip Shield Degradation

\begin{tabular}{|c|c|c|c|}
\hline Row & Value & Parameter Description & Comments \\
\hline 314 & 1 & Condition Number & DSInside \\
\hline 315 & 2 & Condition Number & DSOutside \\
\hline 316 & $\begin{array}{l}\text { CWD_ML_CSNF.FlawProb } \\
\text { (CWD_ML_CDSP.FlawProb) }\end{array}$ & Probability that a Waste Package Has Defects & \\
\hline 317 & 2600 & Number of Flaws Distribution Index & $\begin{array}{l}\text { Discrete probability density } \\
\text { function }\end{array}$ \\
\hline 318 & $\begin{array}{c}12 \\
(16)\end{array}$ & Parameter 1 & $\begin{array}{l}\text { WDCWDNDM_CSNF.cdf } \\
\text { (WDCWDNDM_CDSP.cdf) }\end{array}$ \\
\hline 319 & 0 & Parameter 2 & \\
\hline 320 & 0 & Parameter 3 & \\
\hline 321 & 0 & Parameter 4 & \\
\hline 322 & 2500 & Flaw Size Distribution Index & File CDF \\
\hline 323 & $\begin{array}{c}13 \\
(17)\end{array}$ & Parameter 1 & $\begin{array}{l}\text { WDCWDSizeM_CSNF.cdf } \\
\text { (WDCWDSizeM_CDSP.cdf) }\end{array}$ \\
\hline 324 & 0 & Parameter 2 & \\
\hline 325 & 0 & Parameter 3 & \\
\hline 326 & 0 & Parameter 4 & \\
\hline 327 & 0 & Immediate Failure Flag (-1 or 0 for true or false) & FALSE \\
\hline 328 & 0 & $\begin{array}{l}\text { Number of Localized Corrosion Modes Initiated } \\
(0,1, \text { or } 2)\end{array}$ & \\
\hline 329 & 0 & $\begin{array}{l}\text { Number of Corrosion Modes Accelerated }(0,1 \text {, } \\
2, \text { or } 3)\end{array}$ & \\
\hline 330 & 0 & Number of Thresholds Reduced $(0,1$, or 2$)$ & \\
\hline 331 & 5 & SCC (Slip Dissolution) Event Index & \\
\hline 332 & 1 & Barrier Type & A22 OB \\
\hline 333 & 2 & Number of Water Conditions & \\
\hline 334 & 1 & Condition Number & DSInside \\
\hline 335 & 2 & Condition Number & DSOutside \\
\hline 336 & -1 & Include MFD and rockfall cracks? & TRUE \\
\hline 337 & 0 & Fraction of top surface area subject to SCC & fraction \\
\hline 338 & 1 & Fraction of side surface area subject to SCC & fraction \\
\hline 339 & 0 & Fraction of bottom surface area subject to SCC & fraction \\
\hline 340 & 6 & $\begin{array}{l}\text { File Index for Lookup Table [KI (col1) vs depth } \\
\text { (col2)] }\end{array}$ & WDKISCCO.fil \\
\hline 341 & 7 & $\begin{array}{l}\text { File Index for Lookup Table [stress (col1) vs } \\
\text { depth (col2)] }\end{array}$ & WDStressO.fil \\
\hline 342 & 1000 & Barrier Variance Share Distribution Index $(A, n)$ & Fixed \\
\hline 343 & 1 & Parameter 1 & fraction \\
\hline 344 & 0 & Parameter 2 & \\
\hline 345 & 0 & Parameter 3 & \\
\hline 346 & 0 & Parameter 4 & \\
\hline 347 & 1000 & Patch Variance Share Distribution Index $(A, n)$ & Fixed \\
\hline 348 & 0 & Parameter 1 & fraction \\
\hline 349 & 0 & Parameter 2 & \\
\hline 350 & 0 & Parameter 3 & \\
\hline 351 & 0 & Parameter 4 & \\
\hline 352 & 1000 & A Distribution Index (velocity $\left.=A(K I)^{\star \star} n\right)$ & Fixed \\
\hline 353 & Abar_SCC & Parameter 1 & \\
\hline 354 & $\overline{0}$ & Parameter 2 & \\
\hline 355 & 0 & Parameter 3 & \\
\hline 356 & 0 & Parameter 4 & \\
\hline 357 & 1000 & n Distribution Index & Fixed \\
\hline 358 & nbar_scC & Parameter 1 & \\
\hline 359 & $\overline{0}$ & Parameter 2 & \\
\hline 360 & 0 & Parameter 3 & \\
\hline 361 & 0 & Parameter 4 & \\
\hline 362 & 1000 & Incipient Crack Size Distribution Index & Fixed \\
\hline 363 & 0.05 & Parameter 1 & $\mathrm{~mm}$ \\
\hline
\end{tabular}




\begin{tabular}{|c|c|c|c|}
\hline Row & Value & Parameter Description & Comments \\
\hline 364 & 0 & Parameter 2 & \\
\hline 365 & 0 & Parameter 3 & \\
\hline 366 & 0 & Parameter 4 & \\
\hline 367 & 0 & Sample Type & \\
\hline 368 & 1000 & $\begin{array}{l}\text { Barrier Variance Share Distribution Index (for } \\
\text { thresholds) }\end{array}$ & Fixed \\
\hline 369 & 1 & Parameter 1 & fraction \\
\hline 370 & 0 & Parameter 2 & \\
\hline 371 & 0 & Parameter 3 & \\
\hline 372 & 0 & Parameter 4 & \\
\hline 373 & 1000 & Stress Threshold Distribution Index (Incipient) & Fixed \\
\hline 374 & Stress_Thresh_SCC & Parameter 1 & $\mathrm{MPa}$ \\
\hline 375 & 0 & Parameter 2 & \\
\hline 376 & 0 & Parameter 3 & \\
\hline 377 & 0 & Parameter 4 & \\
\hline 378 & 1000 & KI Threshold Distribution Index (Incipient) & Fixed \\
\hline 379 & KI_Thresh_SCC & Parameter 1 & MPa*sqrt(m) \\
\hline 380 & 0 & Parameter 2 & \\
\hline 381 & 0 & Parameter 3 & \\
\hline 382 & 0 & Parameter 4 & \\
\hline 383 & 1000 & Stress Threshold Distribution Index (MFD) & Fixed \\
\hline 384 & -600 & Parameter 1 & $\mathrm{MPa}$ \\
\hline 385 & 0 & Parameter 2 & \\
\hline 386 & 0 & Parameter 3 & \\
\hline 387 & 0 & Parameter 4 & \\
\hline 388 & 1000 & KI Threshold Distribution Index (MFD) & Fixed \\
\hline 389 & KI_Thresh_SCC & Parameter 1 & MPa*sqrt(m) \\
\hline 390 & 0 & Parameter 2 & \\
\hline 391 & 0 & Parameter 3 & \\
\hline 392 & 0 & Parameter 4 & \\
\hline 393 & 0 & Immediate Failure Flag (-1 or 0 for true or false) & FALSE \\
\hline 394 & 0 & $\begin{array}{l}\text { Number of Localized Corrosion Modes Initiated } \\
(0,1 \text {, or } 2)\end{array}$ & \\
\hline 395 & 1 & $\begin{array}{l}\text { Number of Corrosion Modes Accelerated }(0,1 \text {, } \\
2 \text {, or } 3 \text { ) }\end{array}$ & \\
\hline 396 & 1 & General Corrosion Accelerated & \\
\hline 397 & 1000 & Barrier Variance Share Distribution Index & Fixed \\
\hline 398 & 1 & Parameter 1 & fraction \\
\hline 399 & 0 & Parameter 2 & \\
\hline 400 & 0 & Parameter 3 & \\
\hline 401 & 0 & Parameter 4 & \\
\hline 402 & 1000 & Acceleration Factor & Fixed \\
\hline 403 & $1.00 \mathrm{E}-14$ & Parameter 1 & \\
\hline 404 & 0 & Parameter 2 & \\
\hline 405 & 0 & Parameter 3 & \\
\hline 406 & 0 & Parameter 4 & \\
\hline 407 & 0 & Sample Type & \\
\hline 408 & 0 & Number of Thresholds Reduced $(0,1$, or 2$)$ & \\
\hline 409 & 5 & SCC (Slip Dissolution) Event Index & \\
\hline 410 & 2 & Barrier Type & A22 IB \\
\hline 411 & 2 & Number of Water Conditions & \\
\hline 412 & 1 & Condition Number & DSInside \\
\hline 413 & 2 & Condition Number & DSOutside \\
\hline 414 & 1 & Include MFD and rockfall cracks? & TRUE \\
\hline 415 & 0 & Fraction of top surface area subject to SCC & fraction \\
\hline 416 & 1 & Fraction of side surface area subject to SCC & fraction \\
\hline 417 & 0 & Fraction of bottom surface area subject to SCC & fraction \\
\hline
\end{tabular}




\begin{tabular}{|c|c|c|c|}
\hline Row & Value & Parameter Description & Comments \\
\hline 418 & 8 & $\begin{array}{l}\text { File Index for Lookup Table [KI (col1) vs depth } \\
\text { (col2)] }\end{array}$ & WDKISCCM.fil \\
\hline 419 & 9 & $\begin{array}{l}\text { File Index for Lookup Table [stress (col1) vs } \\
\text { depth (col2)] }\end{array}$ & WDStressM.fil \\
\hline 420 & 1000 & Barrier Variance Share Distribution Index $(\mathrm{A}, \mathrm{n})$ & Fixed \\
\hline 421 & 1 & Parameter 1 & \\
\hline 422 & 0 & Parameter 2 & \\
\hline 423 & 0 & Parameter 3 & \\
\hline 424 & 0 & Parameter 4 & \\
\hline 425 & 1000 & Patch Variance Share Distribution Index $(A, n)$ & Fixed \\
\hline 426 & 0 & Parameter 1 & \\
\hline 427 & 0 & Parameter 2 & \\
\hline 428 & 0 & Parameter 3 & \\
\hline 429 & 0 & Parameter 4 & \\
\hline 430 & 1000 & A Distribution Index (velocity $\left.=A(K I)^{* *} n\right)$ & Fixed \\
\hline 431 & Abar_SCC & Parameter 1 & \\
\hline 432 & 0 & Parameter 2 & \\
\hline 433 & 0 & Parameter 3 & \\
\hline 434 & 0 & Parameter 4 & \\
\hline 435 & 1000 & n Distribution Index & Fixed \\
\hline 436 & nbar_sCC & Parameter 1 & \\
\hline 437 & $\overline{0}$ & Parameter 2 & \\
\hline 438 & 0 & Parameter 3 & \\
\hline 439 & 0 & Parameter 4 & \\
\hline 440 & 1000 & Incipient Crack Size Distribution Index & Fixed \\
\hline 441 & 0.05 & Parameter 1 & $\mathrm{~mm}$ \\
\hline 442 & 0 & Parameter 2 & \\
\hline 443 & 0 & Parameter 3 & \\
\hline 444 & 0 & Parameter 4 & \\
\hline 445 & 0 & Sample Type & \\
\hline 446 & 1000 & $\begin{array}{l}\text { Barrier Variance Share Distribution Index (for } \\
\text { thresholds) }\end{array}$ & Fixed \\
\hline 447 & 1 & Parameter 1 & fraction \\
\hline 448 & 0 & Parameter 2 & \\
\hline 449 & 0 & Parameter 3 & \\
\hline 450 & 0 & Parameter 4 & \\
\hline 451 & 1000 & Stress Threshold Distribution Index (Incipient) & Fixed \\
\hline 452 & Stress_Thresh_SCC & Parameter 1 & $\mathrm{MPa}$ \\
\hline 453 & 0 & Parameter 2 & \\
\hline 454 & 0 & Parameter 3 & \\
\hline 455 & 0 & Parameter 4 & \\
\hline 456 & 1000 & KI Threshold Distribution Index (Incipient) & Fixed \\
\hline 457 & KI_Thresh_SCC & Parameter 1 & $\mathrm{MPa}^{*}$ sqrt(m) \\
\hline 458 & 0 & Parameter 2 & \\
\hline 459 & 0 & Parameter 3 & \\
\hline 460 & 0 & Parameter 4 & \\
\hline 461 & 1000 & Stress Threshold Distribution Index (MFD) & Fixed \\
\hline 462 & -600 & Parameter 1 & $\mathrm{MPa}$ \\
\hline 463 & 0 & Parameter 2 & \\
\hline 464 & 0 & Parameter 3 & \\
\hline 465 & 0 & Parameter 4 & \\
\hline 466 & 1000 & KI Threshold Distribution Index (MFD) & Fixed \\
\hline 467 & KI_Thresh_SCC & Parameter 1 & $\mathrm{MPa}^{*} \mathrm{sqrt}(\mathrm{m})$ \\
\hline 468 & 0 & Parameter 2 & \\
\hline 469 & 0 & Parameter 3 & \\
\hline 470 & 0 & Parameter 4 & \\
\hline 471 & 0 & Immediate Failure Flag (-1 or 0 for true or false) & FALSE \\
\hline
\end{tabular}


WAPDEG Analysis of Waste Package and Drip Shield Degradation

\begin{tabular}{|c|c|c|c|}
\hline Row & Value & Parameter Description & Comments \\
\hline 472 & 0 & $\begin{array}{l}\text { Number of Localized Corrosion Modes Initiated } \\
(0,1, \text { or } 2)\end{array}$ & \\
\hline 473 & 1 & $\begin{array}{l}\text { Number of Corrosion Modes Accelerated }(0,1 \text {, } \\
2, \text { or } 3 \text { ) }\end{array}$ & \\
\hline 474 & 1 & General Corrosion Accelerated & \\
\hline 475 & 1000 & Barrier Variance Share Distribution Index & Fixed \\
\hline 476 & 1 & Parameter 1 & fraction \\
\hline 477 & 0 & Parameter 2 & \\
\hline 478 & 0 & Parameter 3 & \\
\hline 479 & 0 & Parameter 4 & \\
\hline 480 & 1000 & Acceleration Factor & Fixed \\
\hline 481 & $2(2.5)$ & Parameter 1 & $20 / 10(25 / 10)$ \\
\hline 482 & 0 & Parameter 2 & \\
\hline 483 & 0 & Parameter 3 & \\
\hline 484 & 0 & Parameter 4 & \\
\hline 485 & 0 & Sample Type & \\
\hline 486 & 0 & Number of Thresholds Reduced $(0,1$, or 2$)$ & \\
\hline 487 & 10 & MIC Event Index & \\
\hline 488 & 1 & Barrier Type & A22 OB \\
\hline 489 & 2 & Number of Water Conditions & \\
\hline 490 & 1 & Condition Number & DSInside \\
\hline 491 & 2 & Condition Number & DSOutside \\
\hline 492 & 1 & Fraction of surface area subject to MIC & \\
\hline 493 & 0 & Use SCC patches first? & \\
\hline 494 & 1000 & Barrier Variance Share Distribution Index & Fixed \\
\hline 495 & 1 & Parameter 1 & fraction \\
\hline 496 & 0 & Parameter 2 & \\
\hline 497 & 0 & Parameter 3 & \\
\hline 498 & 0 & Parameter 4 & \\
\hline 499 & 1000 & MIC RHcrit Distribution Index & Fixed \\
\hline 500 & 0.9 & Parameter 1 & fraction \\
\hline 501 & 0 & Parameter 2 & \\
\hline 502 & 0 & Parameter 3 & \\
\hline 503 & 0 & Parameter 4 & \\
\hline 504 & 0 & $\begin{array}{l}\text { Sample Type (only one variable so not used, } \\
\text { but must be specified) }\end{array}$ & \\
\hline 505 & 0 & $\begin{array}{l}\text { Immediate Failure Flag (- } 1 \text { or } 0 \text { for true or } \\
\text { false) }\end{array}$ & FALSE \\
\hline 506 & 0 & $\begin{array}{l}\text { Number of Localized Corrosion Modes Initiated } \\
(0,1, \text { or } 2)\end{array}$ & \\
\hline 507 & 1 & $\begin{array}{l}\text { Number of Corrosion Modes Accelerated }(0,1 \text {, } \\
2, \text { or } 3)\end{array}$ & \\
\hline 508 & 1 & Corrosion Mode Number $(1,2$, or 3$)$ & $\begin{array}{l}\text { General Corrosion } \\
\text { Accelerated }\end{array}$ \\
\hline 509 & 1000 & Barrier Variance Share Distribution Index & Fixed \\
\hline 510 & 1 & Parameter 1 & fraction \\
\hline 511 & 0 & Parameter 2 & \\
\hline 512 & 0 & Parameter 3 & \\
\hline 513 & 0 & Parameter 4 & \\
\hline 514 & 1000 & Acceleration Factor Distribution Index & Fixed \\
\hline 515 & MIC_A22 & Parameter 1 & \\
\hline 516 & $\overline{0}$ & Parameter 2 & \\
\hline 517 & 0 & Parameter 3 & \\
\hline 518 & 0 & Parameter 4 & \\
\hline 519 & 0 & Sample Type & \\
\hline 520 & 0 & Number of Thresholds Reduced $(0,1$, or 2$)$ & \\
\hline 521 & 10 & MIC Event Index & \\
\hline 522 & 2 & Barrier Type & A22 IB \\
\hline
\end{tabular}


WAPDEG Analysis of Waste Package and Drip Shield Degradation

\begin{tabular}{|c|c|c|c|}
\hline Row & Value & Parameter Description & Comments \\
\hline 523 & 2 & Number of Water Conditions & \\
\hline 524 & 1 & Condition Number & DSInside \\
\hline 525 & 2 & Condition Number & DSOutside \\
\hline 526 & 1 & Fraction of surface area subject to MIC & \\
\hline 527 & 0 & Use SCC patches first? & \\
\hline 528 & 1000 & Barrier Variance Share Distribution Index & Fixed \\
\hline 529 & 1 & Parameter 1 & fraction \\
\hline 530 & 0 & Parameter 2 & \\
\hline 531 & 0 & Parameter 3 & \\
\hline 532 & 0 & Parameter 4 & \\
\hline 533 & 1000 & MIC RHcrit Distribution Index & Fixed \\
\hline 534 & 0.9 & Parameter 1 & fraction \\
\hline 535 & 0 & Parameter 2 & \\
\hline 536 & 0 & Parameter 3 & \\
\hline 537 & 0 & Parameter 4 & \\
\hline 538 & 0 & $\begin{array}{l}\text { Sample Type (only one variable so not used, } \\
\text { but must be specified) }\end{array}$ & \\
\hline 539 & 0 & $\begin{array}{l}\text { Immediate Failure Flag (- } 1 \text { or } 0 \text { for true or } \\
\text { false) }\end{array}$ & FALSE \\
\hline 540 & 0 & $\begin{array}{l}\text { Number of Localized Corrosion Modes Initiated } \\
(0,1, \text { or } 2)\end{array}$ & \\
\hline 541 & 1 & $\begin{array}{l}\text { Number of Corrosion Modes Accelerated }(0,1 \text {, } \\
2, \text { or } 3 \text { ) }\end{array}$ & \\
\hline 542 & 1 & Corrosion Mode Number $(1,2$, or 3$)$ & $\begin{array}{l}\text { General Corrosion } \\
\text { Accelerated }\end{array}$ \\
\hline 543 & 1000 & Barrier Variance Share Distribution Index & Fixed \\
\hline 544 & 1 & Parameter 1 & fraction \\
\hline 545 & 0 & Parameter 2 & \\
\hline 546 & 0 & Parameter 3 & \\
\hline 547 & 0 & Parameter 4 & \\
\hline 548 & 1000 & Acceleration Factor Distribution Index & Fixed \\
\hline 549 & MIC_A22 & Parameter 1 & \\
\hline 550 & $\overline{0}$ & Parameter 2 & \\
\hline 551 & 0 & Parameter 3 & \\
\hline 552 & 0 & Parameter 4 & \\
\hline 553 & 0 & Sample Type & \\
\hline 554 & 0 & Number of Thresholds Reduced $(0,1$, or 2$)$ & \\
\hline 555 & $\begin{array}{l}\text { WDSeed_CSNF } \\
\text { (WDSeed_CDSP) }\end{array}$ & Seed for the random number generator & \\
\hline 556 & NumBins & $\begin{array}{l}\text { Number of bins for reporting penetrations with } \\
\text { time }\end{array}$ & \\
\hline 557 & BinStart & Bin Start Time & \\
\hline 558 & 0 & $\begin{array}{l}\text { Number of summary times for reporting } \\
\text { penetrations }\end{array}$ & \\
\hline 559 & 0 & Do Subset of Total Package Logical & FALSE \\
\hline 560 & 1 & Number of First Package & \\
\hline 561 & 1 & Number of Last Package & \\
\hline 562 & SimTime & Simulation Time & \\
\hline 563 & 11 & Number of Output files & \\
\hline 564 & 0 & Generate OUT file logical & \\
\hline 565 & 0 & Generate AUX file logical & \\
\hline 566 & 0 & Generate PIT file logical & \\
\hline 567 & 0 & Generate CRK file logical & \\
\hline 568 & 0 & Generate PAT file logical & \\
\hline 569 & 0 & Generate THK file logical & \\
\hline 570 & 0 & Generate EVN file logical & \\
\hline 571 & 0 & Generate DET file logical & \\
\hline 572 & 0 & Generate INA file logical & \\
\hline
\end{tabular}


WAPDEG Analysis of Waste Package and Drip Shield Degradation

\begin{tabular}{|c|c|c|c|}
\hline Row & Value & Parameter Description & Comments \\
\hline 573 & 0 & Generate OUA file logical & \\
\hline 574 & 0 & Generate PDZ file logical & \\
\hline 575 & $\begin{array}{l}\text { (rows } 575 \text { to } 699 \text { are not } \\
\text { referenced and contain } \\
\text { zeros) }\end{array}$ & & \\
\hline . & . & & \\
\hline . & . & & \\
\hline . & . & & \\
\hline 699 & 0 & & \\
\hline 700 & SCC_Outer_Lid.Output1 & & \\
\hline 701 & SCC_Middle_Lid.Output1 & & \\
\hline 702 & 0 & & \\
\hline 703 & 0 & & \\
\hline 704 & $\begin{array}{c}\text { (rows } 704 \text { to } 2,000 \text { are not } \\
\text { referenced and contain } \\
\text { zeros) }\end{array}$ & & \\
\hline . & - & & \\
\hline . & • & & \\
\hline . & • & & \\
\hline 2,000 & 0 & & \\
\hline
\end{tabular}




\section{APPENDIX II}

OTHER SUPPORTING FILES 


\section{INTENTIONALLY LEFT BLANK}




\section{OTHER SUPPORTING FILES}

The integrated waste package degradation (IWPD) analysis uses several external files that must accompany the GoldSim input file in which it is run. The first of these is the WD4DLL.WAP file listed in Table II-1. Note that the line numbers and the column headings in Table II-1 are not part of the WD4DLL.WAP file, but are included for clarity.

Table II-1. Contents of WD4DLL.WAP File

\begin{tabular}{|c|l|}
\hline Line & \multicolumn{1}{|c|}{ File Name } \\
\hline 1 & WDenv_00_07wheader.ou \\
\hline 2 & WDenv_00wh.ou \\
\hline 3 & EMPTY \\
\hline 4 & WDKlinO.fil \\
\hline 5 & WDKlinM.fil \\
\hline 6 & WDKISCCO.fil \\
\hline 7 & WDStressO.fil \\
\hline 8 & WDKISCCM.fil \\
\hline 9 & WDStressM.fil \\
\hline 10 & WDCWDNDO_CSNF.cdf \\
\hline 11 & WDCWDSizeO_CSNF.cdf \\
\hline 12 & WDCWDNDM_CSNF.cdf \\
\hline 13 & WDCWDSizeM_CSNF.cdf \\
\hline 14 & WDCWDNDO_CDSP.cdf \\
\hline 15 & WDCWDSizeO_CDSP.cdf \\
\hline 16 & WDCWDNDM_CDSP.cdf \\
\hline 17 & WDCWDSizeM_CDSP.cdf \\
\hline 18 & WDInRGC.cdf \\
\hline
\end{tabular}

WDenv_00_07wheader.ou and WDenv_00wh.ou are used only in this report. It is expected that another file will actually be used in the TSPA.

There is a dummy filename in position 3 .

The contents of WDKIinO.fil are reproduced below. The first three lines in the WDKIinO.fil file (beginning with exclamation points) are comment lines. The comment lines have no effect on the calculations performed in the SCCD and WAPDEG software. The comment lines allow the user to enhance traceability by uniquely identifying the contents of the file. In this instance (and for the WDKIinM.fil discussed next), the contents of the comment lines are not correct. The first comment line should contain "! WDKIinO.fil". The second comment line should contain "! Laser peened Outer lid DIRS: 169985, Table 8-3" to be consistent with the Stress Corrosion Cracking of the Drip Shield, the Waste Package Outer Barrier, and the Stainless Steel Structural Material (BSC 2004 [DIRS 169985]). The file listing presented is consistent with the output DTN from this report (DTN: MO0310MWDWAPAN.002).

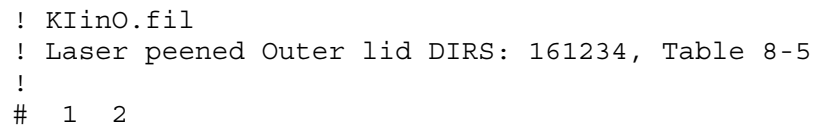




\begin{tabular}{lc}
$\# \quad 50$ & \\
$\# 1.0$ & \\
$!$ KI (MPA*m1/2) & depth (mm) \\
-5.6943 & 0.3988 \\
-6.4965 & 0.8001 \\
-6.1528 & 1.1989 \\
-5.1372 & 1.6002 \\
-3.6697 & 1.9990 \\
-1.8824 & 2.4003 \\
0.1212 & 2.7991 \\
2.2821 & 3.2004 \\
4.5533 & 3.5992 \\
6.8939 & 3.9980 \\
9.2702 & 4.3993 \\
11.6543 & 4.7981 \\
14.0165 & 5.1994 \\
16.3364 & 5.5982 \\
18.6024 & 5.9995 \\
20.8003 & 6.3983 \\
22.9177 & 6.7970 \\
24.9441 & 7.1984 \\
26.9023 & 7.5971 \\
28.8612 & 7.9985 \\
30.7287 & 8.3972 \\
32.5008 & 8.7986 \\
34.1745 & 9.1973 \\
35.7479 & 9.5987 \\
37.2200 & 9.9974 \\
38.4530 & 10.3962 \\
39.5674 & 10.7975 \\
40.5636 & 11.1963 \\
41.4432 & 11.5976 \\
42.2086 & 11.9964 \\
42.8627 & 12.3977 \\
43.4439 & 12.7965 \\
43.9342 & 13.1978 \\
44.3269 & 13.5966 \\
44.6272 & 13.9954 \\
44.8409 & 14.3967 \\
44.9743 & 14.7955 \\
45.0329 & 15.1968 \\
45.0208 & 15.5956 \\
44.9464 & 15.9969 \\
44.8182 & 16.3957 \\
44.6449 & 16.7945 \\
44.4361 & 17.1958 \\
44.2112 & 17.5946 \\
43.9968 & 17.9959 \\
43.7750 & 18.3947 \\
43.5578 & 18.7960 \\
43.3569 & 19.1948 \\
43.1853 & 19.5961 \\
43.0560 & 19.9949 \\
& \\
\hline 19 &
\end{tabular}

The contents of WDKIinM.fil are reproduced below. Similar to the case of WDKIinO.fil discussed above, the first two comment lines in the WDKIinM.fil file (beginning with exclamation points) are not correct. The first comment line should contain "! WDKIinM.fil". The second comment line should contain "!As-Welded Middle Lid DIRS: 169985, Table 8-2" to be consistent with Stress Corrosion Cracking of the Drip Shield, the Waste Package Outer Barrier, and the Stainless Steel Structural Material (BSC 2004 [DIRS 169985]). The file listing presented is consistent with the output DTN from this report (DTN: MO0310MWDWAPAN.002).

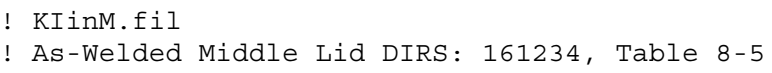




\begin{tabular}{|c|c|}
\hline \# 1 & \\
\hline \# 50 & \\
\hline$\# \quad 1.0$ & \\
\hline ! KI $\left(\mathrm{MPa} * \mathrm{~m}^{1} / 2\right)$ & depth (mm) \\
\hline 7.5754 & 0.1593 \\
\hline 10.9665 & 0.3203 \\
\hline 13.7144 & 0.4797 \\
\hline 16.1330 & 0.6407 \\
\hline 18.3358 & 0.8000 \\
\hline 20.3775 & 0.9593 \\
\hline 22.3816 & 1.1203 \\
\hline 24.3197 & 1.2797 \\
\hline 26.1726 & 1.4407 \\
\hline 27.9459 & 1.6000 \\
\hline 29.6433 & 1.7593 \\
\hline 31.2668 & 1.9203 \\
\hline 32.8922 & 2.0797 \\
\hline 34.5292 & 2.2407 \\
\hline 36.1060 & 2.4000 \\
\hline 37.6220 & 2.5593 \\
\hline 39.0762 & 2.7203 \\
\hline 40.4676 & 2.8797 \\
\hline 41.8264 & 3.0407 \\
\hline 43.2168 & 3.2000 \\
\hline 44.5479 & 3.3593 \\
\hline 45.8181 & 3.5203 \\
\hline 47.0265 & 3.6797 \\
\hline 48.1718 & 3.8407 \\
\hline 49.2531 & 4.0000 \\
\hline 50.3451 & 4.1593 \\
\hline 51.3729 & 4.3203 \\
\hline 52.3351 & 4.4797 \\
\hline 53.2313 & 4.6407 \\
\hline 54.0602 & 4.8000 \\
\hline 54.8214 & 4.9593 \\
\hline 55.4811 & 5.1203 \\
\hline 56.0586 & 5.2797 \\
\hline 56.5637 & 5.4407 \\
\hline 56.9965 & 5.6000 \\
\hline 57.3567 & 5.7593 \\
\hline 57.6444 & 5.9203 \\
\hline 57.7587 & 6.0797 \\
\hline 57.6946 & 6.2407 \\
\hline 57.5522 & 6.4000 \\
\hline 57.3322 & 6.5593 \\
\hline 57.0353 & 6.7203 \\
\hline 56.6626 & 6.8797 \\
\hline 56.1419 & 7.0407 \\
\hline 55.3276 & 7.2000 \\
\hline 54.4422 & 7.3593 \\
\hline 53.4878 & 7.5203 \\
\hline 54.6294 & 7.6797 \\
\hline 56.2191 & 7.8407 \\
\hline 57.7865 & 8.0000 \\
\hline
\end{tabular}

The files WDKISCCO.fil, WDStressO.fil, WDKISCCM.fil, WDStressM.fil, WDCWDNDO_CSNF.cdf, WDCWDSizeO_CSNF.cdf, WDCWDNDM_CSNF.cdf, WDCWDSizeM_CSNF.cdf, WDCWDNDO_CDSP.cdf, WDCWDSizeO_CDSP.cdf, WDCWDNDM_CDSP.cdf, and WDCWDSizeM_CDSP.cdf are all files that are produced at run time and change their contents for each realization of the IWPD analysis.

The contents of WDlnRGC.cdf are reproduced below (column 1 is the natural logarithm of the general corrosion rate, column 2 is the cumulative probability values, column 3 is the general corrosion rate in $\mathrm{mm} / \mathrm{yr}$ (not used but provided for illustration)).

125 ! WDlnRGC.cdf - CDF for Ln[Rate (mm/yr)] for Alloy 22 
$-16.961712197361$

$-16.606332266861$

$-16.250919072358$

$-15.895446698814$

$-15.539869004983$

$-15.184103757973$

$-14.828004150476$

$-14.471307289094$

$-14.113539817716$

$-13.753841023008$

$-13.390617861005$

$-13.020824635104$

$-12.638272586363$

$-12.228771288622$

$-12.095541575836$

$-12.014176485059$

$-11.95450274756$

$-11.906896320413$

$-11.867014466231$

$-11.832515828457$

$-11.801989899202$

$-11.774519377179$

$-11.749473240538$

$-11.726398285935$

$-11.704957708673$

$-11.684894157232$

$-11.666006404304$

$-11.648134015655$

$-11.631146932008$

$-11.614938185062$

$-11.599418678305$

$-11.584513366555$

$-11.570158406341$

$-11.556298994738$

$-11.542887705779$

$-11.529883192646$

$-11.51724916292$

$-11.504953560484$

$-11.492967905824$

$-11.481266759108$

$-11.46982727947$

$-11.458628860377$

$-11.447652825708$

$-11.43688217469$

$-11.42630136642$

$-11.415896136709$

$-11.405653341471$

$-11.39556082205$

$-11.385607288762$

$-11.375782219648$

$-11.366075771986$

$-11.356478704522$

$-11.346982308768$

$-11.337578347973$

$-11.328259002589$

$-11.319016821266$

$-11.309844676534$

$-11.300735724457$

$-11.29168336764$

$-11.282681221066$

$-11.273723080277$

$-11.264802891481$

$-11.255914723223$

\begin{tabular}{|c|c|}
\hline $1 e-015$ & $4.3015204214735 e-008$ \\
\hline$e-014$ & $6.1370764287394 e-008$ \\
\hline$e-013$ & $8.7561969415836 e-008$ \\
\hline-012 & $1.2493819039048 e-007$ \\
\hline$e-011$ & $1.7828739590043 e-007$ \\
\hline-010 & $2.5446468878913 e-007$ \\
\hline$e-009$ & $3.6331189726815 e-007$ \\
\hline$e-008$ & $5.1902837174783 e-007$ \\
\hline-007 & $7.4227962051286 e-007$ \\
\hline $1 e-006$ & $1.0636108004554 e-006$ \\
\hline $1 e-005$ & $1.529426298765 e-006$ \\
\hline .0001 & $2.2137456007201 e-006$ \\
\hline 0.001 & $3.2453979309883 e-006$ \\
\hline 0.01 & $4.8877851647675 e-006$ \\
\hline 0.02 & $5.5843552467729 e-006$ \\
\hline 0.03 & $6.0577235210094 e-006$ \\
\hline 0.04 & $6.4302139435167 e-006$ \\
\hline 0.05 & $6.7437371027708 e-006$ \\
\hline 0.06 & $7.0181250237782 e-006$ \\
\hline 0.07 & $7.2644655516632 e-006$ \\
\hline 0.08 & $7.4896394493125 e-006$ \\
\hline 0.09 & $7.6982357619692 e-006$ \\
\hline 0.1 & $7.8934816984425 e-006$ \\
\hline 0.11 & $8.0777411437344 e-006$ \\
\hline 0.12 & $8.25280257971 e-006$ \\
\hline 0.13 & $8.4200553404489 e-006$ \\
\hline 0.14 & $8.5806026817397 e-006$ \\
\hline 0.15 & $8.7353371663517 e-006$ \\
\hline 0.16 & $8.8849925752487 e-006$ \\
\hline 0.17 & $9.0301806512331 e-006$ \\
\hline 0.18 & $9.1714177309772 e-006$ \\
\hline 0.19 & $9.3091444514342 e-006$ \\
\hline 0.2 & $9.4437405995513 e-006$ \\
\hline 0.21 & $9.5755364846527 e-006$ \\
\hline 0.22 & $9.7048217747851 e-006$ \\
\hline 0.23 & $9.8318524528176 e-006$ \\
\hline 0.24 & $9.9568563577574 e-006$ \\
\hline 0.25 & $1.0080037647227 e-005$ \\
\hline 0.26 & $1.0201580427299 e-005$ \\
\hline 27 & $1.0321651732614 e-005$ \\
\hline 0.28 & $1.0440403994467 e-005$ \\
\hline 0.29 & $1.0557977101684 e-005$ \\
\hline 0.3 & $1.0674500134987 e-005$ \\
\hline 0.31 & $1.0790092837602 e-005$ \\
\hline 0.32 & $1.0904866871379 e-005$ \\
\hline 0.33 & $1.1018926897439 e-005$ \\
\hline 0.34 & $1.1132371512535 e-005$ \\
\hline 0.35 & $1.1245294066247 e-005$ \\
\hline 0.36 & $1.1357783379422 e-005$ \\
\hline 0.37 & $1.1469924380546 e-005$ \\
\hline 0.38 & $1.1581798673867 e-005$ \\
\hline 0.39 & $1.1693485050718 e-005$ \\
\hline & $1.1805059953714 e-005$ \\
\hline 0.41 & $1.1916597901966 e-005$ \\
\hline 0.42 & $1.2028171884343 e-005$ \\
\hline 0.43 & $1.2139853726833 e-005$ \\
\hline 0.44 & $1.225171443934 e-005$ \\
\hline 0.45 & $1.2363824546659 e-005$ \\
\hline 0.46 & $1.2476254407934 e-005$ \\
\hline 0.47 & $1.2589074528536 e-005$ \\
\hline 0.48 & $1.2702355868114 e-005$ \\
\hline 0.49 & $1.2816170148356 e-005$ \\
\hline 0.5 & $1.2930590163975 e-005$ \\
\hline
\end{tabular}


$-11.247052739247$

$-11.238211172251$

$-11.229384298222$

$-11.220566411044$

$-11.21175179711$

$-11.202934709625$

$-11.194109342302$

$-11.185269802139$

$-11.176410080918$

$-11.167524025069$

$-11.15860530346$

$-11.149647372663$

$-11.140643439142$

$-11.131586417741$

$-11.12246888575$

$-11.113283031688$

$-11.104020597771$

$-11.094672814858$

$-11.085230328375$

$-11.075683113423$

$-11.066020376864$

$-11.05623044364$

$-11.046300623925$

$-11.036217056846$

$-11.025964525342$

$-11.015526235268$

$-11.004883549816$

$-10.994015667647$

$-10.982899229434$

$-10.971507832438$

$-10.959811425593$

$-10.947775547458$

$-10.935360354661$

$-10.922519366853$

$-10.909197821533$

$-10.895330481956$

$-10.880838661918$

$-10.865626102186$

$-10.849573116212$

$-10.832528043575$

$-10.814294357166$

$-10.794610437982$

$-10.773116302859$

$-10.74929553616$

$-10.722365979358$

$-10.69105213255$

$-10.653038849576$

$-10.603337771639$

$-10.526951407683$

$-10.325849053552$

$-10.174589906086$

$-10.053211136624$

$-9.9518237288526$

$-9.8647635039768$

$-9.7884780416973$

$-9.7205916556578$

$-9.6594369250961$

$-9.603798439259$

$-9.552764757972$

$-9.5056107132096$

$-9.4614083903465$

$-9.4189122120715$
$0.511 .3045690100432 e-005$

$0.521 .3161545861962 e-005$

$0.531 .3278235413665 e-005$

$0.541 .3395839141646 \mathrm{e}-005$

$0.551 .3514440235511 e-005$

$0.561 .3634125097966 \mathrm{e}-005$

$0.57 \quad 1.3754983786796 \mathrm{e}-005$

$0.58 \quad 1.3877110495173 e-005$

$0.591 .4000604077062 \mathrm{e}-005$

$0.61 .4125568625509 e-005$

$0.611 .4252114112813 e-005$

$0.621 .4380357103089 \mathrm{e}-005$

$0.631 .4510421549568 \mathrm{e}-005$

$0.641 .4642439691204 \mathrm{e}-005$

$0.651 .4776553065942 \mathrm{e}-005$

$0.661 .4912913661378 \mathrm{e}-005$

$0.67 \quad 1.5051685227771 e-005$

$0.68 \quad 1.5193044783627 e-005$

$0.691 .5337184350634 \mathrm{e}-005$

$0.7 \quad 1.5484312963077 e-005$

$0.711 .5634659007344 \mathrm{e}-005$

$0.721 .5788472960683 e-005$

$0.731 .5946030615688 e-005$

$0.74 \quad 1.610763689963 e-005$

$0.751 .6273630427313 e-005$

$0.76 \quad 1.6444388965399 e-005$

$0.77 \quad 1.6620336038545 e-005$

$0.78 \quad 1.6801948978702 \mathrm{e}-005$

$0.791 .6989768816026 \mathrm{e}-005$

$0.81 .7184412544673 e-005$

$0.81 \quad 1.7386588486316 \mathrm{e}-005$

$0.821 .7597115745295 e-005$

$0.83 \quad 1.7816949143246 e-005$

$0.84 \quad 1.8047211604704 \mathrm{e}-005$

$0.85 \quad 1.8289236847896 \mathrm{e}-005$

$0.861 .8544626601422 e-005$

$0.87 \quad 1.8815328738574 \mathrm{e}-005$

$0.881 .9103746273212 \mathrm{e}-005$

$0.891 .9412893170728 e-005$

$0.91 .9746623493742 e-005$

$0.912 .0109979829965 e-005$

$0.92 \quad 2.0509744608982 \mathrm{e}-005$

$0.932 .0955355687502 e-005$

$0.942 .1460521153888 e-005$

$0.952 .2046295397764 e-005$

$0.962 .2747572249932 \mathrm{e}-005$

$0.97 \quad 2.3628927628531 e-005$

$0.98 \quad 2.4832984417707 e-005$

$0.992 .6804214973517 e-005$

$0.9993 .2774851685675 e-005$

$0.99993 .8126922194693 e-005$

$0.999994 .3047296134484 e-005$

$0.9999994 .7640670996241 e-005$

$0.9999999 \quad 5.1974179853622 e-005$

$0.99999999 \quad 5.6094205379008 e-005$

$0.999999999 \quad 6.0034470302955 e-005$

$0.9999999999 \quad 6.3820447508563 e-005$

$0.99999999999 \quad 6.7471960981027 e-005$

$0.999999999999 \quad 7.1004680683796 e-005$

$0.9999999999999 \quad 7.4433033708262 e-005$

$0.99999999999999 \quad 7.7796945354491 \mathrm{e}-005$

$18.1174271693367 e-005$ 


\section{INTENTIONALLY LEFT BLANK}

